\title{
Tropospheric ozone and its precursors from the urban to the global scale from air quality to short-lived climate forcer
}

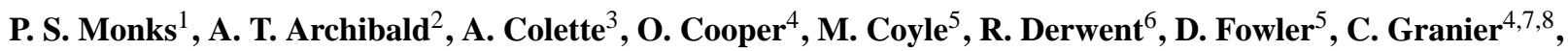 \\ K. S. Law $^{8}$, G. E. Mills ${ }^{9}$, D. S. Stevenson ${ }^{10}$, O. Tarasova ${ }^{11}$, V. Thouret ${ }^{12}$, E. von Schneidemesser ${ }^{13}$, R. Sommariva ${ }^{1}$, \\ O. Wild ${ }^{14}$, and M. L. Williams ${ }^{15}$ \\ ${ }^{1}$ Department of Chemistry, University of Leicester, Leicester LE1 7RH, UK \\ ${ }^{2}$ NCAS-Climate, Department of Chemistry, University of Cambridge, Cambridge CB1 1EW, UK \\ ${ }^{3}$ INERIS, National Institute for Industrial Environment and Risks, Verneuil-en-Halatte, France \\ ${ }^{4}$ Cooperative Institute for Research in Environmental Sciences, University of Colorado, Boulder, CO, USA \\ ${ }^{5}$ NERC Centre for Ecology and Hydrology, Penicuik, Edinburgh EH26 0QB, UK \\ ${ }^{6}$ rdscientific, Newbury, Berkshire RG14 6LH, UK \\ ${ }^{7}$ NOAA Earth System Research Laboratory, Chemical Sciences Division, Boulder, CO, USA \\ ${ }^{8}$ Sorbonne Universités, UPMC Univ. Paris 06, Université Versailles St-Quentin, CNRS/INSU, LATMOS-IPSL, Paris, France \\ ${ }^{9}$ NERC Centre for Ecology and Hydrology, Environment Centre Wales, Deiniol Road, Bangor LL57 2UW, UK \\ ${ }^{10}$ School of GeoSciences, The University of Edinburgh, Edinburgh EH9 3JN, UK \\ ${ }^{11}$ WMO, Geneva, Switzerland \\ ${ }^{12}$ Laboratoire d'Aérologie (CNRS and Université Paul Sabatier), Toulouse, France \\ ${ }^{13}$ Institute for Advanced Sustainability Studies, Potsdam, Germany \\ ${ }^{14}$ Lancaster Environment Centre, Lancaster University, Lancaster LA1 4VQ, UK \\ ${ }^{15}$ MRC-PHE Centre for Environment and Health, Kings College London, 150 Stamford Street, London SE1 9NH, UK
}

Correspondence to: P. S. Monks (p.s.monks@leicester.ac.uk)

Received: 07 November 2014 - Published in Atmos. Chem. Phys. Discuss.: 23 December 2014

Revised: 22 May 2015 - Accepted: 22 June 2015 - Published: 13 August 2015

\begin{abstract}
Ozone holds a certain fascination in atmospheric science. It is ubiquitous in the atmosphere, central to tropospheric oxidation chemistry, yet harmful to human and ecosystem health as well as being an important greenhouse gas. It is not emitted into the atmosphere but is a byproduct of the very oxidation chemistry it largely initiates. Much effort is focused on the reduction of surface levels of ozone owing to its health and vegetation impacts, but recent efforts to achieve reductions in exposure at a country scale have proved difficult to achieve owing to increases in background ozone at the zonal hemispheric scale. There is also a growing realisation that the role of ozone as a short-lived climate pollutant could be important in integrated air quality climate change mitigation. This review examines current understanding of the processes regulating tropospheric ozone at global to local scales from both measurements and models. It takes the view that knowledge across the scales is important for dealing with
\end{abstract}

air quality and climate change in a synergistic manner. The review shows that there remain a number of clear challenges for ozone such as explaining surface trends, incorporating new chemical understanding, ozone-climate coupling, and a better assessment of impacts. There is a clear and present need to treat ozone across the range of scales, a transboundary issue, but with an emphasis on the hemispheric scales. New observational opportunities are offered both by satellites and small sensors that bridge the scales.

\section{Introduction}

Ozone is central to the chemistry of the troposphere owing to its role in the initiation of photochemical oxidation processes via direct reaction, photolysis and the subsequent reactions of the photoproducts to form the hydroxyl radical (Monks, 
2005). Tropospheric ozone is also recognised to be a threat to human health (WHO, 2003; Lim et al., 2012) and have a deleterious impact on vegetation (Fowler et al., 2009), and through plant damage it impedes the uptake of carbon into the biosphere (Sitch et al., 2007) as well as impacting built infrastructure (Kumar and Imam, 2013). It is also an important tropospheric greenhouse gas (IPCC, 2007; Stevenson et al., 2013) and is referred to as a short-lived climate pollutant (Shindell et al., 2012).

Ozone-related deaths are estimated to make up about 5$20 \%$ of all those related to air pollution (e.g. Silva et al., 2013; Anenberg et al., 2009; Lim et al., 2012; Brauer et al., 2012). The OECD (OECD, 2012) have stated that "without new policies, by 2050, air pollution is set to become the world's top environmental cause of premature mortality". The report goes on to state that "because of their ageing and urbanised populations, OECD countries are likely to have one of the highest premature death rates from ground-level ozone".

While ozone has a relatively short atmospheric lifetime, typically hours, in polluted urban regions where concentrations of its precursors are high, its lifetime in the free troposphere is of the order of several weeks (Stevenson et al., 2006; Young et al., 2013), sufficiently long for it to be transported over intercontinental scales. Thus in addition to its role as a priority pollutant on an urban scale, it may influence air quality on a hemispheric scale (Akimoto, 2003; HTAP, 2010). There is little doubt that ozone is a multifarious molecule. Recently, Simpson et al. (2014) described ozone as the "persistent menace". Figure 1 shows some of the key interactions that drive ozone concentrations in the troposphere and some of the feedbacks.

This review examines current understanding of the processes regulating tropospheric ozone at global to local scales from both measurements and models. It takes the view that knowledge across the scales is important for dealing with air quality and climate change in a synergistic manner. It would be a Herculean task to review all the literature on ozone; therefore much of the focus of this review is on the recent findings and discoveries relating to tropospheric ozone. It builds on earlier integrative reviews such as Brasseur et al. (2003) and those of ACCENT (Fowler et al., 2009; Isaksen et al., 2009; Monks et al., 2009; Laj et al., 2009).

The review has four major sections. The first (Sect. 2) reviews the control of ozone across the scales, looking at the interplay of chemistry, transport and deposition, and includes a brief climatological picture of ozone. The second major section (Sect. 3) details the major impact of ozone with respect to health, ecosystems and climate, while the third section (Sect. 4) highlights several current topics in relation to ozone in the troposphere. The final section (Sect. 5) briefly overviews some of the policy context and issues in relation to tropospheric ozone. In the conclusion, some future directions and issues with relation to ozone are discussed.

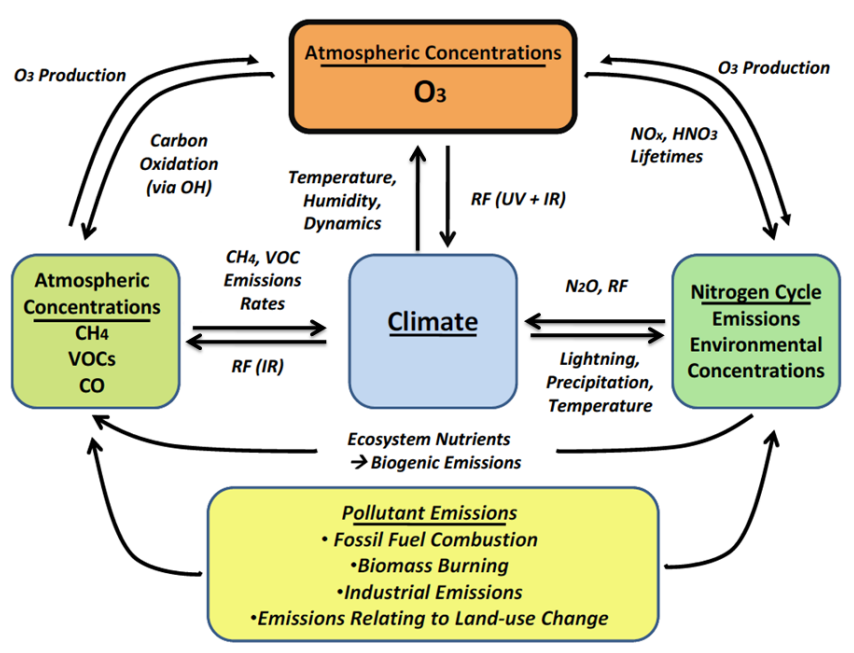

Figure 1. Schematic representation of the interactions of ozone in the Earth system (EPA, 2009).

\section{Ozone - control, precursors and climatology}

\subsection{What controls ozone?}

The annual variation in ozone concentration at any given spatial scale depends on a number of factors, such as the proximity to large sources of ozone precursors, geographical location and the prevailing meteorological conditions (Logan, 1985). The tropospheric ozone budget at a given location is dependent on both photochemical processes and physical processes, including photochemical production and destruction of ozone, transport from upwind sources and removal at the Earth's surface (Monks, 2000; Lelieveld and Dentener, 2000).

Given the substantial stratospheric ozone concentrations, transport from the stratosphere was long thought to be the dominant source of ozone in the troposphere (Danielsen, 1968; Junge, 1962; Fabian and Pruchniewicz, 1977; Chatfield and Harrison, 1976). Photochemical mechanisms for the generation of ozone were first identified in work carried out in California in the 1950s (Haagen-Smit, 1952), and until the 1970s high ozone was thought to be a local phenomenon associated with air pollution (Leighton, 1961). Early in the 1970s, Crutzen (1973) and Chameides and Walker (1973) suggested that tropospheric ozone originated mainly from production within the troposphere by photochemical oxidation of $\mathrm{CO}$ and hydrocarbons catalysed by $\mathrm{HO}_{x}$ and $\mathrm{NO}_{x}$. Since then, improved understanding of the importance of both natural and anthropogenic sources of ozone precursors has highlighted the dominance of this ozone source, and recent model assessments suggest that chemical production contributes about $5000 \mathrm{Tg} \mathrm{yr}^{-1}$ to global tropospheric ozone (Stevenson et al., 2006; Young et al., 2013). In contrast, the net global source of ozone from stratosphere-troposphere exchange (STE) is estimated 

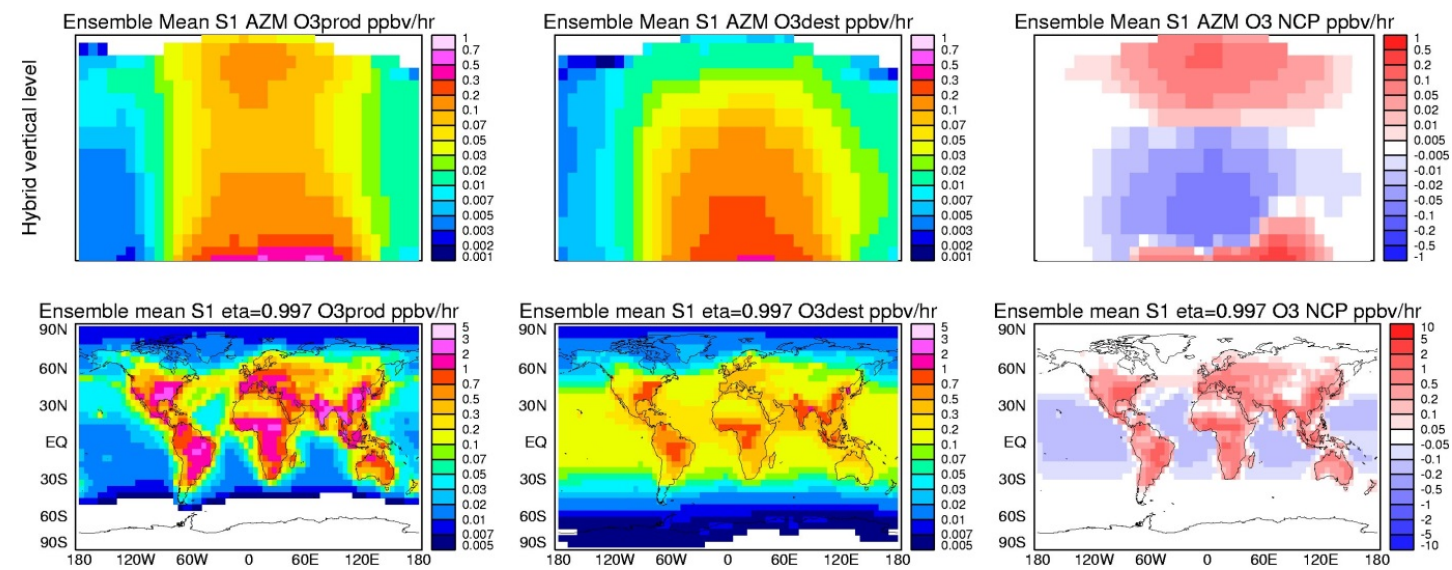

Figure 2. Multi-model mean (20 models) year 2000 ozone budgets (units: ppb ${ }^{-1}$ ). Top row: annual zonal mean (AZM) chemical production, chemical destruction and net chemical production. Vertical scale is from surface to approximately $100 \mathrm{hPa}$. Bottom row: maps of same quantities in the surface model layer (Stevenson et al., 2006).

to be about $550 \pm 140 \mathrm{Tg} \mathrm{yr}^{-1}$ based on observational constraints (Olson et al., 2001; McLinden et al., 2000). The removal of ozone through dry deposition to vegetation and other surfaces at ground level remains poorly constrained on the global scale, although model assessments driven by observed ecosystem fluxes, vegetation types and meteorology suggest net removal of about $1000 \pm 200 \mathrm{Tg} \mathrm{yr}^{-1}$ (Stevenson et al., 2006). Balancing the global tropospheric ozone budget therefore requires that there be net chemical production of about $450 \pm 300 \mathrm{Tg} \mathrm{yr}^{-1}$ (Stevenson et al., 2006). Note that this term is constrained by the estimated STE and deposition terms and by the global tropospheric ozone burden of about $335 \pm 10 \mathrm{Tg}$, and that uncertainty in the absolute magnitude of gross ozone chemical production and destruction remains relatively large (Wild, 2007; Wu et al., 2007).

These global budgets mask substantial regional variation (see Fig. 2), which spans the wide range of chemical environments present in the troposphere. Troposphere-wide chemical production of ozone from long-lived hydrocarbons such as methane is greatest in the tropical lower troposphere, where $\mathrm{OH}$ radical concentrations are high (Bloss et al., 2005), and in continental regions and parts of the free troposphere with fresh $\mathrm{NO}_{x}$ emissions. Chemical destruction of ozone is largest in the lower troposphere, where water vapour concentrations are high, and in highly polluted regions where there is direct removal by reaction with NO. This latter condition is commonly referred to as chemical titration of ozone, and is typically short-lived as the $\mathrm{NO}_{2}$ formed subsequently catalyses further ozone formation once it has been transported into cleaner environments. Localised halogencatalysed ozone destruction may also affect surface ozone in polar regions during springtime (see Halogens section (Sect. 4.4)). Consequently, net chemical production occurs over most of the continental boundary layer, where precursor concentrations are high, and in the upper troposphere, where destruction is slow (Wild and Palmer, 2008; von Kuhlmann et al., 2003b, a). Net chemical destruction occurs in the mid-troposphere and marine boundary layer, where precursor concentrations are low, and in localised urban and polar regions under titration (via reaction with $\mathrm{NO}$ ) and halogen destruction conditions, respectively. Despite large changes in the emissions of ozone precursors and in net chemical production, the general location of these net production and loss regimes is thought to have changed little since pre-industrial times (Wild and Palmer, 2008). However, spatial heterogeneity of anthropogenic precursor emissions and of biogenic hydrocarbons (Zare et al., 2014), along with strong diurnal variability in chemical processes, deposition and meteorology, suggests that local ozone production and loss regimes in the boundary layer may be much more diverse than indicated by these coarse, regional-scale assessments.

\subsubsection{Role of chemistry}

The basic chemistry that leads to the production and destruction of ozone has been detailed elsewhere (Monks, 2005; Ehhalt, 1999; Jenkin and Clemitshaw, 2000). Ozone $\left(\mathrm{O}_{3}\right)$ photochemical production in the troposphere occurs by hydroxyl radical oxidation of carbon monoxide (CO), methane $\left(\mathrm{CH}_{4}\right)$ and non-methane hydrocarbons (generally referred to as NMHC) in the presence of nitrogen oxides $\left(\mathrm{NO}_{x}\right)$. The mechanism of ozone formation in the troposphere, although very well understood, remains a challenge in practice that will, no doubt, require many more years of research to fully unravel. Typical photochemical timescales in the atmosphere are quite short (of the order of seconds to tens of minutes) (Seinfeld and Pandis, 2006). In brief, the production of ozone in the troposphere relies, fundamentally, on the photolysis of $\mathrm{NO}_{2}$ (Reaction R1) and the subsequent association of the photoproduct $\mathrm{O}\left({ }^{3} \mathrm{P}\right)$ (the ground electronic state oxygen atom) with $\mathrm{O}_{2}$ via Reaction (R2) through a termolecular re- 


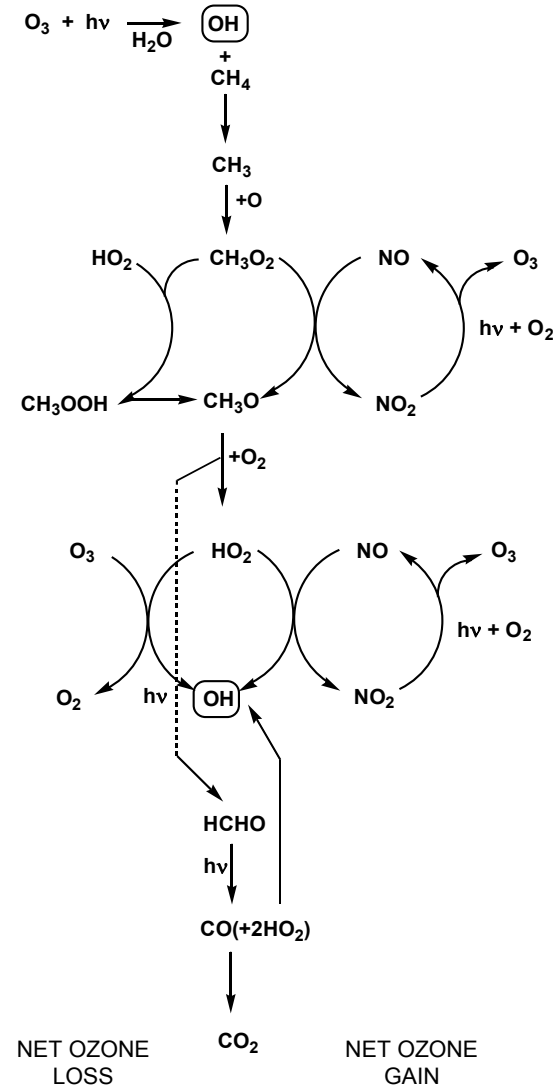

Figure 3. Simplified mechanism for the photochemical oxidation of $\mathrm{CH}_{4}$ in the troposphere (Lightfoot et al., 1992).

action with a third body ( $M$ being used to represent any third co-reactant, i.e. $\mathrm{N}_{2}$ ):

$\mathrm{NO}_{2}+h v \rightarrow \mathrm{NO}+\mathrm{O}\left({ }^{3} \mathrm{P}\right)$,
$\mathrm{O}\left({ }^{3} \mathrm{P}\right)+\mathrm{O}_{2}+M \rightarrow \mathrm{O}_{3}+M$.

The difficulty with understanding the production of $\mathrm{O}_{3}$ in the troposphere comes about through the manifold ways in which $\mathrm{NO}$ and $\mathrm{NO}_{2}$ are interconverted. The rapid interconversion between the two compounds allows them to be treated as a chemical family $-\mathrm{NO}_{x}$. (NB: photolysis of $\mathrm{NO}_{2}$ is fast, and approximately altitude-independent $j_{1} \approx 10^{-2} \mathrm{~s}^{-1}$.) For example, the reactions

$\mathrm{HO}_{2}+\mathrm{NO} \rightarrow \mathrm{NO}_{2}+\mathrm{OH}$,

$\mathrm{O}_{3}+\mathrm{NO} \rightarrow \mathrm{NO}_{2}+\mathrm{O}_{2}$,

both convert $\mathrm{NO}$ into $\mathrm{NO}_{2}$. Considering Reactions (R1), (R2) and (R4) one can derive a ratio of $[\mathrm{NO}] /\left[\mathrm{NO}_{2}\right]$ that depends on the local concentration of $\mathrm{O}_{3}$ and the rate coefficients for Reaction (R4) and the photolysis frequency for Reaction (R1) (at the surface the pseudo-first-order rate constant $k_{2}^{\prime}\left(k_{2}\left[\mathrm{O}_{2}\right] \cdot[M]\right)$ is sufficiently fast that it is not a rate-limiting

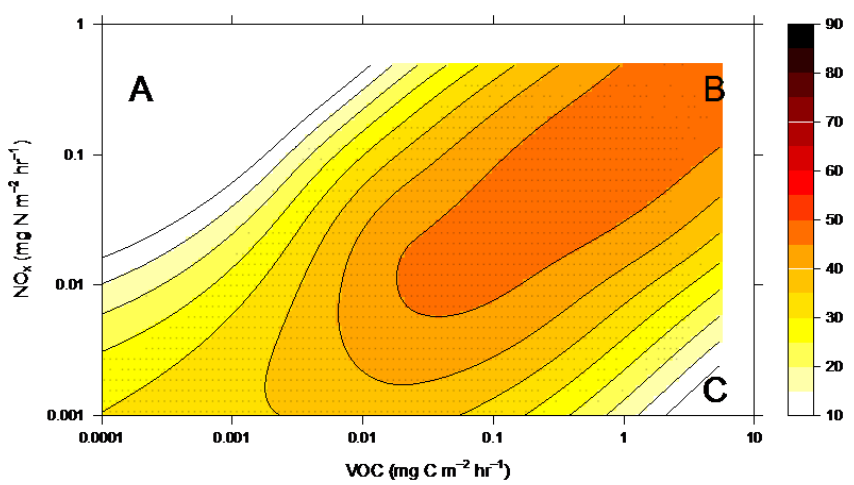

Figure 4. $\mathrm{O}_{3}$ mixing ratios (ppb) as a function of $\mathrm{VOC}$ and $\mathrm{NO}_{x}$ emissions as computed using the UKCA model of atmospheric chemistry (Archibald et al., 2011). Three main regions are identified. Top left corner (A): region of $\mathrm{NO}_{x}$ saturation and $\mathrm{O}_{3}$ titration. Bottom right corner $(\mathrm{C})$ : region of VOC saturation and $\mathrm{O}_{3}$ destruction. Diagonal elements $(\mathrm{A}-\mathrm{C}, \mathrm{B}-\mathrm{C})$ : efficient conversion of $\mathrm{NO}-$ $\mathrm{NO}_{2}$ and hence $\mathrm{O}_{3}$ production increasing with increasing VOC and $\mathrm{NO}_{x}$ emissions (NB: $\log _{10}$ scales for emissions).

step). This ratio is termed the Leighton ratio (Leighton, 1961) and also allows for an expression to be derived for the equilibrium concentration of $\mathrm{O}_{3}$. Whilst this chemistry is important, particularly in urban areas, it does not represent a mechanism for the net production of $\mathrm{O}_{3}$ in the troposphere. With the addition of volatile organic compounds, such as $\mathrm{CO}, \mathrm{viz}$

$\mathrm{CO}+\mathrm{OH}\left(+\mathrm{O}_{2}\right) \rightarrow \mathrm{CO}_{2}+\mathrm{HO}_{2}$,

it is possible to write a mechanism for the formation of $\mathrm{O}_{3}$ that is propagated via VOCs (volatile organic compound) and $\mathrm{NO}_{x}$ (Reactions R5, R3, R2 and R1). In this series of reactions, $\mathrm{O}_{3}$ is used as a source of the hydroxyl radical $(\mathrm{OH})$ through

$\mathrm{O}_{3}+h v \rightarrow \mathrm{O}\left({ }^{1} \mathrm{D}\right)+\mathrm{O}_{2}$,
$\mathrm{O}\left({ }^{1} \mathrm{D}\right)+\mathrm{H}_{2} \mathrm{O} \rightarrow \mathrm{OH}+\mathrm{OH}$,

where $\mathrm{O}\left({ }^{1} \mathrm{D}\right)$ is the electronic excited state atomic oxygen formed through photolysis at wavelengths $<320 \mathrm{~nm}$. However, the presence of $\mathrm{VOC}(\mathrm{CO})$ and $\mathrm{NO}_{x}$ allows $\mathrm{OH}$ to be regenerated (R3) and promote formation of $\mathrm{O}_{3}$ through $\mathrm{NO}_{2}$ photolysis. The production of $\mathrm{O}_{3}$ in the troposphere, mediated through the reactions involving $\mathrm{VOC}\left(\mathrm{CH}_{4}\right)$ and $\mathrm{NO}_{x}$, is shown schematically in Fig. 3 and in relationship to changing precursor concentrations in Fig. 4.

Figure 4 highlights the non-linearity of the $\mathrm{O}_{3}-\mathrm{VOC}-\mathrm{NO}_{x}$ system. The $\mathrm{O}_{3}$ mixing ratios presented in Fig. 4 are generated from photochemical modelling output generated using the UKCA model (O'Connor et al., 2014; Archibald et al., 2011). Regions in Fig. 4 where there is net $\mathrm{O}_{3}$ destruction (top left (a) and bottom right corners (c)) are typically referred to as the VOC-limited and $\mathrm{NO}_{x}$-limited regimes. VOC-limited refers to the fact that the production of $\mathrm{O}_{3}$ is 
limited by the input of VOC (see e.g. Zhou et al., 2014). This can be rationalised by moving from point $\mathrm{A}$ to point $\mathrm{B}$ along a line of constant $\mathrm{NO}_{x}$ emissions and increasing VOC emissions. Moving in this direction it is evident from Fig. 4 that $\mathrm{O}_{3}$ production increases. A similar case applies for the $\mathrm{NO}_{x}$-limited regime, where moving from point $\mathrm{C}$ to point $\mathrm{B}$ this time requires increasing $\mathrm{NO}_{x}$ emissions and results in increasing $\mathrm{O}_{3}$ mixing ratios.

This general mechanism of $\mathrm{OH}$ initiated $\mathrm{O}_{3}$ formation can be extended to more complex VOC such as alkanes:

$$
\begin{aligned}
& \mathrm{C}_{2} \mathrm{H}_{6}+\mathrm{OH}+\mathrm{O}_{2} \rightarrow \mathrm{C}_{2} \mathrm{H}_{5} \mathrm{O}_{2}+\mathrm{H}_{2} \mathrm{O}, \\
& \mathrm{C}_{2} \mathrm{H}_{5} \mathrm{O}_{2}+\mathrm{NO} \rightarrow \mathrm{C}_{2} \mathrm{H}_{5} \mathrm{O}+\mathrm{NO}_{2},
\end{aligned}
$$

where $\mathrm{C}_{2} \mathrm{H}_{5} \mathrm{O}_{2}$ represents a member of a group of radicals termed organic peroxy radicals $\left(\mathrm{RO}_{2}-\right.$ where $\mathrm{R}$ is used to represent alkyl, ally, or aryl groups), all of which possess the ability to convert $\mathrm{NO}$ to $\mathrm{NO}_{2}$. The fate of the alkyl oxy radical $\left(\mathrm{C}_{2} \mathrm{H}_{5} \mathrm{O}\right)$ is more complex and can result in the formation of $\mathrm{HO}_{2}$ and other VOCs. It is the organic atmospheric chemistry of $\mathrm{RO}_{2}$ that remains the great challenge to our full understanding of the production of $\mathrm{O}_{3}$ in the troposphere. Recent advances in our understanding of the fate of $\mathrm{RO}_{2}$ in the atmosphere are reviewed in Sect. 4.10.

There are added complexities to the chemistry outlined above owing to the variety of sources of $\mathrm{OH}$, e.g. from the photolysis of HONO (Kim et al., 2014), HCHO and the reaction of ozone with alkenes. The Monks et al. (2009) review looked at much of the variety of ozone photochemistry in more detail.

\subsubsection{Role of deposition}

The concentration of ozone in the surface boundary layer is regulated by three processes: atmospheric transport, chemical production/destruction and losses to surface by dry deposition. Ozone is physically transported to the surface by atmospheric turbulence, which can be readily measured or modelled using well-established methods. The rate of ozone removal at the surface strongly influences the exposure of vegetation and the human population to ozone and is responsible for much of the nocturnal decline in surface ozone in rural areas as deposition to the surface consumes ozone beneath a nocturnal temperature inversion. During the day, vertical transport of ozone to the surface layers is generally sufficient to maintain mixing ratios within $10 \%$ of the boundary layer mean values, except in urban areas or near major roads, where local nitric oxide sources remove ozone by titration (Colette et al., 2011). Thus the interplay between dry deposition of ozone in the surface layers and mixing from higher levels in the atmosphere plays a major role in regulating ozone exposure of ecosystem and the human population. The mixing in surface layers is largely driven by wind and its interaction with frictional drag at the surface. The large diurnal variability in ozone mixing ratios in rural areas and its

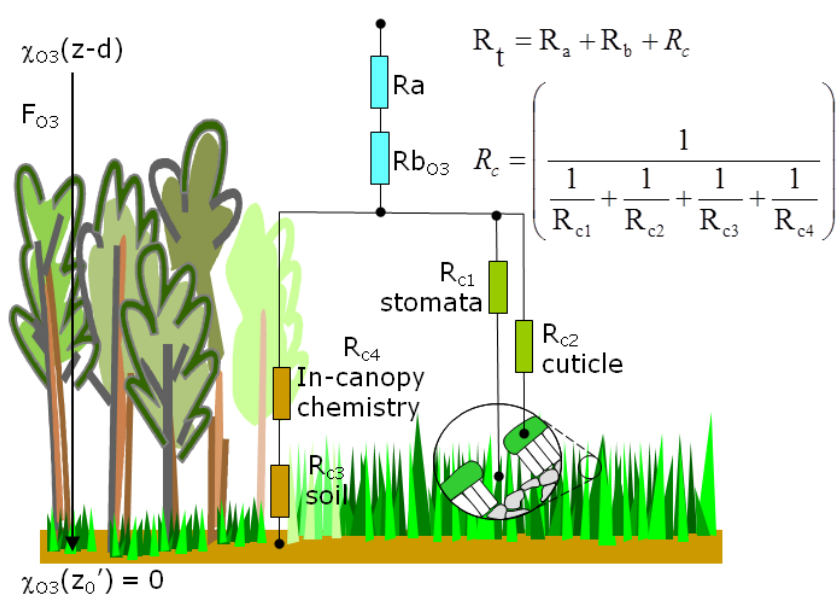

Figure 5. The resistance analogy for ozone deposition to vegetation and soil (for details of nomenclature see text).

variability with altitude has been used to quantify the spatial variability in ozone exposure at the surface.

Ozone dry deposition has been widely measured using micrometeorological methods, which average the flux to the surface at the field to landscape scale, over typically $10^{4}$ $10^{6} \mathrm{~m}^{2}$ (Fowler et al., 2009). The controlling processes in ozone deposition are generally simulated numerically using a resistance analogy (Erisman et al., 1994), as illustrated in Fig. 5. Correct parameterisation in models is critical to the determination of ozone budgets (Val-Martin et al., 2014).

Ozone is a reactive gas and deposits readily on most surfaces simply by oxidative reactions (Grontoft, 2004). Many studies have concluded that stomatal uptake is the main factor regulating surface fluxes, but as stomata are usually open during daylight hours, the smaller rates of deposition to nonstomatal surfaces are often a dominant component of the annual deposition to the surface (Fowler et al., 2009).

We consider the the main sinks for ozone deposition at the surface in turn, namely stomatal uptake, non-stomatal uptake, solar radiation/surface temperature, in-canopy chemistry and uptake to water:

\section{a. Stomatal uptake}

Plants open their stomata to take up $\mathrm{CO}_{2}$ for photosynthesis and regulate stomatal opening to minimise water loss by transpiration (Farquhar et al., 1980). This also allows the uptake of other gases that may not benefit the plant, including ozone, which, as a powerful oxidant, generates free radicals within the apoplast and cell fluids and is responsible for damage to cell metabolism (Mills et al., 2011a). Stomatal opening is controlled by water pressure in the guard cells which the plant regulates depending on the following: light - in general stomata open during the day and close at night; carbon dioxide concentration, with increasing $\mathrm{CO}_{2}$ above current ambient inducing partial closure; soil water content, 
with stomata closing in drier soils to reduce water loss; temperature, with an increase in temperature increasing stomatal opening up to a species-specific maxima above which stomatal closing is induced; humidity, with greatest stomatal opening under low vapour pressure deficits and stomatal closing occurring at high vapour pressure deficits to conserve plant water; and phenology, with stomatal conductance reducing as plants age. An example of the range of stomatal responses to these environmental and plant controls can be found for wheat in Grünhage et al. (2012). Other factors can affect stomatal opening, although not as directly as those listed above - for example, aerosols can damage the guard cells or block stomata and surface water can also block stomata.

The diffusion pathway through stomata as with atmospheric fluxes can be quantified using a resistance analogy as illustrated in Fig. 4. The inverse of stomatal resistance is stomatal conductance $\left(g_{\mathrm{s}}\right)$ and is widely used by plant scientists to quantify stomatal exchanges of $\mathrm{CO}_{2}$ and $\mathrm{H}_{2} \mathrm{O}$, and has also been used to develop stomatal flux-based risk assessments for ozone (Emberson et al., 2000; Mills et al., 2011b). The processes responsible for controlling stomatal function have been extensively studied in the field and laboratory, leading to a variety of instruments and models to quantify stomatal resistance, $R_{\mathrm{c} 1}$, or conductance, $g_{\mathrm{s}}$.

b. Non-stomatal uptake

The reaction of ozone with external surfaces of vegetation is referred to as non-stomatal uptake. In controlled conditions in the laboratory, the flux may be measured quite straightforwardly by treating the vegetation in order to fully close the stomata. In the field, there is the complication that multiple sinks are present (leaf surfaces, senescent vegetation, soil and water), as well as stomatal opening. The usual approach to quantify nonstomatal deposition is by the difference between the total deposition flux and the stomatal flux, choosing surfaces to minimise the soil and senescent vegetation components. With reference to Fig. 5, once $R_{\mathrm{c} 1}$ has been determined from measurements or by modelling, the sum of $R_{\mathrm{c} 2}, R_{\mathrm{c} 3}$ and $R_{\mathrm{c} 4}$ (non-stomatal, $R_{\mathrm{ns}}$ ) can be calculated as the residual term

$$
R_{\mathrm{ns}}=\left(\frac{1}{R_{\mathrm{c}}}-\frac{1}{R_{\mathrm{c} 1}}\right)^{-1} .
$$

Whether it is possible to separate the components of $R_{\mathrm{ns}}$ $\left(R_{\mathrm{c} 2}-\right.$ external surfaces; $R_{\mathrm{c} 3}-$ soil; $R_{\mathrm{c} 4}-$ in-canopy chemistry) depends on the nature of the measurement site and canopy, and there are some models available based on measurements over bare soil, senescent vegetation and in-canopy chemistry (Launiainen et al., 2013;
Fares et al., 2013b, 2012; Büker et al., 2012; Tuzet et al., 2011; Stella et al., 2011). Many research groups have taken this approach, and Table 1 provides a summary of some of the different estimates of the values for $R_{\mathrm{ns}}$ in the literature.

The literature reviewed in Table 1 reports estimates of $R_{\mathrm{ns}}$, although few of the listed studies examine the controlling factors. In some of the studies, surface factors affecting ozone deposition, other than stomatal uptake, have been considered. For example, surface water has been found to both enhance and reduce deposition rates. The remainder of studies have considered solar radiation or surface temperature and found deposition rates increased with both variables, as well as in-canopy chemistry.

\section{c. Solar radiation and surface temperature}

Given its reactive nature it is not unreasonable to find effects of surface temperature on $R_{\mathrm{ns}}$, and indications of such an effect were first reported by Rondon et al. (1993). In their measurements of ozone deposition to a coniferous forest, they found that the surface resistance to ozone was much lower than that predicted by stomatal conductance alone and the residual term $\left(R_{\mathrm{ns}}\right)$ varied with air temperature, radiation and stomatal conductance. It was proposed that this effect was due to temperature increasing the reaction rates of ozone with organic compounds on the canopy surface. Coyle et al. (2009) found similar results in measurements for ozone uptake by potatoes, while also showing that surface wetness could enhance or reduce non-stomatal uptake depending on the initial status of the cuticles. Fowler et al. (2001) showed a clear reduction in $R_{\mathrm{ns}}$ with increasing total solar radiation and temperature. Cape et al. (2009) examined deposition to metals and artificial leaf surfaces and found a strong temperature response, which yielded activation energies for the reaction of $\sim 30 \mathrm{~kJ} \mathrm{~mol}^{-1}$, similar to that found by Fowler et al. (2001) for moorland of $36 \mathrm{~kJ} \mathrm{~mol}^{-1}$ and from other unpublished studies (Coyle et al., 2009). The simplest explanation of non-stomatal ozone deposition is that it represents the thermal decomposition of ozone at the surface, which increases with surface temperature. Other, more complex processes have been suggested including rapid reactions with very reactive hydrocarbon compounds (Hogg et al., 2007).

\section{d. In-canopy chemistry}

The reaction of ozone with nitric oxide (NO) is an important cause of reduced ozone concentrations in urban areas. The same reaction also reduces ozone concentrations close to the surface where soil emissions of NO are large. Some types of vegetation such as coniferous 
Table 1. Selected estimates of the non-stomatal resistance for ozone to snow, water, soil and plant surfaces from measurements.

\begin{tabular}{|c|c|c|c|}
\hline Reference & Type $^{a}$ & Surface & $R_{\mathrm{ns}}, \mathrm{s} \mathrm{m}^{-1}$ \\
\hline Chang et al. (2002) & Chamber & $\begin{array}{l}\text { Agricultural soil (no data on moisture } \\
\text { content) }\end{array}$ & $\begin{array}{l}\text { ca. } 625 \\
\text { ca. } 475\end{array}$ \\
\hline Wesely et al. (1981) & Field $\mu$ met & $\begin{array}{l}\text { Wet bare soil } \\
\text { Snow }-11^{\circ} \mathrm{C} \\
-5^{\circ} \mathrm{C} \\
-1 \text { to } 2{ }^{\circ} \mathrm{C} \\
\text { Lake water }\end{array}$ & $\begin{array}{l}1000 \pm 100 \\
(370-2100) \\
2000 \pm 200 \\
3500 \pm 200 \\
3300 \pm 300 \\
9000 \pm 300\end{array}$ \\
\hline Sanchez et al. (1997) & Field $\mu$ met & Semi-arid steppe (wet and dry) & $\begin{array}{l}\text { Dry } 275 \\
\text { Wet } 437\end{array}$ \\
\hline Rondon et al. (1993) & Field chambers & Coniferous trees & $200-330$ \\
\hline Granat and Richter (1995) & Field chambers & Pine & $500-2500$ \\
\hline Coe et al. (1995) & Field $\mu$ met & Sitka spruce & ca. 133 \\
\hline Fowler et al. (2001) & Field $\mu$ met & Dry moorland & $200-400$ \\
\hline Grantz et al. (1995) & Field $\mu$ met & Wet and dry grape & $\begin{array}{l}\text { Dry } 1020 \\
\text { Wet } 292^{b}\end{array}$ \\
\hline Grantz et al. (1997) & Field $\mu$ met & Wet and dry cotton & $\begin{array}{l}\text { Dry } 770 \\
\text { Wet } 3030\end{array}$ \\
\hline Zhang et al. $(2002)^{\mathrm{c}}$ & Field $\mu$ met & $\begin{array}{l}\text { Wet and dry: } \\
\text { Mixed forest } \\
\text { Deciduous forest } \\
\text { Corn } \\
\text { Soybean } \\
\text { Pasture }\end{array}$ & $\begin{array}{l}244-970 \\
397-1831 \\
308-1332 \\
137-735 \\
571-879\end{array}$ \\
\hline Gerosa et al. $(2005,2009)$ & Field $\mu$ met & Mediterranean oak (Quercus ilex) & $\begin{array}{l}\text { Dry } 249 \\
\text { Wet } 177 \\
\text { Avg. } 67-204\end{array}$ \\
\hline McKay et al. (1992, and references therein) & Laboratory chambers and field & Sea water and saline solutions & $650-6600$ \\
\hline Gallagher et al. (2001) & Field $\mu$ met & Coastal waters & $950 \pm 70$ \\
\hline Coyle et al. (2009) & Field $\mu$ met & $\begin{array}{l}\text { Potatoes } \\
\text { Wet canopy } \\
\text { Dry canopy }\end{array}$ & 276 \\
\hline Neirynck et al. (2012) & Field $\mu$ met & Temperate forest & 136 \\
\hline
\end{tabular}

forests also emit highly reactive volatile organic compounds (Di Carlo et al., 2004) which can rapidly deplete ozone concentrations immediately above the canopy (Neirynck et al., 2012; Stjernberg et al., 2012; Kurpius and Goldstein, 2003). Over some forest canopies the major non-stomatal sink has been attributed to these reactions, although the compound(s) responsible have not been identified. Other transient events such as grass cutting, which releases very reactive hydrocarbons (Davison et al., 2008), can also lead to enhanced ozone deposition as a result (Coyle, 2005).

e. Deposition to water

It has often been assumed that ozone deposition rates to water will be small and relatively constant as ozone has a low solubility in water. The resistance of a water layer to the uptake of ozone by dissolving and diffusing the gas is very large and values of $3 \times 10^{5}$ to $8 \times 10^{5} \mathrm{~s} \mathrm{~m}^{-1}$ have been suggested by Wesely et al. (1981). Wesely et al. (1981) concluded that the far lower values found in their measurements (Table 1) resulted from surface chemical reactions, which has been supported by further work since then. However, measurements have shown that over vegetated surfaces deposition can be either enhanced or suppressed by the presence of water films (Fuentes et al., 1992; Padro, 1994; Grantz et al., 1995, 1997; Pleijel et al., 1995; Coyle et al., 2009), while over open water, deposition varies with water chemistry, turbidity and agitation. The deposition velocity of ozone to open water is generally small, $\sim 0.001$ to $0.04 \mathrm{~cm} \mathrm{~s}^{-1}$ (Wesely et al., 1981; Chang et al., 2004), and increases in deposition velocities to seawater have been observed with disturbance to the surface. McKay et al. (1992) showed that increasing concentrations of chemical sur- 
factants in the seawater also enhanced deposition (see Table 1 for typical resistance values). These results show that although deposition rates to water are generally small they can be significant if other reactive compounds are present in the water, a conclusion also supported by measurements of wet vegetated canopies. Research into ozone reactivity and solubility for the ozone water treatment industry has highlighted the role of $\mathrm{pH}$. Ganzeveld et al. (2009) explored the impact of dry deposition of ozone over oceans. On a global scale, model studies indicate that deposition to the ocean constitutes almost $40 \%$ of the total annual surface dry deposition of ozone, far larger than that from any other land cover class (Hardacre et al., 2015).

\subsubsection{Transport and mixing processes}

\section{a. Long-range transport}

Research over the past two decades has clearly shown that ozone and ozone precursors are regularly exported from their emission source, or point of production, to receptor regions far downwind on the regional, intercontinental and even hemispheric scale (see reviews by Stohl and Eckhardt, 2004; Monks et al., 2009; Council, 2009b; HTAP, 2010). These transport pathways are predominantly from west to east at mid-latitudes, with in situ and satellite-based observations showing that pollution plumes (anthropogenic and biomass burning) not only travel from North America to Europe, or from East Asia to North America, but can also circle the globe (Jacob et al., 1999; Jaffe et al., 1999; Lewis et al., 2007; Wild et al., 2004).

The scientific community has a very good understanding of the meteorological mechanisms that export pollution from the boundary layer of a source region (warm conveyor belts, deep convection and horizontal advection) and then transport these plumes through the free troposphere towards the downwind receptor region. The most recent development is the conceptualisation of intercontinental transport within an isentropic framework that illustrates how transport of pollution plumes from East Asia are constrained by the thermal structure of the atmosphere, preferentially impacting the highelevation terrain of the western USA rather than the relatively low-lying eastern USA (Brown-Steiner and Hess, 2011). The major uncertainty concerning longrange transport is in estimating the contribution of the imported pollution to the total quantity of pollution at the surface of the receptor region. Some unique chemical tracers of upwind pollution sources do exist - for example, stable lead isotopes can indicate events when Asian particulate matter reaches the surface of California (Ewing et al., 2010). However, at present there are no routine and widespread monitoring methods that can distinguish ozone and ozone precursors produced in a receptor region, such as California, from the same species produced in an upwind region, such as East Asia.

The only feasible method for quantifying the impact of imported pollution at the surface of a receptor region is to use chemical transport models or chemistry-climate models. Such models have been used for this purpose since the 1990s but until recently their effectiveness has been limited by their coarse horizontal resolution, typically $2 \times 2^{\circ}$ (HTAP, 2010). Such large grid cells artificially dilute the imported pollution plumes as well as local emissions of ozone precursors in the receptor region, and also smooth the topography of the receptor region, removing the influence of terrain-driven transport mechanisms that affect the mixing of imported pollution down to the surface. However, recent model studies have used finer-scale grids to avoid the problems associated with coarse-resolution models (Lin et al., 2012b; Huang et al., 2013; Zhang et al., 2014; Choi et al., 2014). Because these finer-resolution models provide more realistic simulations of observed pollution plumes scientists have greater confidence in their quantification of the contribution of imported pollution at the surface of a receptor region. Despite the improvements afforded by finer resolution, a recent study of the quantity of background ozone advected into western North America shows monthly mean differences as great at $10 \mathrm{ppbv}$ between models, with the discrepancy attributed to differences in the way that the models handle lightning $\mathrm{NO}_{x}$, biogenic isoprene emissions and chemistry, wildfires, and stratosphere-to-troposphere transport (Fiore et al., 2014).

Future climate change may affect the contribution of long-range transport downwind effects (Glotfelty et al., 2014; Doherty et al., 2013). HTAP (2010) suggests that "changes in climate will affect meteorological transport processes as well as the chemical environment and lifetime of the transported pollutants and hence the concentrations of pollutants arriving at downwind continents". Glotfelty et al. (2014) suggest a larger impact on the USA from East Asian emissions, and Doherty et al. (2013) showed stronger chemistry than transport positive climate feedbacks on increased ozone.

\section{b. Stratosphere-troposphere exchange}

The tropospheric ozone burden varies seasonally as measured by the remotely sensed AURA OMI/MLS tropospheric column product (Ziemke et al., 2006). The region of the Earth with the strongest seasonal ozone variation is the northern mid-latitudes where the ozone burden is at a minimum in October and November and then increases by $30 \%$ through winter and spring until it reaches a maximum in June (Cooper et al., 2014). Much of this seasonal variability can be explained by 
the flux of ozone from the stratosphere to the troposphere with a Northern Hemisphere peak flux in May and a minimum flux in November occurring predominantly in mid-latitudes (Hsu and Prather, 2009). Until recently ozone transport from the stratosphere to the troposphere was believed to be dominated by processes such as tropopause folds and gravity wave breaking, with little attribution given to deep convection (Stohl et al., 2003). However, a new model-based estimate that accounts for deep convection penetrating the lowermost stratosphere increases the Northern Hemisphere peak stratosphere-to-troposphere ozone flux by $19 \%$ and shifts the peak month from May to June (Tang et al., 2011). Sudden STE events are well known to influence ground-based ozone measurements over a short period (see e.g. Dempsey, 2014; Zanis et al., 2003).

While the tropospheric ozone burden responds seasonally to the flux from the stratosphere, the response is not uniform with altitude or latitude. Terao et al. (2008), using a chemical transport model, calculated the stratospheric contribution to monthly mean ozone above four ozonesonde sites between 75 and $36^{\circ} \mathrm{N}$. At $500 \mathrm{hPa}$ the stratospheric contribution to ozone is $\sim 40 \%$ during spring and $25 \%$ in autumn at high latitudes, and $35-40 \%$ during spring and $10-15 \%$ during autumn at mid-latitudes. At $800 \mathrm{hPa}$ these values are slightly less on a percent scale but much less on an absolute scale, being $\sim 20 \mathrm{ppbv}$ during spring and 5-7 ppbv during autumn with relatively little latitudinal gradient. Model estimates of the stratospheric contribution to surface ozone are smaller than those for $800 \mathrm{hPa}$, but the estimates vary greatly depending on the model used and the region under consideration. For example, Lamarque et al. (2005) estimated that the monthly mean stratospheric contribution to a range of sites in the mid-latitudes and tropics of both hemispheres is always less than $5 \mathrm{ppbv}$, regardless of season. In contrast, a study using a different model estimated the stratospheric contribution to US surface ozone during late spring 2010 as being $<5 \mathrm{ppbv}$ along the Gulf of Mexico coast, 8-13 ppbv across the eastern USA, and 10-20 ppbv across the high elevations of the western USA (J. T. Lin et al., 2012a). More recently Hess et al. (2015) have claimed that a large portion of the measured ozone change in the subtropical Northern Hemisphere are not due to changes in emissions, but can be traced to changes in large-scale modes of ozone variability.

c. Seasonal transport patterns (e.g. summer monsoons)

In addition to the seasonal influence of stratospheretroposphere exchange, ozone varies seasonally at most sites around the world (Oltmans et al., 2013) simply due to shifting wind patterns associated with migratory midlatitude cyclone tracks or the transition between winter and summer monsoons. For example, Mauna Loa Observatory, Hawaii, in the northern tropics, is influenced by westerly air masses from Asia in the spring, when it is located beneath the subtropical jet stream. But in autumn the subtropical jet stream is far to the north, leaving the site well within the tropical belt, which reduces transport from Asia, resulting in a $25 \%$ decrease in monthly median ozone (M. Lin et al., 2014). Similarly, Bermuda, in the subtropical North Atlantic Ocean, receives westerly transport from North America during winter and spring, but during summer the westward and northward expansion of the Azores-Bermuda High advects tropical air masses to Bermuda, reducing ozone mixing ratios by $50 \%$ (Moody et al., 1995). The North American summer monsoon becomes established above central North America during July and August, producing a stationary upper tropospheric anticyclone that traps ozone precursors lofted from the surface as well as large quantities of lightning $\mathrm{NO}_{x}$ (Cooper et al., 2009). Over several days the ozone precursors enhance tropospheric ozone within the anticyclone by as much as $30-40 \mathrm{ppbv}$ compared to sites upwind of the anticyclone (Cooper et al., 2007). Ozonesondes launched from Ahmedabad, western India, indicate that an upper tropospheric ozone enhancement does not occur during the Asian summer monsoon despite the presence of an anticyclonic recirculation similar to that found above North America during its summer monsoon. Instead, an abrupt decrease in tropospheric column ozone is observed above Ahmedabad with the onset of the Asian summer monsoon, with decreases occurring at all levels of the troposphere (Ojha et al., 2014).

\section{d. Climate variability}

While mean climatic conditions are typically established over a 30-year period, climate variability occurs on much shorter timescales of one to several years. Short-term climate variability modifies the longrange transport pathways that channel ozone plumes on regional and intercontinental scales, and also impacts regional-scale ozone photochemistry by modifying cloud cover. The impact of climate variability on ozone transport and chemistry is a relatively new field of study that has explored the effects of such phenomena as El Niño-Southern Oscillation (ENSO), the PacificNorth American (PNA) pattern and the North Atlantic Oscillation (NAO). The influence on ozone of low frequency climate variability on timescales longer than 30 years has not yet been assessed due to continuous ozone data sets being limited to durations shorter than 30 40 years.

ENSO has been shown to modulate the tropospheric ozone burden across the tropical Pacific Ocean with lower tropospheric column ozone corresponding to the cloudiest regions (Ziemke and Chandra, 2003; Sekiya 
and Sudo, 2014). Zeng and Pyle (2005) calculated an anomalously large increase in stratosphere-troposphere exchange following a typical El Niño year, increasing the global tropospheric ozone burden. In addition, changes in emissions, especially biomass burning, associated with ENSO affect the ozone burden across the tropics (Doherty et al., 2006). ENSO has also been linked to column ozone changes above Europe with positive anomalies of tropospheric ozone column and surface ozone occurring in the spring following an El Niño year, for a variety of reasons including changes in STE, biomass burning emissions and pollution transport pathways from Asia and North America (Koumoutsaris et al., 2008). Voulgarakis et al. (2010) used a global chemical transport model to determine the interannual variability in the global tropospheric ozone burden for the period 1996-2000, which included the strong El Niño event of 1997-1998. They found that $79 \%$ of the interannual variability was due to changes in meteorology (mostly stratosphere-troposphere exchange) and only $11 \%$ was due to changes in emissions. Changes in cloudiness contributed a small but non-negligible amount $(6 \%)$ to the interannual variability. ENSO and the PNA pattern also control the transport of ozone from East Asia to Mauna Loa, Hawaii. A springtime decrease in transport from Asia to Mauna Loa over the period 1980-2011 has resulted in no significant ozone trend, while an increase in transport during autumn has produced a very strong ozone trend of $3.5 \pm 1.4$ ppb decade $^{-1}$ (M. Lin et al., 2014).

The transport of ozone and other pollutants across the North Atlantic Ocean and the Arctic is heavily influenced by the NAO. During the high phase of the NAO, wintertime pollutant transport into the Arctic is enhanced by $70 \%$ compared to times dominated by the low phase, with the major source region being Europe, followed by North America (Eckhardt et al., 2003). The NAO has also been shown to modulate ozone at the high-elevation site of Izaña in the subtropical North Atlantic Ocean (Cuevas et al., 2013), with a relaxation of the predominantly high positive phase of the NAO since the mid-1990s allowing increased ozone transport from North America and the lower stratosphere to Izaña in more recent years. Across Europe surface ozone observations tend to correlate positively with the NAO (Pausata et al., 2012).

While transport of ozone from the stratosphere to the troposphere has a strong seasonal cycle, recent work has also explored changes in the stratosphere-totroposphere ozone flux and its impact on the tropospheric ozone budget. Several modelling studies have given evidence for such a link (Young et al., 2013; Kawase et al., 2011; Hess and Zbinden, 2013; Voulgarakis et al., 2011; Oman et al., 2013), even demonstrating that the Mount Pinatubo eruption of 1991 reduced the flux of ozone from the stratosphere to the troposphere until 1995 (Tang et al., 2013). According to a modelbased analysis, the interannual variability in the ozone mass flux from the stratosphere to the troposphere is of the order of $15 \%$ for the Northern Hemisphere and $6 \%$ for the Southern Hemisphere (Olsen et al., 2013). Correlations between remotely sensed ozone in the lowermost stratosphere and mid-troposphere indicate that $16 \%$ of the Northern Hemisphere mid-latitude tropospheric interannual ozone variability is controlled by the flux from the stratosphere (Neu et al., 2014). Ordoñez et al. (2007) showed that the positive ozone trends and anomalies in the lower free troposphere over Europe during the 1990s were probably due to enhanced stratospheric ozone contributions (dominated by changes in lower stratospheric ozone concentrations rather than by variations of cross-tropopause air mass transport), particularly in winter-spring. Similarly, Tarasick et al. (2005), using the ozonesonde network over Canada, and Terao et al. (2008), using a global model for the northern extratropics, found positive correlations between ozone in the troposphere and the lowermost stratosphere. Using the same data as Ordoñez et al. (2007) for the lowermost stratosphere, Logan et al. (2012) found no trends in ozone for the decades 1978-1989, 1990-1999 and 2000-2009, except for a marginally significant decrease in winter for 1978-1989, driven by very low values in early 1989 and an increase in winter and spring for 1990-1999. They found no evidence in the time series for the lowermost stratosphere from either ozonesondes over North America (Tarasick et al., 2005) or from satellite data (McPeters et al., 2007) to suggest that changes in stratospheric input can explain the increase in ozone over Europe in the 1980s. However, increases in stratospheric ozone after 1993 may have contributed to the increase in tropospheric ozone in the 1990s.

\subsection{Changing ozone $-\mathbf{a}$ brief history}

The German chemist C. F. Schönbein is credited with the discovery of ozone in 1839 (Schönbein, 1843), and its presence in the atmosphere was one of his earliest concerns (Braslavsky and Rubin, 2011). Early work by Hartley identified its UV spectrum and its role as a UV filter in the atmosphere (Hartley, 1881).

Modelling studies coupled with limited surface measurements from the late 1800s and early 1900s indicate that ozone concentrations have changed across all scales of the troposphere during the modern era due to enhanced emissions of precursors from industrialisation. A recent assessment (Cooper et al., 2014) of the most reliable historical ozone records (reliable due to the quantitative measurement methods employed) indicates that surface tropospheric ozone levels in western Europe increased by a factor of 3-5 between 


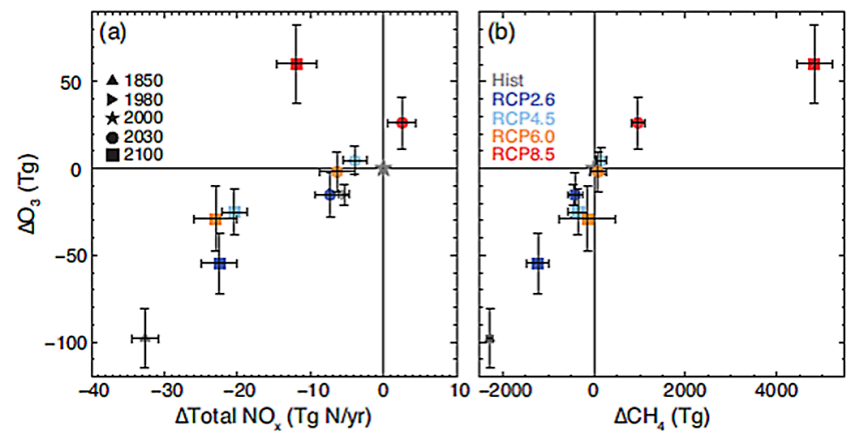

Figure 6. Ensemble mean change in the tropospheric ozone burden compared to the year 2000 simulation as a function of (a) changes in total $\mathrm{NO}_{x}$ emissions and (b) changes in the tropospheric methane burden. Error bars indicate $\pm 1 \mathrm{SD}$ of the changes in ozone, $\mathrm{NO}_{x}$ emissions and methane burdens, calculated from the spread of the models. Different colours represent the different scenarios, whereas different symbols represent the different time slices (Young et al., 2013).

the late 1800s and late 1900s, and by a factor of 2 between the 1950s and 1990s (Wilson et al., 2012; Parrish et al., 2012; Marenco et al., 1994; Staehelin et al., 1994; Volz and Kley, 1988). Many locations around the world monitored ozone in the late 1800 s and early 1900s using the semi-quantitative Schönbein ozonoscope (Marenco et al., 1994; Bojkov, 1986). These estimates indicate that surface ozone was much lower in those days compared to modern times, but the uncertainty of the measurements is so great that no accurate estimate can be made of the absolute increase in ozone (see the review by Cooper et al., 2014).

Recent modelling studies (Young et al., 2013; Lamarque et al., 2005) suggest that the tropospheric ozone burden in 1850 was $30 \%$ lower than the present day (see Fig. 6), with the largest contribution to the change coming from the Northern Hemisphere extratropics. Most current global models are still unable to reproduce the low surface ozone concentrations reliably observed at Montsouris, near Paris, at the end of the 19th century (Young et al., 2013; Hauglustaine and Brasseur, 2001), despite the models having more detailed chemistry schemes, improved emissions estimates and finer spatial resolution (e.g. Lamarque et al., 2010). This suggests either problems with interpretation of the original observations and their context or weaknesses in our assessment of precursor emissions or in our current understanding of atmospheric processes (Mickley et al., 2001). However, the inclusion of bromine chemistry can help models to approach the low ozone values measured at Montsouris in the late 1800s (Parrella et al., 2012).

Establishing quantitative ozone trends from observations is important for testing our understanding of the processes affecting ozone in the troposphere and for the attribution of these ozone changes to changes in precursor emissions, removal processes and meteorology. It is also important from an air quality perspective for determining the effect of emission controls and for identifying the extent to which surface ozone is locally or regionally controllable. Observed ozone trends are a challenge to interpret as there are a number of factors that may be responsible (Cape, 2008), including (a) changes in anthropogenic emissions of precursors (local, regional and global), (b) effects of biomass burning (both regional and global), (c) changes in stratosphere-troposphere exchange, (d) changes in geographical emission patterns, (e) changes in land cover and (f) changes in meteorology (e.g. transport patterns, rain, radiation, temperature). Long time series of high-quality measurement data are required in order to detect the trend above the large interannual variation (Staehelin, 2003; Weatherhead et al., 1998; Weatherhead et al., 2002) and the sensitivity of the extracted trends to location necessitates that this is done at a range of sites to ensure representativeness and permit attribution of the observed changes. Jonson et al. (2006) discussed some of these effects in relation to ozone trends.

Global tropospheric ozone trends were recently assessed by the Intergovernmental Panel on Climate Change (IPCC, 2013) and by Cooper et al. (2014), who provided an expanded discussion and update to the IPCC assessment. Following is a summary of the findings from Cooper et al. (2014). Prior to the 1970s, the only rural or remote quantitative ozone measurements outside of western Europe were some short-term observations from Antarctica (Wexler et al., 1960) and Mauna Loa, Hawaii (Junge, 1962), during the late 1950s. By the early and mid-1970s quantitative and continuous ozone measurements were made at several rural and remote locations around the world for the purposes of detecting long-term changes in the global composition of the atmosphere. Continuous records in southern Germany began at the rural hilltop site of Hohenpeissenberg in 1971 and the mountaintop site of Zugspitze ( $2670 \mathrm{~m}$ ) in 1978, and measurements began at the summit of Whiteface Mountain in upstate New York in 1973. Ozone measurements at remote sites were established by the US National Oceanic and Atmospheric Administration at its baseline observatories of Mauna Loa, Hawaii (1973); Barrow, Alaska (1973); the South Pole (1975); and American Samoa (1976) (Oltmans et al., 2013). Routine ozonesonde profiles became available in Germany, the USA, Japan and Antarctica in the early 1970s (Oltmans et al., 2013), and ship-borne monitoring of the marine boundary layer of the North and South Atlantic Oceans began in the late 1970s (Lelieveld et al., 2004). The number of urban, rural and remote monitoring sites has continued to grow from the 1970 s to the present day.

All available Northern Hemisphere surface monitoring sites indicate increasing ozone from 1950-1979 until 20002010, with 11 of 13 sites having statistically significant trends of $1-5$ ppbv decade ${ }^{-1}$, corresponding to $>100 \%$ ozone increases since the $1950 \mathrm{~s}$, and $9-55 \%$ ozone increases since the 1970s. In the Southern Hemisphere, only six sites are available since the 1970s, all indicating increas- 
ing ozone, with three having statistically significant trends of 2 ppbv decade ${ }^{-1}$. Ozone monitoring in the free troposphere since the 1970s is even more limited than at the surface. Significant positive trends since 1971 have been observed using ozonesondes above western Europe, Japan and coastal Antarctica (rates of increase range from 1 to 3 ppbv decade ${ }^{-1}$ ), but not at all levels. In addition, aircraft have measured significant upper tropospheric trends in one or more seasons above the north-eastern USA, the North Atlantic Ocean, Europe, the Middle East, northern India, southern China and Japan. Notably, no site or region has shown a significant negative ozone trend in the free troposphere since the 1970s. From 1990 until 2010, surface ozone trends have varied by region. Western Europe showed increasing ozone in the 1990s, followed by a levelling off or decrease since 2000 (Cooper et al., 2014). In the eastern USA, rural surface ozone has decreased strongly in summer, is largely unchanged in spring, and has increased in winter. In contrast, few rural sites in the western USA indicate decreasing ozone, with half of all rural sites showing a significant increase in spring. The decrease in ozone in Europe and the eastern USA is consistent with the decrease in ozone precursors in those regions. Meanwhile, in East Asia, surface ozone is generally increasing where ozone precursor emissions are growing.

Parrish et al. (2013) demonstrate that another manifestation of changes in tropospheric $\mathrm{O}_{3}$ is a shift of the seasonal cycle at northern mid-latitudes, so that the observed peak concentrations now appear earlier in the year than they did in previous decades (see Fig. 7). The rate of this shift has been about 3 to 6 days per decade since the 1970s. Parrish et al. (2013) put forward an untested hypothesis that this shift may be due to changes in atmospheric transport patterns combined with spatial and temporal changes in emissions. This study relied on three long-term ( $>20$ years) rural data sets in western Europe and one in the western USA. Cooper et al. (2014) also explored this topic using 21-year data sets from one additional site in western Europe and five additional sites in the USA, all in rural locations but more heavily influenced by regional ozone precursor emissions than those examined by Parrish et al. (2013). Of these six sites only three showed an earlier seasonal ozone peak; therefore the seasonal shift in the ozone cycle is not universal for time periods of 21 years or less. Similar shifts in the ozone seasonal cycle have been observed in the continental USA (Clifton et al., 2014; Simon et al., 2015; Bloomer et al., 2010).

Episodic peak ozone levels in rural areas of Europe have been declining during the last three decades due to regional pollution emission controls applied to the VOC and $\mathrm{NO}_{x}$ emissions from fossil fuel combustion associated with motor vehicles and power plants (Jonson et al., 2006; Jenkin, 2008; Derwent et al., 2010). Long-term downward trends have been observed at many long-running rural monitoring stations in the EMEP ozone monitoring network and appear to be more pronounced at those stations where initial episodic peak levels were highest and insignificant at those
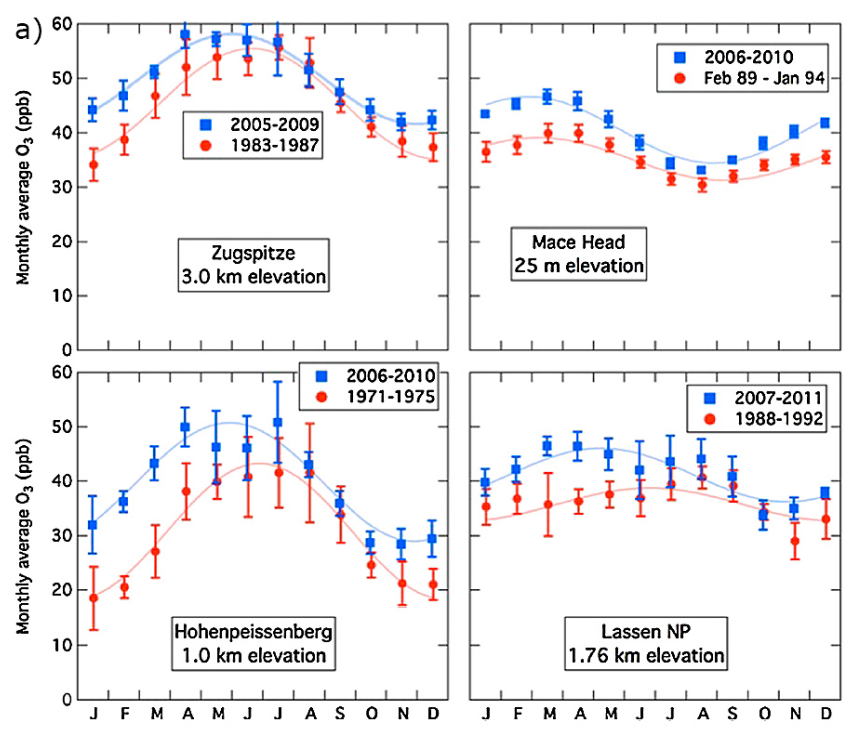

b)

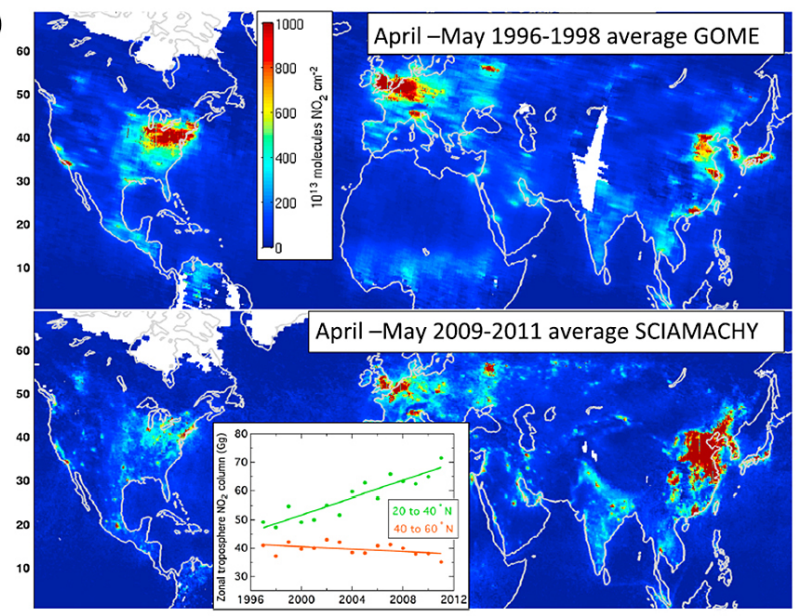

Figure 7. (a) Comparison of $\mathrm{O}_{3}$ seasonal cycles at three European and one North American sites for two periods separated by 17 to 35 years. The data points and error bars indicate 5-year averages and standard deviations of monthly averaged data for the indicated time periods. The curves of the respective colours are sine function fits to the data. (b) Comparison of satellite-measured springtime tropospheric $\mathrm{NO}_{2}$ columns during two time periods separated by 13 years. The inset shows the temporal change in the total zonal troposphere $\mathrm{NO}_{2}$ column for two Northern Hemisphere latitude bands (Parrish et al., 2013).

stations where initial levels were lowest (Derwent and Hjellbrekke, 2013). This behaviour has been interpreted as resulting from the combined effect of regional pollution controls since 1990 (Vautard et al., 2006) and increasing hemispheric ozone levels (Derwent and Hjellbrekke, 2013). In contrast, episodic ozone levels in the high- $\mathrm{NO}_{x}$ environments of major European towns and cities are now rising towards the levels found in the rural areas surrounding them, as exhaust gas catalysts fitted to petrol and diesel motor vehicles reduce the 
scavenging of ozone by chemical reaction with emitted nitric oxide (Wilson et al., 2012; Colette et al., 2011).

Whereas the vast majority of the scientific literature on ozone trends relies on rural supersites dedicated to the assessment of long-term atmospheric change, the records of regulatory monitoring networks are becoming progressively long enough to complete such assessments. In the 1990s European air quality legislation began to include some targets with regards to the ozone monitoring network, so that the network now includes several thousand sites, a few hundred of which have records longer than 10 years. The size and diversity of the data gathered in the Airbase repository (maintained by EEA) offers an unprecedented view into air quality trends in Europe, provided that (1) 10-year records can be considered long enough to assess trends, and (2) the station representativeness of thousands of urban and rural background sites can be compared to the handful of supersites used elsewhere. Colette et al. (2011) and Wilson et al. (2012) propose such assessments and conclude that the dominating picture is towards an increase in ozone in urban areas or non-significance of the rural background trends. They both report that the fraction of sites with an increasing trend is smaller when looking at peaks compared to daily means, but their findings suggest that the earlier reports of opposite signs of trends (Vautard et al., 2006) do not hold for this more recent period using this alternate monitoring data set. By including urban stations in their analysis, Colette et al. (2011) also find an enhanced contribution of upwards trends, hence reinforcing the results of Derwent and Hjellbrekke (2013) regarding the observation that urban ozone concentrations are gradually becoming closer to rural levels.

The anthropogenic contributions to the observed trends are difficult to extract from the measurements, and reflect changes in both the magnitude and distribution of precursor emissions. While global average ozone responds to changes in global precursor emissions, trends at a given location are influenced by local, regional and global emission changes that may offset each other. Multi-model ensemble studies of the contribution of regional anthropogenic emission changes to regional and global surface ozone conducted under the LRTAP Task Force on Hemispheric Transport of Air Pollution, HTAP (Fiore et al., 2009; HTAP, 2010), have been used to assess the relative contributions of long-range transport and regional emission changes to regional ozone (Wild et al., 2012). These show annual mean surface ozone increases of nearly $0.3 \mathrm{ppb} \mathrm{yr}^{-1}$ at northern mid-latitudes between 1960 and 1980, similar to observed changes (e.g. Parrish et al., 2012), but small net decreases in surface ozone over Europe and North America since 1990, when anthropogenic emissions over these regions are believed to have peaked. A recent comparison between ozone observations at northern mid-latitudes and output from three current chemistryclimate models shows that the models (1) overestimate ozone mixing ratios, on average by $\sim 5$ to $17 \mathrm{ppbv}$ in the year 2000; (2) capture only $\sim 50 \%$ of ozone changes observed over the past five to six decades, and little of observed seasonal differences; and (3) capture $\sim 25$ to $45 \%$ of the rate of change of the long-term changes (Parrish et al., 2014). These differences may reflect poor representation of emission changes or ozone changes due to natural sources, or they may reflect more fundamental weaknesses in resolving key chemical, dynamical processes or climate variability over continental regions. Further detailed analysis of the spatial and seasonal variability in local and regional ozone trends should provide a more critical test of our current understanding of the processes affecting ozone as represented in current models.

\subsection{Ozone precursors}

The spatial and temporal distribution of ozone and its precursors are in large part driven by the distribution of their emissions. An accurate knowledge of the surface emissions and of their evolution with time is therefore essential to support the analysis and modelling of air quality and climate change interactions. Up-to-date and consistent emissions are moreover required for the forecasting of the atmospheric composition (Frost et al., 2012).

Gridded global, regional and national emission estimates exist for many of the pollutants that are important for understanding and analysing the distribution of ozone and its precursors, i.e. $\mathrm{NO}_{x}, \mathrm{CO}, \mathrm{CH}_{4}$ and volatile organic compounds (VOCs). Some of these inventories are publicly available, whereas others are developed by individual research groups or government agencies to study specific aspects of emissions or atmospheric processes and are not always easy to access. In this paper, we will focus only on publicly available data sets.

Some inventories provide global coverage with relatively coarse spatial resolution, while others focus only on a specific region for selected species, and provide information at a very high spatial resolution; other inventories consider only specific sectors (such as traffic, shipping)

Over the past few years, several inventories providing the distribution of surface emissions of gaseous and particulate species have been developed, at both the global and regional scales. This section will review the main advances during the past few years concerning surface emissions having the potential to impact ozone distributions and trends. It will also discuss the current information on emissions uncertainties and we will briefly review the most recent studies using inverse modelling techniques to evaluate and optimise emission inventories.

\subsubsection{Quantification of global emissions of ozone precursors during the past decades}

Most anthropogenic emissions estimates are developed using the same methodology, based on the product of estimates for activity data for different sectors and emission factors (mass emitted per activity unit). Activity data are obtained from 

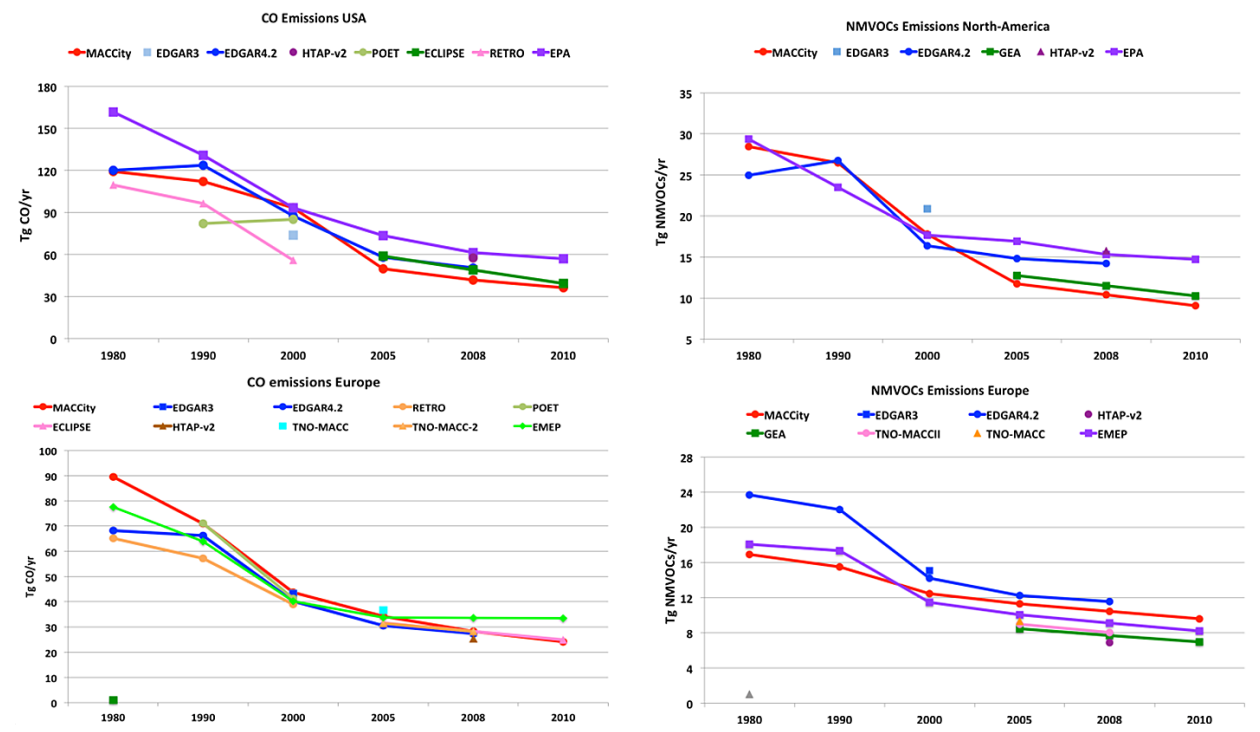

Figure 8. Emissions of CO and NMVOCs in the USA and Europe (western and central Europe) from various emission inventories.

records provided by different countries or from international organisations such as the International Energy Agency or the United Nations. This leads to a country-based quantification of emissions, which are then gridded using different types of proxies such as population, traffic, ship routes or location of power plants/factories. The quality of the gridding depends on the quality and availability of the proxies and therefore varies strongly among the different regions of the world.

The data used for the quantification of emissions are not always consistent and many inventory developers adjust these data based on expert judgment. A priori emission factors are not always available or reported for all countries and for the differing emission sectors. They depend on different factors such as the level of economic development and the type of technology used in each region.

The emissions inventories developed in the past years cover both global and regional scales. Some of these inventories provide emissions at the country level; some provide emissions for a few species or for a larger number of species, and some provide emissions for one year, a few years or a few decades. The main inventories providing emissions of gaseous and particulate compounds currently used in global modelling or analysis of the atmospheric composition at the global scale and its evolution are ACCMIP (1850-2000 on a decadal timescale; Lamarque et al., 2010) and its extension, MACCity (monthly averages for the 1980-2010 period; Granier et al., 2011); EDGARv4.2 (1970-2008; Janssens-Maenhout et al., 2011) and HTAPv2 (2008 and 2010; Janssens-Maenhout et al., 2012); ECLIPSE (2005-2050; Klimont et al., 2013b); RETRO (1960-2000; Schultz et al., 2007a); HYDE (1890-1990; van Aardenne et al., 2001); POET (1990 and 2000; Granier et al., 2005); and EDGAR3.2 (year 2000; Olivier et al., 2005).
Several inventories also provide emissions at the regional scale for different regions of the world. Among these inventories, the TNO-MACC (Kuenen et al., 2011) and TNOMACCII (Kuenen et al., 2014) provide emissions for Europe at a high spatial resolution $\left(1 / 8 \times 1 / 6^{\circ}\right)$, based on the EMEP (Droge et al., 2010) emissions reported by the European countries. In North America, the US Environmental Protection Agency (EPA) has provided emissions since 1980 for the USA (available at http://www.epa.gov/ttnchie1/), and Environment Canada has provided non-gridded emissions for Canada since 1985 (available at http://www.ec.gc.ca). Inventories are provided for Asia by the REAS-v1 $\left(0.5 \times 0.5^{\circ}\right.$ spatial resolution; Ohara et al., 2007) and REAS-v2 $\left(0.25 \times 0.25^{\circ}\right.$ spatial resolution; Kurokawa et al., 2013). The MEIC data set (available at meicmodel.org) also provides emissions for China, at a $0.25 \times 0.25^{\circ}$ resolution; Sahu et al. (2012) provide emissions at a $1 \times 1^{\circ}$ resolution for India, with Garg et al. (2006) providing non-gridded emissions for the same country. Recently, an inventory was also developed for Africa by Liousse et al. (2014) at a $0.25 \times 0.25^{\circ}$ spatial resolution.

\subsubsection{Evolution of emissions in different regions since the 1980s}

During the past three decades and the past few years, surface anthropogenic emissions have shown large changes in a few regions of the world. This section will focus on changes in emissions in Europe, North America and Asia. There is still little information on emissions changes in other areas of the world, and no detailed evaluation of the trends in emissions in these other regions can be made.

a. Emissions in Europe and North America 


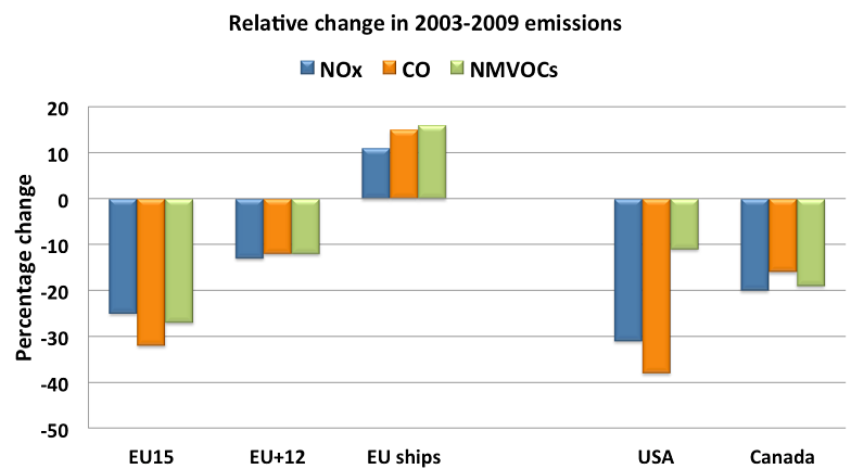

Figure 9. Relative change in $\mathrm{NO}_{x}, \mathrm{CO}$ and NMVOCs emissions from 2003 to 2009 (from Kuenen et al., 2014), per country group: EU15 includes the EU member states in 1995 as well as Norway and Switzerland, EU+12 includes the 12 new member states, and EU ships refers to all European sea regions combined. US emissions are from the USA Environmental Protection Agency (EPA) and data for Canada are from Environment Canada.

The implementation of emissions policies reductions in Europe and in North America over the past few decades has led to significant decreases in the emissions of ozone precursors. The agreement between available global and regional inventories is rather good among these inventories providing emissions of $\mathrm{CO}$ and $\mathrm{NO}_{x}$ for Europe and of $\mathrm{NO}_{x}$ for North America, with differences of $20-30 \%$ between the lowest and highest proposed values. However, larger differences are obtained between inventories providing $\mathrm{CO}$ in the USA and NMVOCs in all regions, as shown in Fig. 8.

A detailed analysis of the changes in emissions of ozone precursors in Europe between 2003 and 2009 was performed by Kuenen et al. (2014). This analysis has been extended in Fig. 9 by adding emissions for the USA and in Canada for the same period. These data highlight the significant decrease in the emissions of $\mathrm{NO}_{x}, \mathrm{CO}$ and NMVOC over the European and North American continental regions. The changes in Fig. 9 include shipping activities around Europe and the European seas. In contrast to industrial activities and to transportation in continental areas of Europe and North America, policies leading to the reduction of emissions from shipping have not yet been defined or implemented, resulting in significant increases in these emissions.

\section{b. Emissions in Asia}

Emissions in Asia have shown dramatic increases over the past few years, which are now well documented, more particularly for China. Figure 10 shows the changes in the emissions of $\mathrm{NO}_{x}, \mathrm{CO}$ and $\mathrm{SO}_{2}$ for different Asian regions since 1980: the data in Fig. 10 highlight the very large increase in $\mathrm{NO}_{x}$ emissions in China over the past few years. The main reasons for these emissions changes are increases in coal use for energy generation and industrial activities as well as a large increase in the number of vehicles (Kurokawa et al., 2013). Zhao et al. (2013) examined the impact of anthropogenic emissions control in China and have shown that these control measures have led to a decrease in the emissions factors and emissions for most compounds, except for nitrogen oxides.

Comparisons between the regional and global inventories show significant differences, as shown in Fig. 11 (C. Granier et al., personal communication, 2014): these figures show the total anthropogenic emissions of $\mathrm{NO}_{x}$ in China and India from 1980 to 2010, based on the data provided by the inventories mentioned in Sect. 2.3.1. All the inventories show an increase in the emissions over the years of the $\mathrm{NO}_{x}$ emissions, but the magnitude of the emissions and the rate of increase differ significantly between the data sets. There is a difference of about $50 \%$ between the lowest and highest total emissions in China. For India, the range of values proposed by the different groups is even larger, with a factor of about 2.5 between the lowest and highest emissions. Since $\mathrm{NO}_{x}$ concentration levels are a key factor in the production of ozone (see Sect. 2.1), such large differences in the emissions could make the analysis of ozone concentrations and their trends rather difficult to achieve. It should be noted that Figs. 8 and 11 do not display any evaluation of the uncertainties on the inventories: since the data used for developing the inventories (activity data, emission factors) are not provided with estimates of the uncertainties, no estimation of the uncertainties on the emissions can be made.

\section{c. Shipping}

It is worth noting that nearly $70 \%$ of ship emissions occur within $400 \mathrm{~km}$ of coastlines, causing air quality problems through the formation of ground-level ozone, sulfur emissions and particulate matter in coastal areas and harbours with heavy traffic (Eyring et al., 2010). Offshore shipping sources of $\mathrm{NO}_{x}$ may become significant as land based-emissions decline (Eyring et al., 2010; Jonson et al., 2009; Dalsøren et al., 2010). The impact of ship emissions on tropospheric oxidants is mainly caused by the relatively large fraction of $\mathrm{NO}_{x}$ in ship exhaust. Dalsøren et al. (2010) showed that typical increases in yearly average surface ozone concentrations in the most impacted areas from shipping emissions are $0.5-2.5 \mathrm{ppbV}$. Transport emissions are predicted to be a significant contributor to US and European ozone by 2050 (Hauglustaine and Koffi, 2012). 

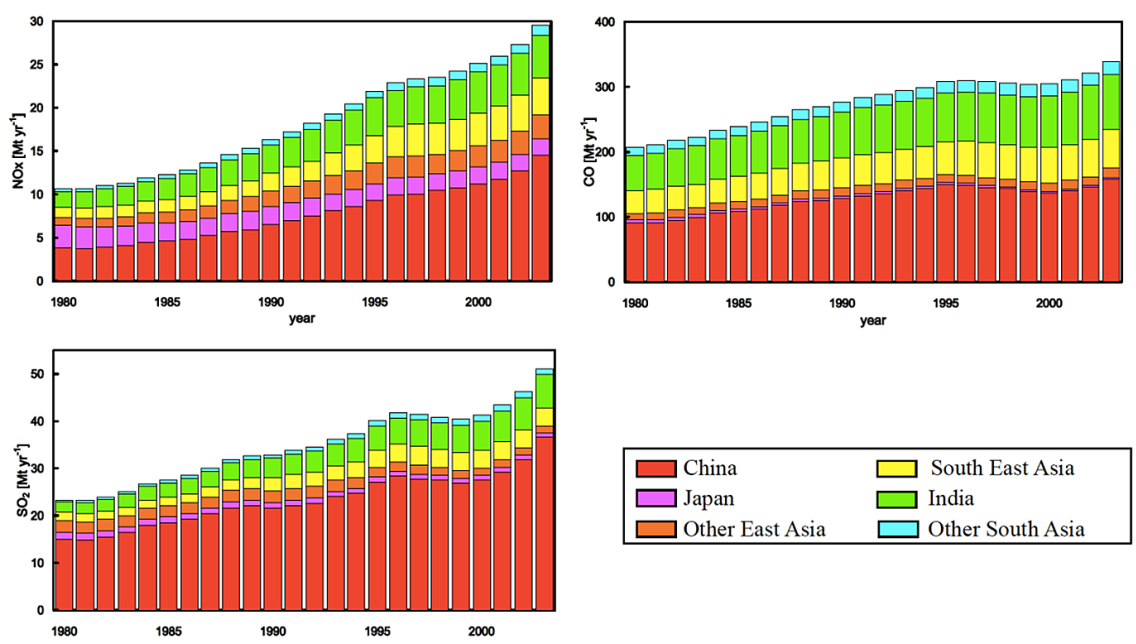

Figure 10. Evolution of surface emissions of $\mathrm{CO}, \mathrm{NO}_{x}$ and $\mathrm{SO}_{2}$ for each Asian region (from Kurokawa et al., 2013).
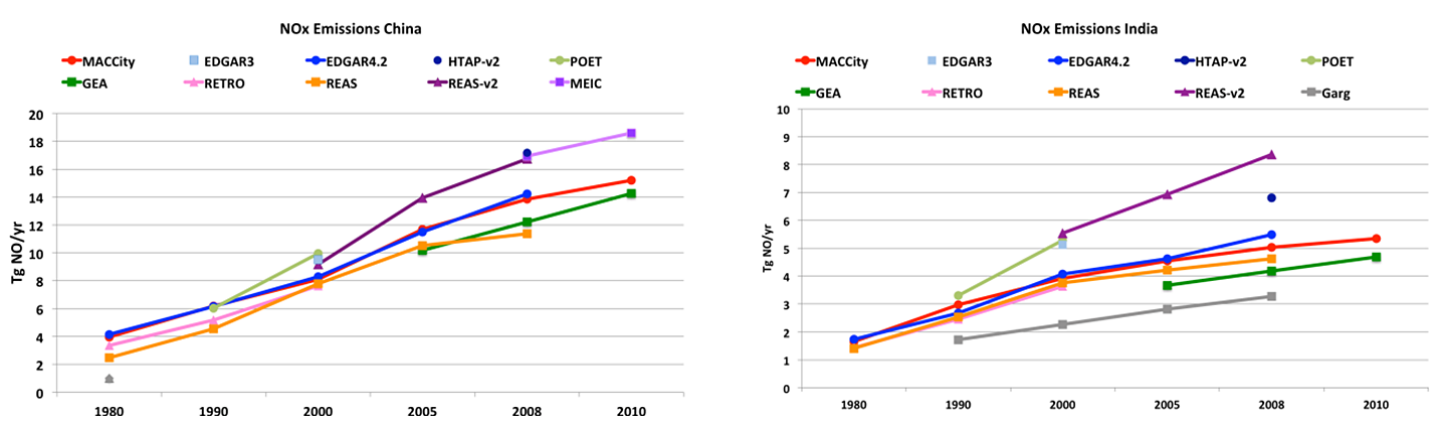

Figure 11. Evolution of $\mathrm{NO}_{x}$ emissions in China and India from 1980 to 2010 provided by different global and regional inventories (units

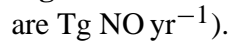

\subsubsection{Uncertainties in anthropogenic emissions in different regions}

As indicated in the previous section, most emission data sets are provided without any information on uncertainties on the data used for quantifying the emissions. Several sources of uncertainties have been identified, which will be summarised in this section.

Activity data and emission factors are generally provided without any information on their uncertainties. Emission factors are empirical functional relations between pollutant emissions and the activity that causes them: a comparison of emission factors is shown in Fig. 12, which displays measurements of emission factors in Chinese cities from different studies (Huo et al., 2012). This study has shown that the differences between emission factors are larger for older vehicles than for newer vehicles, which could be an indication of varying deterioration of emissions as vehicles get older.

The seasonal, weekly and daily variations of the emissions are generally not provided with inventories, and are not well characterised. Simple temporal profiles have been developed to describe the changes in emissions over a day, a week and a season, as shown in Fig. 13 for the European LOTOSEUROS model (Kuenen et al., 2011). These profiles depend on the emission sectors. The same diurnal profiles are applied for all days of the week and to every country in the model domain for all periods, without taking into account differences in the way of living in different countries and its change with time. Similar profiles are not available for most countries of the world, leading to large uncertainties in the temporal profiles of the emissions.

Good speciation of the NMVOC lumped species is important for inventories. The translation of speciation into globaland sometimes regional-model chemical schemes is generally poor: a gridded speciated data set has been developed as part of the RETRO inventory (Schultz et al., 2007a), and has not been revised or updated since. This speciation is currently applied to most global inventories, for all the past and future decades. In different regions, VOC speciated inventories have been developed for specific emission sectors often based on a few individual measurements that are extrapolated with dubious reliability to related unmeasured emission sources. An example of such a speciation is shown in Fig. 14 for China (Wei et al., 2008). Li et al. (2014a) developed a 

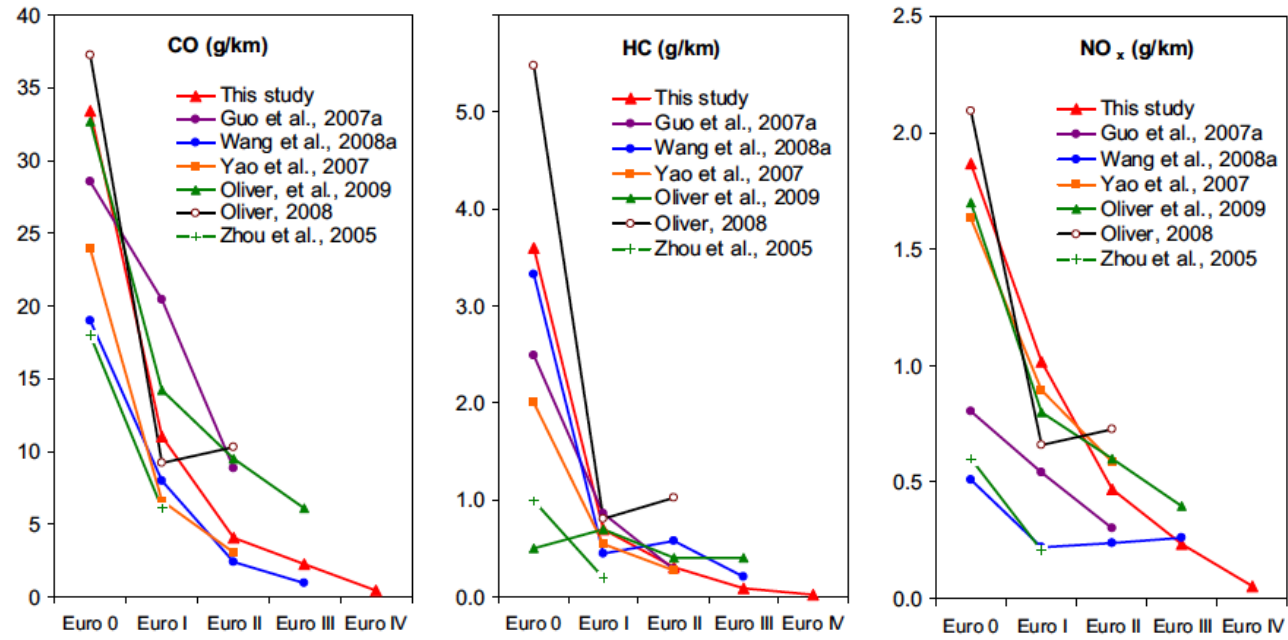

Figure 12. Comparison of emission factors of the LDGVs (light-duty goods vehicles) under real-world driving conditions from different studies showing the greater variation for older vehicles. Note that the emission measurement technologies are different among these studies (from Huo et al., 2012).
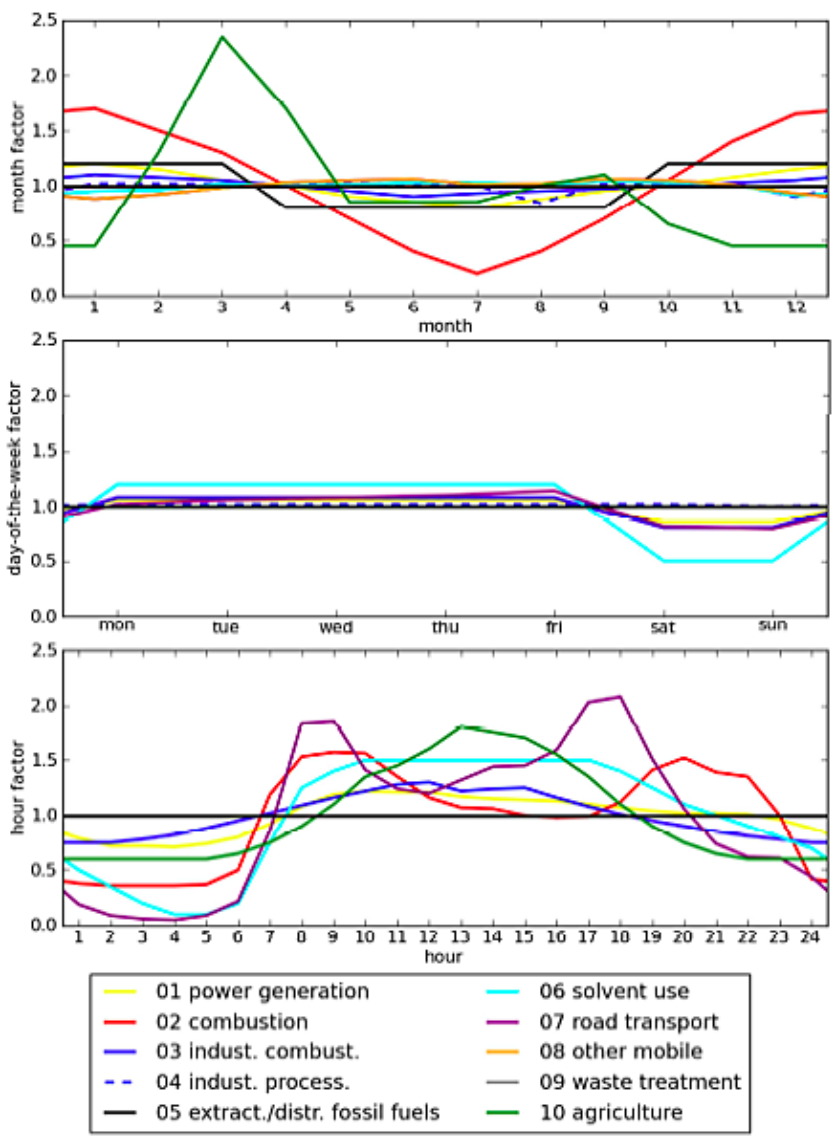

Figure 13. Monthly (top), weekly (middle) and hourly (bottom) time profiles applied to anthropogenic emissions in Europe for different sectors (from Kuenen et al., 2011).

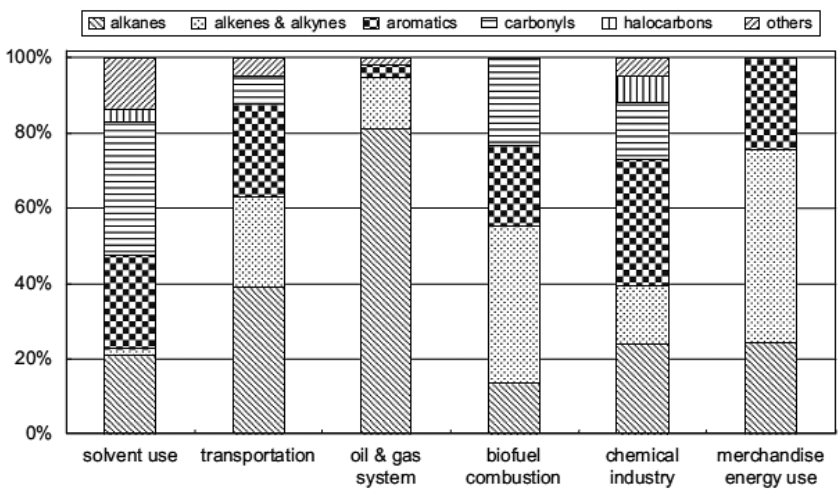

Figure 14. Chemical speciation for various emission sectors in China (Wei et al., 2008) showing the wide variation of VOCs with source that need to be represented in emission inventories.

speciation for Asia which provides emissions of a large set of VOCs for different model chemical schemes, for individual VOCs and lumped species.

Detailed information on the proxies used for the determination of the distribution in space of the emissions, i.e. emissions are also lacking on the proxies used for gridding. Other large uncertainties in the emissions are linked with resources (oil and gas) extraction and flaring, and to inland and international shipping. Emissions from agricultural practices (cattle, fertilisers, agriculture waste burning) are also very uncertain.

In order to summarise the uncertainties on anthropogenic emissions, we have calculated, for all the inventories mentioned in Sect. 2.3.1, the minimum, average and maximum values of the emissions for different world regions for $\mathrm{NO}_{x}$, $\mathrm{CO}$ and NMVOCs emissions in 2005. The ranges shown in Fig. 15 cannot be considered as a quantification of uncertain- 
ties, but they provide information on the differences between currently available data sets. Detailed evaluations of the uncertainties on anthropogenic emissions have started: for example, a methodology applying Monte Carlo simulations to quantify the uncertainties, represented as probability distributions, for the emissions of several compounds in China was proposed by Zhao et al. (2011).

Figure 15 also highlights the emissions in Africa and the rest of Asia (all Asian regions except China and India), regions where more detailed information is required for a better analysis and modelling of the global atmospheric composition.

\subsubsection{Emissions from fires}

In the last few decades biomass burning has been recognised as an important source of ozone precursors (Hao and Liu, 1994; Schultz et al., 2008; Turquety et al., 2007). Since wildfires are strongly dependent on meteorological conditions, drought episodes and human behaviour, they have a large interannual variability (Duncan et al., 2003) and the resulting emissions are very variable in time and space. It is therefore important to accurately characterise fire emissions, since they will partly drive the short-term variability in ozone precursors and ozone (Parrington et al., 2012). A review of the impact of biomass burning emissions on ozone was published by Jaffe and Wigder (Jaffe and Wigder, 2012).

The first inventories relied on data reported by forest services, observations from the ground and from aircraft. Since the late 1990s, several inventories providing emissions from fires have been developed based on observation of active fires and burnt areas by satellites, and more recently of fire radiative energy. Other inventories have also been developed, through the representation of fires in biogeochemical models. The most recent global data sets providing a spatial distribution of the emissions of ozone precursors from fires are MACCity (monthly, 1960-2008, $0.5 \times 0.5^{\circ}$ resolution; Granier et al., 2011), GFAS (daily, 2003 to present, $0.5 \times 0.5^{\circ}$ resolution; Kaiser et al., 2012), GFEDv2 (monthly, 1997$2010,0.5 \times 0.5^{\circ}$ resolution) and GFEDv3 (monthly, 1997$2010,0.5 \times 0.5^{\circ}$ resolution) (van der Werf et al., 2006, 2010), IS4FIRES (daily, 2000-2013, $0.1 \times 0.1^{\circ}$ resolution; Sofiev et al., 2009), FINN (daily, 2002-present, $1 \times 1 \mathrm{~km}$ resolution, Wiedinmyer et al., 2011), GUESS-ES (monthly, 1970-2009, $1 \times 1^{\circ}$ resolution; Knorr et al., 2012), GICC (monthly, 1900$2005,0.5 \times 0.5^{\circ}$ resolution; Mieville et al., 2010), Kloster (monthly, 1900-2004, 1.9 $\times 2.5^{\circ}$ resolution; Kloster et al., 2010 ) and RETRO (monthly, 1980-2000; $0.5 \times 0.5^{\circ}$ resolution; Schultz et al., 2008).

The inventories providing daily emissions have highlighted the very large variability in emissions from fires in the different regions of the world. Only data sets providing emissions at a high temporal resolution are able to provide information on short and intense fire episodes, which happen often in different regions of the world, as a result of specific weather conditions or human-ignited fires. An example of this variability is shown in Fig. 16, from the FINN data sets (Wiedinmyer et al., 2011), which also highlights the large number of high fire episodes in each hemisphere.

Several studies have evaluated the differences between estimates of fire inventories, as well as highlighting the large differences remaining between available data sets in different regions. Figure 17 displays a comparison of several of the data sets previously detailed, for carbon monoxide in Africa and South America (from Granier et al., 2011). Differences in the emissions for each year, as well as in the interannual variability in the emissions, are very large. It should be noted that the AMMA inventory for Africa, which includes the use of satellite observations as well as local information on the fires, provides significantly larger emissions than the other inventories, which are based either on satellite data only or on modelling of fires.

Another view of the differences between data sets is provided in Fig. 18, where $\mathrm{CO}$ emissions from different estimates are reported for different biomes (from Kaiser et al., 2013). The largest differences are reports for peat and savanna fires. The seasonal variation shown in these data sets is relatively consistent, except for temperate forests, where the consistency is very low.

The differences shown in Fig. 18 demonstrate a limit to the accuracy of emissions resulting from biomass burning. In turn, these impact on the distribution of ozone precursors and ozone through uncertainties on burned area, fuel load, emission factors and injection heights.

Data on burned areas from long-term monitoring have become available only recently, i.e. after 1995 , and these data have been evaluated only for a few regions. The satellite data provide good information on spatial and temporal patterns of fire occurrence, but so far they have not provided quantitative information with high accuracy (e.g. Giglio and Kendall, 2004). These data complement data on fires in the midlatitude regions, which are well monitored in many countries. However, monitoring by tropical countries is still scattered and scarce, owing to limited resources at the local level for records and accessibility. The effect of temporal resolution of fire emissions on models has been recently explored (Marlier et al., 2014).

The amount of fuel load and the combustion factors are calculated either from ecosystem models or through empirical formulas: these quantities depend on the fire severity, the fuel characteristics (foliage and biomass density, moisture, vegetation type, organic content and moisture of the soil) and the rate of spreading. These factors are highly variable and different studies have shown that large uncertainties still remain in the spatial and temporal variation of this quantity. A study by Knorr et al. (2012) shows that the choice of the burned-area data set has by far the largest impact on interannual variability in simulated emissions, and that for the quantification of the total global emissions, burned area and com- 

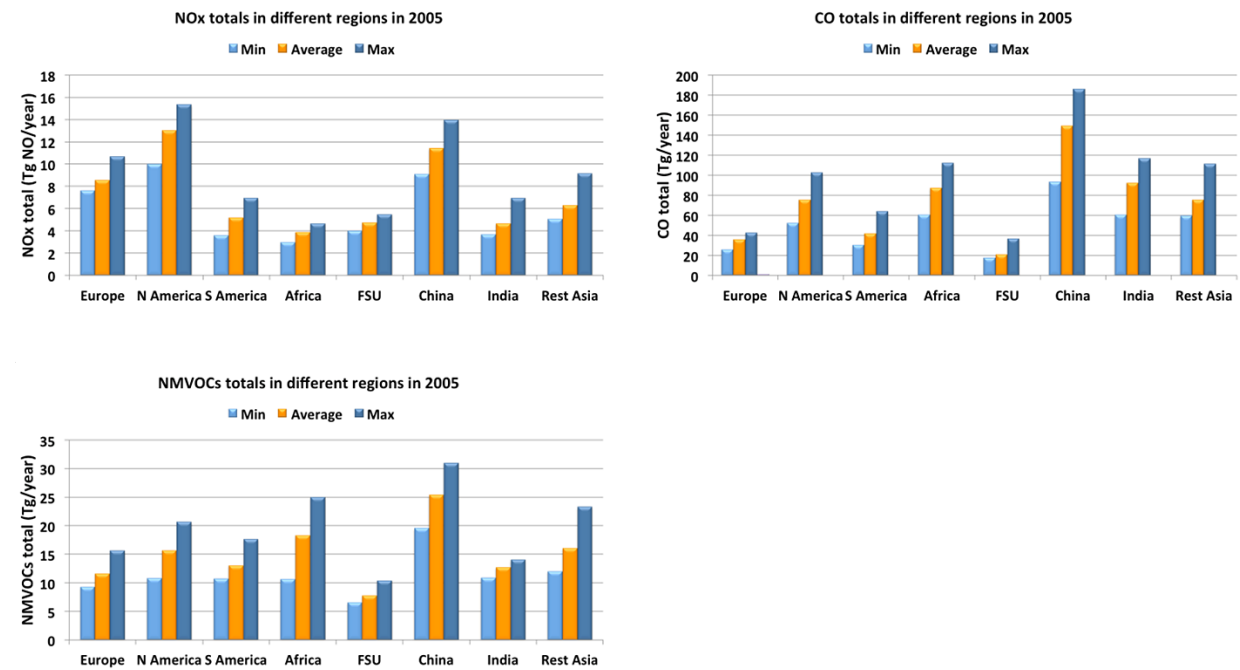

Figure 15. Minimum, average and maximum emissions taken from various inventories of $\mathrm{NO}_{x}, \mathrm{CO}$ and NMVOCs for different regions of the world in 2005 (FSU - former Soviet Union). The emissions of $\mathrm{NO}_{x}$ are reported in $\mathrm{Tg} \mathrm{NO} \mathrm{yr}^{-1}$.

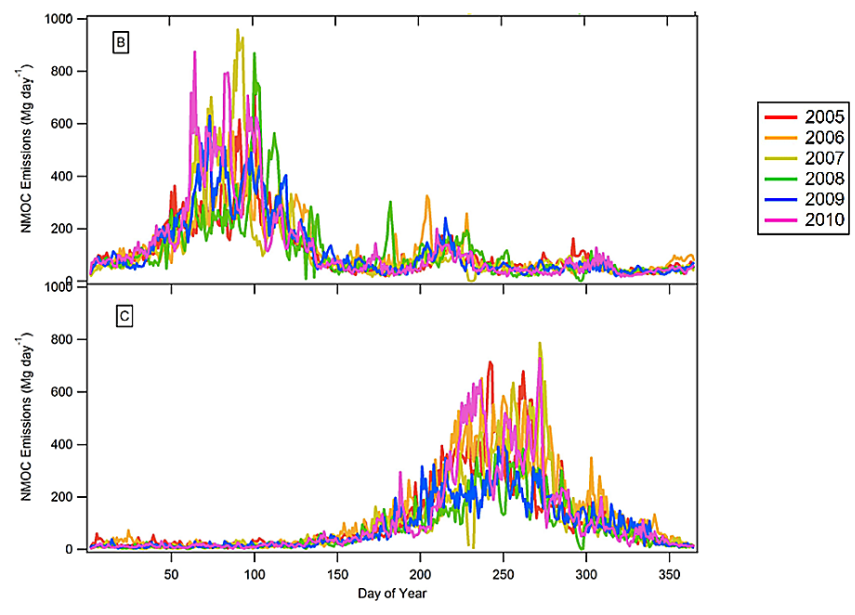

Figure 16. Daily emissions of NMVOC from fires for 2005 through 2010 for the Northern Hemisphere (top) and Southern Hemisphere (bottom) as represented in the FINN data set (Wiedinmyer et al., 2011).

bustion completeness have the largest impact on emissions for most species.

Emissions factors for the different species are generally taken as constant for each type of ecosystem in different countries. However, emissions from a fire depend on the fuel type and fire characteristics, and they are often poorly determined. Most inventories currently use the emission factors compiled by Akagi et al. (2011) or the Andreae and Merlet (Andreae and Merlet, 2001) compilation and following updates. Results from different studies nevertheless stress that more complete combustion, as in flaming fires, would lead to a larger fraction of highly oxidised species (e.g. $\mathrm{CO}_{2}$, $\mathrm{NO}_{x}$ ), while smouldering fires release more material in re- duced form (e.g. $\mathrm{CO}, \mathrm{NH}_{3}$ and NMVOC species), which indicates that emission factors may vary with season, and that fire characteristics can be very different from one fire to another even within the same geographical location. Emissions factors from peat fires are not well quantified with different studies reporting a wide range of values (Akagi et al., 2011).

The lifetime of the species released from fires depends on chemical processes in fire plumes and therefore on the vertical distribution of the plumes. The plume injection height can be critical in the impact of biomass burning (Leung et al., 2007). Several studies have proposed plume models or parameterisation of the top height of the plumes, based on empirical methods or on the use of satellite observations (Tosca et al., 2011; Val Martin et al., 2010). A determination of the vertical profiles of fires emissions at the global scale was proposed by Sofiev et al. (2013), based on satellite observations and semi-empirical formulas. An example is shown in Fig. 19, which highlights the importance of meteorology in the day-night variation of the height of fire plumes. It is worth noting that the diurnal variation of the injection height is significant such that one can practically consider two independent data sets, one for daytime and one for night-time, with transition during morning and evening (Sofiev et al., 2013). The influence on ozone can be a combination of injection height and frequency (Williams et al., 2012).

\subsubsection{Natural emissions}

Natural processes in the atmosphere, vegetation and oceans lead to the emissions of a wide range of compounds (Granier et al., 2004). Emissions resulting from lightning are discussed in Sect. 4.7. This section only focuses on emissions of hydrocarbons from vegetation, since they can have a large impact on the distribution of ozone and its precursors and 

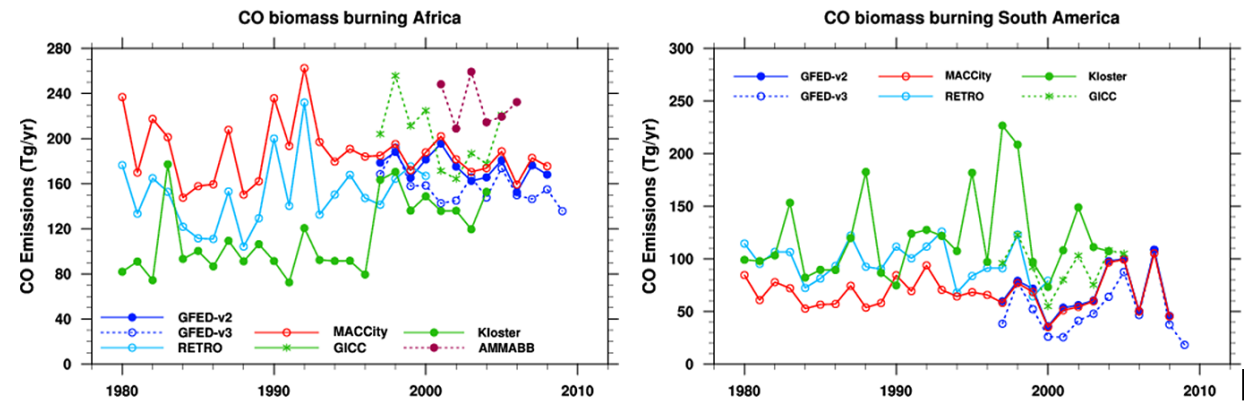

Figure 17. Emissions of CO in Africa (left column) and South America (right column) from 1980 to 2009; from Granier et al. (2011).
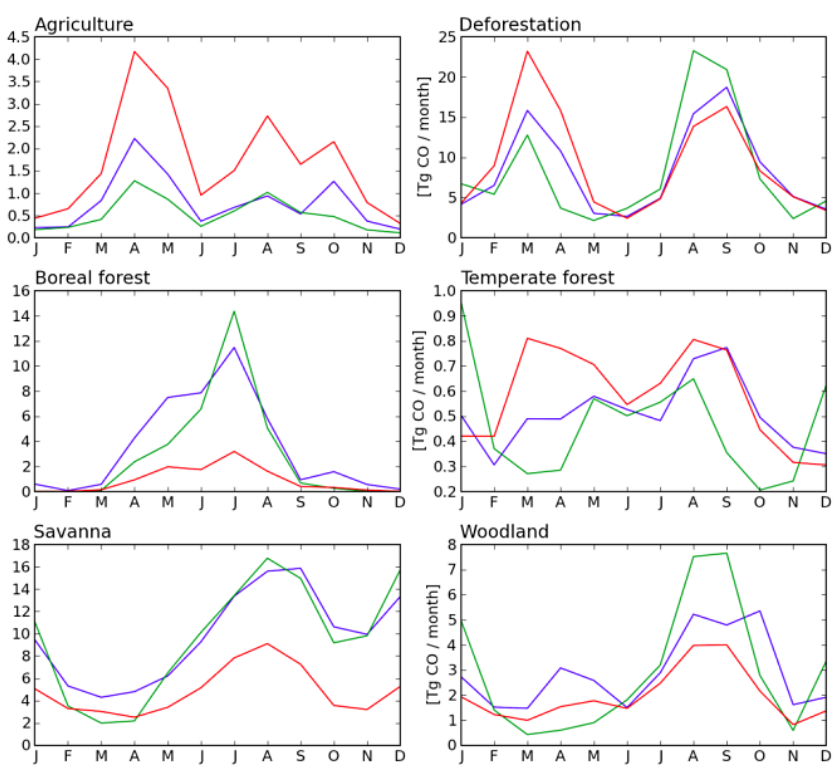

5 Tropical peat

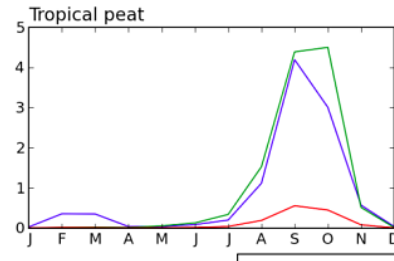

60 World mean

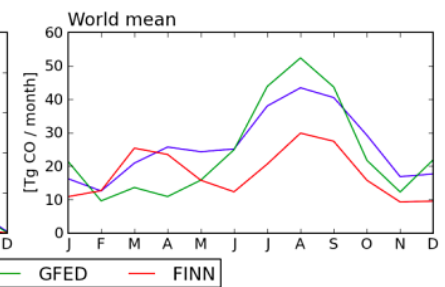

Figure 18. Mean seasonal CO emissions for seven biomes associated with dominant fire type in GFED (see Fig. 17) and the world for 2003 until 2011. Emissions are shown for three different fire emission inventories: GFAS, GFED and FINN (Kaiser et al., 2013).

because terrestrial vegetation is the dominant source of atmospheric VOCs (Guenther et al., 1995). The emissions of isoprene and monoterpenes are the largest, but many other compounds are also emitted. Many studies performed during the past few years have used MEGAN (Model of Emissions of Gases and Aerosols from Nature) to quantify the emissions of biogenic VOCs to the atmosphere. MEGAN is a model system calculating temporal and spatial rates of emission of chemical compounds from terrestrial ecosystems to the atmosphere under varying environmental conditions. It was first introduced by Guenther et al. (1995, 2006, 2003, 1993). The most recent version of the model, MEGAN v2.1, was introduced in Guenther et al. (2012). The current algorithm takes into account the impact of past and present temperature, light (sun-lit and sun-shaded leaves), leaf age, $\mathrm{CO}_{2}$ inhibition of isoprene emissions, losses of primary emissions in the canopy and soil moisture.

Examples of emissions of isoprene, monoterpenes and methanol in 2003 are shown in Fig. 20, together with the relative contribution of the different biogenic VOCs to the total amount emitted. Isoprene emissions account for $56 \%$ of the total, which indicates that the emissions of the other BVOCs and their chemical oxidation schemes (see Sects. 4.3 and 4.10) also need to be taken into account when simulating the atmospheric composition of the atmosphere.

Previous studies show significant differences between the total amount of BVOCs emitted by vegetation (Sindelarova et al., 2014). These differences are related to the large uncertainties of different factors driving BVOC emissions, such as radiation amount, leaf temperature, and parameterisation of the soil moisture factor or the representation of canopy processes. There are also large differences in the vegetation types and in the distribution of plant functional types used in different models and/or their assignment with BVOC emission activity.

Other methods have been used to calculate the emissions of BVOCs by the vegetation. Arneth et al. (2007), for example, calculated the emissions using a dynamic global vegetation model (LPJ-GUESS; Sitch et al., 2003) and a physiological BVOC emission algorithm. Studies conducted using the LPJ-GUESS model (Arneth et al., 2011) have shown that variations of driving input data such as meteorology and vegetation description among different models might lead to substantially different emission estimates.

Figure 21 shows the differences between previous estimates of global total isoprene emissions: the difference between the lowest and highest estimate is $65 \%$. In Fig. 21, the three values indicated by green bars correspond to an optimisation of isoprene emissions using inverse modelling techniques and formaldehyde satellite observations (see next section). The difference between the highest and lowest value 

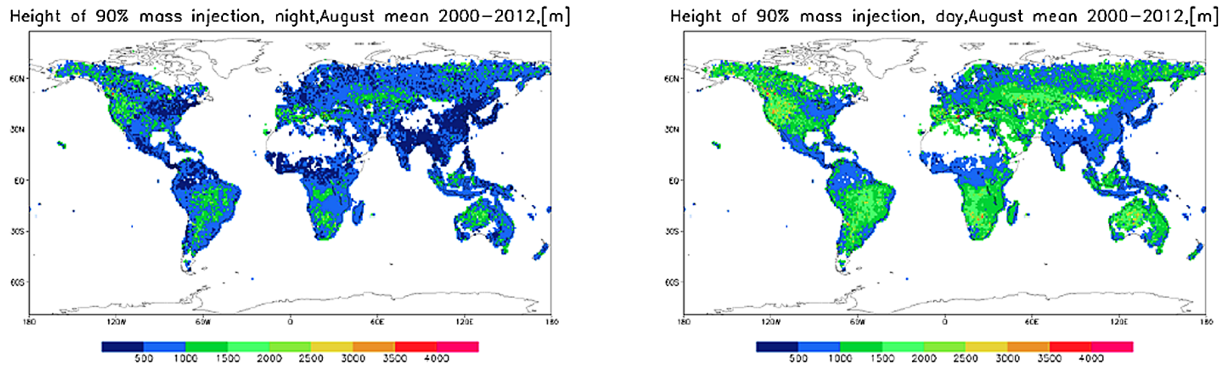

Figure 19. Injection height (in $\mathrm{m}$ ) for $90 \%$ of the mass injection for night (left) and day (right) for August from biomass burning (Sofiev et al., 2013).
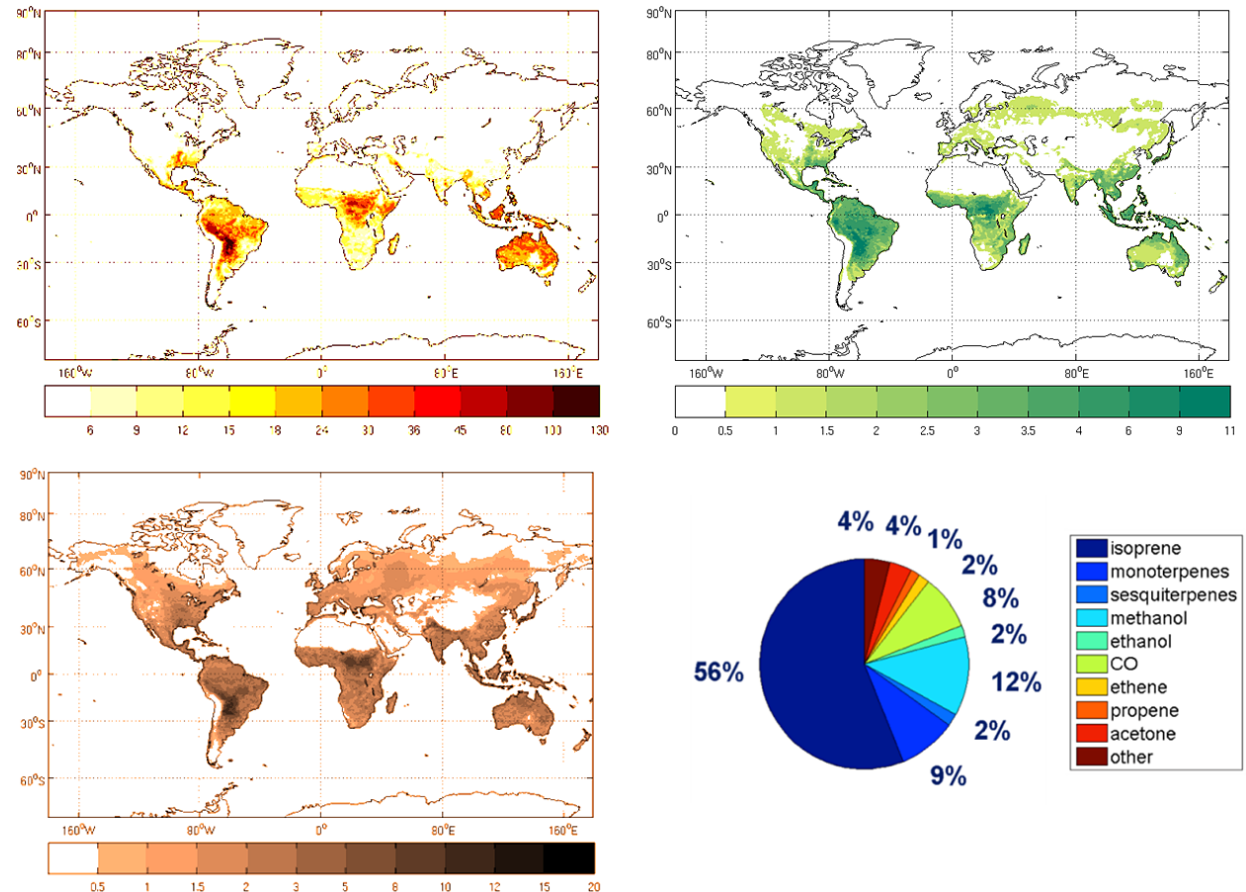

Figure 20. Mean annual emissions (in $\mathrm{mg} \mathrm{m}^{-2}$ day $^{-1}$ ) of isoprene (top left), monoterpenes (top right), methanol (bottom left), and contribution of each BVOCs to the annual global total average (bottom right) (Sindelarova et al., 2014).

is about a factor of 2 , which highlights the large uncertainties on the determination of isoprene emissions.

\subsubsection{Evaluation and optimisation of emissions using inverse modelling techniques}

Inverse modelling techniques have been widely used during the past few years to optimise surface emissions so that simulated atmospheric concentrations can reproduce observed concentrations. Most recent studies either minimise the weighted distance between model and observations (variational approach) or minimise the error variance of the estimated parameters (Kalman filter techniques) (Saide et al., 2011). Differences between the distributions provided by the models and the observations are not only due to inaccuracies on the quantification of emissions or errors in the model data (meteorological fields for example) but also in the representation of physical and chemical processes in the models: all these factors need to be taken into account in inverse systems (Elbern et al., 2007). Estimates of emissions using inverse techniques also depend on the a priori emission data set used, on the meteorological fields used to drive the models used that infer emissions (Arellano and Hess, 2006), and on the data used in the optimisation of the emissions (Hooghiemstra et al., 2012). A review of the current capabilities of inverse techniques to better quantify surface emissions in North America using satellite observations was published by Streets et al. (2013).

These techniques have been mostly applied to the species for which observations from satellite are available or for the optimisation of local/regional emissions when comprehen- 


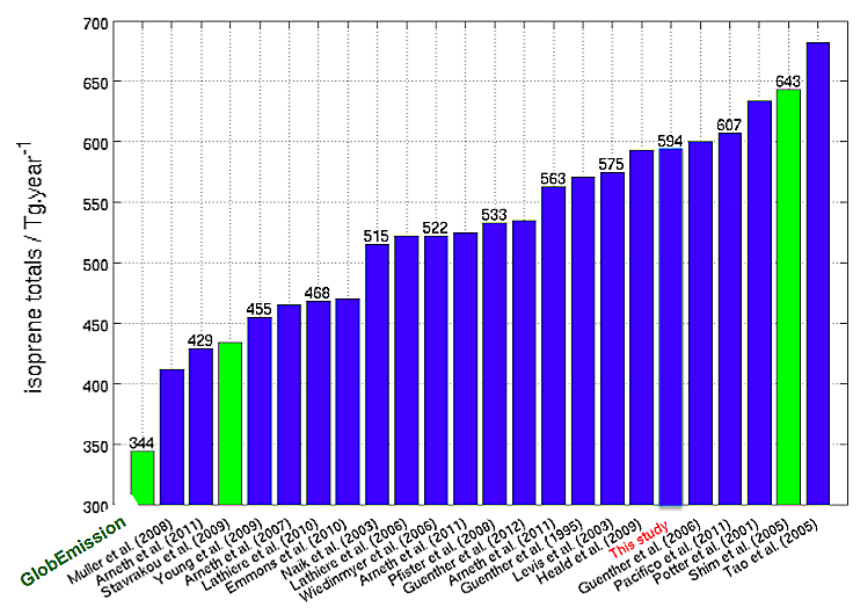

Figure 21. Isoprene global total estimated from different studies. Studies highlighted in green used formaldehyde satellite data and an inversion modelling technique to constrain isoprene emissions (Sindelarova et al., 2014).

sive observation data sets exist. Therefore, most studies have discussed the optimisation of greenhouse gases $\left(\mathrm{CO}_{2}\right.$ and $\mathrm{CH}_{4}$ ), of ozone precursors $\mathrm{CO}$ and $\mathrm{NO}_{2}$, of aerosols and their precursors (see Fuzzi et al., 2015), and of biogenic emissions using satellite observations of formaldehyde.

Several studies have applied inverse modelling techniques to the optimisation of $\mathrm{CO}$ emissions using observations from surface networks (Petron et al., 2004) as well as observations from the MOPITT and IASI satellite instruments. Most of these studies using satellite data have concluded that the a priori anthropogenic emissions of $\mathrm{CO}$ might be underestimated as indicated in Fig. 22a (Fortems-Cheiney et al., 2011) and Fig. 22b (Tohjima et al., 2014), more particularly at midlatitudes of the Northern Hemisphere in winter (Kopacz et al., 2010; Stein et al., 2014). However, an analysis of satellite and aircraft observations has also shown that emissions inventories in North America might provide overestimated values (Miller et al., 2008). Emissions resulting from fires have also been optimised using satellite data, which have shown that current surface inventories might underestimate fires in boreal regions (Pfister et al., 2005). Inverse techniques have also provided information on the seasonal cycles of emissions from fires, for example in Africa as shown by Chevallier et al. (2009).

Several studies have used satellite $\mathrm{NO}_{2}$ column observations to constrain nitrogen oxide emission inventories through inverse or forward modelling (Martin et al., 2004; Kim et al., 2009; Lamsal et al., 2011; Wang et al., 2012). These studies exploited the relatively short lifetime of tropospheric nitrogen oxides, which ranges from several hours to a few days. As a result, $\mathrm{NO}_{2}$ has its largest concentrations in the boundary layer close to emission sources, making measurements of $\mathrm{NO}_{2}$ columns well suited to improving our knowledge of the emissions of $\mathrm{NO}_{x}$. Two examples of optimisations of $\mathrm{NO}_{x}$ emissions using satellite observations are given in Fig. 23. Figure 23 (left) shows a quantification of emissions trends in China as provided by an inventory and optimised using the SCIAMACHY/GOME observation for the 1996-2004 period is shown in Fig. 23 (Zhang et al., 2007). From 1996 to 2004, $\mathrm{NO}_{x}$ emissions over eastern central China region increased by $61 \%$ according to the inventory, while a $95 \%$ increase in the $\mathrm{NO}_{2}$ columns was obtained from the satellite observations during the same period. Stavrakou et al. (2008) evaluated the changes in the emissions in different regions of the world from 1997 to 2006 using an inverse method and found larger increases in the optimised emissions when compared to prior emissions in the East Asia region, with emissions decreasing faster than in the inventories in North America.

Optimisation of the emissions of several other compounds have also been evaluated through inverse methods constrained by satellite observations, such as isoprene, methanol or formaldehyde (Stavrakou et al., 2011, 2009; Palmer et al., 2003; Wells et al., 2014; Barkley et al., 2013), and other studies have focused on the optimisations of the emissions from different sectors, such as ships (de Ruyter de Wildt et al., 2012; Vinken et al., 2014).

\subsection{A climatological view of ozone/linkages across the scales}

The available observations show that tropospheric ozone is highly variable both in space and time, on long and short scales. Over the remote oceans, observations show low ozone amounts within the tropical Hadley circulation with little or no vertical gradient in mole fraction, then higher concentrations at mid-latitudes, with an increase with height, corresponding to the additional source of tropospheric ozone from STE as well as in situ chemistry (see Figs. 24 and $25)$. Over the continents and nearby oceans in the lower troposphere, different behaviour is observed depending on the level of the ozone precursors. Analysis of the seasonaldiurnal variations allows for separation of the following types of ozone variations in the extratropics (Tarasova et al., 2007): clean background; rural; semi-polluted, non-elevated, semipolluted, semi-elevated, elevated, and polar/remote marine. For the "clean background" regime in the Northern Hemisphere, the seasonal maximum is observed in March-April, both for night and day. For those sites with a double maximum or a wide spring-summer maximum, the spring maximum appears both for day and night, while the summer maximum is more pronounced for daytime and hence can be attributed to photochemical processes. There is much debate as to the origin on the spring maximum, which is likely a combination of dynamical/transport processes and photochemistry (Monks, 2000).

In July, northern summer, major regions of elevated lower troposphere ozone are observed over the USA, Europe and East Asia from urban/industrial activities and regions of el- 

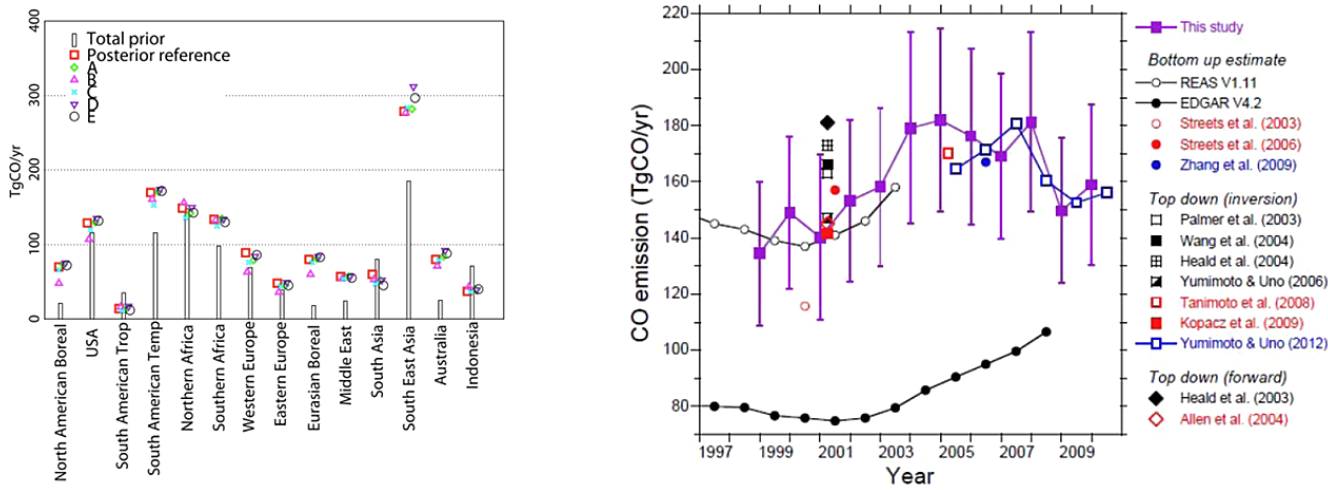

Figure 22. Left panel: annual total posterior CO emissions per region for year 2004 compared to the a priori reference: the different cases correspond to tests on different errors in the model (Fortems-Cheiney et al., 2011). Right panel: comparison of estimated CO annual emissions in China from inventories and inverse studies; "This study" refers to a top-down estimate (Tohjima et al., 2014).
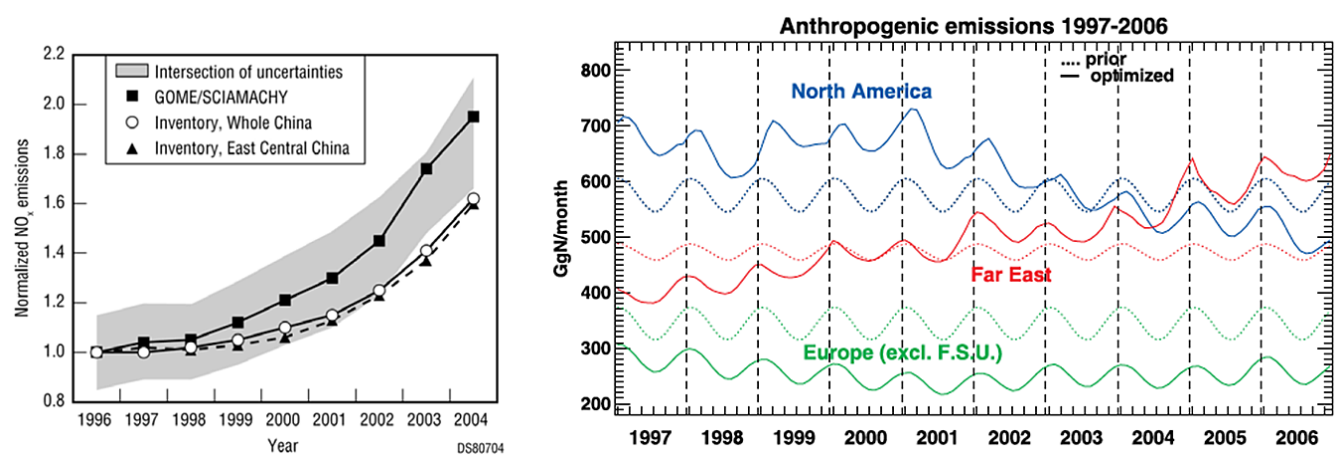

Figure 23. Temporal evolution of $\mathrm{NO}_{x}$ emissions over China from the Zhang et al. (2007) inventory (left panel) and inverse method using satellite observations (right panel). All data are normalised to the year 1996 (Zhang et al., 2007).

evated ozone over the tropics due to both biomass burning and other human activities. Satellite observations of tropospheric ozone have revealed much detail about the spatial distribution, including the discovery of the regional tropospheric ozone maximum off south-west Africa over the Atlantic Ocean (Fig. 24) and the oscillation of tropospheric ozone over the Indonesian archipelago in synchronicity with El Niño (Ziemke et al., 2010). In highly dynamic regions such as the Mediterranean Basin (Lelieveld et al., 2002, 2009), the strength of the meteorological systems (Azores anticyclone and Middle Eastern depression) are key factors in explaining both the variability and the anomalies of ozone in the lower troposphere in this region (Doche et al., 2014). Recent observations have suggested there is a summertime free-tropospheric ozone pool over the Mediterranean (Zanis et al., 2014; Kalabokas et al., 2013).

The data in Fig. 24 clearly highlight the benefits offered by satellite data for investigating the global distribution of tropospheric ozone. However, it should be kept in mind that such data give an incomplete picture (Monks and Bierle, 2011) which requires complementary observing systems (Laj et al., 2009). It is worth noting that there are direct tropospheric

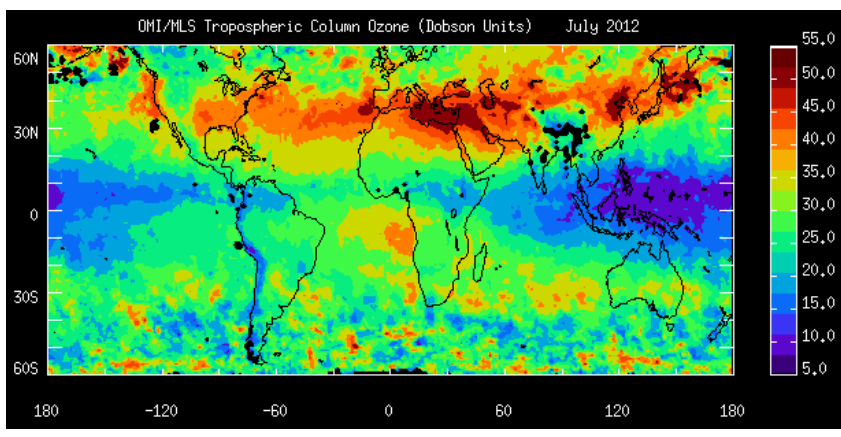

Figure 24. Tropospheric ozone columns determined by residual from OMI observations of total column $\mathrm{O}_{3}$ and MLS observations of stratospheric $\mathrm{O}_{3}$ (Ziemke et al., 2006). Plots retrieved from http: //acd-ext.gsfc.nasa.gov/Data_services/cloud_slice/index.html\#nd.

ozone retrievals from satellite data (Liu et al., 2006). The AMMA campaign (Redelsperger et al., 2006) and associated analysis performed with the in situ MOZAIC (Sauvage et al., 2005) and SHADOZ data (Thompson et al., 2003a, b) have revealed a somewhat different feature of ozone distribution (both in terms of amount of the tropospheric columns 

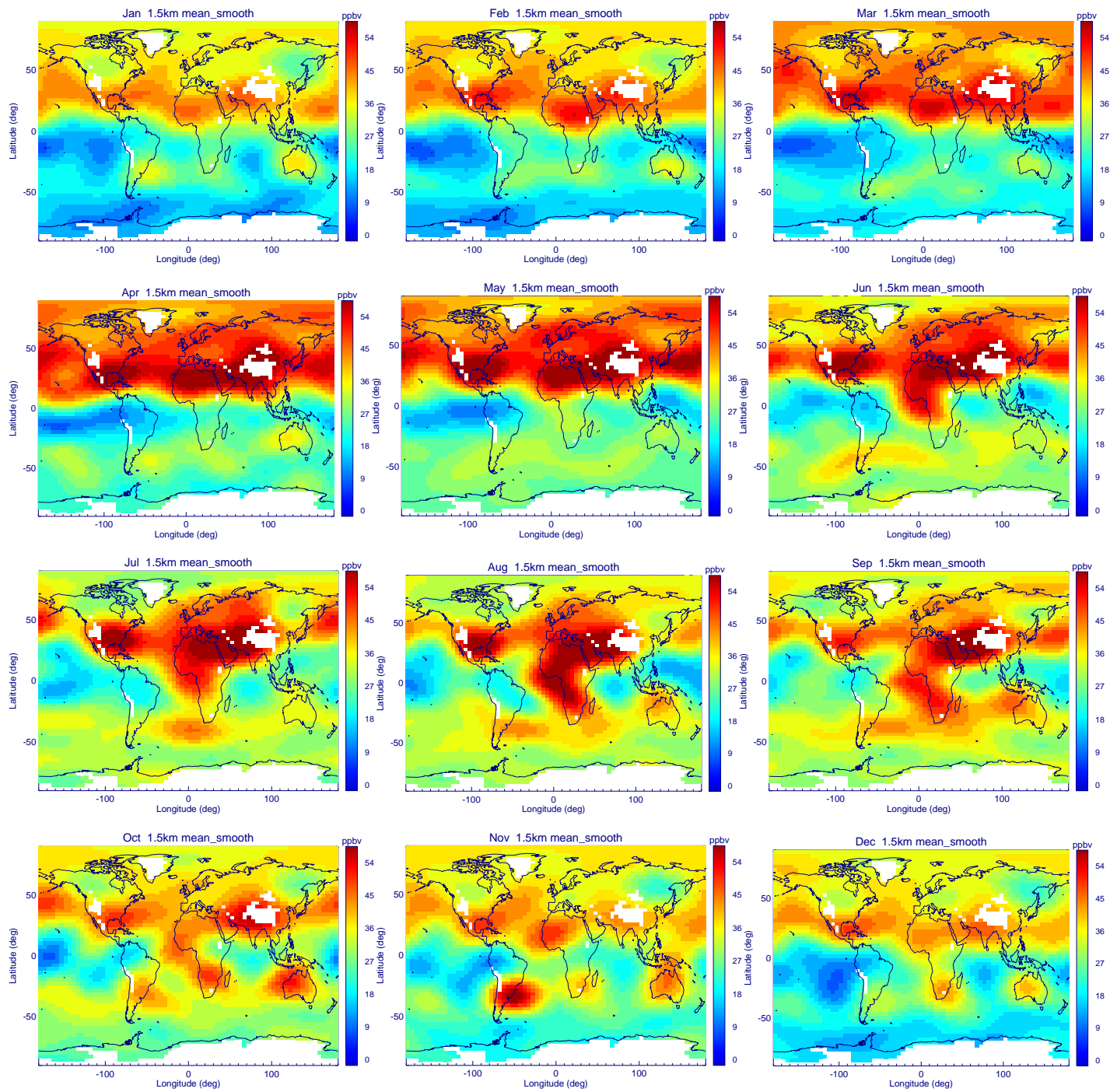

Figure 25. Monthly global ozone distributions at $1.5 \mathrm{~km}$ a.s.1 from trajectory-mapped ozone soundings (G. Liu et al., 2013).

and in the location of the maxima) over western and southern Africa including the adjacent Atlantic Ocean. In July, when biomass burning mainly occurs over the southern tropical part of Africa, the tropospheric ozone column is about 45 DU over the continent (Thompson et al., 2014; Sauvage et al., 2005, 2006). Export of polluted air masses is observed throughout the Gulf of Guinea up to the coast of West Africa in the Northern Hemisphere. Reeves et al. (2010) provide a clear characterisation of the ozone distribution throughout the troposphere over West Africa during the monsoon period. Owing to previous analysis based on MOZAIC data (Sauvage et al., 2007a, 2005) and the regular ozone soundings over Cotonou over 2 years (Thouret et al., 2009), it has been shown that the biomass burning seasons in both hemispheres impact the tropospheric ozone profiles in both hemispheres as well. As a consequence, a picture like the so-called “ozone paradox" (Thompson and Hudson, 1999) was shown to be no longer valid (Sauvage et al., 2006) owing to the insight provided by additional in situ observations. Recent work has shown evidence for the removal of ozone in the Saharan dust plume (Andrey et al., 2014) which is correlated with both dust loading and total amount of water present.

At coastal or island sites in the tropics, diurnal variation in ozone generally show a minimum during the daytime. Occasional air transport events from the mid-latitudes bring in higher ozone concentrations (Lawrence and Lelieveld, 2010). The mole fractions are low, typically $5-20 \mathrm{ppb}$, and the annual maximum occurs in June to September, southern winter, a characteristic of ozone in the Southern Hemisphere troposphere. For more continental tropical regional sources of ozone due to precursor emissions from such activities as biomass burning (e.g. Ojha et al., 2014; Cristofanelli et al., 2010), land clearing, agriculture and human settlements may cause occasional elevated ozone concentrations (Jacob et al., 


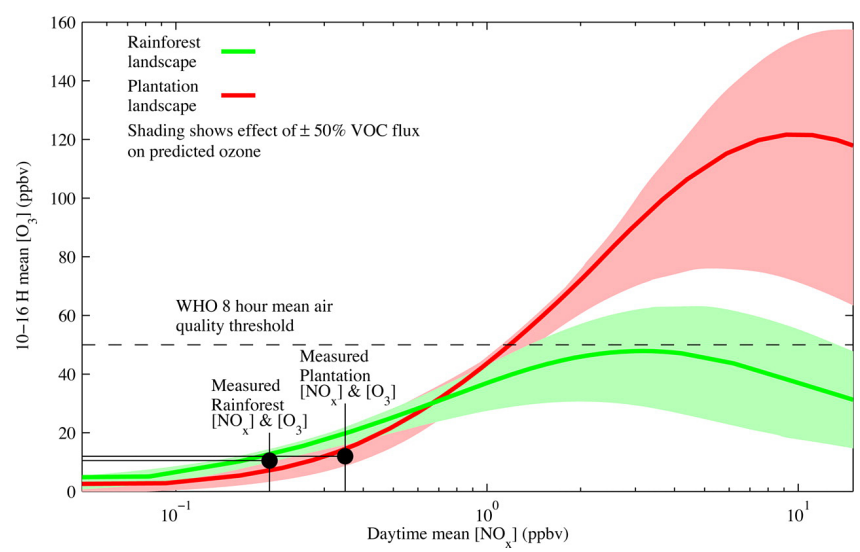

Figure 26. Sensitivity of daytime (10:00-16:00) average ozone concentrations to $\left[\mathrm{NO}_{x}\right]$ in the boundary layer for isoprene and monoterpene emission rates measured in a rainforest and palm oil landscape (Hewitt et al., 2009).

1996). The seasonal ozone variation may be affected by these activities which can be influenced by seasonal meteorological conditions such as the occurrence of a wet/dry seasons (Valks et al., 2014; Rama Gopal et al., 2014; Cristofanelli et al., 2010; Sinha et al., 2014). Under stable conditions, ozone depletion due to ozone deposition and NO titration will occur. The diurnal variation of ozone will generally be characterised by lower concentrations at night and higher concentrations during the daytime (see e.g. Rama Gopal et al., 2014). Vegetation cover plays an important role together with local meteorology in (natural) trace gas emissions. For example, tropical forests and plantations are among the greatest emitters of isoprene, a reactive hydrocarbon species which is involved in the photochemical cycle of tropospheric ozone (see Sect. 4.3). Replacement of tropical forest by agriculture (e.g. palm trees) may cause potential future elevated ozone levels (Hewitt et al., 2009; MacKenzie et al., 2011) (see Fig. 26).

High-latitude sites may be influenced by the nearcontinuous presence of snow or ice cover (Helmig et al., 2007). Polar sites may have wind directions that remain relatively constant for months. Coastal sites may have ozone depletion events, which are related to halogen chemistry (Simpson et al., 2007), and which is evident, for example, at Barrow during northern spring, March to May (Oltmans et al., 2012). The high reflectivity of snow and ice influences the photochemical reaction rates, because more UV radiation is available than would be expected for these latitudes if one assumes a global average value for the surface UV albedo. In stable conditions with bright sunlight, local photochemical production has been observed due to $\mathrm{NO}_{x}$ emission from the snow (Helmig et al., 2008a, b) and this is evident at the South Pole during November to February, centred on southern summer. The ozone concentrations in background air at

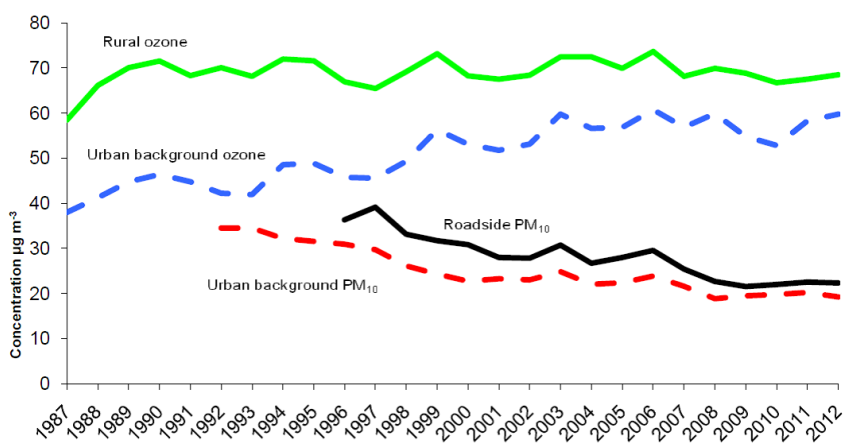

Figure 27. Annual levels of ozone (and $\mathrm{PM}_{10}$ ) in the UK, 19872012 (Defra, 2013), showing the rise of urban ozone concentrations towards the rural ones and the relatively flat rural concentrations over the last decade.

the South Pole peak in winter/spring and fall to a minimum in summer/autumn as with other Southern Hemisphere sites.

Moving to the urban scale, the local coupling of $\mathrm{NO}_{x}$ and $\mathrm{O}_{3}$ is important in that reductions in NO can contribute to increases in ozone (Kley et al., 1994). In areas of high $\mathrm{NO}_{x}$, as is often observed in urban areas, ozone levels can be suppressed through Reaction (R4).

This phenomenon, sometimes dubbed " $\mathrm{NO}_{x}$ titration", thereby leads to the counterintuitive effect that reducing $\mathrm{NO}_{x}$ (NO) reduces the amount of ozone being suppressed and actually increases ozone (Heal et al., 2013; Sicard et al., 2013). The spatial variability in ozone in larger urban areas can be very much driven by "titration" (Escudero et al., 2014). Figure 27 shows the gradual increase in urban ozone, moving towards background levels, driven by reducing $\mathrm{NO}_{x}$ emissions over the last couple of decades in the UK, decreasing the suppression of ozone. Figure 28 shows the "titration" in urban areas across Europe from modelling studies, showing the widespread nature of this effect and the need to couple the regional and hemispheric picture to the urban. In a sense there is an urban decrement driven by this process. Conversely, there has been some work looking at megacity impacts on regional ozone (Tie et al., 2013; Beirle et al., 2011; Guttikunda et al., 2005) (see also Sect. 4.1).

Given the strong $\mathrm{NO}_{x}-\mathrm{O}_{3}$ (sometimes referred to as $\mathrm{O}_{x}$; Zlatev et al., 1992; Yu et al., 2008; see also Fig. 28) couple at the urban scale there are a number of issues regarding the role of an increase in the $\mathrm{NO}_{2}: \mathrm{NO}$ emission ratio caused by an increase in the share of diesel vehicles in Europe and the role that may play in ozone formation (Weiss et al., 2012; Carslaw et al., 2011; Carslaw, 2005). Further, there are questions as to what extent spatially (along roadsides, across urban areas, regionally) primary $\mathrm{NO}_{2}$ emissions affect ozone concentrations (see e.g. Yu et al., 2014). Meteorology also plays a large role in local-scale ozone concentration affecting deposition and transport (e.g. Vieno et al., 2010; Francis et al., 2011) alongside transport and dispersion in urban 

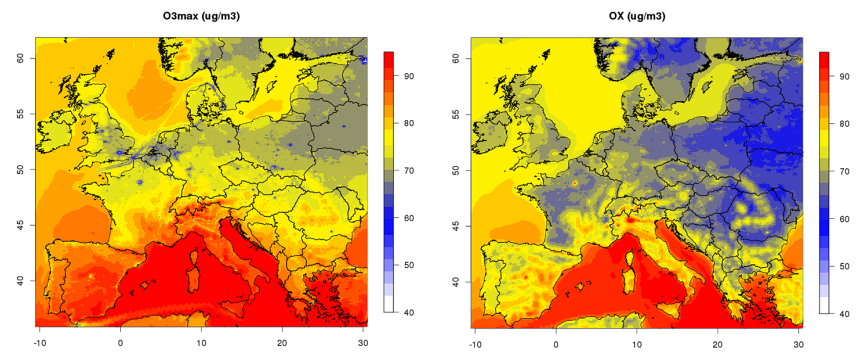

Figure 28. In a continental chemistry transport simulation with the CHIMERE model at a resolution of $8 \mathrm{~km}$, major urban centres in northern and central Europe highlight the $\mathrm{NO}_{x}$ titration process (left: summertime average of daily maximum ozone), while the total oxidant level (right: $\mathrm{O}_{3}$ as $\mathrm{NO}_{2}+\mathrm{O}_{3}$, annual mean) is high in most European cities (adapted from Terrenoire et al., 2015).

landscapes such as street canyons (see e.g. Baker et al., 2004; Zhong et al., 2014; Kwak and Baik, 2014). Urban areas are dynamic regions in terms of emission of ozone precursors that have seen strong changes owing to emission reduction measures (see e.g. von Schneidemesser et al., 2011, 2010; McMeeking et al., 2012; Warneke et al., 2012; Vijayaraghavan et al., 2014).

\section{Impacts}

Surface-level ozone has multiple impacts. As an oxidant it can induce respiratory problems and has been associated with premature human mortality (Bell et al., 2006; Gryparis et al., 2004). Further it can cause tree/vegetation damage (Krupa and Manning, 1988) and reduce photosynthesis and growth (Reich and Amundson, 1985) and therefore crop yields (Fiscus et al., 2005) (see also Felzer et al., 2007, and Ashmore, 2005 , for recent reviews). Ozone is also an important greenhouse gas (IPCC, 2013).

\subsection{Health}

Ozone has long been known to cause adverse effects on health (Bates, 2005). The gas is a powerful oxidant and shortterm inhalation induces inflammation of the entire respiratory tract, although the nasal cavity and the zone between the conducting and gas-exchange airways are potentially more susceptible. Significant inflammation can be detected at ambient levels of ozone in controlled human exposure studies, and although there is some degree of adaptation after repeated exposures, pulmonary inflammation may persist, mainly in the terminal bronchiolar units. As well as elucidating these effects in exposure studies, which naturally exclude the most sensitive or susceptible parts of the population, associations between ozone and mortality and morbidity have also been shown in epidemiological studies, covering the population at large.
Early work on ozone health effects involved mainly exposure studies in chambers. On the basis of this work ozone was included in the first tranche of National Air Quality Standards in the USA, with a standard of $80 \mathrm{ppb}$ as a $1 \mathrm{~h}$ average, promulgated in 1971 as part of the US Clean Air Act. In Europe, the first edition of the WHO Air quality guidelines for Europe in 1987 set a $1 \mathrm{~h}$ guideline value of $75-100 \mathrm{ppb}$. This guideline was also based primarily on chamber studies. Since then much more evidence has accumulated regarding ozone effects, not least from epidemiology studies, and in the Global Update 2005 (WHO, 2005), the most recent WHO guideline is now $50 \mathrm{ppb}$, expressed as the maximum $8 \mathrm{~h}$ mean in a day. The same document also sets an interim target of $80 \mathrm{ppb}$ as a daily maximum $8 \mathrm{~h}$ mean, and a "high level" of $120 \mathrm{ppb}$ daily maximum $8 \mathrm{~h}$ mean, where it notes that "significant health effects could occur" (interim) and that a "substantial proportion of [the] vulnerable population [would be] affected" (high).

Earlier WHO guidelines were based on these chamber studies on humans and animals, but the more recent Global Update 2005 from WHO mentioned above additionally used time series epidemiological studies (WHO, 2005). However, all guidelines up to and including 2005 referred to short-term exposures and health effects, but the 2005 report noted that at that time there was some evidence that long-term exposure to ozone may have chronic effects; however the review concluded that the evidence was insufficient to recommend a guideline. The policy implications of these purely healthbased guidelines are discussed in Sect. 5 .

As part of their "Year of the Air" in 2013 the European Commission requested that WHO review the health effect evidence on the pollutants covered in EU air quality legislation, including ozone. The review was in two parts, firstly a review (REVIHAAP) of the health effect evidence itself, in the form of answers to policy-relevant questions prepared by the European Commission, in consultation with the WHO. The final REVIHAAP report is available at http: //www.euro.who.int/_data/assets/pdf_file/0004/193108/ REVIHAAP-Final-technical-report-final-version.pdf.

The second part of the process involved a shorter project (HRAPIE) which recommended concentrationresponse functions for use in health impact assessments and other quantification, for example in integrated assessment modelling to underpin the EU policy process. The HRAPIE report is available at http://www.euro.who.int/_data/assets/pdf_file/0006/238956/ Health-risks-of-air-pollution-in-Europe-HRAPIE-project, -Recommendations-for-concentrationresponse-functionsfor-costbenefit-analysis-of-particulate-matter,-ozone-andnitrogen-dioxide.pdf.

The REVIHAAP report addressed three questions relating to ozone where WHO and the European Commission felt a more recent assessment was warranted. The questions posed were the following: 
1. What new evidence on health effects has emerged since the review work done for the 2005 global update of the WHO air quality guidelines, particularly with regard to the strength of the evidence of the health impacts associated with short-term and long-term exposure to ozone?

2. What new health evidence has been published in relation to the evidence or likeliness of a threshold below which impacts are not expected?

3. Based on currently available health evidence, what ozone metrics, health outcomes and concentrationresponse functions can be used for health impact assessment?

The answer to the first question noted that the earlier 2005 global update found evidence only for short-term effects on mortality and morbidity. However an important advance is that several cohort studies have now emerged showing associations between long-term exposures and mortality. Of particular importance are the studies using the large American Cancer Society cohort. A study by Krewski et al. (2009) using single-pollutant models found an association between summertime average ozone and all-cause mortality as well as cardiopulmonary mortality, although the high correlation between $\mathrm{PM}_{2.5}$ and ozone in the summer months made it difficult to separate the effects of the two pollutants. A further study by Jerrett et al. (2009) using the same cohort found unstable risk estimates for ozone and all-cause, cardiopulmonary and cardiovascular mortality, with only respiratory mortality being associated with ozone after adjustment for $\mathrm{PM}_{2.5}$. For a more detailed discussion of these and other recent cohort studies (Smith et al., 2009; Zanobetti and Schwartz, 2011; Lipsett et al., 2011) than space here permits, the reader is referred to the REVIHAAP report.

In answering the second question regarding evidence for a threshold, the REVIHAAP report noted that epidemiological studies reporting an effect of long-term exposures to ozone on mortality do not, in general, permit the firm identification of a threshold. However the report did draw some conclusions which are helpful to health impact studies.

Earlier chamber exposure studies referred to above have been supplemented by more recent studies showing effects at lower levels. Studies since the 2005 global update have shown that healthy exercising human subjects showed impaired lung function at concentrations of $60 \mathrm{ppb}$ for $6.6 \mathrm{~h}$, relative to clean air controls (Kim et al., 2011). The report noted that the subjects were healthy adults and thus not representative of the general population, or of real-world combinations of susceptibility and exposure. The REVIHAAP report discusses a number of other studies which report adverse effects at concentrations lower than those in the above study, and the reader is referred to that report for a more detailed discussion. The REVIHAAP report concluded that the evidence from epidemiological studies for a threshold for short-term exposures is inconsistent with some large multi-city studies which reported little evidence for a threshold down to nearbackground ozone concentrations, whereas other short-term studies suggest a threshold between 10 and $45 \mathrm{ppb}$ daily maximum $1 \mathrm{~h}$ ozone. The report concluded that in summary the evidence for a threshold for short-term exposure is inconsistent but where a threshold is observed it is likely to lie below $45 \mathrm{ppb}$ maximum $1 \mathrm{~h}$ ozone.

The third question, relating to quantification of the health impacts of ozone, overlaps with the HRAPIE project, the second part of the WHO review for the European Commission. The REVIHAAP report concluded that a range of health outcomes could be used where baseline rates are known, including all-age, all-cause, cardiovascular and respiratory mortality, and for ages 65 and over respiratory and cardiovascular hospital admissions. The report concluded that the evidence supports the use of all-year coefficients for daily maximum $8 \mathrm{~h}$ average ozone concentrations. Bearing in mind the discussions on a threshold, REVIHAAP recommended that cutoff points be used at $35 \mathrm{ppb}$ for daily maximum $8 \mathrm{~h}$ ozone "for consistency with previous work using SOMO35" (for definition of SOMO, see Sect. 5 or e.g. AQEG, 2009). In an important further step, the report also recommended using a cut-off at $10 \mathrm{ppb}$, i.e. SOMO10.

This latter step is significant in that use of SOMO10 in assessing the effects of most future control strategies already in place or proposed in Europe (and probably elsewhere) are likely to lead to increases in health impacts from ozone exposures. The conclusions of the HRAPIE report essentially endorsed the findings of the REVIHAAP report, suggesting the use of SOMO10 and SOMO35, and an assessment of longterm exposure impacts as a sensitivity study.

Interestingly, the impact assessment for the EU Clean Air package published on 18 December 2013 (http://ec. europa.eu/environment/air/clean_air_policy.htm) only used SOMO35 to assess the health impact of proposed policies. This was justified on the grounds that below this level there are uncertainties in ozone modelling. However, it is convenient that using SOMO35 minimises the impact of increased ozone health impacts which are likely to result if SOMO10 is used. The policy process has yet to come to terms with the possibility that existing and planned control measures are likely to result in increased health impacts from ozone if a low threshold, or a long-term (annual or summer) average concentration is used in impact assessments. A recent modelling study by Heal et al. (2013), which looked at the burden of health impacts from ozone in 12 regions in the UK, incorporated the uncertainty over thresholds using a population weighted daily maximum $8 \mathrm{~h}$ mean ozone metric with a cut-off at $35 \mathrm{ppb}$ and also with no threshold. They also incorporated future temperature increases and changes in the tropospheric baseline of ozone, and showed that, as expected, the assumption of zero threshold gave much larger health impacts. Moreover they showed that under a no-threshold assumption health impacts (deaths brought forward and hospital admissions) in the "current legislation" scenario increase 
due to the no-threshold assumption but also with the assumption of an increasing tropospheric ozone baseline. This interplay between the threshold assumption and the future trend in the tropospheric baseline has important implications for policy as discussed in Sect. 5 below.

A not dissimilar process in followed the US context as part of the periodic review process for NAAQS (National Ambient Air Quality Standards). In 2013 the US EPA produced its most recent and substantial integrated science assessment for ozone (http://www.epa.gov/ncea/isa/).

Finally, an interesting new development bridging the gap between atmospheric chemistry and epidemiology is a time series study of the associations between $\mathrm{O}_{x}$ (defined as $\mathrm{O}_{3}+$ $\mathrm{NO}_{2}$ ) and health outcomes (Williams et al., 2014). As well as having a sound basis in atmospheric chemistry given the rapid interchange between ozone and $\mathrm{NO}_{2}$, this also has a toxicological rationale since it is probable that both ozone and $\mathrm{NO}_{2}$ cause harmful effects via oxidative stress (although it is recognised that $\mathrm{NO}_{2}$ could also act via other mechanisms). The study showed that the associations between $\mathrm{O}_{x}$ and mortality were stronger than for either of the two pollutants individually, but similar to the pollutants when used in a two-pollutant model. The preliminary conclusion is that in epidemiological studies of either ozone or $\mathrm{NO}_{2}$, some form of interaction should be incorporated, either as $\mathrm{O}_{x}$ or in a two-pollutant model. Single-pollutant models for ozone or $\mathrm{NO}_{2}$ should not be used.

\subsection{Ecosystems}

Ozone is phytotoxic. The primary ecosystem impact of ozone is via the stomatal uptake of ozone followed by reaction with the internal plant tissues generating highly reactive oxidants that interfere with physiological processes (see also Sect. 2.1.2) (Fowler et al., 2009; Matyssek et al., 2008, 2010). Ozone may also react with leaf cuticles and other external plant surfaces as well as the volatile compounds emitted by vegetation. Typical ozone effects on plants include reduced growth, less seed production, lower functional leaf area and earlier leaf senescence. Data compilation studies have shown that many species of plants are sensitive to ozone, including agricultural crops such as wheat, tomato, soybean and rice, and salad crops such as lettuce, spinach and onion (Mills et al., 2007a); grassland species such as clover species, buttercup and harebell (Hayes et al., 2007; Mills et al., 2007b); and tree species such as beech, birch and Holm oak (Karlsson et al., 2007). These effects impact on the important ecosystem services provided by plants, including food security, carbon sequestration, timber production, and protection against soil erosion, avalanches and flooding.

Ozone has been recognised as a pollutant causing damage to vegetation since the 1960 s, and a research programme to quantify crop loss in North America was established during the 1970s (Karnosky et al., 2007; Adams et al., 1982). These early studies showed that reductions in exposure to ozone of $40 \%$ would reduce the annual costs of ozone damage by USD 3 billion (at 1980 prices). These early studies used metrics for ozone exposure which were simply the product of ozone mixing ratio and time above a threshold value (40 ppb) and had units of ppb hours (AOT 40; see also Sect. 5). Since then, analysis of data from over 700 studies of field-based ozone exposure of crops has indicated that many of our most globally important food crops such as wheat, soybean, maize and rice are sensitive or moderately sensitive to ozone (Mills et al., 2007a), with estimated global crop production losses owing to ozone totalling 79-121 million tonnes, worth USD 11-18 billion annually (Avnery et al., 2011a). Global modelling results show that China, India and the United States are currently by far the most affected countries, bearing more than half of all global losses and threatened areas from ozone crop exposure (Teixeira et al., 2011; Sinha et al., 2015). In the USA, recent work by Yue and Unger has shown that $\mathrm{O}_{3}$ damage decreases GPP (gross primary productivity) by $4-8 \%$ on average in the eastern USA and leads to significant decreases of 11-17\% in east coast hotspots (Yue and Unger, 2014). Research in China has looked at the ozone exposure for rice regions, finding that regions along the Yangtze and South China regions had the highest risks in 2000, and these risks will double or triple by 2020 (Tang et al., 2014). In India, the total economic cost losses for ozone on crop yields in the Indian states of Punjab and Haryana amounted to USD 6.5 billion in the fiscal year 2012-2013 and USD 3.7 billion in the fiscal year 2013-2014 (Sinha et al., 2015). It has been recently estimated that the nationally aggregated yield loss owing to ozone in India is sufficient to feed about 94 million people living below the poverty line (Ghude et al., 2014). In Europe, wheat yield losses were estimated at $14 \%$ due to ozone in the year 2000 in EU27 (plus Switzerland and Norway), equivalent to EUR 3.2 billion, falling to $9 \%$ and EUR 2 billion in 2020 with implementation of current legislation (Mills and Harmens, 2011). It has been argued that plant breeding that incorporates $\mathrm{O}_{3}$ sensitivity into selection strategies will be increasingly necessary to achieve sustainable production with changing atmospheric composition (Wilkinson et al., 2012; Booker et al., 2009). Future moves to biofuel crops could enhance the formation of ozone with concomitant negative health impacts (Hardacre et al., 2013; Ashworth et al., 2013).

Critical levels for effects of ozone on vegetation have been set and revised at a series of LRTAP Convention workshops from 1988 to date. Initial critical levels were based on mean concentrations, followed by AOT40-based values reflecting appreciation of the cumulative nature of effects and most recently critical levels have been derived based on stomatal fluxes. The latter take into account the modifying effects of climate (temperature, vapour pressure deficit, light), soil moisture, ozone and plant growth stage (phenology) on the amount of ozone absorbed by leaves (discussed in a in Sect. 2.1.2). Calculated using the $\mathrm{DO}_{3} \mathrm{SE}$ model (Emberson et al., 2000), the stomatal ozone flux method thus allows the 
dynamics of stomatal opening and therefore ozone uptake to be modelled throughout the growing season. For example, using the $\mathrm{DO}_{3} \mathrm{SE}$ model parameterised for a specific species, the substantially higher stomatal uptake of $80 \mathrm{ppb}$ of ozone under warm humid conditions with adequate soil moisture than at higher temperatures with lower humidity and drier soils would be captured. The flux methodology also incorporates the natural ozone detoxification capacity of plants by accumulating the phytotoxic ozone dose of ozone above an ozone threshold flux of $Y \mathrm{nmol} \mathrm{m}^{-2} \mathrm{~s}^{-1}\left(\mathrm{POD}_{Y}\right.$, units nmol m${ }^{-2}$ projected leaf area). The value for " $Y$ " varies between species, with the highest values being for crops such as wheat and potato and the lowest for some tree species such as beech and birch. The LRTAP Convention's Modelling and Mapping Manual now contains flux-based critical levels for ozone effects on food security (wheat, potato, tomato yield), carbon sequestration and timber production (Norway spruce, beech and birch) and biodiversity in conservationgrade grasslands (Mills et al., 2011b; Mills, 2014).

The use of the flux-based methodology is supported by recent analyses indicating that field evidence of ozone effects in Europe fits more closely with areas of greatest risk when flux-based rather than AOT40-based maps are produced. Furthermore, Fares et al. (2013a) showed a strong correlation between measured and modelled fluxes in a mixed pine and oak Mediterranean forest and epidemiological studies conducted in Switzerland provided supporting evidence for both critical levels for deciduous trees and the $\mathrm{DO}_{3} \mathrm{SE}$ parameterisation.

Reduced carbon assimilation owing to ozone by forests globally has been estimated by Sitch et al. (2007) to represent a substantial contribution to the indirect radiative forcing of climate by ozone (see Fig. 29). Through these effects on the productivity of ecosystems and the potential effects on biodiversity, ozone has become the most important pollutant threat to terrestrial ecosystems globally and is likely to remain so through most of the current century. Witting et al. (2009) showed that the carbon sink strength of Northern Hemisphere forests is likely reduced by current ozone and will be further reduced in future if ozone rises therefore implying that a key carbon sink currently offsetting a significant portion of global fossil fuel $\mathrm{CO}_{2}$ emissions could be diminished or lost in the future (Wittig et al., 2009).

In a recent review, Fuhrer (2009) looked at the ozone risk for crops and pastures in respect of future climate and concluded that the facets of exposure, leaf uptake and the plant's defence capacity are likely to change with a combination of changing anthropogenic ozone precursor emissions and climatic conditions. For example, in areas where the frequency of hot/dry periods is projected to increase, ozone episodes may become more frequent and cumulative exposures will grow, but leaf uptake of ozone will decline. In contrast, in more remote rural areas with rapid warming and less drying, ozone risks are likely to grow because of increasing hemispheric transport of pollution leading to peak ozone levels at times when plant sensitivity is high. Tai et al. (2014) showed
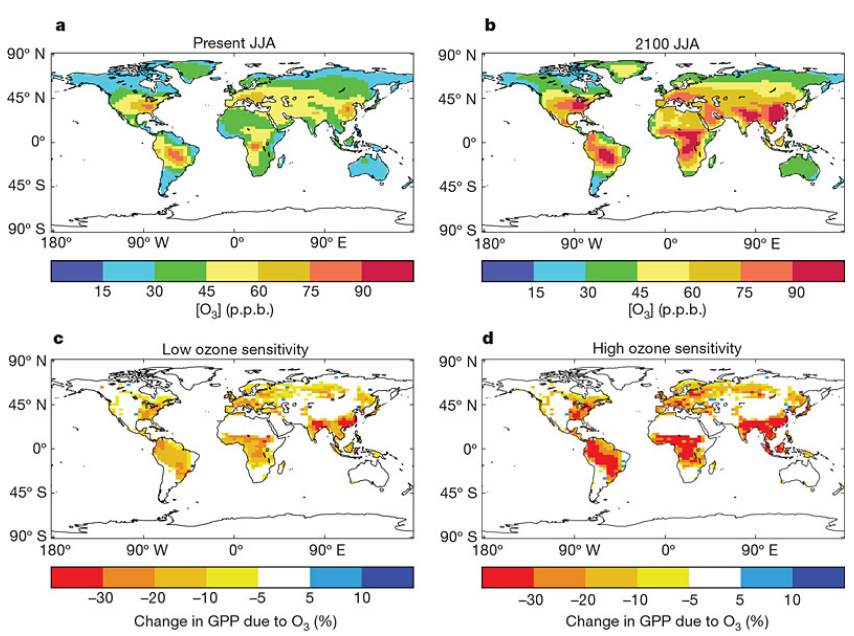

Figure 29. (a, b) Modelled diurnal $(24 \mathrm{~h})$ mean surface $\left[\mathrm{O}_{3}\right]$ in pbb averaged over June, July and August (JJA) for the present day (a) and the year 2100 under the highly polluted SRES A2 emissions scenario (b). (c, d) Simulated percentage change in gross primary productivity (GPP) between 1901 and 2100 due to $\mathrm{O}_{3}$ effects at fixed pre-industrial atmospheric $\left[\mathrm{CO}_{2}\right]$ for "low" (c) and "high" (d) ozone plant sensitivity (Sitch et al., 2007).

that warming reduces global crop production by $>10 \%$ by 2050 . In the range of the scenarios used ozone changes either exacerbate or offset a substantial part of the climate impacts. The authors note that, given the competing sensitivities to heat or ozone, it is possible to measure the relative benefits for climate adaptation versus air pollution regulation for food security (see also Avnery et al., 2011b). It is of further concern that new evidence suggests that ozone can reduce the sensitivity of plants to drought by interfering with stomatal control mechanisms (Wilkinson and Davies, 2010; Wagg et al., 2012), thereby exacerbating effects of extreme weather events.

\subsection{Impact of ozone on climate}

Tropospheric ozone interacts with both solar (short-wave, SW) and terrestrial (long-wave, LW) radiation - consequently changes in its distribution can generate radiative forcings (RF) and lead to changes in climate. In their Fifth Assessment Report of climate change, IPCC found that changes in tropospheric ozone between 1750 and 2010 had generated a global mean radiative forcing of $+0.40 \mathrm{~W} \mathrm{~m}^{-2}$ (90\% confidence range: 0.20 to $0.60 \mathrm{~W} \mathrm{~m}^{-2}$ ) (Myhre et al., 2013). This was largely based on the ACCMIP assessment which considered changes in ozone (1850-2000) simulated by 17 different global models, and calculations from three different radiation schemes (Stevenson et al., 2013). The ACCMIP results were augmented by simulations back to 1750 and up to 2010 by the OsloCTM2 model (Skeie et al., 2011), and were broadly consistent with earlier assessments from the literature. 
(c) MMM 2000s-1850s $\mathrm{O}_{3} \mathrm{~T}$ RF (355) $\mathrm{mWm}^{-2}$

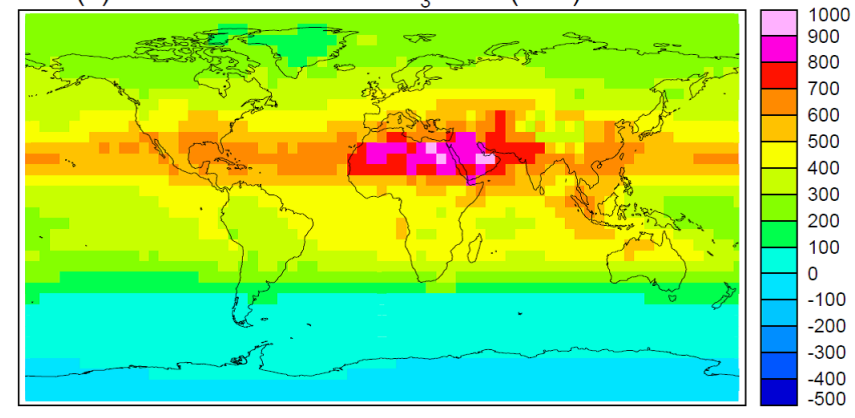

Figure 30. The global distribution of (annual mean) tropospheric ozone $\left(\mathrm{O}_{3} \mathrm{~T}\right)$ radiative forcing (1850-2000, net $\mathrm{SW}+\mathrm{LW}$, including stratospheric adjustment, in $\mathrm{mW} \mathrm{m}^{-2}$ ), based on results from the multi-model mean (MMM) of the ACCMIP models, using the Edwards-Slingo radiation scheme (Stevenson et al., 2013). (NB: the value of $0.355 \mathrm{~W} \mathrm{~m}^{-2}$ shown here compares to the recommended IPCC value for the $1750-2010 \mathrm{O}_{3} \mathrm{RF}$ of $0.40 \mathrm{~W} \mathrm{~m}^{-2}$; the IPCC value includes the additional time periods 1750-1850 and 20002010 (see Myhre et al., 2013, for details).

An important feature of the $\mathrm{O}_{3} \mathrm{RF}$ is that, in comparison to the RFs from the well-mixed greenhouse gases, it is more spatially variable (see Fig. 30). The largest changes in ozone since 1750 have occurred over the industrial regions that are the main sources of ozone's precursors $\left(\mathrm{NO}_{x}, \mathrm{CO}\right.$, and VOCs) (see also Sect. 2.3). The industrial emission focus is tempered somewhat by ozone's other key precursor, $\mathrm{CH}_{4}$, which is relatively well mixed due to its decadal lifetime, and also by ozone's lifetime of a few weeks, which allows transport to reduce zonal heterogeneities. In addition to the variations in ozone changes, the spatial distribution of the $\mathrm{O}_{3} \mathrm{RF}$ also depends on other factors. The LW RF is largest where the temperature difference between the surface and the tropopause reaches a maximum: that is, over land in the tropics and subtropics. The SW RF is largest over more reflective surfaces, e.g. snow/ice and desert. The presence of clouds reduces the LW RF and also modulates the SW RF. This combination of contributing factors leads to the net $(\mathrm{LW}+\mathrm{SW})$ $\mathrm{O}_{3} \mathrm{RF}$ peaking over the southern margins of the northern mid-latitudes and subtropics over land, and in particular over northern Africa and the Middle East (Fig. 30).

Shindell et al. (2009, 2005) and Stevenson et al. (2013) have attributed the $\mathrm{O}_{3} \mathrm{RF}$ to $\mathrm{O}_{3}$ precursor emissions $\left(\mathrm{CH}_{4}\right.$, $\mathrm{NO}_{x}, \mathrm{CO}$ and VOCs). Results from these studies are reported in the "emissions-based" RF summary diagram of the IPCC-AR5-WGI Summary for Policymakers (IPCC, 2013). Stevenson et al. (2013) found that increases in anthropogenic emissions of $\mathrm{CH}_{4}, \mathrm{NO}_{x}, \mathrm{CO}$ and NMVOCs are respectively responsible for $44 \pm 12 \%$ ( \pm 1 standard deviation range, based on results from 6 different global models), $31 \pm 9$, $15 \pm 3$ and $9 \pm 2 \%$ of the 1850s-2000s ozone RF. All these $\mathrm{O}_{3}$ precursors also affect the abundance of atmospheric $\mathrm{OH}$ and hence the lifetime of longer-lived greenhouse gases such as $\mathrm{CH}_{4}$. Consequently, emissions of ozone precursors generate further impacts on climate in addition to those related to changes in ozone; often these additional climate impacts occur over different timescales, and the net integrated impact on climate of emissions of a particular ozone precursor are complex to diagnose (e.g. Fuglestvedt et al., 2010). A further complication is that the net impact on atmospheric composition, and hence climate, depends upon the location of ozone precursor emissions, both in the horizontal (e.g. Fry et al. 2012) and vertical (e.g. Stevenson and Derwent 2009).

A major source of uncertainty in the $\mathrm{O}_{3} \mathrm{RF}$ is the preindustrial distribution of ozone (see Sect. 2.2). The few measurements that do exist are mainly thought to be unreliable, but the two more rigorous data sets, from Montsouris in Paris and Pic du Midi, a mountain-top site in central France (Marenco et al., 1994), suggest that current-generation models significantly overestimate late 19th century ozone levels (Cooper et al., 2014). Cooper et al. (2014) highlight that global models significantly underestimate recent trends in surface ozone, suggesting that they overestimate past ozone levels. Consequently, there are suggestions that the ozone RF may be substantially underestimated (also see e.g. Mickley et al., 2001). It is unclear how these apparent discrepancies in surface ozone translate into uncertainties in $\mathrm{O}_{3} \mathrm{RF}$, which is more strongly related to changes in the upper troposphere. The error estimate given by IPCC makes only a cursory attempt to include this source of uncertainty. Other sources of uncertainty are estimated from the model spread in the 1850-2000 change in ozone and differences between radiation schemes. Nevertheless, the uncertainties associated with $\mathrm{O}_{3} \mathrm{RF}$ are far smaller than those due to, for example, aerosol, because the key source of uncertainty is the $\mathrm{O}_{3}$ change rather than our understanding of the fundamental processes involved. For example, the radiative forcing from aerosols has a larger uncertainty because we are less sure of the changes in aerosol since the pre-industrial, both in terms of their magnitude and geographical distribution, but also because the aerosol forcing originates from changes in multiple different aerosol types, including mixtures of different aerosol species, with highly uncertain optical properties (Fuzzi et al., 2015).

The spatial structure of the climate response to a particular radiative forcing is not directly related to the spatial distribution of the RF, but the climate response is typically spread out over the same latitudes (e.g. Shindell et al., 2010).

The efficacy, or relative effectiveness of an $\mathrm{O}_{3} \mathrm{RF}$ relative to a $\mathrm{CO}_{2} \mathrm{RF}$ in generating a global mean surface temperature change, has been estimated by Hansen et al. (2005) and Stuber et al. (2005). For stratospherically adjusted RFs, Stuber et al. (2005) found that the tropospheric $\mathrm{O}_{3}$ efficacy has values in the range 0.7-1.7, with $\mathrm{O}_{3}$ changes in the lower troposphere showing higher efficacies than the upper troposphere, and $\mathrm{O}_{3}$ changes in the extratropical Northern Hemisphere showing higher efficacies than globally uniform changes. The spatial dependence of the efficacy appears to 
relate to the interactions with climate feedback mechanisms (e.g. Shindell 2014).

It is quite arbitrary to consider RFs owing to ozone changes in the troposphere and stratosphere separately, not least because the tropopause is often difficult to locate (e.g. Prather et al., 2011), and because coherent ozone changes often straddle the tropopause (e.g. Gauss et al., 2006; Shindell et al., 2013). Changes in tropopause height and morphology associated with climate change (e.g. Wilcox et al., 2012) suggest that there may be very important chemistry-climate feedbacks related to ozone, such as those related to changes in the Brewer-Dobson circulation (e.g. Hegglin and Shepherd, 2009; Nowack et al., 2015).

\section{Recent advances}

The topics in this section have been selected to represent areas of active research highlighting recent advances associated with key sources or with particular chemical environments. The diversity of topics reflect the improved understanding of the richer and more diverse range of interactions between atmospheric ozone, other parts of the Earth system and human activity.

\subsection{Megacities}

As of 2007, more than half of the world's population now live in urban areas, and many in megacities (Zhu et al., 2012). This statistic is often cited, but what defines an "urban" area or a "megacity"? While these definitions evolve and differ often depending on the context, here we will consider a common definition of a megacity that is a city or urban agglomeration of greater than 10 million people (Molina and Molina, 2004). As per Parrish et al. (2011), megacities are dense centres of population, economic activity and pollutant emissions, but they are also areas where effective pollution control strategies could realise maximum benefit (Parrish et al., 2011). Ground-level ozone is a serious air quality issue in many of the world's megacities. Monitoring and measurement campaigns have documented ozone levels exceeding air quality standards in many megacities. For example, based on the UNECE and WHO guidelines for protection of human health, daily $8 \mathrm{~h}$ ozone should not exceed $60 \mathrm{ppb}$ on more than 25 days per calendar year. In Delhi, India this threshold was exceeded approximately 45 days per year on average during the 7-year period 1997-2004, a significant concern for human health in the megacity (Ghude et al., 2008), especially since ozone concentrations there are still on the rise (Chelani, 2012). While some cities have extensive monitoring of ozone (and ozone precursors, more often $\mathrm{NO}_{x}$ than $\mathrm{NO}_{x}$ and NMVOCs), others have limited to no measurements. Consider South America. Buenos Aires, Argentina, for example, has very few ozone measurements, so that the overall situation with regard to ozone pollution cannot be thoroughly assessed for the city (Zhu et al., 2012). Sao Paulo, Brazil, on the other hand, has a more extensive monitoring network and increasing ozone concentrations have been observed over the last decade, despite decreases in other pollutants such as $\mathrm{NO}_{x}$ and $\mathrm{CO}$, as well as regular violations of the national ozone air quality standard (Sanchez-Ccoyllo et al., 2006; Zhu et al., 2012). A variety of reported ozone concentrations from megacities are shown in Table 2.

Sources of ozone precursors in megacities include, but are not limited to, traffic-related emissions, combustion of fossil fuels, solvent use, domestic biofuel usage and industrial activities such as power generation. The relative contribution of sources and specific activities leading to the local ozone precursor compound mix varies depending on location, including between cities. For example, in Sao Paulo, Brazil, light-duty vehicles are run on ethanol or petrol/ethanol mix fuels and ethanol from sugar cane accounts for $65 \%$ of all fuel consumed (de Fatima et al., 2012); light-duty vehicles in North America predominantly run on petrol which in some cases contains a small fraction of ethanol; in China petrolpowered vehicles dominate the vehicle fleet, but there is also significant use of liquefied petroleum gas (LPG) for some types of vehicles in the fleet (Liu et al., 2008). Overall, the emissions from vehicles/traffic dominate as a major (if not the main) source of ozone precursors in many megacities, especially because growing vehicle fleets generally accompany megacity development (Parrish and Zhu, 2009). For example, Shanghai, the largest city in China with a population of roughly 23 million, has undergone rapid development; between 1996 and 2008 industrial gross output increased by $\approx 4$ times and the number of cars increased from 0.47 to 2.61 million (Tie et al., 2013). Other megacities in which vehicles are cited as the top or among the top sources of ozone precursors are Cairo, Delhi, Istanbul, Los Angeles, New York, Mexico City, Sao Paulo and the Ruhr-Rhein metropolitan region (Chelani, 2012; de Fatima et al., 2012; Parrish et al., 2011; Khoder, 2009; Im and Kanakidou, 2012; Melkonyan and Kuttler, 2012; Bon et al., 2011). In cities like Lagos in Nigeria it is a combination of traffic and open biomass burning driving large ozone exceedances from emission of NMVOCs (Marais et al., 2014).

Extreme events in terms of air quality have also been documented in a number of megacities. These result from a combination of elevated emissions and meteorological conditions (e.g. stagnant, hot, sunny) that lead to extremely high concentrations of ozone, typically for a short duration. During the summer of 2010 in Moscow, blocking anticyclonic meteorological conditions with record-breaking high temperatures led to larger than normal evaporative emissions from fuels, paints, etc., as well as emissions from a large number of forest and turf fires, in addition to the "normal" megacity emissions (Zvyagintsev et al., 2011; Elansky et al., 2011). These conditions, which persisted from July through midAugust, resulted in maximum hourly mean concentrations of ozone that peaked at $134.2 \mathrm{ppbv}$ (Elansky et al., 2011). 
An oft-cited example of extreme ozone was during the European heat wave during summer 2003, which adversely affect the residents of a number of European megacities. For about 2 weeks at the beginning of August, a high-pressure system was centred on western Europe, resulting in record-setting temperatures exceeding $40^{\circ} \mathrm{C}$, and accompanied by a persistent photochemical episode. In France, the highest hourly ozone value reached $208.5 \mathrm{ppbV}$ and concentrations regularly exceeded the EU threshold of 90 ppbV (Lee et al., 2006; Vautard et al., 2005; Stedman, 2004; Tressol et al., 2008).

Because of their high population density, the adverse health effects of elevated ozone levels affect a disproportionately large fraction of the population. A recent study investigated the health impacts of air pollutants in Tehran, Iran, where the annual $8 \mathrm{~h}$ average ozone concentration in 2010 was $34 \mathrm{ppbV}$, with a maximum $8 \mathrm{~h}$ concentration of $93.5 \mathrm{ppbV}$ during the summer period. The health impact owing to ozone was estimated to cause an excess total mortality of 819 out of 47284 people in a year, relative to 2194 cases for $\mathrm{PM}_{10}$ (Naddafi et al., 2012). For comparison (from a study using the same method), Naddafi et al. (2012) cited the excess total mortality for $\mathrm{PM}_{10}$ was 677 out of 1308000 people for Milan, Italy, located in the megacity region of the Po Valley. Cifuentes et al. (2001) assessed the health benefits associated with reductions of $\mathrm{PM}$ and $\mathrm{O}_{3}$ from climate change mitigation strategies (2000-2020) in four megacities - Santiago, Sao Paulo, Mexico City and New York. Without going into detail, substantial premature deaths could be avoided from such policies; in all cases the adverse health effects avoided from ozone were significantly less than those from PM (Cifuentes et al., 2001). Generally, small but substantial associations between ozone and total mortality are found in epidemiological studies (Bates, 2005).

The emissions from megacities also have an effect on the surrounding region. In many cases the urban areas have been identified to be VOC-limited, where high $\mathrm{NO}_{x}$ concentrations in the cities suppress ozone concentrations (Im and Kanakidou, 2012; Tie et al., 2013). For example, a modelling study conducted in the context of the MILAGRO measurement campaign in Mexico City identified that reductions in VOC emissions led to decreases in maximum ozone concentrations, while $\mathrm{NO}_{x}$ emission reductions led to increased maximum ozone concentrations, demonstrating that the urban core of the Mexico City metropolitan area was VOC-limited, a conclusion supported by the in situ measurements. The surrounding mountain/rural areas were identified as mostly $\mathrm{NO}_{x}$-limited, although the range of these areas was meteorologically dependent (Song et al., 2010). This suppression of ozone by high $\mathrm{NO}_{x}$ has been identified as generally more characteristic of extratropical megacities in the Northern Hemisphere, relative to tropical cities, because of differences in transport patterns. Tropical cities are more influenced by rapid convective transport, while the extratropical cities (despite the Mexico City example) allow for a greater build-up of local pollution (Butler and Lawrence,
2009). Local/regional transport of these air masses into the surrounding areas can lead to greater concentrations outside of the megacities. For example, in Tokyo, modelling studies showed that sea breezes which developed during the daytime transported emissions from the urban centre to the north, which caused enhanced ozone in downwind areas 50$100 \mathrm{~km}$ away (Kondo et al., 2010). Furthermore, regional enhancements of ozone during summer were found in the area $(200 \mathrm{~km} \times 200 \mathrm{~km})$ surrounding the Tokyo metro area (Kondo et al., 2010). A modelling study looking at the impacts of Istanbul (and Athens) on air quality in the eastern Mediterranean also found much lower concentrations of ozone within the (mega)cities owing to significant $\mathrm{NO}_{x}$ emissions depressing $\mathrm{O}_{3}$. The rural sites in the surrounding area had much higher ozone concentrations, 11-24 ppbv (9$14 \mathrm{ppbv}$ ) greater in summer (winter) than in the urban areas, emphasising the importance of the megacity emissions on regional air quality (Im and Kanakidou, 2012). Further sources of emissions in areas surrounding the megacity regions also play a role in ozone formation. For example, the photochemistry in plumes transported out of London or the Ruhr-Rhein region will be influenced significantly by further emissions sources, while this is much less the case for Cairo, for example, which has far fewer emissions sources in the surrounding area (Hodnebrog et al., 2011). Biogenic emissions will also influence ozone formation downwind of cities. For the Shanghai region, results from a model study suggested that ozone formation was enhanced in the city plumes in the downwind region because of the strongly VOC-limited conditions in the plume, which resulted in continuous ozone production during transport. Reasons for this were oxidation of OVOCs and CO in the plume, as well as biogenic isoprene emissions (Tie et al., 2013). Finally, an estimate of the footprint of south-eastern megacities in South America found contributions in excess of $30 \%$ to downwind levels of surface ozone under certain conditions (Zhu et al., 2012).

Considering ozone concentrations as a relative contribution to the global scale, megacities contribute a small amount to global ozone (Stock et al., 2013). In a model "annihilation" experiment where the emissions from grid cells containing megacities were removed, emissions from megacities contributed only $0.84 \%$ to the global average tropospheric ozone column density, proportionally smaller than the $6 \%$ of global anthropogenic ozone precursor emissions from megacities (Butler et al., 2012). This does not, however, represent human health exposure to ozone in megacities and is also a global average.

Previous work has shown that individual megacities are not well represented by global emission inventories compared to the detailed city-scale inventories (Butler et al., 2012), which can be an issue when trying to model ozone on a larger scale. Additional complexity is added by the nonlinearity of the atmospheric chemistry involved in ozone production processes. Hodnebrog et al. (2011) investigated the importance of resolution for the representation of large-scale 
tropospheric ozone from megacity emissions and found that higher resolution was much more important for local air pollution studies than for larger climate studies, as might be expected, due to the integration of relatively small changes over a large volume (changes in the resolution of meteorology were not considered). A key point was whether or not the model resolution could capture the $\mathrm{NO}_{x}$-saturated regime within the plume common to many megacities (Hodnebrog et al., 2011). That said, recent work by Siour et al. (2013) has shown that for chemistry transport models, using a "zooming" technique (introducing higher resolution "zooms" to certain areas within a coarser overall resolution) allows for better representation of scale interactions, including better representation of megacity areas, such as the Benelux region. With the growing interest in the study of urbanisation, more research and improved methods are still needed to develop a better understanding of pollutants such as ozone in megacities and their effects on all scales.

\subsection{Biomass burning}

Wildfires/biomass burning are the second largest source of carbon dioxide emissions, after fossil fuel combustion with ca. 1-2 $\mathrm{GtC} \mathrm{yr}^{-1}$ (IPCC, 2013). Tropical biomass burning dominates total emissions with boreal fires $\left(50-70^{\circ} \mathrm{N}\right)$ accounting for around $9 \%$ of all fire carbon emissions. Burning is thus a major component of the carbon cycle having a direct global impact on climate (van der Werf et al., 2010). Further, there is also an indirect impact because biomass burning is a significant source of ozone precursors (e.g. CO, $\mathrm{NO}_{x}$, VOCs) and aerosol particles. Indeed, Jaffe and Widger (Jaffe and Wigder, 2012) estimated that global wildfires produce approximately $170 \mathrm{Tg}$ of ozone per year, which is $3.5 \%$ of all tropospheric ozone production. However, as they pointed out, many areas of uncertainty remain in wildfirerelated ozone production. These uncertainties centre around the interplay of fire emissions, chemical reactions within the plumes, aerosols effects on chemistry and radiation, and atmospheric dynamics (local and downwind meteorological patterns). These factors, along with a strong interannual variability in the fire activity itself, make the assessment of global impact a challenge. The impact of boreal forest fires is less documented and quantified than tropical biomass burning.

Recently, the atmospheric chemistry challenge of biomass burning in boreal regions provided the motivation for the BORTAS (Quantifying the impact of BOReal forest fires on Tropospheric oxidants over the Atlantic using Aircraft and Satellites) campaign, held in July-August 2010 and 2011 over eastern Canada and the western Atlantic. The objective of BORTAS was to better understand the chemical evolution of plumes emitted from the burning of biomass, with a particular emphasis on the net production of tropospheric ozone and downwind impacts on air quality (Palmer et al., 2013, and references therein) (see Fig. 31). Parrington et al. (2013) showed that ozone formation in- creases with plume age. They used NMHC ratios (extensively described for this BORTAS campaign in Lewis et al., 2013) to estimate photochemical ages of the observed biomass burning plumes between 0 and 10 days. Parrington et al. (2013) found that ozone production efficiency (OPE) increased with plume ages as calculated by NMHC ratios. They show $\Delta \mathrm{O}_{3} / \Delta \mathrm{CO}$ enhancement ratios increasing from $0.020 \pm 0.008 \mathrm{ppbv} \mathrm{ppbv}^{-1}$ in plumes with photochemical ages less than 2 days to $0.55 \pm 0.29 \mathrm{ppbv} \mathrm{ppbv}^{-1}$ in plumes with photochemical ages greater than 5 days. According to this study, it seems that the aerosol loading is one of the main drivers of such OPE, as aged plumes were typically associated with low aerosol loading and relatively high OPE. In one of the BORTAS flights that made multiple interceptions of a plume with high aerosol loading, Parrington et al. (2013) report that the photolysis rate of $\mathrm{NO}_{2}$ was reduced by a factor of approximately 2 within this plume, suggesting that increased optical depth of the plume can reduce the photolysis rate of $\mathrm{NO}_{2}$ to form ozone.

Still in the frame of BORTAS and WMO-GAW programme, results exploring NMVOC ozone precursors from measurements of biomass burning (Lewis et al., 2013) have suggested that biomass burning can be the largest fractional contributor to observed benzene, toluene, ethene and propene levels in many global locations. The extrapolated widespread biomass burning contribution to atmospheric benzene, a heavily regulated air pollutant, suggests a pragmatic approach when setting air quality targets as tailpipe and solvent emissions decline in developed countries.

Jaffe and Widger (2012) also indicated that boreal wildfires are likely to produce less $\mathrm{NO}_{x}$ on average than fires in other biomes. This observation makes sense with a more obvious impact of biomass burning on ozone production in the tropics than at middle-high northern latitudes. However, boreal wildfires may have diverse impacts on the global ozone distribution as they are also often linked to convection and pyro-convection, thus allowing the injection of ozone precursors and particulate matter up into the upper tropospherelower stratosphere, where long-range transport processes can widely distribute the emissions. Subsequent photochemical processes leading to ozone production and their impact on larger scale may be different than in the tropics. Several groups are actively developing algorithms and models to derive appropriate injections heights for biomass burning emissions (e.g. Kaiser et al., 2012; Freitas et al., 2007). Freitas et al. (2007) showed that plumes from fires are likely able to reach $10 \mathrm{~km}$ altitude, the ultimate height depending on the fire radiative power (FRP) and fire size. Based on a statistical analysis of 5 years of satellite observation by MISR (Multiangle Imaging Spectrometer) over North America, Val Martin et al. (2010) showed that the median altitude of plumes is found below $3 \mathrm{~km}$ altitude for boreal forest fires. A significant fraction (4-12\%) of those plumes are injected above the boundary layer and are more spread out vertically depending on the atmospheric stability conditions. In comparison, trop- 
Table 2. Reported mean $\mathrm{O}_{3}$ for megacities.

\begin{tabular}{|c|c|c|c|}
\hline Location & Mean $\mathrm{O}_{3}(\mathrm{ppbv})^{*}$ & Statistic/year & Ref. \\
\hline Beijing, China & 31 & $\begin{array}{l}\text { 6-site average, 2001-2006, } \\
\text { JJAS }\end{array}$ & Tang et al. (2009) \\
\hline Bangkok, Thailand & 17 & $\begin{array}{l}\text { Annual average, } 1 \mathrm{~h}, \quad 1995- \\
2008\end{array}$ & Zhu et al. (2012) \\
\hline Cairo, Egypt & 46 & Dec 2004-Nov 2005 & Khoder (2009) \\
\hline Delhi, India & 24 & 1997-2004, annual avg. & Ghude et al. (2008) \\
\hline London, UK & $19\left(38 \mu \mathrm{g} \mathrm{m}^{-3}\right)$ & $\begin{array}{l}\text { Annual average hourly data; } \\
\text { suburban site (Eltham) } 2009\end{array}$ & http://uk-air.defra.gov.uk \\
\hline Los Angeles, CA, USA & 122 & $\begin{array}{l}\text { 2005-2007, national } 8 \mathrm{~h} \text { ozone } \\
\text { design values (daily } 8 \mathrm{~h} \max \\
\text { from running avgs) }\end{array}$ & Cox et al. (2009) \\
\hline Mexico City, Mexico & 93 & $\begin{array}{l}\text { City plume, avg. from flight } \\
\text { measurements, MIRAGE-MEX } \\
\text { campaign }\end{array}$ & Tie et al. (2009) \\
\hline Tehran, Iran & $34\left(68.84 \mu \mathrm{g} \mathrm{m}^{-3}\right)$ & 2010 , annual $8 \mathrm{~h}$ avg. & Naddafi et al. (2012) \\
\hline
\end{tabular}

ical biomass burning plumes are mostly limited to the first kilometre of the atmosphere.

Numerous studies report high mixing ratios of biomass burning products, $\mathrm{CO}$ in particular, measured in the middle to upper troposphere and eventually up to the lower stratosphere, thousands of kilometre from the fire sources (e.g. Nedelec et al., 2005; Cammas et al., 2009; Fromm et al., 2010; Elguindi et al., 2010). Biomass burning signatures from Canadian forest fires have also been observed in the lower troposphere at the Pico Observatory on the opposite side of the North Atlantic (Val Martin et al., 2006). Implications for the ozone budget in boreal regions are not as direct as in the tropics. Photochemical impact remains uncertain. Clearly, long-range-transported biomass burning plumes can influence Europe (Cook et al., 2007; Real et al., 2007), though the impact is variable (Hudman et al., 2004). More recently, European fires in Portugal and Russia have been shown to contribute to air pollution (Tressol et al., 2008; Martins et al., 2012), and the frequency is expected to increase with climate change (Carvalho et al., 2011). Besides their impact on air quality over populated mid-latitudes, boreal fires are also of particular importance for the Arctic region. For example, the ARCTAS mission carried out in April 2008 and June-July 2008 was designed to observe springtime fires from Siberia, and summertime fires plumes from Canada and Siberia along with their impact on Arctic pollution (Jacob et al., 2010) (see also Sect. 4.8).

Biomass burning in the tropics has long been recognised as the major source of tropospheric ozone locally and regionally (Fishman et al., 1990; Thompson et al., 1996, 2003b;
Sauvage et al., 2006; Jonquieres et al., 1998). Tropospheric seasonal cycles of ozone are in phase with the local biomass burning season (coinciding with the dry season) of each region. It is worth noting one exception over equatorial Africa (Gulf of Guinea and adjacent continent) which is impacted by two biomass burning regions, one from each hemisphere. For example, over Lagos, Nigeria, ozone-enhanced layers are observed in December-February, when burning occurs regionally, and also in July-August, when biomass burning occurs over southern equatorial Africa (Sauvage et al., 2005, $2007 b$ ). Such processes have been further investigated in the frame of AMMA (Reeves et al., 2010; Thouret et al., 2009; Mari et al., 2008). Similarly, over Brazzaville, the seasonal cycle of ozone peaks in July-August but a secondary maximum appears in January-February due to transport of ozone and precursors from fires occurring in the Northern Hemisphere (Sauvage et al., 2005, 2007b). Thus, the so-called zonal wave-one as described by Thompson et al. (1999) and Sauvage et al. (2006), which describes the ozone maximum over the South Atlantic and adjacent continents, clearly designates biomass burning as the main contributor of the ozone burden in the tropical lower to middle troposphere at least. Biomass burning in the tropics may have a global impact too. The extreme El Niño event in 1997 and the consequent long-lasting fires in Indonesia (Siegert et al., 2001) have contributed to the increase in $\mathrm{CO}$ and other trace gases (e.g. $\mathrm{CO}_{2}$ ) observed globally from late 1997 through to 1998 . 
(a)

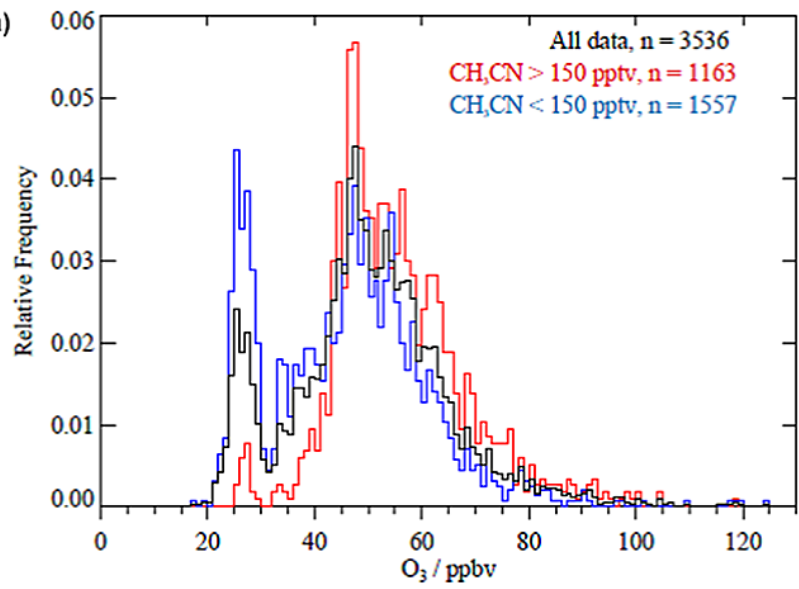

(b)

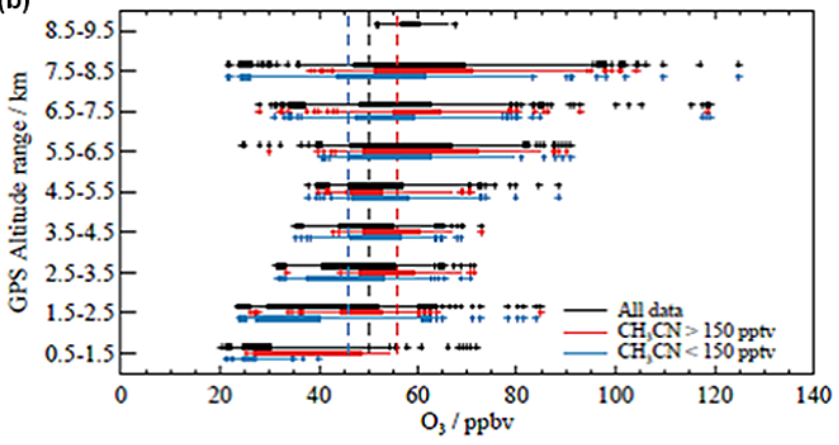

Figure 31. (a) Frequency distribution for ozone over the BORTAS (Palmer et al., 2013) flights, the black line are the measured mixing ratios, where the red line shows the distribution of measurements identified as biomass burning plumes using a threshold of $\mathrm{CH}_{3} \mathrm{CN}$ mixing ratios greater than $150 \mathrm{pptv}$, and the blue line shows measurements made in air masses with $\mathrm{CH}_{3} \mathrm{CN}$ mixing ratios less than 150 pptv. (b) The same data plotted as box-and-whisker plots (solid boxes show the range of the 25 th to 75 th percentiles and whiskers show the range of the 5th to 95th percentiles, with outliers shown as plus symbols) (GPS) altitude profile (Parrington et al., 2013).

\subsection{Role of biogenics in the formation of ozone}

There is much debate as to the influence of biogenic VOCs in urban (Calfapietra et al., 2013), regional and global ozone budgets. Variation in natural plant emissions of ozone precursors can influence ozone concentrations. Goldstein and Galbally (2007) suggested that we cannot account for the loss of approximately half the non-methane organic carbon entering the atmosphere, much of which is of biogenic origin.

Much of the focus on biogenic VOCs and ozone is on isoprene and the monoterpenes owing to their apparent dominance of the global VOC budgets (see Fig. 22). New insights from field observations, models and quantum chemistry into isoprene chemistry and its impacts have been recently reviewed by Whalley et al. (2014). Some of the new radical chemistry from isoprene oxidation is detailed in Sect. 4.10 and the emissions in Sect. 2.3. This section deals with the relationships between biogenics and formation of ozone.

Work by Hewitt et al. (2011) suggests that the circadian rhythms of the isoprene emitters have an effect on the ozone budgets (see Fig. 32), but there has been some debate as to the nature of the circadian control (Keenan and Niinemets, 2012).

Model calculations have indicated that the biogenic isoprene emissions represent a major uncertainty in the achievement of AOT40 levels by a factor of at least 2 (EEA, 2009). The impact of North American (NA) isoprene on European ozone has been assessed, and it has been shown that future increases in NA isoprene emissions could offset decreases in EU surface $\mathrm{O}_{3}$ resulting from controls on NA anthropogenic emissions (Fiore et al., 2011). Archibald et al. (2011) showed that there is a significant impact of mechanism uncertainties on the global impact of isoprene chemistry on ozone. Recent estimates from Zare et al. (2014) found BVOC to be the most significant contributor to ozone formation over land areas in the Northern Hemisphere enhancing the mixing ratio by about $11 \%$. In the Pearl River Delta in China (Situ et al., 2013) ozone is sensitive to the BVOC levels particularly in urban areas. At a regional European scale, biogenic emissions increase $\mathrm{O}_{3}$ locally, while reducing $\mathrm{PM}_{2.5}$ levels (Tagaris et al., 2014). At the city scale, modelling has shown that $\mathrm{O}_{3}$ concentration can be increased by $37 \mathrm{ppb}$ in Seoul, Korea, owing to biogenic isoprene emission and transport of its key oxidation products into the metropolitan area (Lee et al., 2014).

The role of isoprene nitrates has been highlighted as a key uncertainty in ozone and $\mathrm{NO}_{x}$ chemistry (Horowitz et al., 2007). In the tropics, regional simulation of ozone is shown to be very sensitive to the removal and export of $\mathrm{NO}_{x}$ by isoprene nitrates (Paulot et al., 2012). For example, in South America and New Guinea, the high ratio of isoprene to $\mathrm{NO}_{x}$ emissions makes isoprene nitrates chemistry the primary sink of $\mathrm{NO}_{x}$. Paulot et al. (2012) suggest that the impact of isoprene photooxidation on tropical ozone is not limited to the regional scale but can have a long-range effect as a result of dynamic and photochemical processes such as efficient vertical mixing (through deep convection) and low boundary layer $\mathrm{HO}_{x}$ (as a result of high biogenics and low $\mathrm{NO}_{x}$ emissions). It is suggested that these physical and chemical conditions promote the oxidation of isoprene outside of the boundary layer, where its contribution to ozone production is amplified (Paulot et al., 2012). Enhancing the isoprene oxidation mechanism for isoprene nitrates in a global model and running it over the USA, Mao et al. (2013) showed that the dependence of surface ozone on isoprene emission is positive throughout the USA, even if $\mathrm{NO}_{x}$ emissions are reduced by a factor of 4 , as well as the chemistry leading to the export of nitrates to the background atmosphere. Browne et al. (2014) showed that the monoterpene nitrates have the potential to impact ozone levels over the remote continental boundary layer. The change in global $\mathrm{O}_{3}$ burden due to an increase in 

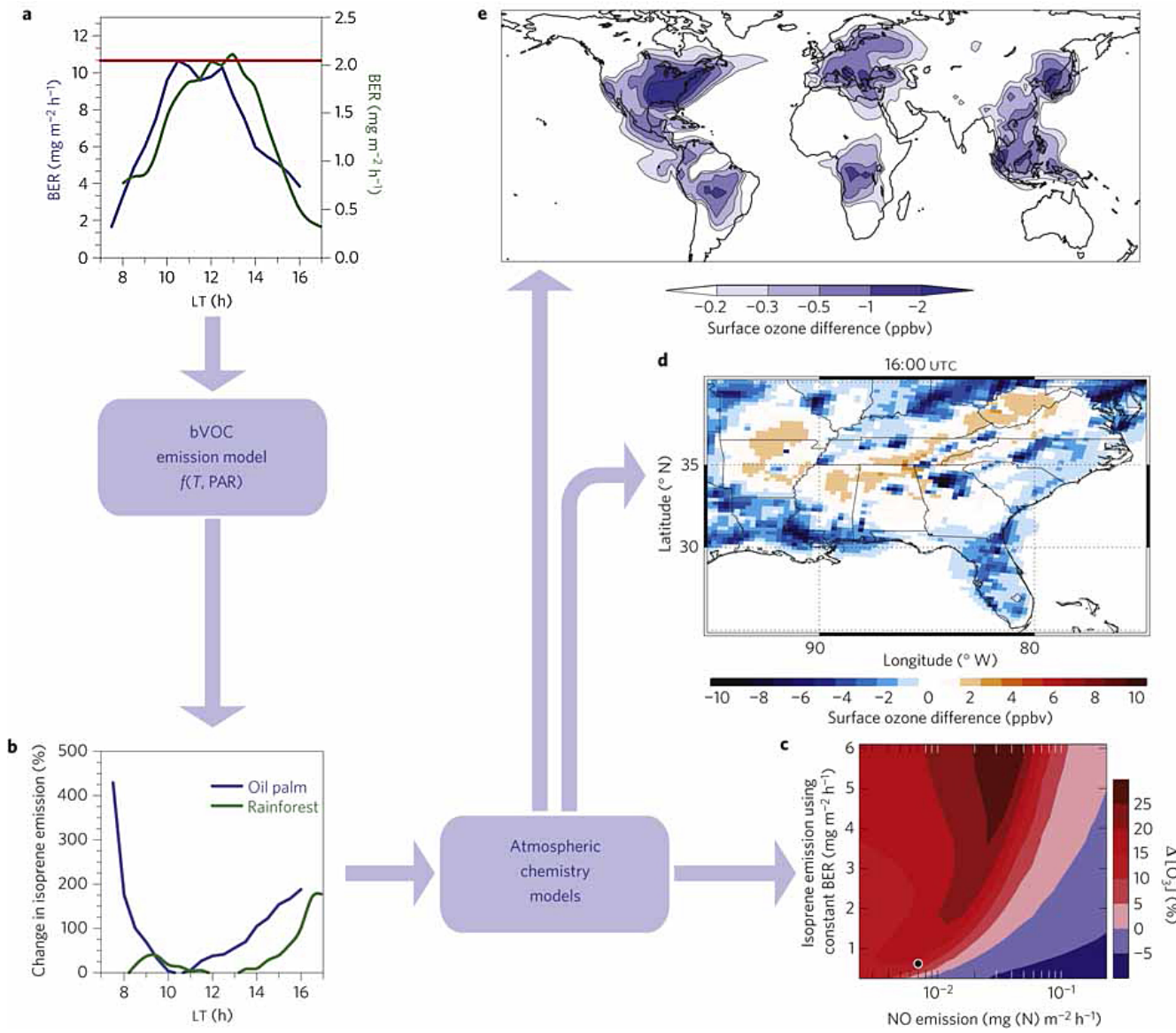

Figure 32. The effect of a circadian rhythm based biogenic emission rate (BER) on ozone. (a) The oil palm plantation (blue) and rainforest (green) BERs of isoprene compared with a constant BER (red). (b) The differences in isoprene emission rates between constant (red line in a) and circadian-controlled BERs (oil palm: blue; rainforest: green). (c) Changes in ground-level ozone resulting from changing isoprene and nitrogen oxide emission rates. (d) Changes in regional-scale modelled ground-level ozone for 11:00 LT using an "oil palm" circadiancontrolled BER compared with a constant BER. (e) Changes in global-scale modelled ground-level ozone for July using the same scenario as (d) (Hewitt et al., 2011).

BVOC emissions associated with temperature depends critically on the assumed treatment for the fraction of $\mathrm{NO}_{x}$ recycled from isoprene nitrates (Ito et al., 2009).

A future uncertainty revolves around the impact of biofuels on ozone concentrations, via changes to vegetation (Ashworth et al., 2013) and BVOC emissions (Porter et al., 2012).

There is significant debate about the role of a wide range of biogenics in ozone chemistry under future climate (e.g. Andersson and Engardt, 2010; Wiedinmyer et al., 2006) with up to a factor of 5 difference between different models for Europe (Langner et al., 2012b). It has been recently shown that the choice of isoprene chemical schemes in climate models can be important (Squire et al., 2015). A limiting role of increased $\mathrm{CO}_{2}$ on the potential of ozone precursor emissions from the vegetation has been recently noted at the global scale (Lathiere et al., 2010). Earlier studies have showed that the vegetation response to climate change is important in driving BVOC emissions and subsequent formation of ozone (Sanderson et al., 2003).

Several other studies have focused only on the regional impact of climate change (Langner et al., 2012a, b; Andersson and Engardt, 2010; Manders et al., 2012; Hedegaard et al., 2008, 2013; Katragkou et al., 2011). They found a general increase in ozone concentrations owing to increasing biogenic emissions and favourable conditions for the build-up of ozone pollution as a result of increased temperature, more frequent summer blocking and heat waves and increased short-wave radiation. Whereas all these studies agreed on the main outcome of climate change on ozone in Europe, they also pointed out significant differences depending on the regional climate model used. The main factors influencing these differences are the projections of cloud cover and frequency of stagnation episodes that are highly variable across the ensembles of regional climate projections. 


\subsection{Halogens}

Halogens (chlorine, bromine, iodine) influence the concentrations of ozone in the troposphere either directly, by reacting with $\mathrm{O}_{3}$ itself, e.g.

$\mathrm{Br}+\mathrm{O}_{3} \rightarrow \mathrm{BrO}+\mathrm{O}_{2}$,

or indirectly, by affecting its sources and sinks. Indirect influence results in production or destruction of $\mathrm{O}_{3}$, depending on the conditions. Halogens, especially chlorine, react with VOCs to form peroxy radicals, which convert $\mathrm{NO}$ into $\mathrm{NO}_{2}$, and change the $\mathrm{OH} / \mathrm{HO}_{2}$ ratio, e.g. via

$\mathrm{BrO}+\mathrm{HO}_{2} \rightarrow \mathrm{HOBr}+\mathrm{O}_{2}$,

followed by $\mathrm{HOBr}$ photolysis to give $\mathrm{OH}$. Reactions between halogen species and nitrogen oxides also affect the $\mathrm{NO} / \mathrm{NO}_{2}$ ratio, and form stable compounds, which can act as nitrogen reservoirs and allow long-range transport of $\mathrm{O}_{3}$ precursors. A detailed model analysis by Saiz-Lopez et al. (2012a) estimated that halogens are responsible for up to $10 \%$ yearly depletion of the total tropospheric $\mathrm{O}_{3}$ column (and up to $20 \%$ in the tropical troposphere), especially in the middle and upper troposphere. The model calculations by Parrella et al. (2012) and Long et al. (2014) generally agree with these estimates. The Long et al. (2014) model analysis suggest that models may overestimate the role of bromine (and the extent of ozone destruction), because they tend to overestimate marine aerosol, especially in the Southern Hemisphere.

Our understanding of the role of halogens in ozone chemistry ultimately depends on our understanding of the physiochemical processes that release, transform and destroy halogen species into the atmosphere. There are significant uncertainties in our knowledge of the source processes and geographical distribution of halogens and severe limitations in the databases of chemical kinetics parameters (Abbatt et al., 2014). Part of the problem is related to the difficulty in measuring halogens species at the low concentrations found in the atmosphere (Finlayson-Pitts, 2010): this area of research has been very active in recent years and many of the most recent advancements in our knowledge are related to developments in the field of analytical chemistry, particularly mass spectrometry.

Very detailed reviews have been published in recent years both on halogen chemistry in general Saiz-Lopez and von Glasow (2012) and on specific aspects of halogen chemistry, such as bromine (Sander et al., 2003), iodine (Saiz-Lopez et al., 2012b; Carpenter, 2003) and polar chemistry (Simpson et al., 2007). These reviews detail the broader picture of halogen chemistry and the focus hereafter will be on recent advances that directly affect tropospheric ozone.

Overall, observations of halogen species in the boundary layer show a consistent picture across the globe (see SaizLopez and von Glasow, 2012), with comparable levels of reactive halogens in different unpolluted/semi-polluted re- gions, and more variable levels of reactive halogens in continental/coastal environments, reflecting the larger variability in their sources and sinks under polluted conditions.

The major source of chlorine and bromine in the boundary layer is known to be sea salt: current model parameterisations are able to reproduce measured $\mathrm{BrO}$ levels in the unpolluted MBL reasonably well (Keene et al., 2009; Sommariva and von Glasow, 2012; Saiz-Lopez et al., 2012a). However, models struggle to reproduce total bromine and particulate bromide concentrations and their diurnal cycles, suggesting that our understanding may be limited by the lack of speciation of bromine in current analytical techniques.

Inorganic chlorine observations are better constrained, although concurrent measurements of $\mathrm{Cl}_{2}$ and $\mathrm{HOCl}$, especially under semi-polluted conditions (Keene et al., 2009; Lawler et al., 2009, 2011), are difficult to reconcile and $\mathrm{BrCl}$, which the models predict as one of the major components of total $\mathrm{Br}$, has not been detected in marine environments. It is unclear whether the model-measurement disagreements are due to instrumental issues or to some fundamental problem in our understanding of the chemistry, particularly in the aqueous phase (Long et al., 2014; Sommariva and von Glasow, 2012), but they make it difficult to accurately assess the effect of chlorine and bromine on ozone under unpolluted and semi-polluted conditions.

In the past few years, several groups have reported observations of significant concentrations of $\mathrm{ClNO}_{2}$ (from $80 \mathrm{ppt}$ to over $2000 \mathrm{ppt}$ ) in a variety of environments and under different conditions (Osthoff et al., 2008; Kercher et al., 2009; Thornton et al., 2010; Mielke et al., 2011, 2013; Phillips et al., 2012; Riedel et al., 2012, 2013; Wagner et al., 2012). These studies indicate that nocturnal formation of $\mathrm{ClNO}_{2}$, via reaction of $\mathrm{N}_{2} \mathrm{O}_{5}$ with aerosol chloride, followed by its photolysis at sunrise to form $\mathrm{Cl}+\mathrm{NO}_{2}$ is a strong and widespread source of reactive chlorine in the polluted troposphere. In addition to kick-starting VOC oxidation in the morning before the formation of $\mathrm{OH}$, the $\mathrm{ClNO}_{2}$ mechanism also acts as a $\mathrm{NO}_{x}$ reservoir, preventing $\mathrm{NO}_{2}$ loss overnight as $\mathrm{HNO}_{3}$ and hence making it available in the morning to form $\mathrm{O}_{3}$. Although these two effects are not yet fully decoupled and understood (see discussion in Young et al., 2014), it is clear that this chemistry is potentially very important for ozone formation in polluted environments. Osthoff et al. (2008) and Thornton et al. (2010) estimated that up to $13 \mathrm{ppb}$ of additional ozone can be formed via this chemistry. It must be noted, however, that the actual impact on local ozone may be much less than that, because of the effect of transport and local circulation on ozone levels (Sarwar et al., 2012; Simon et al., 2010, 2009). Furthermore, model analysis suggests that recirculation of air masses from urban coastal areas over the ocean may lead to high $\mathrm{Cl}_{2}$ levels during the night, thus increasing VOC oxidation and ozone formation at sunrise (Pechtl and von Glasow, 2007), a mechanism which has particular relevance for coastal megacities. 
There are several inconsistencies in the observations of reactive iodine, especially under conditions representative of the open ocean: for example, Carpenter et al. (2010) highlighted the discrepancy between observations of IO made by different groups at Cabo Verde, while Mahajan et al. (2010) found that IO concentrations in the eastern Pacific did not agree with the observations of chlorophyll $a$ and dissolved organic matter, and were much lower than the SCIAMACHY satellite observations. Additionally, the measured emission rates of iodinated VOCs are unable to explain the observed levels of IO and $\mathrm{I}_{2}$ (Carpenter et al., 2013; Jones et al., 2010b; Großmann et al., 2013; Lawler et al., 2014). Several mechanisms have been introduced to explain the observations and are still under active discussion (e.g. Lawler et al., 2014; Carpenter et al., 2013; MacDonald et al., 2014). Some of these discrepancies may be explained by assuming seasonal or yearly cycles of the iodine sources, but there are also several uncertainties in the iodine chemical mechanism (Sommariva et al., 2012; Saiz-Lopez et al., 2012b). The many uncertainties in iodine sources and chemistry make it difficult to assess accurately the role of iodine as ozone sink in unpolluted/semi-polluted conditions, especially over the open ocean. Although the sources and chemistry of iodine species are still being debated, it is well established that iodine species do not react with VOC and, when $\mathrm{NO}_{x}$ levels are high, they form stable iodine nitrates $\left(\mathrm{INO}_{x}\right)$ which can be taken up on aerosol, leading to net loss of $\mathrm{NO}_{x}$ (and hence $\mathrm{O}_{3}$ ). In addition, recycling of $\mathrm{INO}_{3}$ in the gas phase,

$\mathrm{INO}_{3}+\mathrm{I} \rightarrow \mathrm{I}_{2}+\mathrm{NO}_{3}$,

may increase ozone depletion by up to $60 \%$ (Mahajan et al., 2009).

The interaction between iodine and ozone also leads to the formation of ultra-fine particles under certain conditions (e.g. coastal regions with strong emissions of iodine from macroalgae; McFiggans, 2005), although this process, and its impact on local $\mathrm{O}_{3}$ concentrations, is not yet completely understood. Recent work has shown increased $\mathrm{O}_{3}$ deposition velocities during low tides, owing to direct deposition to macroalgae and/or to $\mathrm{O}_{3}$ involvement in iodine-mediated particle formation (McFiggans et al., 2010).

All recent observational and modelling studies of halogen chemistry generally agree that reactive halogen species are present in the unpolluted/semi-polluted marine boundary layer at levels that result in significant depletion of tropospheric ozone and loss of $\mathrm{O}_{x}$. Read et al. (2008), Sommariva and von Glasow (2012) and Saiz-Lopez et al. (2012s) calculated the contribution of halogens to ozone destruction using different models. The results, varying from 3 to $14 \mathrm{ppb}$ per day, indicate that halogens are overall the second most important sink for $\mathrm{O}_{x}$ in unpolluted and semi-polluted conditions, accounting for up to a third of total ozone loss in the tropical troposphere (Fig. 33). Bromine is twice as important as chlorine as an ozone sink, and iodine is potentially more efficient than bromine although its concentration shows
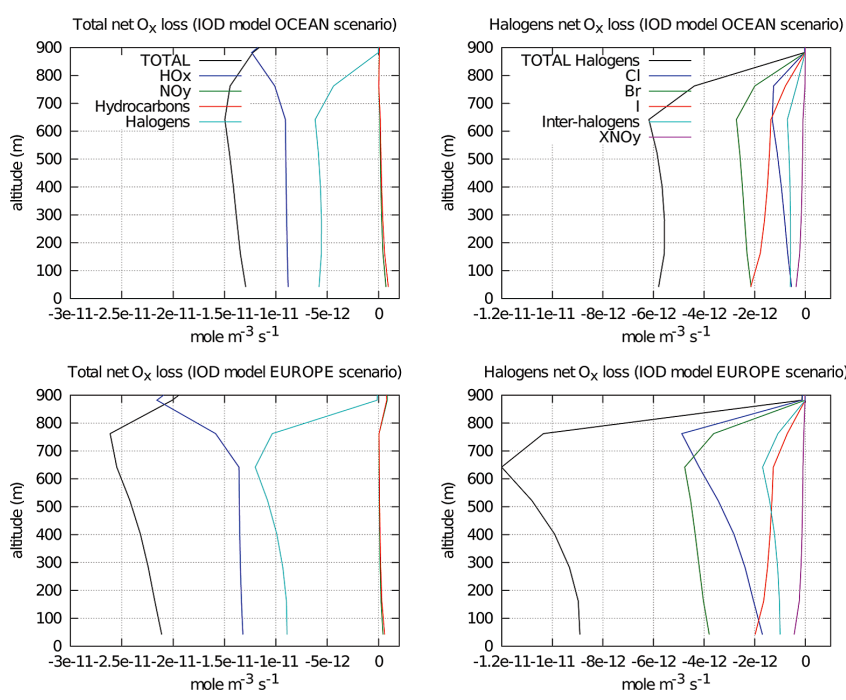

Figure 33. Vertical profiles at midday of total and halogen-induced net $\mathrm{O}_{x}$ loss in an unpolluted (OCEAN scenario) and semi-polluted (EUROPE scenario) marine boundary layer (Sommariva and von Glasow, 2012).

a steeper vertical gradient, making it less important than bromine and chlorine above 500-600 $\mathrm{m}$ (Sommariva and von Glasow, 2012). It must also be noted that the co-presence of iodine and bromine makes the loss of ozone more efficient than if bromine alone were present, due to the multiplying effect of inter-halogen reactions (e.g. IO + BrO; Read et al., 2008). In polluted regions, due to the higher concentrations of $\mathrm{NO}_{x}$, the oxidation of $\mathrm{VOC}$ by $\mathrm{Cl}$ and, to a lesser extent, $\mathrm{Br}$ results in net ozone production. For example, Finley and Saltzmann (2008) calculated that the levels of dihalogens (up to $26 \mathrm{ppt}$ of $\mathrm{Cl}_{2}$ and up to $9 \mathrm{ppt}$ of $\mathrm{Br}_{2}$ ) observed in California could account for up to $10 \%$ of measured ozone.

The role of halogens in the boundary layer is likely to be impacted, and possibly become even more relevant for $\mathrm{O}_{3}$ photochemistry, by changes in the Earth system, which may alter the formation of marine aerosol, as well as increased emissions of acids and acid precursors, which affect the halogen activation processes (Long et al., 2014).

At polar latitudes $\left(>60^{\circ}\right)$, periodic ozone depletion events (ODEs) have been observed since the mid-1980s and have been linked to bromine release from the snowpack (Simpson et al., 2007) with observed $\mathrm{BrO}$ levels ranging from 5 to 41 ppt (Roscoe et al., 2014; Saiz-Lopez and von Glasow, 2012). Recently, novel observations of BrO (Liao et al., 2011) have shown that "BrO clouds" tend to be distributed homogeneously over scales of a few kilometres during ODEs, while Salawitch et al. (2010) found that BrO columns are correlated with the height of the tropopause, although some "hotspots" are related to free-tropospheric or stratospheric intrusions.

There is much less information regarding iodine and chlorine in polar regions. Chlorine presence has been inferred 
only by VOC ratios in the past; recently Pohler et al. (2010) and Liao et al. (2014) reported the first observations of OClO (up to $24 \mathrm{ppt}$ ) and $\mathrm{Cl}_{2}$ (up to $100 \mathrm{ppt}$ ) in the Arctic. These findings suggest that $\mathrm{Cl}$ may enhance $\mathrm{O}_{3}$ depletion in the polar regions, mostly via its close coupling with bromine chemistry (with the $\mathrm{ClO}+\mathrm{BrO}$ reaction contributing up to $73 \%$ to ozone depletion). Iodine species (IO) have been detected in Antarctica at levels comparable to $\mathrm{BrO}(\sim 20 \mathrm{ppt}$; SaizLopez et al., 2008), which increase $\mathrm{O}_{3}$ loss rate by up to 3 times. Only one study reported IO in the Arctic at $<3.4 \mathrm{ppt}$ (Mahajan et al., 2010); whether this is due to differences between the two polar regions (e.g. biological communities or sea ice characteristic) is at present unclear.

Many questions remain on the mechanism of release of chlorine/bromine species from the snowpack (see Abbatt et al., 2012, for a detailed review). An important issue is whether it can explain observed $\mathrm{HO}_{x}$ and $\mathrm{NO}_{x}$ levels (SaizLopez et al., 2008; Bloss et al., 2010), as well as observed halogens levels. A modelling study by Thomas et al. (2011, 2012) indicated that up to $10 \mathrm{ppt}$ of tropospheric $\mathrm{BrO}$ can be explained by a mechanism involving nitrate formation in the interstitial snow; if this is the case, the resulting formation of $\mathrm{NO}_{x}$ may compensate for the depletion of $\mathrm{O}_{3}$ due to reactive $\mathrm{Br}$, possibly leading to net ozone formation. Additionally, since bromine release is connected with first-year sea ice (Saiz-Lopez and von Glasow, 2012), changes in sea ice formation due to climatic change are likely to affect ozone photochemistry significantly.

The importance of localised sources of halogens, such as salt lakes, salt beds, saline soils and marshes, for $\mathrm{O}_{3}$ photochemistry is at present unclear. Large concentrations of bromine and iodine (up to $200 \mathrm{ppt}$ of $\mathrm{BrO}$ - Tas et al., 2005, and up to $10 \mathrm{ppt}$ of IO - Zingler and Platt, 2005) have been reported over the Dead Sea (Israel) causing $\mathrm{O}_{3}$ as low as $2 \mathrm{ppb}$; however, observations in other locations have shown much lower values (e.g. $6 \mathrm{ppt}$ of $\mathrm{BrO}$ and $15 \mathrm{ppt}$ of $\mathrm{ClO}$ over the Great Salt Lake; Stutz et al., 2002). The database of observations is very sparse and shows large variability between different locations, suggesting that the local characteristics (e.g. latitude, $\mathrm{pH}$, geology, ecosystem and local meteorology) of the salt lakes are crucial in determining the strength of halogen emissions and therefore of the magnitude of the ODE they trigger (Smoydzin and von Glasow, 2009).

Chlorine and bromine species have also been detected in volcanic plumes at ppm and ppb levels, respectively (SaizLopez and von Glasow, 2012), leading to ozone depletion inside the plume which can persist for at least 3 days and possibly longer (see von Glasow, 2010, for a detailed discussion). Similar chemistry may be expected from other types of volcanic activity, such as volcanic fields, vents and fumaroles, and may affect ozone levels both in the boundary layer and in the free troposphere. The extent to which halogens from volcanic activity affect ozone photochemistry on a larger (regional/global) scale depends on several variables, including the type, frequency and extent of volcanic activity, the mixing with the background air and the synoptic circulation.

Besides the injection of halogen species by volcanic activity (see above), the main sources of halogens in the free troposphere are believed to be the oxidation of halocarbons, the uplift of aerosol and stratospheric intrusions (Saiz-Lopez and von Glasow, 2012), although direct observations are scarce. Pommier et al. (2012) found evidence of biomass burning from Siberian fires as a source of $\mathrm{BrO}(>5 \mathrm{ppt})$ in the Arctic free troposphere, although the release mechanism is unclear; Roscoe et al. (2014) compared ground-based and remote sensing measurements in Antarctica and concluded that they could only be reconciled by assuming large amounts of $\mathrm{BrO}$ at high altitudes, in broad agreement with the findings by Koo et al. (2012).

Jones et al. (2010a) found a strong association between high altitude ODEs and atmospheric low-pressure systems which drive the formation of large-scale $\mathrm{BrO}$ clouds over Antarctica. Free troposphere-boundary layer dynamics may also be important outside the polar regions. For example, Long et al. (2014) suggested that the accumulation of insoluble bromine in the free troposphere (via sulfur oxidation by $\mathrm{HOBr}$ and/or $\mathrm{HBr}$ condensation on aerosol) may explain the observed $\mathrm{Br}$ enrichment of submicron aerosol after entrainment of these species back in the boundary layer. These recent findings suggest the presence of large concentrations of inorganic $\mathrm{Br}$ at high altitudes in the troposphere, and model calculations show that they may account for $3-15 \%$ reduction in tropospheric $\mathrm{O}_{3}$ (von Glasow and Crutzen, 2004). Lary (2005) has examined the role of halogens in the free troposphere using chemical data assimilation technique and concluded that chlorine and bromine can significantly affect the levels of methane (10-50\% of the total oxidation rate) and ozone in the upper troposphere, especially at polar and tropical latitudes.

Recently, IO has also been observed in the tropical and subtropical free troposphere at concentrations between 0.2 and 0.4 ppt (Dix et al., 2013; Puentedura et al., 2012). Assuming 0.5 ppt of $\mathrm{BrO}$ and $0.6 \mathrm{ppt}$ of IO, Dix et al. (2012) estimated that iodine accounts for 11 and $26 \%$ of total ozone loss in the free troposphere and in the boundary layer-free troposphere transition region, respectively.

\subsection{Tropospheric ozone and global perturbation of the nitrogen cycle}

The drivers of enhanced tropospheric ozone are emissions of the precursors, $\mathrm{NO}_{x}$ and $\mathrm{VOC}$, and viewed globally the hotspots for ozone production coincide with the areas of largest $\mathrm{NO}_{x}$ emissions (Stevenson et al., 2006), most notably in Europe, North America and Asia. Thus the effects of elevated tropospheric ozone are coupled with anthropogenic emissions of $\mathrm{NO}_{x}$, an important anthropogenic contribution to the current global cycling of fixed nitrogen $(\mathrm{Nr})$, to distinguish it from the atmospheric reservoir of unreactive $\mathrm{N}_{2}$. 
Recent assessments of the global nitrogen cycle have quantified the major natural and anthropogenic fluxes of $\mathrm{Nr}$ (Sutton et al., 2011; Galloway et al., 2004). The scale of the human perturbation of the global nitrogen cycle is substantial, with approximately half of the $413 \mathrm{Tg} \mathrm{N}$ annual fixation of atmospheric nitrogen into reactive oxidised $\mathrm{NO}_{y}$ and reduced, $\mathrm{NH}_{x}$ forms (Fowler et al., 2013b) contributed by anthropogenic activities (Lu et al., 2013). Within this total, most of the nitrogen fixed annually is by industrial production of ammonia in Haber-Bosch industrial plants and within soils and oceans by microbial processes. Only a small fraction of this $\mathrm{Nr}$ is emitted to the atmosphere (see Fig. 34). The emissions most important for tropospheric ozone production are of $\mathrm{NO}_{x}$ from combustion, in vehicles and industry, which totals approximately $40 \mathrm{Tg} \mathrm{N}$ annually, just $10 \%$ of total $\mathrm{Nr}$ production.

While the focus of this review is tropospheric ozone, it is important to recognise the wider impacts of the human perturbation of the nitrogen cycle (Fowler et al., 2015). These include eutrophication of terrestrial and marine ecosystems, reductions in biodiversity of terrestrial ecosystems over Europe and North America, widespread effects on human health from the aerosols containing nitrogen compounds and radiative effects on global climate and reductions in stratospheric ozone from elevated $\mathrm{N}_{2} \mathrm{O}$ emission, as detailed by Erisman et al. (2013). The negative effects of contamination of the environment by nitrogen compounds has been extensively documented for Europe (Sutton et al., 2011) and North America (Suddick et al., 2013). However, evidence from Asia and especially China and India is increasing rapidly and the absolute values for deposition of $\mathrm{Nr}$ in these regions are among the largest globally, and effects on ozone production and terrestrial eutrophication are widespread.

Relatively little research on the effects of nitrogen emission has been reported in the tropics, but new evidence from work in SE Asia by Hewitt et al. (2009) suggests that these regions are very sensitive to emissions of $\mathrm{NO}_{x}$, which are projected to increase substantially over coming decades as natural rainforest ecosystems are replaced by agriculture, e.g. plantations of oil palm.

One of the distinctive features of the nitrogen cycle is the rapid transformation of nitrogen compounds within, and transfers between, the atmosphere, vegetation, soils, fresh and marine waters. Thus emissions of oxidised nitrogen to the atmosphere are rapidly oxidised and deposited into terrestrial ecosystems, where it may be transformed into amino acids and subsequently decomposed to ammonium following decay and returned to the atmosphere as ammonia. In the processes within this short sequence, the $\mathrm{NO}_{x}$ in the atmosphere may have generated ozone, reduced the lives of humans breathing $\mathrm{NH}_{4} \mathrm{NO}_{3}$-containing aerosols and contributed to species loss in terrestrial ecosystems. The same emitted $\mathrm{N}$ atom may have contributed to a series of different effects within the Earth system before it is returned back to the atmospheric reservoir as $\mathrm{N}_{2}$ following denitrification in soils or within the ocean. This effect has been referred to as the nitrogen cascade (Galloway et al., 2003) and shows a very large range of effects of reactive nitrogen on climate, terrestrial and marine ecosystems and on human health. A full analysis of the global effect of nitrogen has yet to be completed, but assessments have been recently published for Europe (Sutton et al., 2011) and North America (Suddick et al., 2013).

One further aspect for consideration is the coupling between tropospheric ozone, carbon uptake in the terrestrial biosphere and nitrogen (Simpson et al., 2014). It has been recently shown that limitations of available nitrogen for sufficient plant growth reduce the negative impact of tropospheric ozone on carbon uptake in plants, leading to a smaller indirect change in radiative forcing than previously calculated (Kvalevåg and Myhre, 2013).

\subsection{Challenges in modelling ozone}

Models are the integrator of the chemical and physical knowledge with respect to ozone in the atmosphere. They are much relied on for analysis of observational data, hindcasting, policy support and forecasting across a range of temporal and spatial scales. Models vary much in scale and resolution and with physical/chemical complexity.

With respect to current global ozone, Young et al. (2013) compared modelled (ACCMIP models) and observed (ozonesonde and satellite (OMI/MLS)) present-day spatial distributions and seasonality of global tropospheric ozone. The models captured the seasonality well at most locations. Based on the comparison to OMI/MLS data, the models typically overestimated annual mean tropospheric column ozone at $0-50^{\circ} \mathrm{N}$ by $\approx 0-30 \%$ and underestimate it at $0-50^{\circ} \mathrm{S}$ by $\approx 0-25 \%$. Similarly, reanalysis model data for ozone from MACC shows biases of -5 to $+10 \%$ with respect to ozonesondes and aircraft data in the extratropics, but with larger negative biases in the tropics (Inness et al., 2013). These results indicate that models do not fully represent the processes controlling the present-day ozone distribution.

Parrish et al. (2014) showed that three of the ACCMIP models, driven by trends in emissions, underestimate observed trends in surface ozone over the period since $\sim 1950$, at northern hemispheric mid-latitudes; similar results have been found earlier (e.g. Schultz et al., 2007b). Cooper et al. (2014) extended this analysis to show that models also underestimate trends in other regions. These observations suggest that modelled ozone appears to be rather too insensitive to emissions perturbations (or possibly that historical emissions changes are not well described; see Sect. 2.3). Emissions remain a key uncertainty for global models (Frost et al., 2012).

Hess and Zbinden (2013) and Hess et al. (2014) find that the evolution of stratospheric ozone, and how this ozone is transported into the troposphere, is a major determinant of historical interannual variability in Northern Hemisphere 


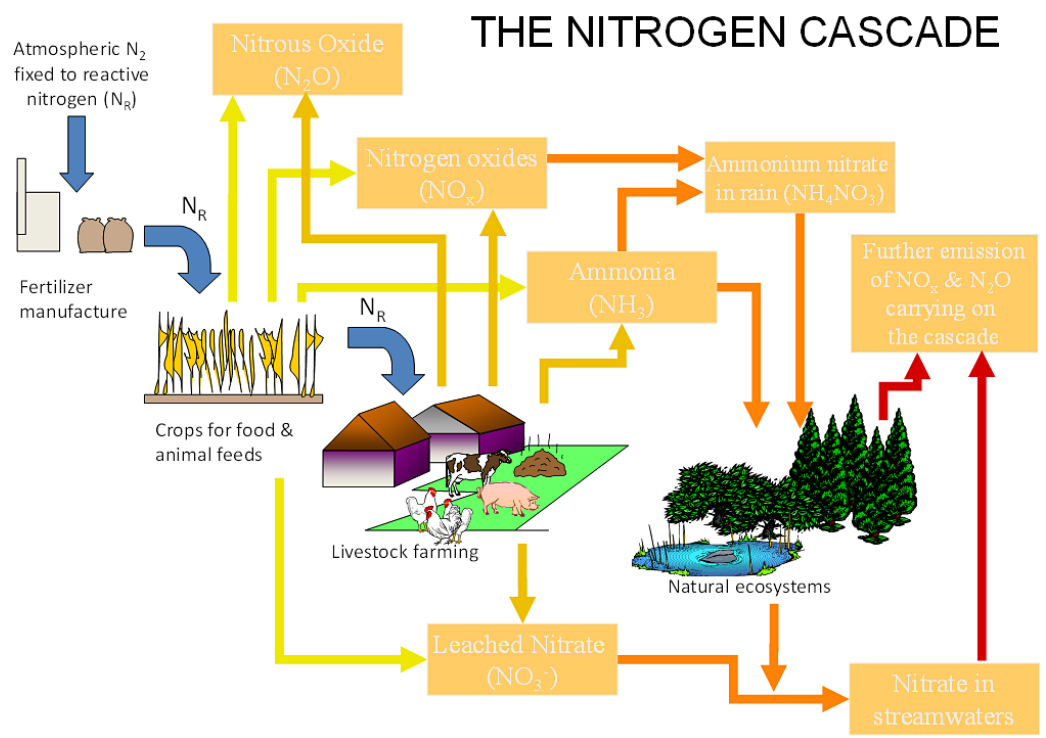

Abatement may swap one pollutant for another in the nitrogen cascade

Figure 34. The nitrogen cascade adapted from Sutton et al. (2011) showing the interrelationships of nitrogen sources of importance for the production of ozone.

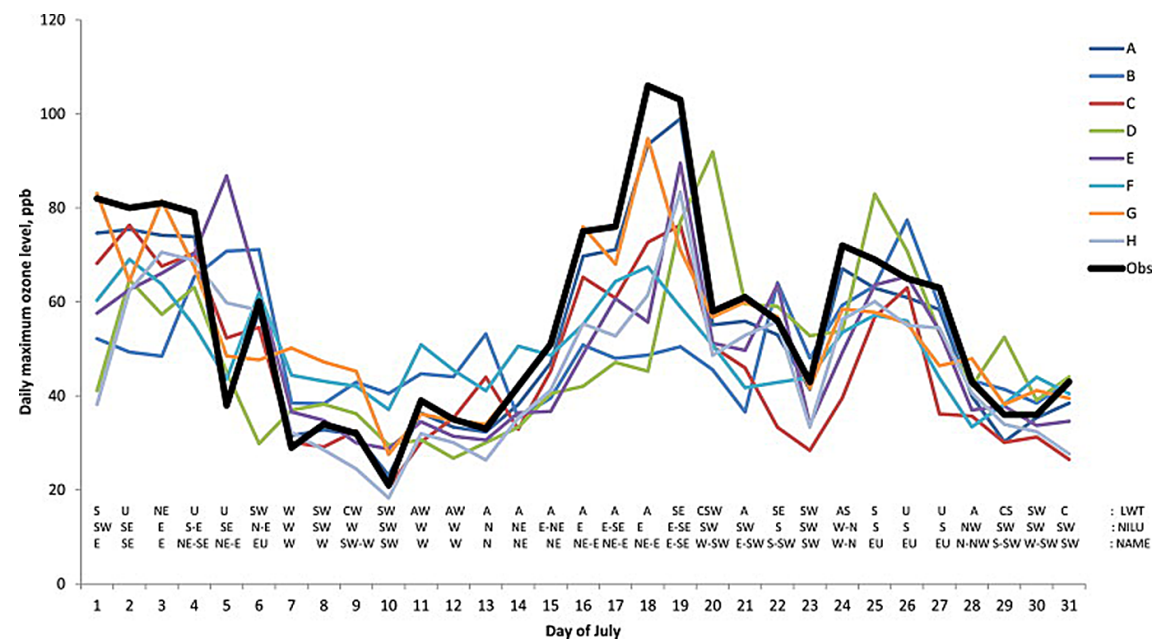

Figure 35. Daily maximum hourly ozone concentrations for eight models, A-H, in a comparison exercise against observations for July 2006 at Harwell, Oxfordshire, UK. Also shown are the daily advection regimes as Lamb weather types (LWT), NILU FLEXTRA trajectories (NILU) and NAME air history maps (NAME); see Derwent et al. (2014).

mid-latitude ozone throughout the troposphere, and may have significantly contributed to long-term trends. This work indicates that global models need a detailed representation of stratospheric and upper troposphere/lower stratosphere processes in order to simulate ozone trends and variability correctly.

Further challenges to models include, the representation of different aspects of ozone chemistry (e.g. isoprene Archibald et al., 2010; Dunker et al., 2014; halogens - Yang et al., 2005; Saiz-Lopez et al., 2012a; and chemical mechanism - Saylor and Stein, 2012) and deposition (Val-Martin et al., 2014). For models to represent many of these processes, adequate resolution is required (Colette et al., 2014).

A couple of studies (Wu et al., 2007; Wild, 2007) have argued that much of the variance in ozone production across models can be explained by differences in $\mathrm{NO}_{x}$ emissions, inclusion of non-methane volatile organic compounds (NMVOCs, mostly biogenic isoprene) and ozone influx from stratosphere-troposphere exchange. Model tagging offers insights into separating processes such as transport and chemistry (see e.g. Garny et al., 2011). 
The challenge for global modellers is prioritising and including all relevant processes in a model with sufficient resolution and while keeping it sufficiently computationally efficient so that it can be useful for a wide range of studies.

A large range of models are used to address ground-level ozone at the regional scale (Kukkonen et al., 2012). Taking into account only emission control policies for the present or near future (2010 or 2020), several multi-model exercises have been conducted in support to the Clean Air For Europe (CAFE) programme. The CityDelta project (Cuvelier et al., 2007) aimed to predict the impact and uncertainty of emission reductions of several emission scenarios for 2010 in several European cities. The same exercise was carried out at the larger scale of the European continent (EuroDelta: van Loon et al., 2007). At the continental scale the efficiency of emission reductions was demonstrated but models provided a large spread of responses in city centres. The ability of an ensemble of six chemistry transport models to capture recent observed ozone trends was also discussed by Colette et al. (2012). They found that models efficiently captured the increase in $\mathrm{NO}_{x}$-saturated areas, such as the Benelux region and the decrease in $\mathrm{NO}_{x}$-limited areas (many rural regions in Europe). The quantitative skill of the model was, however, difficult to retrieve owing to the lack of significant trends throughout Europe over the period selected for the experiment. They also emphasised that modelled trends where highly sensitive to the trends in precursors prescribed in the inventory which exhibited some significant inconsistencies compared to observations of $\mathrm{NO}_{2}$, in particular.

A regional model comparison of ozone is shown in Fig. 35. The comparison found that no one model was the "best" model on all days, indicating that no single air quality model could currently be relied upon to inform policymakers robustly in terms of $\mathrm{NO}_{x}$ versus VOC sensitivity. For this reason, coupled with basic statistical arguments, it was argued that it is important to maintain diversity in model approaches (Derwent et al., 2014).

With respect to regional models, Kukkonen et al. (2012) highlighted the most prominent gaps of knowledge for chemical weather forecasting models; these include emission inventories, the integration of numerical weather prediction and atmospheric chemical transport models, boundary conditions and nesting of models, data assimilation of the various chemical species (see e.g. Gaubert et al., 2014), improved understanding and parameterisation of physical processes, better evaluation of models against data and the construction of model ensembles.

It is clear that next generation models will push to greater resolution on the regional scale (Colette et al., 2014).

\subsection{Lightning}

Globally, lightning flashes occur about 50 times per second, equal to 4.3 million times per day and roughly 1.5 billion times per year. Lightning flashes dissociate $\mathrm{N}_{2}$ molecules, leading to NO production (Schumann and Huntrieser, 2007), a key source of $\mathrm{NO}_{x}$ in much of the troposphere, especially the tropical upper troposphere (Schumann and Huntrieser, 2007; Grewe, 2008; Grewe et al., 2012a; Levy et al., 1996). More than $80 \%$ of summertime upper tropospheric $\mathrm{NO}_{x}$ above the eastern United States is produced by lightning (Cooper et al., 2009) and can be a significant contributor to surface ozone (Hudman et al., 2009). Lightning $\mathrm{NO}_{x}\left(\mathrm{NO}_{2}\right)$ has been detected from space (Beirle et al., 2010; Choi et al., 2005). The lightning-produced NO perturbs atmospheric composition in several ways relevant to climate, as NO is an important determinant of $\mathrm{OH} / \mathrm{HO}_{2}$ ratios via Reaction (R3).

Given sufficient UV radiation and a supply of $\mathrm{HO}_{2}, \mathrm{NO}_{x}$ will efficiently generate $\mathrm{O}_{3}$ (see Sect. 2.1.1). Figure 36 shows modelled contribution of individual sectors in terms of $\mathrm{NO}_{x}$ emissions, including lightning, to the tropospheric ozone column (Grewe et al., 2012a). Toumi et al. (1996) highlighted that $\mathrm{O}_{3}$ production from lightning $\mathrm{NO}_{x}\left(L_{\mathrm{NO}_{\mathrm{x}}}\right)$ may represent an important positive climate feedback if a warmer world generates more lightning (Reeve and Toumi, 1999).

However, in addition to leading to $\mathrm{O}_{3}$ production (see Sect. 2.1.1), Reaction (R3) enhances OH. This increases the methane removal via the reaction

$\mathrm{CH}_{4}+\mathrm{OH}+\mathrm{O}_{2} \rightarrow \mathrm{CH}_{3} \mathrm{O}_{2}+\mathrm{H}_{2} \mathrm{O}$

shortening the $\mathrm{CH}_{4}$ lifetime and hence reducing its atmospheric concentration, exerting reducing radiative forcing (RF) (e.g. Derwent et al., 2001; Wild, 2007; Wild et al., 2001).

Any perturbations to $\mathrm{NO}_{x}$ (including lightning) will potentially lead to climate feedbacks via the biosphere, through deposition of $\mathrm{NO}_{3}$ and $\mathrm{O}_{3}$, and impacts on the carbon cycle (e.g. enhanced or reduced uptake of $\mathrm{CO}_{2}$ by vegetation; Sitch et al., 2007; Felzer et al., 2007). It is unclear whether the net effect on $\mathrm{CO}_{2}$ would result in a positive or negative RF.

Most studies suggest more lightning $\left(\mathrm{NO}_{x}\right)$ in a warmer world (Schumann and Huntrieser, 2007; Williams, 2005; Banerjee et al., 2014), but these studies are typically based on the Price and Rind (Price and Rind, 1992) parameterisation that links $L_{\mathrm{NO}_{x}}$ emissions to cloud top height (raised to the power 4.9 over land; to a lower power over ocean). Other parameterisations link $L_{\mathrm{NO}_{x}}$ emissions to cloud ice (see e.g. Finney et al., 2014; Tost et al., 2007), and as warming increases, ice declines, as does $L_{\mathrm{NO}_{x}}$ (Jacobson and Streets, 2009). In addition, some schemes relate $L_{\mathrm{NO}_{x}}$ to aerosols (Yuan et al., 2012; Venevsky, 2014), with potentially complex links between climate and $L_{\mathrm{NO}_{x}}$. With global warming, tropical stability increases (Held and Soden, 2006; Chou et al., 2013) tending to reduce convection. However, the tropopause tends to rise, allowing convection to reach greater heights. In the Price and Rind (1992) scheme, the higher tropopause affect typically dominates, although there can be regional increases/decreases in some models (e.g. Stevenson et al., 2005). 


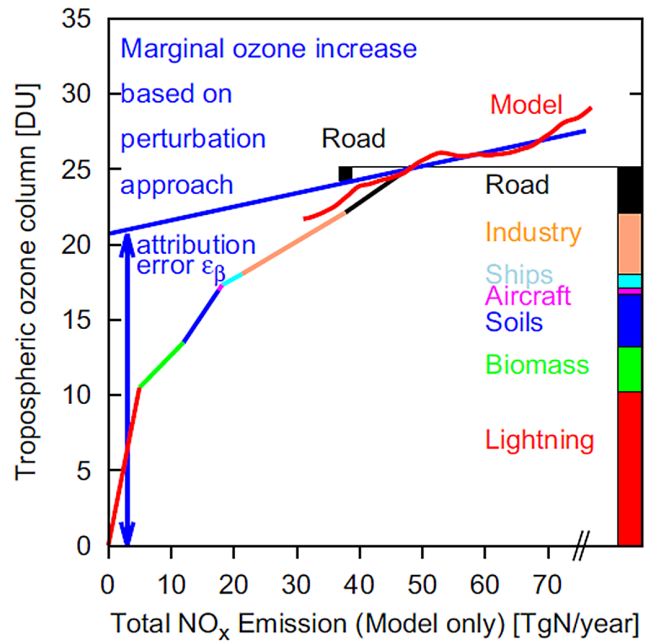

Figure 36. Contribution of individual sectors in terms of $\mathrm{NO}_{x}$ emissions to the tropospheric ozone column (Grewe et al., 2012b).

In summary, the literature suggests that $L_{\mathrm{NO}_{x}}$ increases lead to higher levels of $\mathrm{O}_{3}, \mathrm{OH}$, nitrate, and secondary aerosols in general, but less $\mathrm{CH}_{4}$, and have unknown impacts on $\mathrm{CO}_{2}$. It remains unclear whether the net impact of increases in $L_{\mathrm{NO}_{x}}$ on climate is warming or cooling; it is also unclear whether $L_{\mathrm{NO}}$ represents a positive or negative climate feedback.

\subsection{Arctic}

The Arctic is undergoing rapid change as a result of global warming. This can, in part, be attributed to production of ozone from tropical and mid-latitude emissions of ozone precursors, especially methane. Climate change, together with economic drivers, is also opening up the Arctic to new sources of pollution, such as shipping or oil/gas extraction, which may lead to significant local or regional increases in surface ozone and associated impacts on Arctic air quality and deposition to fragile ecosystems (Law and Stohl, 2007).

Observed Arctic $\mathrm{O}_{3}$ mixing ratios vary between 20 and $40 \mathrm{ppbv}$ at the surface and increase with altitude up to the tropopause (8-10 km) (Hirdman et al., 2010). Even though annual data on Arctic $\mathrm{O}_{3}$ are rather limited, significant differences can be seen in the seasonal cycle at different locations, driven by both remote and local processes (see Fig. 37) (Hirdman et al., 2010). Certain sites, such as Barrow (Alaska) or Alert (Canada), show evidence of halogen-influenced depletion during the spring months. As discussed in Sect. 4.4, halogen chemistry over sea-ice- or snow-covered regions can lead to very low or even near-zero $\mathrm{O}_{3}$ concentrations near the surface in the Arctic spring (e.g. Barrie et al., 1988). Other sites, such as Zeppelin, exhibit a spring maximum. Higher concentrations in the spring appear to be due to $\mathrm{O}_{3}$ formation from precursors related to the breakdown of Arctic haze at this time of year in the lower and middle troposphere (Em-

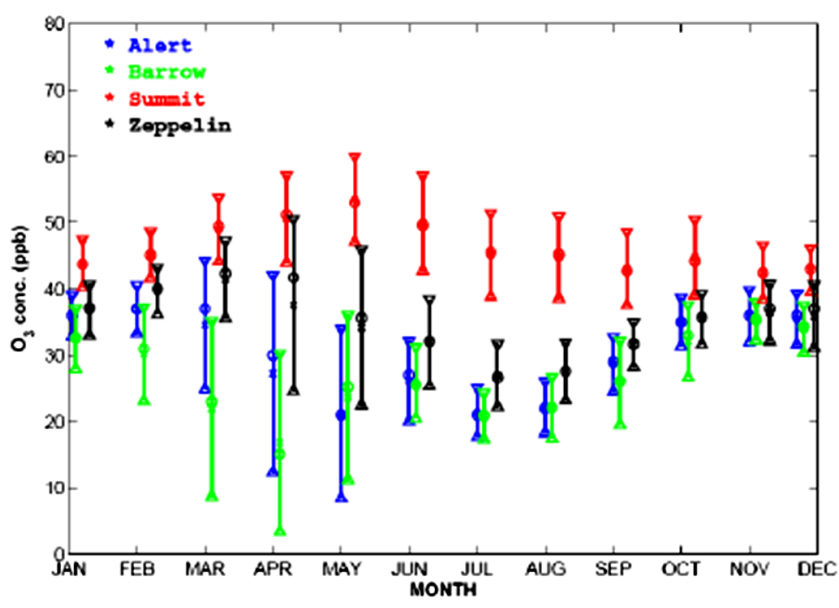

Figure 37. Seasonal cycle of $\mathrm{O}_{3}$ at various surface sites in the Arctic. From Hirdman et al. (2010).

mons et al., 2003). Arctic haze builds up during the winter each year as a result of transport of mid-latitude pollution into the polar dome (e.g. Barrie et al., 1981) and contains elevated levels of $\mathrm{O}_{3}$ precursors $\left(\mathrm{CO}, \mathrm{VOCs}, \mathrm{NO}_{x}\right)$ as well as PAN, an important source of $\mathrm{NO}_{x}$ (e.g. Hov et al., 1989).

Summit, which is at a higher elevation $(3 \mathrm{~km})$, in Greenland, has a late spring/early summer maximum, likely owing to transport of polluted air masses, primarily from North America, but which could also include a contribution from snow $\mathrm{NO}_{x}$ emissions (e.g. Grannas et al., 2007) or from the stratosphere. There are indications that $\mathrm{O}_{3}$ concentrations continue to increase in the Arctic both at the surface and at higher altitudes in the troposphere. Hess and Zbinden (Hess and Zbinden, 2013) reported an increasing trend in the European Arctic middle troposphere $(500 \mathrm{hPa})$ of $0.36 \pm 0.23 \mathrm{ppb} \mathrm{yr}^{-1}$ from ozonesonde measurements over the period 1996-2010, and Oltmans et al. $(2006,2013)$ reported a trend of $0.87 \pm 0.50 \% \mathrm{yr}^{-1}$ from surface measurements in 1992-2004 at Alert in the Canadian Arctic.

Several studies have examined sources of pollution transported to the Arctic (Mauzerall et al., 1996). In a multimodel assessment, Shindell et al. (2008) examined precursor emission sensitivities to emissions from different midlatitude source regions on the Arctic and found, for example, European $\mathrm{CO}$ emissions to be important in the winter. However, surface Arctic $\mathrm{O}_{3}$ in winter was most sensitive to $\mathrm{Eu}-$ ropean $\mathrm{NO}_{x}$ owing to the domination of strong titration $\left(\mathrm{O}_{3}\right.$ removal) in air masses. This was also confirmed by Hirdman et al. (2010). Emissions from Asia and Europe have been found to be important sources of Arctic $\mathrm{O}_{3}$ in spring in the free troposphere together with stratospheric injection although relative contributions vary between studies and years (Wespes et al., 2012; Shindell et al., 2008). Based on analysis of ARCTAS data (Jacob et al., 2010), Wespes et al. (2012) found that European anthropogenic emissions were important for lower tropospheric summertime Arctic $\mathrm{O}_{3}$ in con- 
trast to a previous study (Shindell et al., 2008). Production of $\mathrm{O}_{3}$ from PAN decomposition in air masses transported from mid-latitudes has also been identified as an important source of Arctic tropospheric ozone in the summer months (Walker et al., 2012). Indeed, aircraft observations collected during POLARCAT-IPY show elevated PAN and CO concentrations in air masses transported from Asian and North American anthropogenic emission regions in summer 2008 (Law et al., 2014, and references therein). Boreal forest fires are also an important source of PAN and, due to their proximity to the Arctic, plumes can be transported to high latitudes during the spring and summer months (Brock et al., 2011; Singh et al., 2010). Whilst little $\mathrm{O}_{3}$ production appears to occur close to boreal fires (Alvarado et al., 2010; Paris et al., 2010), several recent studies have shown $\mathrm{O}_{3}$ production downwind from boreal fires in the Arctic during the summer months (Wespes et al., 2012; Parrington et al., 2012; Thomas et al., 2013). Nevertheless, $\mathrm{O}_{3}$ production is higher in air masses influenced by anthropogenic emissions.

However, global and regional models still struggle to capture vertical distributions of trace gases, including ozone in the Arctic. CO concentrations are often underestimated even in multi-model simulations carried out as part of the POLARCAT model intercomparison project (POLMIP) using the same emission data sets (Monks et al., 2015; Emmons et al., 2015). Discrepancies appear to be related to either differences in oxidative capacity $(\mathrm{OH})$ or vertical transport of pollutants from mid-latitude source regions into the Arctic. Modelled concentrations of $\mathrm{NO}_{y}$ species such as PAN or $\mathrm{HNO}_{3}$ also show large variability and significant discrepancies compared to measurements (Arnold et al., 2015), pointing to a lack in our understanding about chemical processing in polluted air masses transported to the Arctic (Law et al., 2014).

As a short-lived climate forcer, tropospheric $\mathrm{O}_{3}$ contributes to Arctic warming. For example, Shindell et al. (2006) estimated that anthropogenic emission increases since 1900 could be responsible for $25 \%$ of surface temperature changes in the Arctic. Shindell (2007) estimated, based on the results from one model, that about $50 \%$ of the Arctic radiative forcing owing to ozone may be coming from $\mathrm{O}_{3}$ produced at mid-latitudes (impacting poleward heat transport) and about $50 \%$ from ozone produced in the Arctic. New local sources of pollution may also impact Arctic $\mathrm{O}_{3}$ in the future such as increased emissions from shipping (Granier et al., 2006) or oil and gas production. Dalsøren et al. (2013) examined impacts of future shipping on radiative forcing in the Arctic and found, particularly in the high-end scenario (from Corbett et al., 2010), that $\mathrm{O}_{3}$ radiative forcing from shipping is important in the summer and transit season (May to October) when sea ice is at a minimum.

\subsection{Unconventional oil and natural gas production: "fracking" and air quality}

Fossil fuel energy production is rapidly transforming and expanding owing to unconventional oil and natural gas extraction techniques, with implications for regional-scale ozone production. Unconventional oil and natural gas is extracted from tight geological formations (such as sandstone, coal and shale) through the use of hydraulic fracturing (also known as fracking) and directional drilling (Field et al., 2014; Bickle, 2012). These techniques allow wells to be drilled vertically into a shale formation and then horizontally through the formation, after which a mixture of water, sand and chemicals is pumped into the well at high pressure, fracturing the rock and allowing oil and gas to escape.

In the USA, the most extensive extractors of unconventional gas/oil, the shale plays (a name for the deposits) are located in many large basins across the country, primarily in the Rocky Mountains, Great Plains and the Appalachian Mountains. In terms of natural gas, the most productive shale plays are the Marcellus Shale (West Virginia, Pennsylvania, New York) (Kargbo et al., 2010) and the HaynesvilleBossier Shale (Texas and Louisiana). The greatest unconventional oil production is from the Bakken (North Dakota, Montana), Eagle Ford (Texas) and Niobrara (Wyoming and Colorado) shale formations (U.S. Energy Information Administration, 2014b).

In 2012 the USA produced 8.9 million barrels of oil per day (this includes crude oil, shale oil, oil sands and natural gas liquids), the third largest producer in the world, behind Russia and Saudi Arabia. However, the USA is the world leader in producing oil and natural gas from hydraulic fracturing, with 1.6 million barrels per day extracted from tight oil formations in 2012. Projections suggest that hydraulic fracturing will produce 4.5 million barrels per day by 2035 , accounting for most of the US increase in oil production (BP, 2013). The USA is poised to become the largest producer of liquid fuels in the world, primarily due to tight oil growth (BP, 2014a).

In 2012 the USA was the world's largest producer of natural gas, producing 681 billion cubic metres $(\mathrm{Bcm})$. US production of shale gas output is projected to rise from $255 \mathrm{Bcm} \mathrm{yr}^{-1}$ in 2012 (37\% of total production) to $672 \mathrm{Bcm} \mathrm{yr}^{-1}$ in 2035 (BP, 2014b). Shale gas was just $2 \%$ of US natural gas production in 2004, but by 2035 it will be $63 \%$. However, these oil and natural gas projections are highly uncertain with the quantity of oil produced in 2040 differing by a factor of 2 under a scenario of high oil and gas resources vs. a scenario of low oil and gas resources (U.S. Energy Information Administration, 2014a).

With the increase in unconventional oil and natural gas has come an increase in fugitive emissions of hydrocarbons to the atmosphere in quantities great enough to influence local- and regional-scale ozone production (Katzenstein et al., 2003; Kemball-Cook et al., 2010; Edwards et al., 2014). This im- 
pact was revealed in an unexpected way during early 2008 , when hourly average ozone mixing ratios exceeded $140 \mathrm{ppbv}$ during February in the rural Upper Green River basin of Wyoming (Schnell et al., 2009). In situ measurements revealed that the high wintertime ozone levels were due to a strong temperature inversion that trapped $\mathrm{NO}_{x}$ and hydrocarbon emissions from the natural gas industry. The trapping of the emissions was facilitated by high mountains on three sides of the basin. A key contributor to the ozone formation was deep snow cover, which reinforced the temperature inversion, and also reflected UV radiation back through the inversion layer, essentially doubling the amount of available UV radiation necessary for ozone production. This phenomenon has also been observed in the Uintah Basin, Utah, impacted by both oil and natural gas extraction (Edwards et al., 2013, 2014). Multiple years of data from these two regions demonstrate that without deep snow cover, the high ozone values do not occur (Oltmans et al., 2014). Recent work in the UK context (Sommariva et al., 2014) has shown the range and difference in UK shale VOC profiles.

The impact of emissions from the oil and natural gas industry on ozone outside of these rural, mountain-ringed basins is less certain. For example, field studies have been carried out across the Denver-Julesburg Basin in northeastern Colorado to quantify emissions from the oil and natural gas industry but accurate estimates for some gases are complicated by emissions from nearby urban areas (Pétron et al., 2012). However, relationships between particular VOCs can be used to clearly distinguish oil and natural gas emissions from urban emissions. VOC measurements from a site on the northern edge of the Denver metropolitan area were analysed to demonstrate that more than $50 \%$ of the VOC$\mathrm{OH}$ reactivity was attributable to emissions from oil and natural gas operations, indicating that these emissions are a significant source of ozone precursors (Gilman et al., 2013).

Several recent studies using chemical transport models suggest that emissions from the oil and natural gas industry can produce local- and regional-scale ozone enhancements (Kemball-Cook et al., 2010; Rodriguez et al., 2009; Carter and Seinfeld, 2012; Olaguer, 2012). The reliability of these modelling studies is limited by the emissions inventories, which are difficult to accurately produce owing to the heterogeneity of sources: type of gases emitted from a shale play, number of active well heads, integrity of infrastructure, emissions associated with well completion vs. well operation, and usage of venting or flaring (Field et al., 2014). The most recent US EPA estimates indicate that $\mathrm{NO}_{x}$ emissions from US petroleum and related industries only amounted to $5 \%$ of total US anthropogenic $\mathrm{NO}_{x}$ emissions in 2013, but doubled between 2004 and 2013 (U.S. EPA, 2014). Likewise VOC emissions increased by a factor of 4 over the same period, accounting for $14 \%$ of total US anthropogenic VOC emissions in 2013. However, these US EPA estimates are highly uncertain. The US EPA recently stated that it had not anticipated the tremendous nationwide growth in this sector and that it

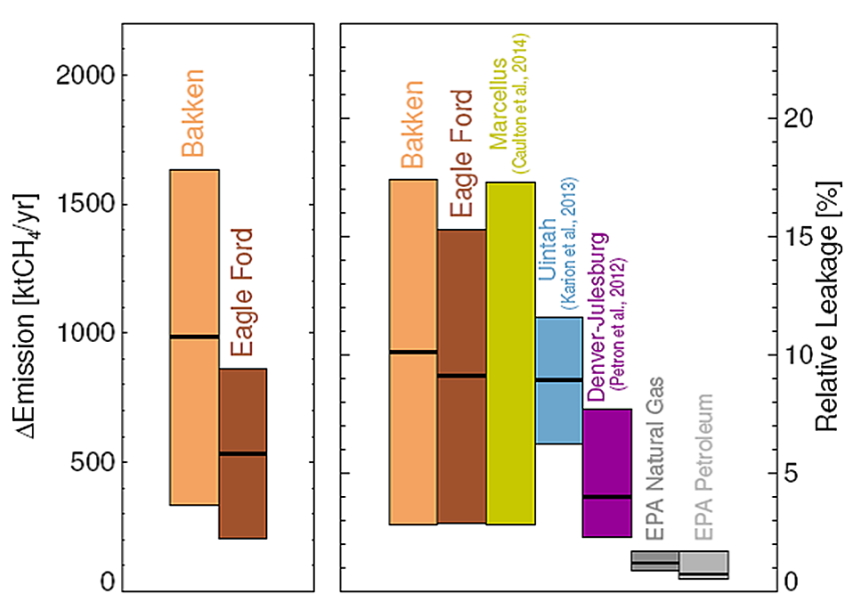

Figure 38. Estimated methane emissions are shown for the targeted regions Bakken in light brown, and Eagle Ford in dark brown from satellite remote sensing measurements (Schneising et al., 2014). Shown are absolute emission increases (2009-2011 relative to 2006-2008) in the left panel, and the leakage rates relative to production in the right panel, with the $1 \sigma$ uncertainty ranges. For comparison, leakage estimates from previous studies in Marcellus (2012) (Caulton et al., 2014), Uintah (2012) (Karion et al., 2013), Denver-Julesburg (2008) (Pétron et al., 2012). EPA bottom-up inventory estimates for natural gas and petroleum systems (2011) are shown for comparison (EPA, 2014).

has limited directly measured air emissions data from several important oil and gas production processes. The report recommends that the EPA produce a comprehensive strategy for improving air emissions estimates for oil and natural gas production (U.S. EPA, 2013). Until the emission inventories can be improved great uncertainty will surround model estimates of the impact of the oil and natural gas industry on ozone pollution.

One final consideration of the potential for the oil and gas industry to affect tropospheric ozone is through its impact on global methane levels. Methane leaks from the oil natural gas industry may be a contributing factor to the renewed increase in global methane concentrations (Nisbet et al., 2014). For example, hydraulic fracturing in Utah may locally leak 6 to $12 \%$ of gas production to the air (Karion et al., 2013). Kang et al. (2014) highlighted the issue of abandoned wells and their significance. Figure 38 shows data from a series of studies including satellite remotely sensed data that all show significant methane leakage beyond official EPA estimates (Schneising et al., 2014; Kort et al., 2014). However, owing to the great uncertainty of many aspects of global methane emissions, especially from US unconventional oil and natural gas activities (see e.g. Allen et al., 2013), much more research is required to understand the impact of unconventional oil and natural gas activities on global methane concentrations (Brandt et al., 2014). 


\subsection{Radical chemistry, radical changes}

Radicals are central to the chemistry of the atmosphere; from the destruction of $\mathrm{O}_{3}$ in the stratosphere, to the production and destruction of $\mathrm{O}_{3}$ in the troposphere, radicals drive atmospheric composition change (Monks, 2005). The inorganic $\mathrm{HO}_{x}$ radicals $\left(\mathrm{OH}, \mathrm{HO}_{2}\right)$ are regarded by many in the field of atmospheric chemistry as the most influential of all radicals, as such a great amount of effort has gone into understanding their impacts and fate in the atmosphere (Heard and Pilling, 2003; Monks, 2005; Stone et al., 2012).

Recent laboratory and modelling studies have shifted attention to improved understanding of the fate and role of organic radicals. The organic radicals of importance to atmospheric chemistry can be classified as organic peroxy radicals $\left(\mathrm{RO}_{2}\right)$ (Sect. 2.1.1), organic oxy radicals (RO) and the so-called Criegee intermediates (CIs), a class of bi-radical compounds believed to be formed mainly from the reaction of $\mathrm{O}_{3}$ with alkenes.

In the following section we briefly review the main aspects of the chemistry of organic radicals and highlight the latest discoveries in their chemistry. Significant use of the review of Orlando and Tyndall (Orlando and Tyndall, 2012) is made and for further details we refer the reader to their work.

$\mathrm{RO}_{2}$ are produced in the atmosphere by the $\mathrm{OH}$ - (and $\mathrm{NO}_{3}-$ ) initiated oxidation of VOCs. Once formed, peroxy radicals are lost via reaction with $\mathrm{NO}, \mathrm{HO}_{2}$ and other $\mathrm{RO}_{2}$. Whilst reactions with halogens $(\mathrm{X})$ and halogen oxides (XO) have been known about for several decades, their importance for inclusion in studies of tropospheric $\mathrm{O}_{3}$ chemistry has traditionally been expected to be small (see Sect. 4.4 for more details). The $\mathrm{RO}_{2}+\mathrm{NO}$ reaction is known to have two product channels. The first of these forms $\mathrm{NO}_{2}$, hence propagating tropospheric $\mathrm{O}_{3}$ formation; the second channel leads to the production of an organic nitrate $\left(\mathrm{RONO}_{2}\right)$ via a complex rearrangement, the exact mechanism of which is still uncertain (Dibble, 2008). We will not dwell on the chemistry of $\mathrm{RONO}_{2}$ here, but suffice it to say these moieties allow $\mathrm{O}_{3}$ precursors to be transported over great distances owing to their much longer atmospheric lifetime than $\mathrm{NO}_{2}$. The kinetics of the $\mathrm{RO}_{2}+\mathrm{NO}$ reaction limit the $\mathrm{RO}_{2}$ lifetime to only a few seconds when $[\mathrm{NO}]>1 \mathrm{ppbv}$ (see Sect. 3.1 of Orlando and Tyndall, 2012, for references). Broadly speaking, the $\mathrm{RO} 2+\mathrm{NO}$ reaction can be classed as the most important of the $\mathrm{RO}_{2}$ loss reactions to include for modelling $\mathrm{O}_{3}$ production in the troposphere. The products of the reaction between $\mathrm{RO}_{2}$ and $\mathrm{HO}_{2}$ depend strongly on the structure of the $\mathrm{RO}_{2}$ (Orlando and Tyndall, 2012). Traditionally the reaction between $\mathrm{RO}_{2}$ and $\mathrm{HO}_{2}$ has been thought of as a radical sink, hence limiting the propagation of $\mathrm{RO}_{2}+\mathrm{NO}$ reactions and so reducing the potential $\mathrm{O}_{3}$ production. The major product of this reaction for an alkyl $\mathrm{RO}_{2}\left(\mathrm{R}^{\prime} \mathrm{RCHOO}\right)$ is an organic hydroperoxide $(\mathrm{ROOH})$, a compound that is predicted to be lost from the atmosphere via deposition or aqueous uptake faster than its photodissociation can reform precursor radicals. The kinetics of the self- $\left(\mathrm{RO}_{2}+\mathrm{RO}_{2}\right)$ and cross-reactions $\left(\mathrm{RO}_{2}+\right.$ $\mathrm{R}^{\prime} \mathrm{O}_{2}$ ) of $\mathrm{RO}_{2}$ (see Sect. 3.5 of Orlando and Tyndall, 2012, for references) limit the importance of these reactions to laboratory studies and parts of the atmosphere where concentrations of $\mathrm{RO}_{2}$ are high (e.g. high BVOC emission regions).

For $\mathrm{RO}_{2}$ to have a big impact on the composition and chemistry of the atmosphere they must propagate radical production. $\mathrm{RO}$ are produced almost exclusively as products of the reactions of $\mathrm{RO}_{2}$ with $\mathrm{NO}$. In general RO are very reactive and either undergo unimolecular decomposition (on the timescale of milliseconds) or react with $\mathrm{O}_{2}$-producing $\mathrm{HO}_{2}$ radicals (see Sect. 2.1.1). Archibald et al. (2007) used a box model to investigate the importance of the reaction

$\mathrm{RO}+\mathrm{NO}_{2}+M \rightarrow \mathrm{RONO}_{2}+M$,

and concluded that, for $\mathrm{CH}_{3} \mathrm{O}$, Reaction (R14) could be a significant source of $\mathrm{CH}_{3} \mathrm{ONO}_{2}$ under the high- $\mathrm{NO}_{2}$ conditions found in many megacities, but that the unimolecular decomposition and reaction of $\mathrm{O}_{2}$ with $\mathrm{RO}$ limits the importance of Reaction (R15) to $\mathrm{CH}_{3} \mathrm{O}$ only.

Owing to very significant disagreement between model simulations and observations of $\mathrm{HO}_{x}$ radicals in pristine environments (Whalley et al., 2011; Lelieveld et al., 2008), a number of recent studies have focused on trying to better understand the role of $\mathrm{NO}_{x}$ free-radical-propagating chemistry for $\mathrm{RO}_{2}$. In pristine environments the loss of $\mathrm{RO}_{2}$ was traditionally thought to be dominated by the radical terminating reaction between $\mathrm{RO}_{2}$ and $\mathrm{HO}_{2}$. However, for acyl $\mathrm{RO}_{2}(\mathrm{RC}(\mathrm{O}) \mathrm{OO})$, recent work has shown that the reaction of $\mathrm{RO}_{2}$ with $\mathrm{HO}_{2}$ has a major radical-propagating product channel generating $\mathrm{OH}$ and $\mathrm{RO}_{2}$ (see Sect. 3.4 of Orlando and Tyndall, 2012, for references). Based on this evidence Lelieveld et al. (2008) postulated that the reaction of $\mathrm{RO}_{2}$ with $\mathrm{X}$ (where $\mathrm{X}$ reacted with a rate coefficient similar to that for $\mathrm{RO}_{2}+\mathrm{NO}$ ) propagated radicals and was able to reconcile the model measurement disagreement for $\mathrm{HO}_{x}$ in the Amazon. However, Lelieveld et al. (2008) were unable to provide direct evidence for the structure of the unknown reaction partner, X. In much earlier modelling work, Frost et al. (1999) speculated that near-IR absorption by $\mathrm{RO}_{2}$ could lead to intramolecular conversion and yield $\mathrm{HO}_{x}$ radicals. Whilst a great deal of work has been performed identifying the absorbance features of $\mathrm{RO}_{2}$ in the near IR (e.g. Kline and Miller, 2014), to date there has been almost no laboratory evidence of $\mathrm{HO}_{x}$ formation following absorption by $\mathrm{RO}_{2}$ in the near IR. However, Maccarone et al. (2013) recently showed that arylperoxy radicals $\left(\mathrm{RO}_{2}\right.$ derived from aromatic hydrocarbons) are able to photodissociate in the visible spectrum to yield $\mathrm{O}\left({ }^{3} \mathrm{P}\right)$ and hence produce $\mathrm{O}_{3}$ in the troposphere, without the need for $\mathrm{NO}_{x}$. As highlighted by the work of Lelieveld et al. (2008) and Frost et al. (1999), modelling experiments are increasingly being used to help direct laboratory studies in the search for radical propagating reactions. Archibald et al. (2009) investigated the possible reaction between $\mathrm{RO}_{2}$ and $\mathrm{OH}$ using a simple box model of the marine 
boundary layer (MBL). In their study Archibald et al. (2009) suggested three different mechanisms for the $\mathrm{RO}_{2}+\mathrm{OH}$ reaction yielding three unique product sets - two propagating radicals and a further one leading to the formation of alcohols. The reaction they modelled was, at the time, very speculative as no kinetic studies had been performed. Archibald et al. (2009) used the kinetics of $\mathrm{RO}_{2}+\mathrm{X}$ and $\mathrm{RO}_{2}+\mathrm{XO}$ reactions as an analogy. Their model calculations concluded that the $\mathrm{RO}_{2}+\mathrm{OH}$ reaction would have little impact on $\mathrm{HO}_{x}$ under conditions encountered in the MBL. Recently, Bossolasco et al. (2014) measured the direct kinetics for the reaction between $\mathrm{RO}_{2}$ and $\mathrm{OH}$ and showed that it is extremely fast $\left(k \approx 2.8 \pm 1.4 \times 10^{-10} \mathrm{~cm}^{3} \mathrm{~s}^{-1}\right)$, potentially twice as fast as the upper limit used by Archibald et al. (2009). The importance of this reaction under conditions similar to those found by Lelieveld et al. (2008) is yet to be explored.

Whilst unimolecular $\mathrm{RO}_{2}$ isomerisations have been known about in combustion chemistry (where $T>600 \mathrm{~K}$ ) for several decades (e.g. Hughes et al., 1992), the importance of this process for the loss of $\mathrm{RO}_{2}$ in the troposphere was thought insignificant - until recently. The $\mathrm{RO}_{2}$ isomerisation proceeds via internal $\mathrm{H}$ atom abstraction from the terminal oxygen of the $-\mathrm{OO}$ group to produce what in combustion chemistry is referred to as a QOOH (see Fig. 39). Using ab initio calculation, Peeters et al. (2009) and Da Silva et al. (2009) independently suggested a mechanism for $\mathrm{RO}_{2}$ isomerisations in the oxidation of isoprene that they postulated could help improve the model-measurement mismatch reported by Lelieveld et al. (2008) for $\mathrm{HO}_{x}$ in pristine conditions. The focus on isoprene peroxy radicals has led to a number of new discoveries in the lab as well as from a theoretical point of view. Thanks, largely to developments in mass spectrometry and other analytical techniques, new products (isoprene epoxydiols - IEPOX; hydroperoxy aldehydes - HPALDs) have been elucidated, and their mechanisms and impacts on reconciling the " $\mathrm{HO}_{x}$ problem" tested (Crounse et al., 2011; Paulot et al., 2009). In their work on updates to the chemical mechanism of isoprene oxidation, Archibald et al. (2010) reviewed several of the proposed mechanisms and concluded that whilst the isomerisation reactions proposed by Peeters et al. (2009) had the most promise in reconciling the model-measurement disagreement, the reported parameters could not be fully reconciled with atmospheric observations of other species and existing laboratory data without some degree of parameter refinement and optimisation, which would probably include a reduction in the peroxy radical isomerisation rates and a consequent reduction in the $\mathrm{OH}$ enhancement. Indeed, Crounse et al. (2011) provided the first laboratory evidence for the $\mathrm{RO}_{2}$ isomerisations in the isoprene system but derived rate coefficients for the processes that where much smaller than those calculated by Peeters et al. (2009). However, modelling studies using the kinetics derived from their study suggested that $10-20 \%$ of isoprene $\mathrm{RO}_{2}$ would undergo unimolecular isomerisations (Crounse et al., 2011) and as such this is an important process to include.

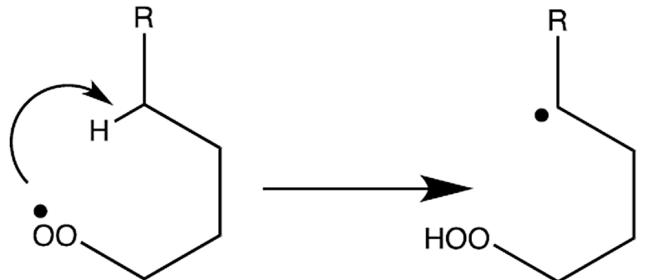

Figure 39. $\mathrm{RO}_{2}$ isomerisation to QOOH. In this mechanism, well known in combustion chemistry, the terminal $\mathrm{O}$ atom of the $\mathrm{RO}_{2}$ abstracts a labile $\mathrm{H}$ (through the formation of a ring-structured intermediate).

An astonishing amount has been learnt about the atmospheric chemistry of the Criegee intermediates (CIs) over the last few years. Pioneering work carried out at the synchrotron Advanced Light Source (Taatjes et al., 2008) provided the first detection and subsequent direct measurements of the kinetics of the CIs (Welz et al., 2012). Traditionally CIs have been thought to have been formed exclusively from the ozonolysis reaction of alkenes (as originally proposed by Criegee, 1948). However, the recent laboratory studies on small CIs have utilised novel chemical routes, which avoid the reaction with $\mathrm{O}_{3}$. For example, a large number of groups have used $\mathrm{CH}_{2} \mathrm{I}_{2}$ as a reagent for the formation of $\mathrm{CH}_{2} \mathrm{OO}$ (via photolysis and reaction with $\mathrm{O}_{2}$ ). It should be noted that $\mathrm{CH}_{2} \mathrm{I}_{2}$ one of the major iodine containing VOCs emitted in the marine boundary layer (Saiz-Lopez et al., 2011) and may be a direct source of CIs in this environment. McCarthy et al. (2013) showed that $\mathrm{CH}_{2} \mathrm{OO}$ can also be produced via passing a mixture of $\mathrm{CH}_{4}$ and $\mathrm{O}_{2}$ through an electric discharge (through what remains an as yet unknown mechanism). Based on this evidence McCarthy et al. (2013) have postulated that it is likely that $\mathrm{CH}_{2} \mathrm{OO}$ can be formed in the upper and free troposphere, given the large mixing ratios of $\mathrm{CH}_{4}$ and $\mathrm{O}_{2}$ in the upper troposphere and the relatively high density of electrical discharge (in the form of lightning flashes). Given that many of the reactions between $\mathrm{O}_{3}$ and alkenes have small rate coefficients $\left(\sim 10^{-17} \mathrm{~cm}^{3} \mathrm{~s}^{-1}\right)$, it is important that these non-ozonolysis routes to $\mathrm{CI}$ production be quantified using model studies in order to better understand the burden of CIs in the troposphere (see Fig. 40).

Of fundamental importance to understanding the chemistry of CIs is knowledge of their physical properties. McCarthy et al. (2013) have used a combination of methods to determine the geometry of $\mathrm{CH}_{2} \mathrm{OO}$, in good agreement with the work of Su et al. (2014). As well as having insight into the geometry of $\mathrm{CH}_{2} \mathrm{OO}$, a number of studies have shed light on the absorption spectrum of $\mathrm{CH}_{2} \mathrm{OO}$ in the UVvisible (e.g. Beames et al., 2012; Sheps, 2013). Beames et al. (2012) and Sheps (2013) showed that there is strong absorption by $\mathrm{CH}_{2} \mathrm{OO}$ in the $320-400 \mathrm{~nm}$ range. Whilst this may have implications for additional loss of $\mathrm{CH}_{2} \mathrm{OO}$ by photolysis, the large cross section in this region has the benefit 


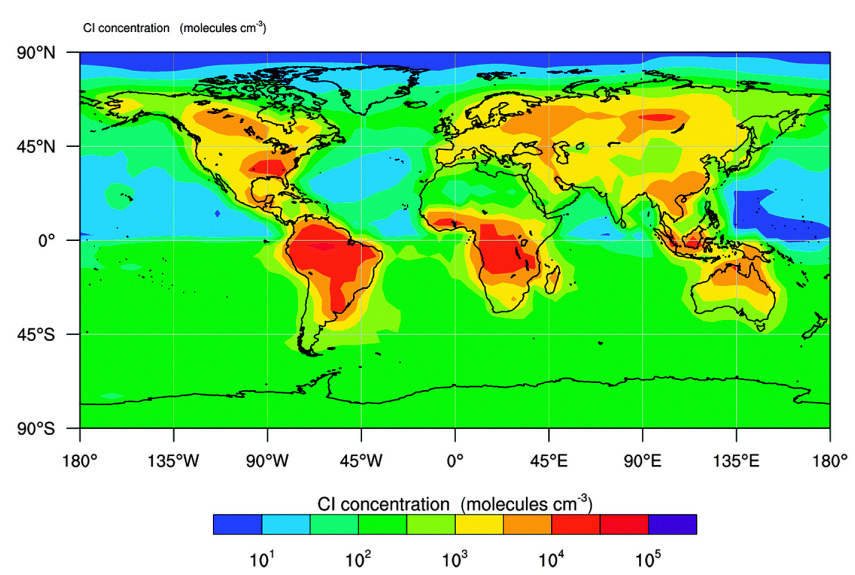

Figure 40. Global surface average model concentrations of the Criegee intermediate concentration (Taatjes et al., 2014).

of making cavity ring-down spectroscopy laboratory studies of the kinetics of $\mathrm{CH}_{2} \mathrm{OO}$ (and other CIs) possible, opening up a number of avenues for greater understanding of these ephemeral but crucial intermediates in the oxidation of VOCs in the atmosphere.

What seems to be emerging from the plethora of laboratory studies on the kinetics of CI reactions is that they react very fast. For example, Su et al. (2014) showed that the bimolecular self-reaction of $\mathrm{CH}_{2} \mathrm{OO}$ has a rate constant near the gas kinetic limit $\left(k=4 \times 10^{-10} \mathrm{~cm}^{3} \mathrm{~s}^{-1}\right)$. Su et al. (2014) determined that the reaction proceeds via a $\mathrm{CH}_{2} \mathrm{OO}$ dimer where the zwitterionic character of the $\mathrm{CH}_{2} \mathrm{OO}$ allows for barrierless addition of the terminal $\mathrm{O}$ atoms with the central $\mathrm{C}$ atom. This dimer is predicted to dissociate to produce two $\mathrm{CH}_{2} \mathrm{O}$ (formaldehyde) and $\mathrm{O}_{2}$ in its excited electronic state $\left(\mathrm{O}_{2}\left({ }^{1} \Sigma_{\mathrm{g}}\right)\right)$. Such a fast self-reaction has implications for the analysis of previous laboratory studies in this system. Similarly fast kinetics have been observed for CIs reacting with organic acids. Using a combination of time resolved laboratory experiments, Welz et al. (2014) have very recently shown that the reactions of the $\mathrm{C} 1$ and $\mathrm{C} 2 \mathrm{CIs}$ with $\mathrm{HCOOH}$ and $\mathrm{CH}_{3} \mathrm{COOH}$ are several orders of magnitude faster than previously inferred from alkene ozonolysis reactions $\left(k \sim 1.0 \times 10^{-10} \mathrm{~cm}^{3} \mathrm{~s}^{-1}\right)$. Although products of the reaction were not detected, it is likely that highly condensable products will form, potentially contributing to SOA formation and growth. Although it is interesting to note that the CIs seem more reactive than $\mathrm{RO}_{2}$ with a number of compounds, it is paramount to understand the dominant loss processes of the CIs in order to understand their abundance. Before many of these direct kinetic experiments were performed it was widely assumed that, in the troposphere, the reaction with $\mathrm{H}_{2} \mathrm{O}$ would dominate over other loss reactions, in spite of slow (although uncertain) kinetics. Welz et al. (2012) reported an upper limit for the $\mathrm{CH}_{2} \mathrm{OO}+\mathrm{H}_{2} \mathrm{O}$ reaction rate coefficient $\left(k=4 \times 10^{-15} \mathrm{~cm}^{3} \mathrm{~s}^{-1}\right)$. Relative rate experiments have yielded a number of other estimates of the rate coefficient for this. Ouyang et al. (2013), who studied the reaction of $\mathrm{NO}_{2}$ with $\mathrm{CH}_{2} \mathrm{OO}$, estimated $k=2.5 \times 10^{-17} \mathrm{~cm}^{3} \mathrm{~s}^{-1}$. In their study, Ouyang et al. (2013) were able to show that the reaction produces $\mathrm{NO}_{3}$ - the most important oxidant at night. So far this reaction has not been included into modelling studies and estimates of the importance of this process for night-time chemistry are needed. Based on detection of HCHO, Stone et al. (2014) were able to put an upper limit on the reaction of the CI with $\mathrm{H}_{2} \mathrm{O}$ of $k=9 \times 10^{-17} \mathrm{~cm}^{3} \mathrm{~s}^{-1}$, significantly smaller than the estimates for this reaction by Welz et al. (2012). They suggested that this much lower reactivity may mean that previous conclusions from modelling studies where $\mathrm{H}_{2} \mathrm{O}$ was calculated as the dominant loss process may need to be revised. Combining the results of Welz et al. (2014) and Stone et al. (2014) we speculate that it is possible that in many environments where organic acids are present at the ppb level, reaction with these acids may be the dominant loss process for CIs. Interestingly, Taatjes et al. (2013) showed that the anti- $\mathrm{CH}_{3} \mathrm{CHOO} \mathrm{CI}$ reacts with $\mathrm{H}_{2} \mathrm{O}$ very fast $\left(k=1.0 \times 10^{-14} \mathrm{~cm}^{3} \mathrm{~s}^{-1}\right)$, suggesting that the lack of reaction between $\mathrm{CH}_{2} \mathrm{OO}$ and $\mathrm{H}_{2} \mathrm{O}$ may not be representative of all CIs.

\section{Policy context}

Within the policy context, much of the focus on ozone has been on ozone as an air pollutant (e.g. OECD, 2012; EEA, 2007, 2009, 2011; Royal Society, 2008; Fowler et al., 2013a). As recently stated, the aim of much policy with respect to ozone and air quality is "to achieve levels of air quality that do not result in unacceptable impacts on, and risks to, human health and the environment" (Fowler et al., 2013a) (see also Sect. 3) within some measure of reasonable cost. This process requires an understanding of the messages from research and monitoring activities to develop new insights. Policy, to date, requires methods of assessing compliance to metrics that quantify impact. Owing to the transboundary nature of ozone, much focus has been on regional and hemispheric impact of metrics and mitigation.

Throughout this section, certain metrics will be detailed, the main two of which are AOT40, the seasonal accumulated exposure above $40 \mathrm{ppb}\left(80 \mu \mathrm{g} \mathrm{m}^{-3}\right)$ during daylight hours (this is normally expressed as a cumulative exposure (ppb h or ppm h)), and SOMO35, the sum of the amounts by which maximum daily $8 \mathrm{~h}$ concentrations of ozone (in $\mu \mathrm{g} \mathrm{m}^{-3}$ ) exceed $70 \mu \mathrm{g} \mathrm{m}^{-3}$ (35 ppb) on each day in a calendar year.

\subsection{Policy metrics for ozone}

Ozone is a powerful oxidant which can cause adverse effects on human health and vegetation. As a result, air quality standards for ozone have been established to mitigate these effects. Ozone can also damage some materials, particularly 


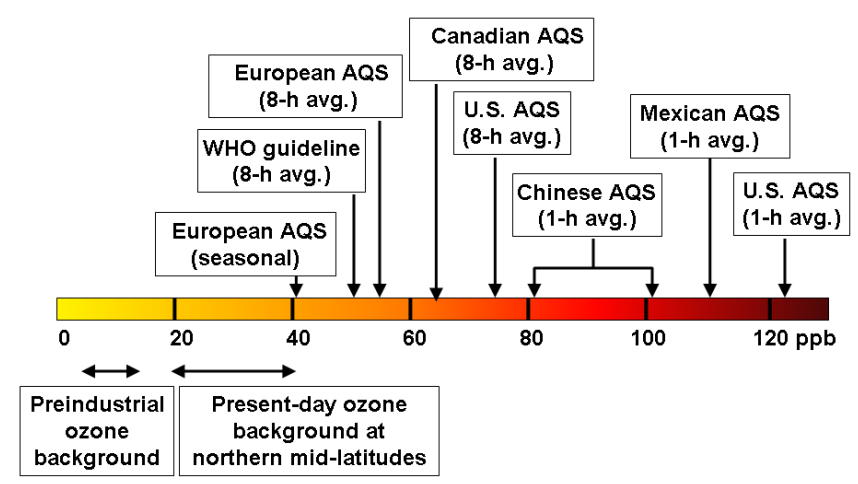

Figure 41. Ozone air quality standards (AQS) in ppb. Different national and international standards are noted as well as estimates for northern mid-latitudes of the pre-industrial background (i.e. $\mathrm{O}_{3}$ abundances with all anthropogenic emissions of $\mathrm{NO}_{x}, \mathrm{CO}, \mathrm{VOC}$, and $\mathrm{CH}_{4}$ switched off, and before current climate and stratospheric $\mathrm{O}_{3}$ change) and the present-day baseline abundances (i.e. the statistically defined lowest abundances of $\mathrm{O}_{3}$ in air flowing into the continents, typical of clean-air, remote marine sites) from Council (2009a).

rubber and plastics, but no standards specifically address these effects. Ozone is a unique pollutant in that different areas of the ozone concentration frequency distribution are affected by different mechanisms and hence could require significantly different policy responses. The averaging times of different ozone metrics are also of crucial importance for policy (see e.g. Pappin and Hakami, 2013; Lefohn et al., 2010).

Health-related standards have up to now been expressed as $1 \mathrm{~h}$ or $8 \mathrm{~h}$ averages, the latter arising originally from chamber studies of human exposures where the maximum effects were observed over exposures of around $8 \mathrm{~h}$. Such short-term peak ozone concentrations based on averaging times of the order of hours, such as those observed in "smog" episodes, are formed from the well-known VOC / $\mathrm{NO}_{x}$ chemistry (see Sect. 2.1.1). These reactions occur typically over timescales of hours to a few days, in conditions of low wind speed and strong sunlight, and hence the spatial scale of such episodes and the policy response area is of the order of hundreds to $\sim 1000 \mathrm{~km}$. Controls on precursor emissions across Europe are therefore required to mitigate these peaks within European nations. Figure 41 shows a comparison of a number of national and international ozone air quality standards.

Effects on vegetation, however, are more closely related to longer-term exposures and in the recent EU Ambient Air Quality Directive (Directive 2008/50/EC), for example, the target value (see below) for the protection of vegetation is expressed in terms of AOT40 as an accumulated value from May to July (defined in more detail later). This longer exposure period, with a threshold close to the tropospheric baseline ozone level means that emission controls would be required over a much wider area than those to mitigate the health-related $1 \mathrm{~h} / 8 \mathrm{~h}$ average concentrations discussed above, and could also involve other, more long-lived precursors such as methane.

There are several levels of "standard" in use, with differing legal statuses. For example, the fundamental health effect evidence is used to inform the setting of WHO Air Quality Guidelines, below which the pollutant in question will not have adverse effects on public health. The guidelines are set without regard to the technological, economic or social issues which might affect their achievability. In setting legally based standards, however, some flexibility is often introduced to allow for difficulties of achieving the levels and/or to allow for year-to-year meteorological variability. For short-term standards this usually takes the form of allowing a number of exceedances of a given concentration over a year, and/or averaging over several years as in the case of the USA. Some health standards in place around the world are shown in Table 3.

Although in some cases the "headline" concentration value in different countries' standards may be similar, the number of allowed exceedances of short-term levels is crucially important in determining their relative stringency. These criteria are shown on the footnote to the Table 3 . Moreover, the status of the standards is also very important. In the USA, the National Ambient Air Quality Standard (NAAQS) for ozone has the same mandatory legal status as those for the other criteria pollutants. In the EU, however, this is not the case as it was recognised that no single member state could control the ozone levels measured within its territory because of the transboundary nature of ozone formation during "smog" episodes (Royal Society, 2008). In the EU directives, therefore, the ozone standard is a target value as opposed to a mandatory limit value in the case of the other pollutants. A limit value is "to be attained within a given period and not to be exceeded once attained". Target values, in contrast, are "to be attained where possible over a given period". The mandatory aspects of ozone control in the EU are contained within the National Emission Ceilings Directive which sets mandatory emission ceilings for individual member states for $\mathrm{NO}_{x}$ and VOCs, which are designed, inter alia, to achieve reductions in ozone levels.

There are also standards in place to protect against damage to vegetation. In the EU Directive (2008/50/EC) there is a target value of $18000 \mathrm{\mu g} \mathrm{m}^{-3} \times$ hours for AOT40, defined as the sum of the difference between observed hourly concentrations greater than $80 \mu \mathrm{g} \mathrm{m}^{-3}(\approx 40$ parts per billion) and $80 \mu \mathrm{g} \mathrm{m}^{-3}$ over a given period using only the $1 \mathrm{~h}$ values measured between 08:00 and 20:00 Central European Time (CET) each day. In the USA the 8-hourly NAAQS in Table 3 is also designed to protect against damage to vegetation, so the spatial scales of policy responses to protect against vegetation damage in the EU and the USA are potentially quite different (see http://www.epa.gov/ncea/isa/). In the last decade, the LRTAP Convention (Convention on Long-range Transboundary Air Pollution) has introduced stomatal fluxbased critical levels for vegetation that are species-specific 
Table 3. Comparison of world health standards for ozone.

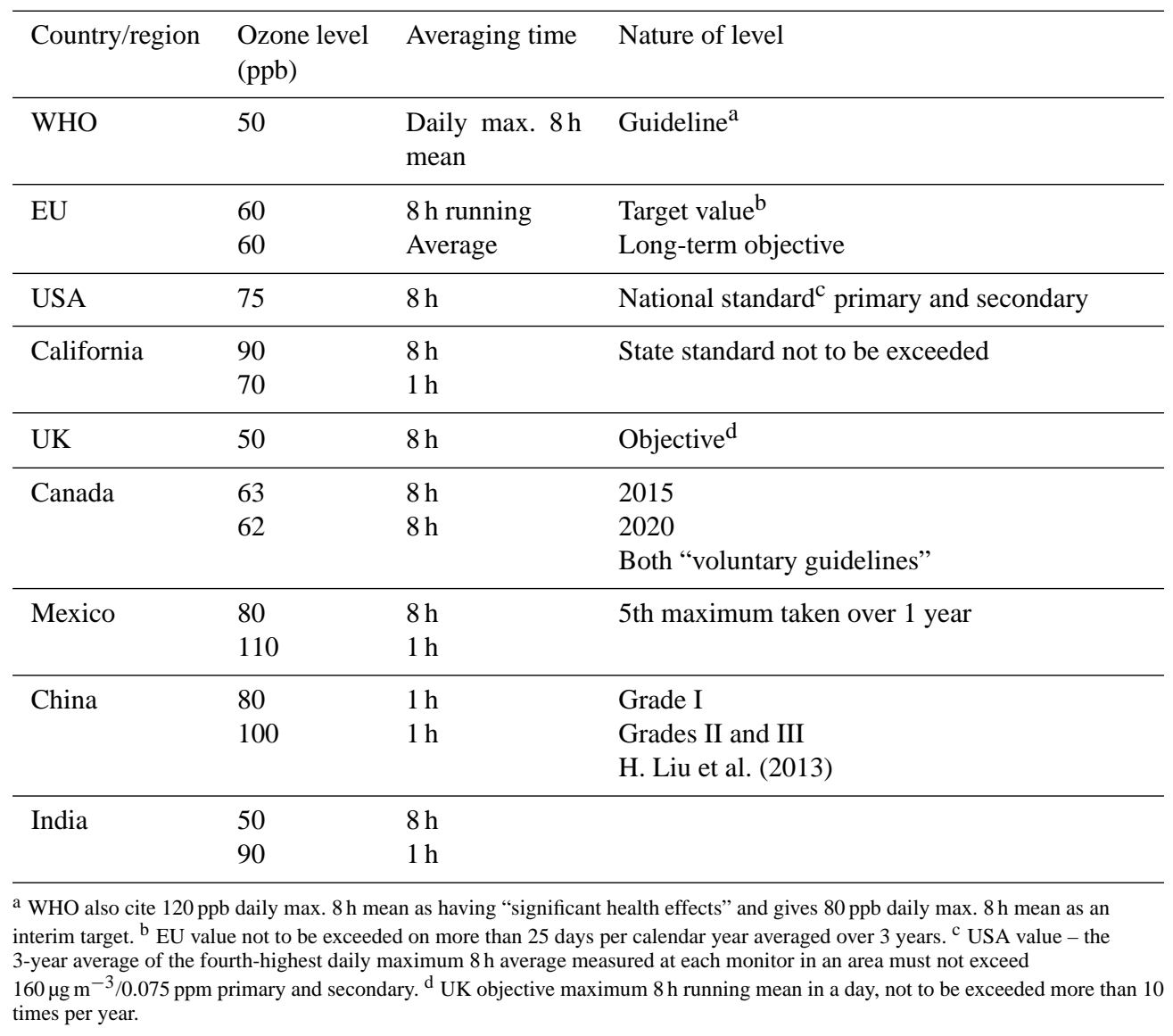

and relevant for protecting against effects of ozone on food security, carbon sequestration and timber production, and biodiversity (see Sect. 3.2 and Mills et al., 2011a for further details).

Two further recent developments have important implications for policy responses for mitigating ozone concentrations. First, the work of the LRTAP Task Force on Hemispheric Transport of Air Pollution has highlighted that intercontinental transport of ozone and its precursors can make significant contributions to the exceedance of air quality standards and can even cause exceedances in their own right (HTAP, 2010). This has already led to challenges to air quality standard enforcement in California (Hand, 2014). In the case of Europe this suggests that emission reduction strategies should take into account measures and policies in North America. Likewise, plans to reduce ozone in North America should take into account emissions in Asia.

The second development relates directly to potentially new metrics to protect human health from adverse effects of ozone and the existence or otherwise of a no-effect threshold. The recent review of the health effect literature by WHO (2013) has concluded that there is now evidence showing associations between long-term (summer mean) ozone concentrations and respiratory mortality, and weaker associations with cardiorespiratory mortality. WHO recognised the uncertainties in this area but nonetheless suggested that long-term average WHO guidelines and a long-term (possibly a summer mean) target value should be considered by the European Commission.

In parallel with these conclusions, the REVIHAAP report (WHO, 2013) also noted that evidence for a no-effect threshold for short-term impacts was inconclusive but recommended that SOMO10 as well as SOMO35 should be used in health impact assessments. These findings are significant for future policy on ozone. Long-term (summer) averages, as noted earlier, are partly determined by hemispheric or global emissions; attaining a threshold of $10 \mathrm{ppb}$ hourly average in SOMO10 would also imply reductions of emissions on a global scale. If the evidence behind these emerging conclusions strengthens then the geographical scale of ozone reductions strategies will need to be extended beyond the regional level to hemispheric or global scales (Hsu et al., 2013).

\subsection{Ozone mitigation and baseline ozone}

Observational evidence suggests that baseline ozone concentrations as they effect Europe had been increasing until about 
2000 (Wilson et al., 2012; Parrish et al., 2009; Simmonds et al., 2004; Jenkin, 2008; Derwent et al., 2006), though currently they appear to be falling (Logan et al., 2012; Parrish et al., 2012). An increasing background contribution to European ozone levels could represent a substantial future challenge to the attainment of ozone limit values (Derwent et al., 2010). With an increasing background contribution there is a requirement to control more ozone of anthropogenic European origin to achieve the limit. Models have shown (Derwent et al., 2010; Szopa et al., 2006) that the benefit to European emission controls can be significantly counterbalanced by increasing background ozone. These results were confirmed in a long-term perspective (2050) by Colette et al. (2013), who emphasised that air quality legislation was indeed anticipated to bear its fruit in reducing ozone exposure in the future, even if under a business-as-usual scenario such as the RCP8.5, climate change and long-range transport.

Similarly, in the US context there has been much debate as to the contribution and quantification of background ozone and its effect on the attainment of standards (Lefohn et al., 2014; Fiore et al., 2014, 2002; Prather et al., 2003). Lefohn et al. (2014) explored the concept of an emissions-influenced background in an attempt on a continental scale to partition the controllable ozone (see Fig. 42). Fiore et al. (2014) noted that the largest model differences in the calculation of North American background ozone, in this case a model construct, were linked to differences in contributions from the stratosphere, wildfires, lightning and isoprene chemistry. Prather et al. (2003) noted in a model study that the background ozone might be a northern hemispheric problem given future emission scenarios.

The recent results of the 2013 revision (Amann et al., 2013a) of the European Thematic Strategy on Air Pollution (TSAP) indicate that the reduction of $10 \%$ of the 25000 anticipated deaths attributed to ozone aimed for by the 2005 TSAP for European emission reductions should be safely achieved in 2025, with about 18000 annual premature deaths estimated under the currently planned scenario.

Fowler et al. (2013a), in their recent report on research findings in support of the EU air quality policy argued that "more attention needs to be given to treating ozone as a hemispheric transboundary issue" (see Sect. 5.3).

\subsection{Hemispheric transport of ozone and it precursors in the policy context}

Substantial efforts have been undertaken to quantify the importance of long-range transport of ozone from distant source regions as part of UNECE HTAP (HTAP, 2010). More than 20 global models conducted idealised source-receptor experiments to quantify hemispheric transport of ozone and its precursors, and the key findings are reported in Fiore et al. (2009) and HTAP (HTAP, 2010). Twenty-percent reductions in anthropogenic precursor emissions from North American, East Asian and South Asian sources reduce an-
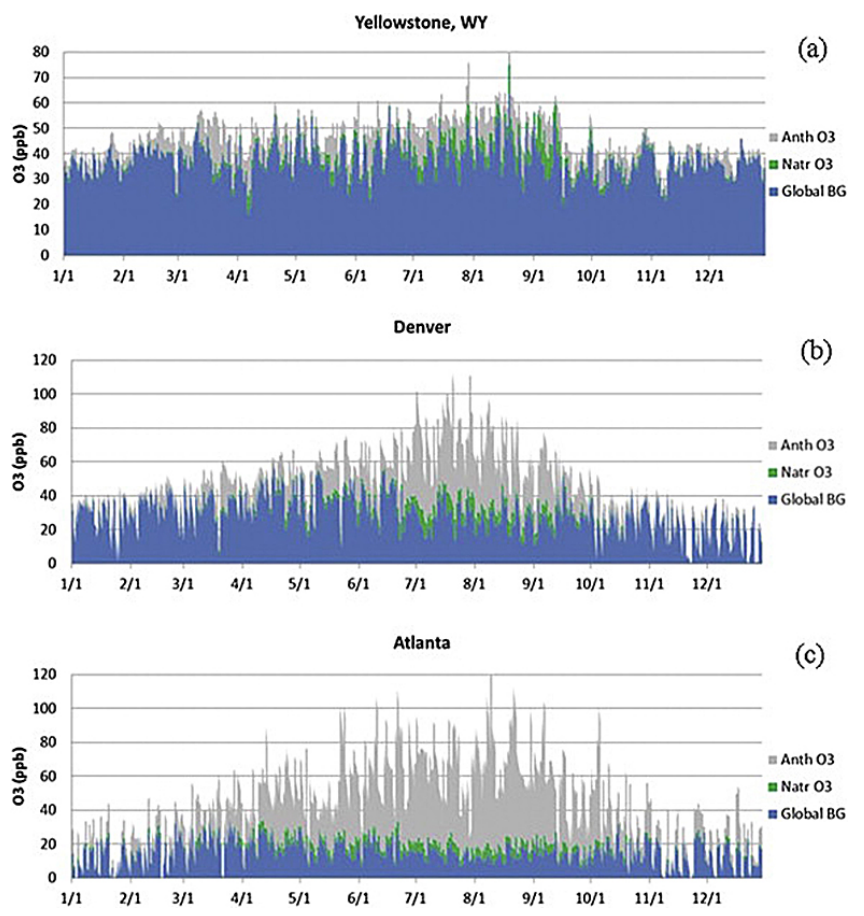

Figure 42. Modelled contributions of hourly $\mathrm{GBO}_{3}$ (global tropospheric $\mathrm{O}_{3}$ plus stratospheric $\mathrm{O}_{3}$ ), natural $\left(\mathrm{Natr} \mathrm{O}_{3}\right)$, and anthropogenic (Anth $\mathrm{O}_{3}$ ) adding to total hourly $\mathrm{O}_{3}$ for (a) Yellowstone National Park, (b) Denver and (c) Atlanta (Lefohn et al., 2014).

nual mean EU $\mathrm{O}_{3}$ by about $0.4,0.2$ and $0.1 \mathrm{ppbV}$, respectively (HTAP, 2010). The influence of LRT has a seasonality, with the largest impact in spring (March-April: $\sim 0.8 \mathrm{ppbV}$ ) and minimum impact in late summer (JulySeptember: $\sim 0.45 \mathrm{ppbV}$ ) (HTAP, 2010). This influence may appear small, but the equivalent $\mathrm{O}_{3}$ response to a $20 \%$ emission change over Europe itself is $1.5-2.0 \mathrm{ppbV}$ in summertime, and is close to zero on a regional mean basis in winter when titration is important. It is worth noting that the HTAP emission reductions (20\%) have been exceeded in reality over Europe for the 1990-2009 period (EEA, 2011). By scaling the $20 \%$ emission changes to the actual regional emission changes and accounting for the non-linearity in ozone responses, Wild et al. (2012) derived the ozone trend over Europe from 1960 to 2000 along with the contributions from the EU, external sources (i.e. LRT) and changing atmospheric $\mathrm{CH}_{4}$. An increase of about $6.5 \mathrm{ppbV}$ is calculated between 1960 and 1990, and a slight decrease from 1990 to 2000. More than half of the 1960-1990 trend came from nonEuropean sources $(2.1 \mathrm{ppb})$ and $\mathrm{CH}_{4}(1.6 \mathrm{ppb})$, with only $2.8 \mathrm{ppb}$ from changes in EU emissions. Interestingly transEurasian transport of air pollutants has been implicated in the enhancement of ozone in western China (Li et al., 2014b).

A number of studies have focused on the contribution of increasing precursor emissions over Asia to ozone over North America. Reidmiller et al. (2009) used the HTAP simula- 
tions to demonstrate that precursor emissions from both East Asia and Europe influence the policy-relevant maximum $8 \mathrm{~h}$ average (MDA8) ozone metric, but note that regional emission controls over North America are 2-10 times as effective at reducing this ozone metric as the equivalent controls in the other two regions. However, Lin et al. (2012a) demonstrate that Asian emissions may contribute as much as 8$15 \mathrm{ppb}$ ozone to MDA8 in the south-western USA in springtime on days when ozone exceeds $60 \mathrm{ppb}$, indicating the important role that long-range transport may play in ozone exceedances. More recent work by J. T. Lin et al. (2014) shows that transport of the export-related Chinese pollution contributed $0.5-1.5 \%$ of ozone over the western United States in 2006. This Chinese pollution also resulted in one extra day or more of noncompliance with the US ozone standard in 2006 over the Los Angeles area and many regions in the eastern United States. Equivalent studies focusing on air quality metrics in Europe have yet to be performed but are likely to show smaller impacts given the greater transport distances from regions showing substantial emission increases.

Transport within Asia has been considered in a recent HTAP study showing that $\mathrm{O}_{3}$ from East Asian sources affects the most densely populated parts of South Asia (Chakraborty et al., 2015).

\subsubsection{Impacts of climate change}

Jacob and Winner (2009) and more recently von Schneidemesser et al. (2015) have undertaken a comprehensive review of the impacts of climate change on air quality, including ozone. Despite regional differences, the dominating signal is one towards an increase in ozone levels induced by global warming (Stevenson et al., 2006), which led Wu et al. (2008) to coin the term "climate penalty". The possible pathways for such a penalty include increasing continental temperatures, changing atmospheric humidity, and changes in the prevalence of stable, anticyclonic conditions trapping pollutants in the boundary layer and possibly leading to higher surface ozone even without changes in anthropogenic precursor emissions. These meteorological factors may be supplemented by climate-driven changes in biogenic emissions of isoprene and in dry deposition of ozone. It is worth noting that, in the lower free troposphere and remote surface regions, ozone is expected to decrease owing to increased water vapour in a warmer world (Jacob and Winner, 2009). There is some debate as to the magnitude of any climate penalty; for example, the study of Tai et al. (2013) indicates that, in the presence of $\mathrm{CO}_{2}$-isoprene interaction, the projected change in isoprene emission by 2050 will be largely offset or even reverse in sign, leading to much reduced sensitivity of ozone and SOA (by $>50 \%$ ) to climate and natural vegetation.

Bloomer et al. (2009) estimated the magnitude of these effects from surface ozone observations over the US at about $2.2 \mathrm{ppb}$ per degree Celcius and Pfister et al. (2014) showed increasing summertime ozone levels under various climate scenarios. These effects have been quantified over Europe in several model studies (Colette et al., 2013; Meleux et al., 2007; Langner et al., 2012a, b; Andersson and Engardt, 2010; Manders et al., 2012; Hedegaard et al., 2008, 2013b; Katragkou et al., 2011). The general order of magnitude of the climate penalty over Europe is a few ppb by the middle of the century. Langer et al. (2012b) point out a larger increase at the 95th percentile of hourly ozone, suggesting that the effects of climate change may be particularly important during high-ozone events. The effects of changes in isoprene emissions and dry deposition have been quantified separately by Andersson and Engardt (Andersson and Engardt, 2010), who find increases in mean ozone of up to $5 \mathrm{ppb}$ by 2050 in some parts of western Europe, with as much as $60 \%$ of this change attributed to decreased dry deposition, and with increased isoprene emissions contributing up to $1 \mathrm{ppb}$. As noted above large uncertainties remain regarding the impact of climate change on biogenic emissions, with up to a factor of 5 difference in isoprene change reported in a multi-model ensemble (Langner et al., 2012b).

There are few studies that proposed quantitative comparisons of the relative impact of climate change and air pollution mitigation strategies on surface ozone. Existing investigations all agree on a larger impact of air quality policies (Tagaris et al., 2007; Hedegaard et al., 2013; Colette et al., 2013), supporting the efficiency of currently planned mitigation strategies, despite external penalties brought about by climate change and long-range transport.

It should be noted, however, that studies focusing on the impacts of climate change use long-term projections (typically 2050), which have substantive precursor mitigation. Given the magnitude of the response to precursors changes, the sensitivity to the choice of the scenario is worth noting (Fiore et al., 2012a). Pioneering studies have relied on projections originally designed for climate projections (SRES; Nakicenovic et al., 2000) or RCPs (van Vuuren et al., 2011), but the ozone precursor information in such scenarios was solely provided to assess radiative forcing and their use for surface air quality projections constitutes a deviation from their original purpose. The various scenarios make differing assumptions for future air pollution emissions and therefore describe a wide range of future emissions over large world regions. Any downscaling in regions that exhibit large spatial heterogeneities could be problematic, leading to inaccurate results (Amann et al., 2013b). The use of emission projections relying on policy relevant emissions factors such as the Global Energy Assessment (Riahi et al., 2012), the ECLIPSE (Klimont et al., 2013a) or PEGASOS data sets are more reliable.

While the implications of these effects for surface ozone and air quality policy are substantial, there is still considerable uncertainty in the magnitude of these indirect climate effects, and improved understanding of the processes controlling these atmosphere-land surface interactions is needed. 


\subsection{The future - air quality and climate}

Recently, pollutants that typically fall under the "air quality" categorisation have been receiving increasing attention for their role in climate change and their impact on radiative forcing. More specifically, significant focus has been on ozone, methane (as a greenhouse gas and an ozone precursor), and aerosol constituents (mostly the black carbon (BC) component). Significant potential exists for co-benefits with coordinated air quality and climate policies. A number of reviews have recently addressed various aspects of the linkages between air quality and climate, from the chemistry interactions to the policy implications (von Schneidemesser and Monks, 2013; Isaksen et al., 2009; Fiore et al., 2012b; Unger, 2012). For more details, see these reviews. Here, a brief overview of the topic will be given, with a focus on ozone and the latest developments.

In addition to being an air pollutant with significant adverse health effects, ozone is also a greenhouse gas. A recent estimate of ozone's radiative forcing effect (from preindustrial times to the present day) is $+0.40 \mathrm{~W} \mathrm{~m}^{-2}$ (Myhre et al., 2013), other estimates include +0.44 and +0.23 (Unger, 2012; Fiore et al., 2012b). For comparison, the RFs attributed to methane and $\mathrm{CO}_{2}$ are +0.48 and $+1.66 \mathrm{~W} \mathrm{~m}^{-2}$, respectively (Myhre et al., 2013). The ozone precursors $\mathrm{NO}_{x}$, NMVOCs and CO have little to no direct effect on climate but influence climate and radiative forcing through their effects on ozone and methane, as well as atmospheric oxidant concentrations and indirect ecosystem effects (von Schneidemesser and Monks, 2013, and references therein). Reductions in NMVOCs and CO tend to be synergistic and result in overall decreases in RF, although the effects can be fairly minor, especially for NMVOCs (Collins et al., 2013). The effect of $\mathrm{NO}_{x}$ on climate/radiative forcing is much less straightforward. A variety of interactions, feedbacks and ecosystem effects confound the picture for $\mathrm{NO}_{x}$, resulting in significant uncertainty and often times competing effects on climate. A variety of modelling studies have evaluated the various direct and indirect effects (Collins et al., 2010, 2013; Shindell et al., 2009; Fry et al., 2012; Colette et al., 2011) and a summary can be found in von Schneidemesser and Monks (2013). More research is needed on this topic.

Methane, an important greenhouse gas in its own right, is also an ozone precursor. With a lifetime of approximately a decade in the atmosphere, methane is well mixed globally and therefore has a significant influence on background ozone levels. Methane is a distinct win-win possibility for air quality and climate in that reductions in methane emissions would decrease ozone, including baseline ozone, and thereby lessen adverse impacts on vegetation and human health, but also benefit climate by reducing two greenhouse gases simultaneously (Fry et al., 2012; Shindell et al., 2012; Isaksen et al., 2014). A model study investigated the air quality $\left(\mathrm{O}_{3}\right)$ and climate benefits of methane reductions and found that $\mathrm{O}_{3}$ reductions were relatively linear with respect to reduc-

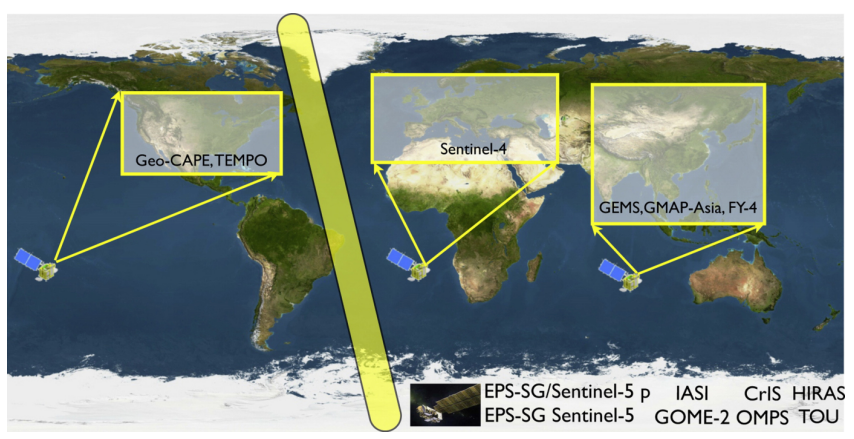

Figure 43. Constellation of geostationary and low-Earth orbiting satellites planned for the coming decade that will measure tropospheric ozone. Current instruments that measure tropospheric ozone, e.g. TES or OMI, but will not be continued in the future are not listed (from Bowman, 2013).

tions in methane emissions. In addition, the $\mathrm{CH}_{4}$ emission reductions did not depend strongly on location, as the climate and air quality benefits were realised globally, which would allow for the most cost effective emission controls to be implemented (Fiore et al., 2008).

However, the interactions go both ways. Not only does ozone affect the climate, but changes owing to climate change will also influence ozone production. This effect is known as the "climate penalty". A variety of effects resulting from a changing climate will potentially influence ozone concentrations, some increasing ozone, some decreasing ozone (Rasmussen et al., 2013). Many of these effects are associated with a significant amount of uncertainty. Climatechange-induced increases in methane emissions from wetlands, stratosphere-troposphere exchange of ozone, lightning $\mathrm{NO}_{x}$, and regional stagnation all consistently lead to increased ozone when investigated, while increases in dry deposition and humidity consistently lead to decreases in ozone (Fiore et al., 2012b; Isaksen et al., 2009). Other climatechange-induced effects such as increased wildfires have a much more uncertain effect on ozone. For example, for a regional study in California, climate-related perturbations (temperature, biogenics and water vapour) led to combined peak $1 \mathrm{~h}$ ozone increases of up to $11 \mathrm{ppb}$ (Millstein and Harley, 2009).

In a model ensemble study by Colette et al. (2012), future (2030) air quality in Europe owing to just air quality policy or air quality and climate policy was compared. The base case included all current and planned air quality measures up to 2030 and was compared to a "sustainable" case with the air quality as well as climate measures $\left(2^{\circ} \mathrm{C}\right.$ target and energy efficiency improvements). Depending on the scenario, annual mean $\mathrm{O}_{3}$ was found to slightly increase over $\mathrm{NO}_{x}$-saturated areas but the overall $\mathrm{O}_{3}$ burden would decrease substantially, including exposure to detrimental levels of $\mathrm{O}_{3}$ for health (Kinney, 2008). The air pollution measures were responsible for the main improvements in ozone, 


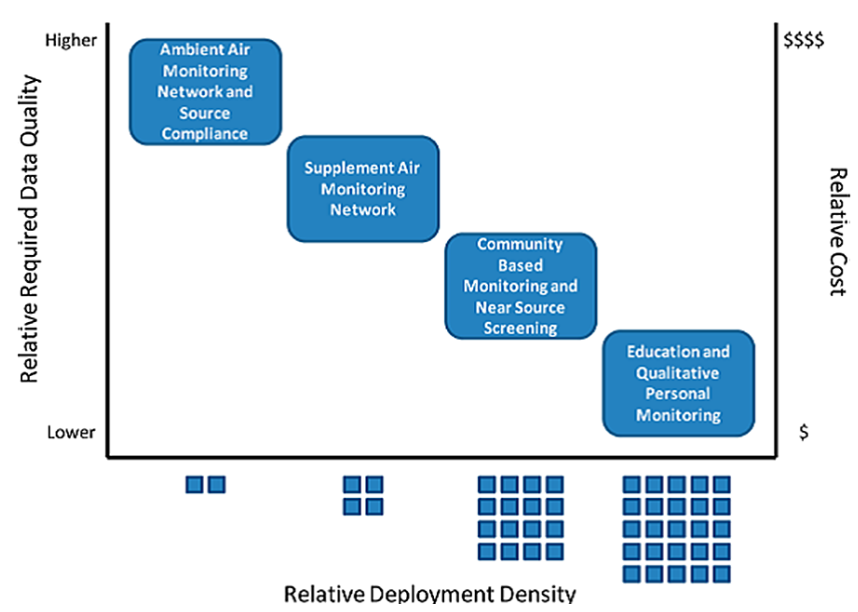

Figure 44. Relative data, quality, cost and deployment density for small sensor networks for air quality (Snyder et al., 2013).

but an additional co-benefit of at least $40 \%$ (depending on the indicator) was attributed to the climate policy (Colette et al., 2012). A study by Crawford-Brown et al. (2012) focused on the co-benefits to $\mathrm{O}_{3}$ - and PM-related health effects resulting from implementation of climate policy in Mexico. A base case scenario was compared to a decarbonisation scenario where $\mathrm{CO}_{2}$ emissions in Mexico would be reduced by $77 \%$ by 2050 . The co-benefits to air quality were reductions in $\mathrm{O}_{3}$ of $11-13 \%$ by 2050 . The reduction in non-fatal diseases from $\mathrm{O}_{3}$ - and PM-related health co-benefits was valued at USD 0.6 billion per year (Crawford-Brown et al., 2012). Both of these studies show that there are significant benefits to pursuing coordinated policies for air quality and climate, and not only for the improvement of $\mathrm{O}_{3}$-related air quality. Rypdal et al. (2005) commented on the challenges for putting tropospheric ozone in climate agreements.

\section{Conclusions}

Ozone remains central to atmospheric chemistry as the initiator, propagator and product of photochemistry. Its influence is felt on human health, ecosystems and climate. Ozone though ubiquitous remains an enigma. In many places in the Northern Hemisphere mid-latitudes ozone in some senses remains a paradox, the high summertime peak levels decreasing but the regional background levels increasing (Fishman et al., 2014; Parrish et al., 2012). Globally this points to the need to treat ozone across the range of scales, a transboundary issue, but with an emphasis on the hemispheric scales (Fowler et al., 2013a; Simpson et al., 2014). Recent air pollution episodes in Europe have pointed to the continuing need to think about the how climate change policies interact with air quality policy and what can be learnt from current episodes (Monks, 2014). There remain a number of clear challenges for ozone such as explaining surface trends, incor- porating new chemical understanding, ozone-climate coupling and a better assessment of impacts.

With respect to the future, studying the atmospheric chemistry of ozone relies on the continuing interplay of laboratory studies of fundamental parameters being integrated with our best theories using numerical models and evaluated against in situ observations. This "three-legged stool" approach is generic, but it is a vital model to use to understand not only ozone but the wider chemistry in the atmosphere (Abbatt et al., 2014).

One area implicit in this review which has not been discussed explicitly is the role of observations in understanding, quantifying and describing ozone across the scales. Observations of ozone and its precursors underpin and drive the development of our knowledge base (Laj et al., 2009). Bowman (2013) argued that the global nature of pollution and climate change requires a new observing system for ozone. A key feature of the system should be the ability to predict and attribute ozone to emissions. A combination of satellites, ground-based remote sensing and ground-based observations are needed with geostationary observations (Lahoz et al., 2011) being an observational anchor (see Fig. 43).

It is clear that space observations offer the global view and repeatability not easily available from other observing systems. Measurement of ground-level ozone from space still remains a significant challenge (Foret et al., 2014; Duncan et al., 2014). There is future potential for global observations of tropospheric ozone from space either directly (Sellitto et al., 2013) or through a combination with models (Zoogman et al., 2014; Martin, 2008). Duncan et al. (2014) recently reviewed the application of satellite data to air quality application including common mistakes to avoid.

The growth of small sensors for a range of trace species including ozone has the potential to offer insights on unheralded spatial and temporal timescales (Snyder et al., 2013; Mead et al., 2013; Piedrahita et al., 2014). As illustrated in Fig. 44, there are potential new avenues opened up for air quality monitoring by the deployment of extensive networks of these sensors all the way down to personal sensing (e.g. Wheeler et al., 2011; Andersen et al., 2010). The absolute measurement of ozone remains a challenge with some of these sensors owing to interferences (Mead et al., 2013). New developments suggest these configurations of sensor technologies can give long-term atmospheric performance for the measurements of ozone (Williams et al., 2013; Bart et al., 2014).

There may yet be new links and biospheric feedbacks driven by ozone to be explored. For example, the effect of elevated $\mathrm{O}_{3}$ and whitefly herbivory significantly increased tomato volatiles, which attracted Encarsia formosa wasps and reduced the whitefly feeding on tomatoes (Cui et al., 2014).

There are interesting attempts to make public outreach on the effects of ozone on plants and crops. Fishman et al. (2014) described a establishment of an "ozone garden". 
The garden provides real-time measurements of $\mathrm{O}_{3}$ concentrations as well as firsthand observations of the detrimental effects of this pollutant. Meteorological data, as well as the $\mathrm{O}_{3}$ concentrations from the monitor, are recorded and publicly disseminated in near-real time via the internet.

Looking forward it is clear that levels and patterns of global ozone will continue to change, impacting global warming, air quality, global food production and ecosystem function. There remains a need for continuing research to quantify impacts and interactions across all the scales. The issues around tropospheric ozone are not "solved" (Guerreiro et al., 2014) and new data continue to shed light on more aspects of ozone and its interactions in the global atmosphere.

Acknowledgements. This review was prepared as part of the European Commission project ACCENT Plus (grant agreement 265119).

Edited by: G. Brasseur

\section{References}

Abbatt, J., George, C., Melamed, M., Monks, P., Pandis, S., and Rudich, Y.: New Directions: Fundamentals of atmospheric chemistry: Keeping a three-legged stool balanced, Atmos. Environ., 84, 390-391, doi:10.1016/j.atmosenv.2013.10.025, 2014.

Abbatt, J. P. D., Thomas, J. L., Abrahamsson, K., Boxe, C., Granfors, A., Jones, A. E., King, M. D., Saiz-Lopez, A., Shepson, P. B., Sodeau, J., Toohey, D. W., Toubin, C., von Glasow, R., Wren, S. N., and Yang, X.: Halogen activation via interactions with environmental ice and snow in the polar lower troposphere and other regions, Atmos. Chem. Phys., 12, 6237-6271, doi:10.5194/acp-12-6237-2012, 2012.

Adams, R. M., Crocker, T. D., and Thanavibulchai, N.: An economic assessment of air pollution damages to selectes annual crops in souhtern California, J. Environ. Econ. Manage., 9, 4258, doi:10.1016/0095-0696(82)90005-5, 1982.

U.S. EPA: National Emissions Inventory (NEI) Air Pollutant Emissions Trends Data, 2014.

U.S. EPA: EPA needs to improve air emissions data for the oil and natural gas production sector, Office of Inspector General, 2013.

Akagi, S. K., Yokelson, R. J., Wiedinmyer, C., Alvarado, M. J., Reid, J. S., Karl, T., Crounse, J. D., and Wennberg, P. O.: Emission factors for open and domestic biomass burning for use in atmospheric models, Atmos. Chem. Phys., 11, 4039-4072, doi:10.5194/acp-11-4039-2011, 2011.

Akimoto, H.: Global air quality and pollution, Science, 302, 17161719, 2003.

Allen, D. T., Torres, V. M., Thomas, J., Sullivan, D. W., Harrison, M., Hendler, A., Herndon, S. C., Kolb, C. E., Fraser, M. P., Hill, A. D., Lamb, B. K., Miskimins, J., Sawyer, R. F., and Seinfeld, J. H.: Measurements of methane emissions at natural gas production sites in the United States, Proc. Natl. Aca. Sci., 110, 1776817773, doi:10.1073/pnas.1304880110, 2013.

Alvarado, M. J., Logan, J. A., Mao, J., Apel, E., Riemer, D., Blake, D., Cohen, R. C., Min, K.-E., Perring, A. E., Browne, E. C.,
Wooldridge, P. J., Diskin, G. S., Sachse, G. W., Fuelberg, H., Sessions, W. R., Harrigan, D. L., Huey, G., Liao, J., Case-Hanks, A., Jimenez, J. L., Cubison, M. J., Vay, S. A., Weinheimer, A. J., Knapp, D. J., Montzka, D. D., Flocke, F. M., Pollack, I. B., Wennberg, P. O., Kurten, A., Crounse, J., Clair, J. M. St., Wisthaler, A., Mikoviny, T., Yantosca, R. M., Carouge, C. C., and Le Sager, P.: Nitrogen oxides and PAN in plumes from boreal fires during ARCTAS-B and their impact on ozone: an integrated analysis of aircraft and satellite observations, Atmos. Chem. Phys., 10, 9739-9760, doi:10.5194/acp-10-9739-2010, 2010.

Amann, M., Bertok, I., Borken-Kleefeld, J., Cofala, J., Hettelingh, J.-P., Heyes, C., Holland, M., Kiesewetter, G., Klimont, Z., Rafaj, P., Paasonen, P., Posch, M., Sander, R., Schöpp, W., Wagner, F., and Winiwarter, W.: Policy Scenarios for the Revision of the Thematic Strategy on Air Pollution, IIASA, Vienna, 2013a.

Amann, M., Klimont, Z., and Wagner, F.: Regional and Global Emissions of Air Pollutants: Recent Trends and Future Scenarios, Annu. Rev. Environ. Resour, 38, 31-55, doi:10.1146/annurev-environ-052912-173303, 2013 b.

Andersen, P. C., Williford, C. J., and Birks, J. W.: Miniature Personal Ozone Monitor Based on UV Absorbance, Anal. Chem., 82, 7924-7928, doi:10.1021/ac1013578, 2010.

Andersson, C. and Engardt, M.: European ozone in a future climate: Importance of changes in dry deposition and isoprene emissions, J. Geophys. Res.-Atmos., 115, D02303, doi:10.1029/2008jd011690, 2010.

Andreae, M. O. and Merlet, P.: Emission of trace gases and aerosols from biomass burning, Global Biogeochem. Cy., 15, 955-966, 2001.

Andrey, J., Cuevas, E., Parrondo, M. C., Alonso-Pérez, S., Redondas, A., and Gil-Ojeda, M.: Quantification of ozone reductions within the Saharan air layer through a 13-year climatologic analysis of ozone profiles, Atmos. Environ., 84, 28-34, doi:10.1016/j.atmosenv.2013.11.030, 2014.

Anenberg, S. C., West, J. J., Fiore, A. M., Jaffe, D. A., Prather, M. J., Bergmann, D., Cuvelier, K., Dentener, F. J., Duncan, B. N., Gauss, M., Hess, P., Jonson, J. E., Lupu, A., MacKenzie, I. A., Marmer, E., Park, R. J., Sanderson, M. G., Schultz, M., Shindell, D. T., Szopa, S., Vivanco, M. G., Wild, O., and Zang, G.: Intercontinental Impacts of Ozone Pollution on Human Mortality, Environ. Sci. Technol., 43, 6482-6487, doi:10.1021/es900518z, 2009.

AQEG: Air Quality Expert Group, Ozone in the United Kingdom, HMSO, London, 2009.

Archibald, A., Khan, M., Watson, L., Clemitshaw, K., Utembe, S., Jenkin, M., and Shallcross, D.: Comment on "Long-term atmospheric measurements of $\mathrm{C}_{1}-\mathrm{C}_{5}$ alkyl nitrates in the Pearl River Delta region of southeast China" by Simpson et al., Atmos. Environ., 41, 7369-7370, 2007.

Archibald, A., Petit, A., Percival, C., Harvey, J., and Shallcross, D.: On the importance of the reaction between $\mathrm{OH}$ and $\mathrm{RO}_{2}$ radicals, Atmos. Sci. Lett., 10, 102-108, 2009.

Archibald, A. T., Cooke, M. C., Utembe, S. R., Shallcross, D. E., Derwent, R. G., and Jenkin, M. E.: Impacts of mechanistic changes on $\mathrm{HO}_{\mathrm{x}}$ formation and recycling in the oxidation of isoprene, Atmos. Chem. Phys., 10, 8097-8118, doi:10.5194/acp-108097-2010, 2010.

Archibald, A. T., Levine, J. G., Abraham, N. L., Cooke, M. C., Edwards, P. M., Heard, D. E., Jenkin, M. E., Karunaharan, A., Pike, 
R. C., Monks, P. S., Shallcross, D. E., Telford, P. J., Whalley, L. K., and Pyle, J. A.: Impacts of $\mathrm{HO}(\mathrm{x})$ regeneration and recycling in the oxidation of isoprene: Consequences for the composition of past, present and future atmospheres, Geophys. Res. Lett., 38, L05804 doi:10.1029/2010g1046520, 2011.

Arellano, A. F. and Hess, P. G.: Sensitivity of top-down estimates of CO sources to GCTM transport, Geophys. Res. Lett., 33, L21807, doi:10.1029/2006g1027371, 2006.

Arneth, A., Niinemets, Ü., Pressley, S., Bäck, J., Hari, P., Karl, T., Noe, S., Prentice, I. C., Serça, D., Hickler, T., Wolf, A., and Smith, B.: Process-based estimates of terrestrial ecosystem isoprene emissions: incorporating the effects of a direct CO2-isoprene interaction, Atmos. Chem. Phys., 7, 31-53, doi:10.5194/acp-7-31-2007, 2007.

Arneth, A., Schurgers, G., Lathiere, J., Duhl, T., Beerling, D. J., Hewitt, C. N., Martin, M., and Guenther, A.: Global terrestrial isoprene emission models: sensitivity to variability in climate and vegetation, Atmos. Chem. Phys., 11, 8037-8052, doi:10.5194/acp-11-8037-2011, 2011.

Arnold, S. R., Emmons, L. K., Monks, S. A., Law, K. S., Ridley, D. A., Turquety, S., Tilmes, S., Thomas, J. L., Bouarar, I., Flemming, J., Huijnen, V., Mao, J., Duncan, B. N., Steenrod, S., Yoshida, Y., Langner, J., and Long, Y.: Biomass burning influence on high-latitude tropospheric ozone and reactive nitrogen in summer 2008: a multi-model analysis based on POLMIP simulations, Atmos. Chem. Phys., 15, 6047-6068, doi:10.5194/acp15-6047-2015, 2015.

Ashmore, M.: Assessing the Future Global Impacts of Ozone on Vegetation, Plant Cell Environ. 28, 949-964, 2005.

Ashworth, K., Wild, O., and Hewitt, C. N.: Impacts of biofuel cultivation on mortality and crop yields, Nat. Clim. Chang., 3, 492496, doi:10.1038/nclimate1788, 2013.

Avnery, S., Mauzerall, D. L., Liu, J., and Horowitz, L. W.: Global crop yield reductions due to surface ozone exposure: 1. Year 2000 crop production losses and economic damage, Atmos. Environ., 45, 2284-2296, doi:10.1016/j.atmosenv.2010.11.045, 2011a.

Avnery, S., Mauzerall, D. L., Liu, J., and Horowitz, L. W.: Global crop yield reductions due to surface ozone exposure: 2. Year 2030 potential crop production losses and economic damage under two scenarios of O-3 pollution, Atmos. Environ., 45, $2297-$ 2309, doi:10.1016/j.atmosenv.2011.01.002, 2011 b.

Baker, J., Walker, H. L., and Cai, X. M.: A study of the dispersion and transport of reactive pollutants in and above street canyons - a large eddy simulation, Atmos. Environ., 38, 6883-6892, doi:10.1016/j.atmosenv.2004.08.051, 2004.

Banerjee, A., Archibald, A. T., Maycock, A. C., Telford, P., Abraham, N. L., Yang, X., Braesicke, P., and Pyle, J. A.: Lightning $\mathrm{NO}_{\mathrm{x}}$, a key chemistry-climate interaction: impacts of future climate change and consequences for tropospheric oxidising capacity, Atmos. Chem. Phys., 14, 9871-9881, doi:10.5194/acp-149871-2014, 2014.

Barkley, M. P., De Smedt, I., Van Roozendael, M., Kurosu, T. P., Chance, K., Arneth, A., Hagberg, D., Guenther, A., Paulot, F., Marais, E., and Mao, J. Q.: Top-down isoprene emissions over tropical South America inferred from SCIAMACHY and OMI formaldehyde columns, J. Geophys. Res.-Atmos., 118, 68496868, doi:10.1002/jgrd.50552, 2013.
Barrie, L. A., Hoff, R. M., and Daggupaty, S. M.: The Influence of mid-latitudinal pollution sources on haze in the Canadian Arctic, Atmos. Environ., 15, 1407-1419, doi:10.1016/00046981(81)90347-4, 1981.

Barrie, L. A., Bottenheim, J. W., Schnell, R. C., Crutzen, P. J., and Rasmussen, R. A.: Ozone destruction and photochemical reactions at polar sunrise in the lower Arctic atmosphere, Nature, 334, 138-140, 1988.

Bart, M., Williams, D. E., Ainslie, B., McKendry, I., Salmond, J., Grange, S. K., Alavi-Shoshtari, M., Steyn, D., and Henshaw, G. S.: High Density Ozone Monitoring Using Gas Sensitive SemiConductor Sensors in the Lower Fraser Valley, British Columbia, Environ. Sci. Technol., 48, 3970-3977, doi:10.1021/es404610t, 2014.

Bates, D. V.: Ambient ozone and mortality, Epidemiology, 16, $427-$ 429, doi:10.1097/01.ede.0000165793.71278.ec, 2005.

Beames, J. M., Liu, F., Lu, L., and Lester, M. I.: Ultraviolet Spectrum and Photochemistry of the Simplest Criegee Intermediate $\mathrm{CH}_{2} \mathrm{OO}$, J. Am. Chem. Soc., 134, 20045-20048, 2012.

Beirle, S., Huntrieser, H., and Wagner, T.: Direct satellite observation of lightning-produced $\mathrm{NO}_{\mathrm{x}}$, Atmos. Chem. Phys., 10, 10965-10986, doi:10.5194/acp-10-10965-2010, 2010.

Beirle, S., Boersma, K. F., Platt, U., Lawrence, M. G., and Wagner, T.: Megacity Emissions and Lifetimes of Nitrogen Oxides Probed from Space, Science, 333, 1737-1739, doi:10.1126/science.1207824, 2011.

Bell, M. L., Peng, R. D., and Domenici, F.: The exposure-response curve for ozone and risk of mortality and the adequacy of current ozone regulations, Environ. Health Perspect., 114, 532-536, 2006.

Bickle, M.: Shale gas extraction in the UK: a review of hydraulic fracturing, The Royal Society and The Royal Academy of Engineering, London, 2012

Bloomer, B. J., Stehr, J. W., Piety, C. A., Salawitch, R. J., and Dickerson, R. R.: Observed relationships of ozone air pollution with temperature and emissions, Geophys. Res. Lett., 36, L09803, doi:10.1029/2009g1037308, 2009.

Bloomer, B. J., Vinnikov, K. Y., and Dickerson, R. R.: Changes in seasonal and diurnal cycles of ozone and temperature in the eastern US, Atmos. Environ., 44, 2543-2551, doi:10.1016/j.atmosenv.2010.04.031, 2010.

Bloss, W. J., Evans, M. J., Lee, J. D., Sommariva, R., Heard, D. E., and Pilling, M. J.: The oxidative capacity of the troposphere: Coupling of field measurements of $\mathrm{OH}$ and a global chemistry transport model, Faraday Discuss., 130, 425-436, doi:10.1039/b419090d, 2005.

Bloss, W. J., Camredon, M., Lee, J. D., Heard, D. E., Plane, J. M. C., Saiz-Lopez, A., Bauguitte, S. J.-B., Salmon, R. A., and Jones, A. E.: Coupling of $\mathrm{HO}_{\mathrm{x}}, \mathrm{NO}_{\mathrm{x}}$ and halogen chemistry in the antarctic boundary layer, Atmos. Chem. Phys., 10, 10187 10209, doi:10.5194/acp-10-10187-2010, 2010.

Bojkov, R. D.: Surface ozone during the 2nd half of the 19th century, J. Clim. Appl. Meteorol., 25, 343-352, doi:10.1175/15200450(1986)025<0343: sodtsh>2.0.co;2, 1986.

Bon, D. M., Ulbrich, I. M., de Gouw, J. A., Warneke, C., Kuster, W. C., Alexander, M. L., Baker, A., Beyersdorf, A. J., Blake, D., Fall, R., Jimenez, J. L., Herndon, S. C., Huey, L. G., Knighton, W. B., Ortega, J., Springston, S., and Vargas, O.: Measurements of volatile organic compounds at a suburban ground site (T1) 
in Mexico City during the MILAGRO 2006 campaign: measurement comparison, emission ratios, and source attribution, Atmos. Chem. Phys., 11, 2399-2421, doi:10.5194/acp-11-23992011, 2011.

Booker, F., Muntifering, R., McGrath, M., Burkey, K., Decoteau, D., Fiscus, E., Manning, W., Krupa, S., Chappelka, A., and Grantz, D.: The Ozone Component of Global Change: Potential Effects on Agricultural and Horticultural Plant Yield, Product Quality and Interactions with Invasive Species, J. Integr. Plant Biol., 51, 337-351, doi:10.1111/j.17447909.2008.00805.x, 2009.

Bossolasco, A., Farago, E. P., Schoemaecker, C., and Fittschen, C.: Rate constant of the reaction between $\mathrm{CH}_{3} \mathrm{O}_{2}$ and $\mathrm{OH}$ radicals, Chem. Phys. Lett., 593, 7-13, doi:10.1016/j.cplett.2013.12.052, 2014.

Bowman, K. W.: Toward the next generation of air quality monitoring: Ozone, Atmos. Environ., 80, 571-583, doi:10.1016/j.atmosenv.2013.07.007, 2013.

BP: BP Statistical Review of World Energy, available at: bp.com/ statisticalreview (last access: 4 August 2015), 2013.

BP: BP Energy Outlook 2035, available at: bp.com/energyoutlook (last access: 4 August 2015), 2014a.

BP: BP Energy Outlook 2035: Focus on North America, available at: http://www.bp.com/content/dam/ bp/pdf/Energy-economics/statistical-review-2015/

Energy-Outlook-2035-Focus-on-North-America.pdf,

(last access: 4 August 2015), 2014b.

Brandt, A. R., Heath, G. A., Kort, E. A., O'Sullivan, F., Petron, G., Jordaan, S. M., Tans, P., Wilcox, J., Gopstein, A. M., Arent, D., Wofsy, S., Brown, N. J., Bradley, R., Stucky, G. D., Eardley, D., and Harriss, R.: Methane Leaks from North American Natural Gas Systems, Science, 343, 733-735, doi:10.1126/science.1247045, 2014.

Braslavsky, S. E. and Rubin, M. B.: The history of ozone Part VIII. Photochemical formation of ozone, Photochem. Photobiol. Sci., 10, 1515-1520, doi:10.1039/c1pp05121k, 2011.

Brasseur, G. P., Prinn, R. G., and Pszenny, A. A. P.: Atmospheric Chemistry in a Changing World, Global Change - IGBP Series, Springer, 2003.

Brauer, M., Amann, M., Burnett, R. T., Cohen, A., Dentener, F., Ezzati, M., Henderson, S. B., Krzyzanowski, M., Martin, R. V., Van Dingenen, R., van Donkelaar, A., and Thurston, G. D.: Exposure Assessment for Estimation of the Global Burden of Disease Attributable to Outdoor Air Pollution, Environ. Sci. Technol., 46, 652-660, doi:10.1021/es2025752, 2012.

Brock, C. A., Cozic, J., Bahreini, R., Froyd, K. D., Middlebrook, A. M., McComiskey, A., Brioude, J., Cooper, O. R., Stohl, A., Aikin, K. C., de Gouw, J. A., Fahey, D. W., Ferrare, R. A., Gao, R.-S., Gore, W., Holloway, J. S., Hübler, G., Jefferson, A., Lack, D. A., Lance, S., Moore, R. H., Murphy, D. M., Nenes, A., Novelli, P. C., Nowak, J. B., Ogren, J. A., Peischl, J., Pierce, R. B., Pilewskie, P., Quinn, P. K., Ryerson, T. B., Schmidt, K. S., Schwarz, J. P., Sodemann, H., Spackman, J. R., Stark, H., Thomson, D. S., Thornberry, T., Veres, P., Watts, L. A., Warneke, C., and Wollny, A. G.: Characteristics, sources, and transport of aerosols measured in spring 2008 during the aerosol, radiation, and cloud processes affecting Arctic Climate (ARCPAC) Project, Atmos. Chem. Phys., 11, 2423-2453, doi:10.5194/acp-11-24232011, 2011.
Browne, E. C., Wooldridge, P. J., Min, K.-E., and Cohen, R. C.: On the role of monoterpene chemistry in the remote continental boundary layer, Atmos. Chem. Phys., 14, 1225-1238, doi:10.5194/acp-14-1225-2014, 2014.

Brown-Steiner, B. and Hess, P.: Asian influence on surface ozone in the United States: A comparison of chemistry, seasonality, and transport mechanisms, J. Geophys. Res.-Atmos., 116, doi:10.1029/2011jd015846, 2011.

Büker, P., Morrissey, T., Briolat, A., Falk, R., Simpson, D., Tuovinen, J.-P., Alonso, R., Barth, S., Baumgarten, M., Grulke, N., Karlsson, P. E., King, J., Lagergren, F., Matyssek, R., Nunn, A., Ogaya, R., Peñuelas, J., Rhea, L., Schaub, M., Uddling, J., Werner, W., and Emberson, L. D.: $\mathrm{DO}_{3} \mathrm{SE}$ modelling of soil moisture to determine ozone flux to forest trees, Atmos. Chem. Phys., 12, 5537-5562, doi:10.5194/acp-12-5537-2012, 2012.

Butler, T. M. and Lawrence, M. G.: The influence of megacities on global atmospheric chemistry: a modelling study, Environ. Chem., 6, 219-225, doi:10.1071/en08110, 2009.

Butler, T. M., Stock, Z. S., Russo, M. R., Denier van der Gon, H. A. C., and Lawrence, M. G.: Megacity ozone air quality under four alternative future scenarios, Atmos. Chem. Phys., 12, 44134428, doi:10.5194/acp-12-4413-2012, 2012.

Calfapietra, C., Fares, S., Manes, F., Morani, A., Sgrigna, G., and Loreto, F.: Role of Biogenic Volatile Organic Compounds (BVOC) emitted by urban trees on ozone concentration in cities: A review, Environ. Pollut., 183, 71-80, doi:10.1016/j.envpol.2013.03.012, 2013.

Cammas, J.-P., Brioude, J., Chaboureau, J.-P., Duron, J., Mari, C., Mascart, P., Nédélec, P., Smit, H., Pätz, H.-W., Volz-Thomas, A., Stohl, A., and Fromm, M.: Injection in the lower stratosphere of biomass fire emissions followed by long-range transport: a MOZAIC case study, Atmos. Chem. Phys., 9, 5829-5846, doi:10.5194/acp-9-5829-2009, 2009.

Cape, J. N.: Surface ozone concentrations and ecosystem health: Past trends and a guide to future projections, Sci. Total Environ., 400, 257-269, doi:10.1016/j.scitotenv.2008.06.025, 2008.

Cape, J. N., Hamilton, R., and Heal, M. R.: Reactive uptake of ozone at simulated leaf surfaces: Implications for "non-stomatal" ozone flux, Atmos. Environ., 43, 1116-1123, 2009.

Carpenter, L. J.: Iodine in the marine boundary layer, Chem. Rev., 103, 4953-4962, 2003.

Carpenter, L. J., Fleming, Z. L., Read, K. A., Lee, J. D., Moller, S. J., Hopkins, J. R., Purvis, R. M., Lewis, A. C., Mueller, K., Heinold, B., Herrmann, H., Fomba, K. W., van Pinxteren, D., Mueller, C., Tegen, I., Wiedensohler, A., Mueller, T., Niedermeier, N., Achterberg, E. P., Patey, M. D., Kozlova, E. A., Heimann, M., Heard, D. E., Plane, J. M. C., Mahajan, A., Oetjen, H., Ingham, T., Stone, D., Whalley, L. K., Evans, M. J., Pilling, M. J., Leigh, R. J., Monks, P. S., Karunaharan, A., Vaughan, S., Arnold, S. R., Tschritter, J., Poehler, D., Friess, U., Holla, R., Mendes, L. M., Lopez, H., Faria, B., Manning, A. J., and Wallace, D. W. R.: Seasonal characteristics of tropical marine boundary layer air measured at the Cape Verde Atmospheric Observatory, J. Atmos. Chem., 67, 87-140, doi:10.1007/s10874-011-9206-1, 2010.

Carpenter, L. J., MacDonald, S. M., Shaw, M. D., Kumar, R., Saunders, R. W., Parthipan, R., Wilson, J., and Plane, J. M. C.: Atmospheric iodine levels influenced by sea surface emissions of inorganic iodine, Nat. Geosci., 6, 108-111, doi:10.1038/ngeo1687, 2013. 
Carslaw, D. C.: On the changing seasonal cycles and trends of ozone at Mace Head, Ireland, Atmos. Chem. Phys., 5, 34413450, doi:10.5194/acp-5-3441-2005, 2005.

Carslaw, D. C., Beevers, S. D., Tate, J. E., Westmoreland, E. J., and Williams, M. L.: Recent evidence concerning higher NOx emissions from passenger cars and light duty vehicles, Atmos. Environ., 45, 7053-7063, doi:10.1016/j.atmosenv.2011.09.063, 2011.

Carter, W. P. L. and Seinfeld, J. H.: Winter ozone formation and VOC incremental reactivities in the Upper Green River Basin of Wyoming, Atmos. Environ., 50, 255-266, doi:10.1016/j.atmosenv.2011.12.025, 2012.

Carvalho, A., Monteiro, A., Flannigan, M., Solman, S., Miranda, A. I., and Borrego, C.: Forest fires in a changing climate and their impacts on air quality, Atmos. Environ., 45, 5545-5553, doi:10.1016/j.atmosenv.2011.05.010, 2011.

Caulton, D. R., Shepson, P. B., Santoro, R. L., Sparks, J. P., Howarth, R. W., Ingraffea, A. R., Cambaliza, M. O. L., Sweeney, C., Karion, A., Davis, K. J., Stirm, B. H., Montzka, S. A., and Miller, B. R.: Toward a better understanding and quantification of methane emissions from shale gas development, Proc. Natl. Acad. Sci. USA, 111, 6237-6242, doi:10.1073/pnas.1316546111, 2014.

Chakraborty, T., Beig, G., Dentener, F. J., and Wild, O.: Atmospheric transport of ozone between Southern and Eastern Asia, Sci. Total Environ., 523, 28-39, doi:10.1016/j.scitotenv.2015.03.066, 2015.

Chameides, W. L. and Walker, J. C. G.: A photochemical theory for tropospheric ozone, J. Geophys. Res., 78, 8751-8760, 1973.

Chang, H. M., Chang, L. F. W., and Jeng, F. T.: Interfacial transfer resistances of ozone dry deposition over agricultural soil of Tainan County, Taiwan, Environ. Eng. Sci., 19, 133-141, 2002.

Chang, W., Heikes, B. G., and Lee, M.: Ozone deposition to the sea surface: chemical enhancement and wind speed dependence, Atmos. Environ., 38, 1053-1059, 2004.

Chatfield, R. and Harrison, H.: Ozone in the remote troposphere mixing versus photochemistry, J. Geophys. Res.-Ocean. Atmos., 81, 421-423, doi:10.1029/JC081i003p00421, 1976.

Chelani, A. B.: Persistence analysis of extreme $\mathrm{CO}, \mathrm{NO}_{2}$ and $\mathrm{O}_{3}$ concentrations in ambient air of Delhi, Atmos. Res., 108, 128134, doi:10.1016/j.atmosres.2012.02.001, 2012.

Chevallier, F., Fortems, A., Bousquet, P., Pison, I., Szopa, S., Devaux, M., and Hauglustaine, D. A.: African CO emissions between years 2000 and 2006 as estimated from MOPITT observations, Biogeosciences, 6, 103-111, doi:10.5194/bg-6-103-2009, 2009

Choi, K. C., Lee, J. J., Bae, C. H., Kim, C. H., Kim, S., Chang, L. S., Ban, S. J., Lee, S. J., Kim, J., and Woo, J. H.: Assessment of transboundary ozone contribution toward South Korea using multiple source-receptor modeling techniques, Atmos. Environ., 92, 118-129, doi:10.1016/j.atmosenv.2014.03.055, 2014.

Choi, Y., Wang, Y., Zeng, T., Martin, R. V., Kurosu, T. P., and Chance, K.: Evidence of lightning $\mathrm{NO}_{x}$ and convective transport of pollutants in satellite observations over North America, Geophys. Res. Lett., 32, L02805, doi:10.1029/2004GL021436, 2005.

Chou, C., Wu, T. C., and Tan, P. H.: Changes in gross moist stability in the tropics under global warming, Clim. Dynam., 41, 24812496, doi:10.1007/s00382-013-1703-2, 2013.
Cifuentes, L., Borja-Aburto, V. H., Gouveia, N., Thurston, G., and Davis, D. L.: Assessing the health benefits of urban air pollution reductions associated with climate change mitigation (20002020): Santiago, Sao Paulo, Mexico City, and New York City, Environ. Health Perspect., 109, 419-425, doi:10.2307/3434790, 2001.

Clifton, O. E., Fiore, A. M., Correa, G., Horowitz, L. W., and Naik, V.: Twenty-first century reversal of the surface ozone seasonal cycle over the northeastern United States, Geophys. Res. Lett., 41, 7343-7350, doi:10.1002/2014gl061378, 2014.

Coe, H., Gallagher, M. W., Choularton, T. W., and Dore, C.: Canopy scale measurements of stomatal and cuticular $\mathrm{O}_{3}$ uptake by sitka spruce, Atmos. Environ., 29, 1413-1423, 1995.

Colette, A., Granier, C., Hodnebrog, Ø., Jakobs, H., Maurizi, A., Nyiri, A., Bessagnet, B., D’Angiola, A., D’Isidoro, M., Gauss, M., Meleux, F., Memmesheimer, M., Mieville, A., Rouïl, L., Russo, F., Solberg, S., Stordal, F., and Tampieri, F.: Air quality trends in Europe over the past decade: a first multi-model assessment, Atmos. Chem. Phys., 11, 11657-11678, doi:10.5194/acp11-11657-2011, 2011.

Colette, A., Granier, C., Hodnebrog, Ø., Jakobs, H., Maurizi, A., Nyiri, A., Rao, S., Amann, M., Bessagnet, B., D’Angiola, A., Gauss, M., Heyes, C., Klimont, Z., Meleux, F., Memmesheimer, M., Mieville, A., Rouïl, L., Russo, F., Schucht, S., Simpson, D., Stordal, F., Tampieri, F., and Vrac, M.: Future air quality in Europe: a multi-model assessment of projected exposure to ozone, Atmos. Chem. Phys., 12, 10613-10630, doi:10.5194/acp12-10613-2012, 2012.

Colette, A., Bessagnet, B., Vautard, R., Szopa, S., Rao, S., Schucht, S., Klimont, Z., Menut, L., Clain, G., Meleux, F., Curci, G., and Rouïl, L.: European atmosphere in 2050, a regional air quality and climate perspective under CMIP5 scenarios, Atmos. Chem. Phys., 13, 7451-7471, doi:10.5194/acp-13-7451-2013, 2013.

Colette, A., Bessagnet, B., Meleux, F., Terrenoire, E., and Rouïl, L.: Frontiers in air quality modelling, Geosci. Model Dev., 7, 203 210, doi:10.5194/gmd-7-203-2014, 2014.

Collins, W. J., Sitch, S., and Boucher, O.: How vegetation impacts affect climate metrics for ozone precursors, J. Geophys. Res.Atmos., 115, D23308, doi:10.1029/2010jd014187, 2010.

Collins, W. J., Fry, M. M., Yu, H., Fuglestvedt, J. S., Shindell, D. T., and West, J. J.: Global and regional temperature-change potentials for near-term climate forcers, Atmos. Chem. Phys., 13, 2471-2485, doi:10.5194/acp-13-2471-2013, 2013.

Cook, P. A., Savage, N. H., Turquety, S., Carver, G. D., O’Connor, F. M., Heckel, A., D., S., Whalley, L. K., Parker, A. E., Schlager H., Singh, H. B., Avery, M. A., Sachse, G. W., Brune, W., Richter, A., Burrows, J. P., Purvis, R., Lewis, A. C., Reeves, C. E., Monks, P. S., Levine, J. S., and Pyle, D. M.: Forest fire plumes over the North Atlantic: p-TOMCAT model simulations with aircraft and satellite measurements from the ITOP/ICARTT campaign, J. Geophys. Res., 112, D10S43, doi:10.1029/2006JD007563, 2007.

Cooper, O. R., Trainer, M., Thompson, A. M., Oltmans, S. J., Tarasick, D. W., Witte, J. C., Stohl, A., Eckhardt, S., Lelieveld, J., Newchurch, M. J., Johnson, B. J., Portmann, R. W., Kalnajs, L., Dubey, M. K., Leblanc, T., McDermid, I. S., Forbes, G., Wolfe, D., Carey-Smith, T., Morris, G. A., Lefer, B., Rappengluck, B., Joseph, E., Schmidlin, F., Meagher, J., Fehsenfeld, F. C., Keating, T. J., Van Curen, R. A., and Minschwaner, K.: Evidence for a recurring eastern North America upper tropospheric ozone max- 
imum during summer, J. Geophys. Res.-Atmos., 112, D23304, doi:10.1029/2007jd008710, 2007.

Cooper, O. R., Eckhardt, S., Crawford, J. H., Brown, C. C., Cohen, R. C., Bertram, T. H., Wooldridge, P., Perring, A., Brune, W. H., Ren, X., Brunner, D., and Baughcum, S. L.: Summertime buildup and decay of lightning $\mathrm{NO}_{x}$ and aged thunderstorm outflow above North America, J. Geophys. Res.-Atmos., 114, D01101, doi:10.1029/2008jd010293, 2009.

Cooper, O. R., Parrish, D. D., Ziemke, J., Balashov, N. V., Cupeiro, M., Galbally, I. E., Gilge, S., Horowitz, L., Jensen, N. R., Lamarque, J. F., Naik, V., Oltmans, S. J., Schwab, J., Shindell, D. T., Thompson, A. M., Thouret, V., Wang, Y., and Zbinden, R. M.: Global distribution and trends of tropospheric ozone: An observation-based review, Elem. Sci. Anth., 2, 000029 , doi:10.12952/journal.elementa.000029, 2014.

Corbett, J. J., Lack, D. A., Winebrake, J. J., Harder, S., Silberman, J. A., and Gold, M.: Arctic shipping emissions inventories and future scenarios, Atmos. Chem. Phys., 10, 9689-9704, doi:10.5194/acp-10-9689-2010, 2010.

Council: Global Sources of Local Pollution: An Assessment of Long-Range Transport of Key Air Pollutants to and from the United States, The National Academies Press, 2009a.

Council: Global Sources of Local pollution: An Assessment of Long-Range Transport of Key Air Pollutants to and from the United States, The National Academies Press, 2009b.

Cox, P., Delao, A., Komorniczak, A., and Weller, R.: The California Almanac of Emissions and Air Quality, California Air Resources Board, available at: http://www.arb.ca.gov/aqd/almanac/ almanac09/almanac2009all.pdf (last access: 4 August 2015), 2009.

Coyle, M.: The Gaseous Exchange of Ozone at Terrestrial Surfaces: Non-stomatal Deposition to Grassland, School of Geosciences, Faculty of Science and Engineering, The University of Edinburgh, Edinburgh, 270 pp., 2005.

Coyle, M., Nemitz, E., Storeton-West, R., Fowler, D., and Cape, J. N.: Measurements of ozone deposition to a potato canopy, Agr. Forest Meteorol., 149, 655-666, doi:10.1016/j.agrformet.2008.10.020, 2009.

Crawford-Brown, D., Barker, T., Anger, A., and Dessens, O.: Ozone and PM related health co-benefits of climate change policies in Mexico, Environ. Sci. Policy, 17, 33-40, doi:10.1016/j.envsci.2011.12.006, 2012.

Criegee, R.: Die Umlagerung der Dekalin-peroxydester als Folge von kationischem Sauerstoff, Justus Liebigs Annalen der Chemie, 560, 127-135, doi:10.1002/jlac.19485600106, 1948.

Cristofanelli, P., Bracci, A., Sprenger, M., Marinoni, A., Bonafè, U., Calzolari, F., Duchi, R., Laj, P., Pichon, J.M., Roccato, F., Venzac, H., Vuillermoz, E., and Bonasoni, P.: Tropospheric ozone variations at the Nepal Climate ObservatoryPyramid (Himalayas, $5079 \mathrm{~m}$ a.s.l.) and influence of deep stratospheric intrusion events, Atmos. Chem. Phys., 10, 6537-6549, doi:10.5194/acp-10-6537-2010, 2010.

Crounse, J. D., Paulot, F., Kjaergaard, H. G., and Wennberg, P. O.: Peroxy radical isomerization in the oxidation of isoprene, Phys. Chem. Chem. Phys., 13, 13607-13613, 2011.

Crutzen, P. J.: Photochemical reactions initiated by and influencing ozone in the unpolluted troposphere, Tellus, 26, 47-57, 1973.

Cuevas, E., González, Y., Rodríguez, S., Guerra, J. C., GómezPeláez, A. J., Alonso-Pérez, S., Bustos, J., and Milford, C.: As- sessment of atmospheric processes driving ozone variations in the subtropical North Atlantic free troposphere, Atmos. Chem. Phys., 13, 1973-1998, doi:10.5194/acp-13-1973-2013, 2013.

Cui, H. Y., Su, J. W., Wei, J. N., Hu, Y. J., and Ge, F.: Elevated $\mathrm{O}_{3}$ enhances the attraction of whitefly-infested tomato plants to Encarsia formosa, Sci. Rep, 4, 5350, doi:10.1038/srep05350, 2014.

Cuvelier, C., Thunis, P., Vautard, R., Amann, M., Bessagnet, B., Bedogni, M., Berkowicz, R., Brandt, J., Brocheton, F., Builtjes, P., Coppalle, A., Denby, B., G., D., Graf, A., Hellmuth, O., Honoré, C., Hodzic, A., Jonson, J., Kerschbaumer, A., de Leeuw, F., Minguzzi, E., Moussiopoulos, N., Pertot, C., Pirovano, G., Rouil, L., Schaap, M., Stern, R., Tarrason, L., Vignati, E., Volta, M., White, L., Wind, P., and Zuber, A.: CityDelta: A model intercomparison to explore the impact of emission reductions in 2010 in European cities, Atmos. Environ., 41, 189-207, doi:10.1016/j.atmosenv.2006.07.036, 2007.

Dalsøren, S. B., Eide, M. S., Myhre, G., Endresen, Ø., Isaksen, I. S. A., and Fuglestvedt, J. S.: Impacts of the Large Increase in International Ship Traffic 2000-2007 on Tropospheric Ozone and Methane, Environ. Sci. Technol., 44, 2482-2489, doi:10.1021/es902628e, 2010.

Dalsøren, S. B., Samset, B. H., Myhre, G., Corbett, J. J., Minjares, R., Lack, D., and Fuglestvedt, J. S.: Environmental impacts of shipping in 2030 with a particular focus on the Arctic region, Atmos. Chem. Phys., 13, 1941-1955, doi:10.5194/acp-13-19412013, 2013.

Danielsen, E. F.: Stratospheric-tropospheric exchange based on radioactivity, ozone and potential vorticity, J. Atmos. Sci., 25, 502 518, 1968 .

Davison, B., Brunner, A., Ammann, C., Spirig, C., Jocher, M., and Neftel, A.: Cut-induced VOC emissions from agricultural grasslands, Plant Biol., 10, 76-85, doi:10.1055/s-2007-965043, 2008.

de Fatima, A. M., Fornaro, A., Dias de, F. E., Mazzoli, C. R., Martins, L. D., Boian, C., Oliveira, M. G. L., Peres, J., Carbone, S., Alvala, P., and Leme, N. P.: Ozone sounding in the Metropolitan Area of Sao Paulo, Brazil: Wet and dry season campaigns of 2006, Atmos. Environ., 61, 627-640, doi:10.1016/j.atmosenv.2012.07.083, 2012.

Defra: Air Quality Statistics in the UK 1987-2012, Defra, London, 2013.

Dempsey, F.: Observations of stratospheric $\mathrm{O}_{3}$ intrusions in air quality monitoring data in Ontario, Canada, Atmos. Environ., 98, 111-122, doi:10.1016/j.atmosenv.2014.08.024, 2014.

de Ruyter de Wildt, M., Eskes, H., and Boersma, K. F.: The global economic cycle and satellite-derived $\mathrm{NO}_{2}$ trends over shipping lanes, Geophys. Res. Lett., 39, L01802, doi:10.1029/2011g1049541, 2012.

Derwent, R., Beevers, S., Chemel, C., Cooke, S., Francis, X., Fraser, A., Heal, M. R., Kitwiroon, N., Lingard, J., Redington, A., Sokhi, R., and Vieno, M.: Analysis of UK and European $\mathrm{NO}_{x}$ and VOC emission scenarios in the Defra model intercomparison exercise, Atmos. Environ., 94, 249-257, doi:10.1016/j.atmosenv.2014.05.036, 2014.

Derwent, R. G. and Hjellbrekke, A.-G.: Air Pollution by Ozone Across Europe, Urban Air Quality in Europe, edited by: Viana, M., Springer, 2013.

Derwent, R. G., Collins, W. J., Johnson, C. E., and Stevenson, D. S.: Transient behaviour of tropospheric ozone precursors in a 
global 3-D CTM and their indirect greenhouse effects, Climatic Change, 49, 463-487, doi:10.1023/a:1010648913655, 2001.

Derwent, R. G., Simmonds, P. G., O’Doherty, S., Stevenson, D. S., Collins, W. J., Sanderson, M. G., Johnson, C. E., Dentener, F., Cofala, J., Mechler, R., and Amann, M.: External influences on Europe's air quality: Baseline methane, carbon monoxide and ozone from 1990 to 2030 at Mace Head, Ireland, Atmos. Environ., 40, 844-855, doi:10.1016/j.atmosenv.2005.09.077, 2006.

Derwent, R. G., Witham, C. S., Utembe, S. R., Jenkin, M. E., and Passant, N. R.: Ozone in Central England: the impact of 20 years of precursor emission controls in Europe, Environ. Sci. Policy, 13, 195-204, doi:10.1016/j.envsci.2010.02.001, 2010.

Di Carlo, P., Brune, W. H., Martinez, M., Harder, H., Lesher, R., Ren, X. R., Thornberry, T., Carroll, M. A., Young, V., Shepson, P. B., Riemer, D., Apel, E., and Campbell, C.: Missing OH reactivity in a forest: Evidence for unknown reactive biogenic VOCs, Science, 304, 722-725, 2004.

Dibble, T. S.: Failures and limitations of quantum chemistry for two key problems in the atmospheric chemistry of peroxy radicals, Atmos. Environ., 42, 5837-5848, 2008.

Dix, B., Baidara, S., Bresch, J. F., Hall, S. R., Schmidt, K. S., Wang, S., and Volkamer, R.: Detection of iodine monoxide in the tropical free troposphere, Proc. Natl. Acad. Sci. USA, 110, 20352040, doi:10.1073/pnas.1212386110, 2013.

Doche, C., Dufour, G., Foret, G., Eremenko, M., Cuesta, J., Beekmann, M., and Kalabokas, P.: Summertime tropospheric-ozone variability over the Mediterranean basin observed with IASI, Atmos. Chem. Phys., 14, 10589-10600, doi:10.5194/acp-1410589-2014, 2014.

Doherty, R. M., Stevenson, D. S., Johnson, C. E., Collins, W. J., and Sanderson, M. G.: Tropospheric ozone and El Nino-Southern Oscillation: Influence of atmospheric dynamics, biomass burning emissions, and future climate change, J. Geophys. Res.-Atmos., 111, doi:10.1029/2005jd006849, 2006.

Doherty, R. M., Wild, O., Shindell, D. T., Zeng, G., MacKenzie, I. A., Collins, W. J., Fiore, A. M., Stevenson, D. S., Dentener, F. J., Schultz, M. G., Hess, P., Derwent, R. G., and Keating, T. J.: Impacts of climate change on surface ozone and intercontinental ozone pollution: A multi-model study, J. Geophys. Res.-Atmos., 118, 3744-3763, doi:10.1002/jgrd.50266, 2013.

Droge, R., Kuenen, J. J. P., Pulles, M. P. J., and Heslinga, D. C.: The revised EMEP/EEA Guidebook compared to the country specific inventory system in the Netherlands, Atmos. Environ., 44, 35033510, doi:10.1016/j.atmosenv.2010.06.020, 2010.

Duncan, B. N., Martin, R. V., Staudt, A. C., Yevich, R., and Logan, J. A.: Interannual and seasonal variability of biomass burning emissions constrained by satellite observations, J. Geophys. Res.-Atmos., 108, 4100, doi:10.1029/2002jd002378, 2003.

Duncan, B. N., Prados, A. I., Lamsal, L. N., Liu, Y., Streets, D. G., Gupta, P., Hilsenrath, E., Kahn, R. A., Nielsen, J. E., Beyersdorf, A. J., Burton, S. P., Fiore, A. M., Fishman, J., Henze, D. K., Hostetler, C. A., Krotkov, N. A., Lee, P., Lin, M. Y., Pawson, S., Pfister, G., Pickering, K. E., Pierce, R. B., Yoshida, Y., and Ziemba, L. D.: Satellite data of atmospheric pollution for US air quality applications: Examples of applications, summary of data end-user resources, answers to FAQs, and common mistakes to avoid, Atmos. Environ., 94, 647-662, doi:10.1016/j.atmosenv.2014.05.061, 2014.
Dunker, A. M., Koo, B., and Yarwood, G.: Sensitivity of atmospheric models to rate terms within complex chemical mechanisms, Atmos. Environ., 98, 224-230, doi:10.1016/j.atmosenv.2014.08.074, 2014.

Eckhardt, S., Stohl, A., Beirle, S., Spichtinger, N., James, P., Forster, C., Junker, C., Wagner, T., Platt, U., and Jennings, S. G.: The North Atlantic Oscillation controls air pollution transport to the Arctic, Atmos. Chem. Phys., 3, 1769-1778, doi:10.5194/acp-31769-2003, 2003.

Edwards, P. M., Young, C. J., Aikin, K., deGouw, J., Dubé, W. P., Geiger, F., Gilman, J., Helmig, D., Holloway, J. S., Kercher, J., Lerner, B., Martin, R., McLaren, R., Parrish, D. D., Peischl, J., Roberts, J. M., Ryerson, T. B., Thornton, J., Warneke, C., Williams, E. J., and Brown, S. S.: Ozone photochemistry in an oil and natural gas extraction region during winter: simulations of a snow-free season in the Uintah Basin, Utah, Atmos. Chem. Phys., 13, 8955-8971, doi:10.5194/acp-13-8955-2013, 2013.

Edwards, P. M., Brown, S. S., Roberts, J. M., Ahmadov, R., Banta, R. M., deGouw, J. A., Dube, W. P., Field, R. A., Flynn, J. H., Gilman, J. B., Graus, M., Helmig, D., Koss, A., Langford, A. O., Lefer, B. L., Lerner, B. M., Li, R., Li, S.-M., McKeen, S. A., Murphy, S. M., Parrish, D. D., Senff, C. J., Soltis, J., Stutz, J., Sweeney, C., Thompson, C. R., Trainer, M. K., Tsai, C., Veres, P. R., Washenfelder, R. A., Warneke, C., Wild, R. J., Young, C. J., Yuan, B., and Zamora, R.: High winter ozone pollution from carbonyl photolysis in an oil and gas basin, Nature, doi:10.1038/nature13767, online first, 2014.

EEA: Air Pollution in Europe 1990-2004, European Environment Agency: Copenhagen, 2007.

EEA: Assessment of ground-level ozone in EEA member countries, with a focus on long-term trends, 2009.

EEA: Air quality in Europe - 2011 report, EEA, 80, 2011.

Ehhalt, D. H.: Photooxidation of trace gases in the troposphere, Phys. Chem. Chem. Phys., 1, 5401-5408, 1999.

Elansky, N. F., Mokhov, I. I., Belikov, I. B., Berezina, E. V., Elokhov, A. S., Ivanov, V. A., Pankratova, N. V., Postylyakov, O. V., Safronov, A. N., Skorokhod, A. I., and Shumskii, R. A.: Gaseous admixtures in the atmosphere over Moscow during the 2010 summer, Izv. Atmos. Ocean. Phys., 47, 672-681, doi:10.1134/s000143381106003x, 2011.

Elbern, H., Strunk, A., Schmidt, H., and Talagrand, O.: Emission rate and chemical state estimation by 4-dimensional variational inversion, Atmos. Chem. Phys., 7, 3749-3769, doi:10.5194/acp7-3749-2007, 2007.

Elguindi, N., Clark, H., Ordóñez, C., Thouret, V., Flemming, J., Stein, O., Huijnen, V., Moinat, P., Inness, A., Peuch, V.-H., Stohl, A., Turquety, S., Athier, G., Cammas, J.-P., and Schultz, M.: Current status of the ability of the GEMS/MACC models to reproduce the tropospheric $\mathrm{CO}$ vertical distribution as measured by MOZAIC, Geosci. Model Dev., 3, 501-518, doi:10.5194/gmd-3501-2010, 2010.

Emberson, L. D., Ashmore, M. R., Cambridge, H. M., Simpson, D., and Tuovinen, J. P.: Modelling stomatal ozone flux across Europe, Environmental Pollution, 109, 403-413, doi:10.1016/s0269-7491(00)00043-9, 2000.

Emmons, L. K., Hess, P., Klonecki, A., Tie, X., Horowitz, L., Lamarque, J. F., Kinnison, D., Brasseur, G., Atlas, E., Browell, E., Cantrell, C., Eisele, F., Mauldin, R. L., Merrill, J., Ridley, B., and Shetter, R.: Budget of tropospheric ozone during TOPSE 
from two chemical transport models, J. Geophys. Res.-Atmos., 108, 8372, doi:10.1029/2002jd002665, 2003.

Emmons, L. K., Arnold, S. R., Monks, S. A., Huijnen, V., Tilmes, S., Law, K. S., Thomas, J. L., Raut, J.-C., Bouarar, I., Turquety, S., Long, Y., Duncan, B., Steenrod, S., Strode, S., Flemming, J., Mao, J., Langner, J., Thompson, A. M., Tarasick, D., Apel, E. C., Blake, D. R., Cohen, R. C., Dibb, J., Diskin, G. S., Fried, A., Hall, S. R., Huey, L. G., Weinheimer, A. J., Wisthaler, A., Mikoviny, T., Nowak, J., Peischl, J., Roberts, J. M., Ryerson, T., Warneke, C., and Helmig, D.: The POLARCAT Model Intercomparison Project (POLMIP): overview and evaluation with observations, Atmos. Chem. Phys., 15, 6721-6744, doi:10.5194/acp15-6721-2015, 2015.

EPA: Assessment of the impacts of global change on regional U.S. air quality: a synthesis of climate change impacts on ground-level ozone, National Center for Environmental Assessment Washington DC, 2009.

EPA: Environmental Protection Agency: Inventory of U.S. Greenhouse Gas Emissions and Sinks: 1990-2012, available at: http://www.epa.gov/climatechange/Downloads/ ghgemissions/US-GHG-Inventory-2014-Main-Text.pdf and http://www.epa.gov/climatechange/Downloads/ghgemissions/ US-GHGInventory-2014-Annexes.pdf (last access: $4 \mathrm{Au}-$ gust 2015), 2014

Erisman, J. W., Vanpul, A., and Wyers, P.: Parameterrizaton of surface-resistance for the quantification of atmospheric deposition of acidifying pollutants and ozone, Atmos. Environ., 28, 2595-2607, doi:10.1016/1352-2310(94)90433-2, 1994.

Erisman, J. W., Galloway, J. N., Seitzinger, S., Bleeker, A., Dise, N. B., Petrescu, A. M. R., Leach, A. M., and de Vries, W.: Consequences of human modification of the global nitrogen cycle, Philos. Trans. R. Soc. B-Biol. Sci., 368, doi:10.1098/rstb.2013.0116, 2013.

Escudero, M., Lozano, A., Hierro, J., Valle, J. D., and Mantilla, E.: Urban influence on increasing ozone concentrations in a characteristic Mediterranean agglomeration, Atmos. Environ., 99, 322 332, doi:10.1016/j.atmosenv.2014.09.061, 2014.

Ewing, S. A., Christensen, J. N., Brown, S. T., Vancuren, R. A., Cliff, S. S., and Depaolo, D. J.: Pb Isotopes as an Indicator of the Asian Contribution to Particulate Air Pollution in Urban California, Environ. Sci. Technol., 44, 8911-8916, doi:10.1021/es101450t, 2010.

Eyring, V., Isaksen, I. S. A., Berntsen, T., Collins, W. J., Corbett, J. J., Endresen, Ø., Grainger, R. G., Moldanova, J., Schlager, H., and Stevenson, D. S.: Assessment of Transport Impacts on Climate and Ozone: Shipping, Atmos. Environ., 44, 4735-4771 2010.

Fabian, P. and Pruchniewicz, P. G.: Meridional distribution of ozone in the troposphere and its seasonal variations, J. Geophys. Res., 82, 2063-2073, 1977.

Fares, S., Weber, R., Park, J.-H., Gentner, D., Karlik, J., and Goldstein, A. H.: Ozone deposition to an orange orchard: Partitioning between stomatal and non-stomatal sinks, Environ. Pollut., 169, 258-266, doi:10.1016/j.envpol.2012.01.030, 2012.

Fares, S., Matteucci, G., Mugnozza, G. S., Morani, A., Calfapietra, C., Salvatori, E., Fusaro, L., Manes, F., and Loreto, F.: Testing of models of stomatal ozone fluxes with field measurements in a mixed Mediterranean forest, Atmos. Environ., 67, 242-251, doi:10.1016/j.atmosenv.2012.11.007, 2013a.
Fares, S., Matteucci, G., Scarascia Mugnozza, G., Morani, A., Calfapietra, C., Salvatori, E., Fusaro, L., Manes, F., and Loreto, F.: Testing of models of stomatal ozone fluxes with field measurements in a mixed Mediterranean forest, Atmos. Environ., 67, 242-251, doi:10.1016/j.atmosenv.2012.11.007, 2013 b.

Farquhar, G. D., Schulze, E. D., and Kuppers, M.: Response to humidity by stomata of Nicotiana-Gluaca L and Corylus-Avellana $\mathrm{L}$ are consisutent with the optimization of carbon-dioxide uptake with repect to water-loss, Aust. J. Plant Physiol., 7, 315-327, 1980.

Felzer, B., Cronin, T., Reilly, J. M., and Wang, X.: Impact of ozone on trees and crops, Comptes Rendus Geoscience, 339, 784-798, 2007.

Field, R. A., Soltis, J., and Murphy, S.: Air quality concerns of unconventional oil and natural gas production, Environ. Sci.Process Impacts, 16, 954-969, doi:10.1039/c4em00081a, 2014.

Finlayson-Pitts, B. J.: Halogens in the Troposphere, Anal. Chem., 82, 770-776, doi:10.1021/ac901478p, 2010.

Finley, B. D. and Saltzman, E. S.: Observations of $\mathrm{Cl}_{2}, \mathrm{Br}_{2}$, and $\mathrm{I}_{2}$ in coastal marine air, J. Geophys. Res.-Atmos., 113, D21301, doi:10.1029/2008jd010269, 2008.

Finney, D. L., Doherty, R. M., Wild, O., Huntrieser, H., Pumphrey, H. C., and Blyth, A. M.: Using cloud ice flux to parametrise large-scale lightning, Atmos. Chem. Phys., 14, 12665-12682, doi:10.5194/acp-14-12665-2014, 2014.

Fiore, A. M., Jacob, D. J., Bey, I., Yantosca, R. M., Field, B. D., Fusco, A. C., and Wilkinson, J. G.: Background ozone over the United States in summer: Origin, trend, and contribution to pollution episodes, J. Geophys. Res.-Atmos., 107, 4275, doi:10.1029/2001jd000982, 2002.

Fiore, A. M., West, J. J., Horowitz, L. W., Naik, V., and Schwarzkopf, M. D.: Characterizing the tropospheric ozone response to methane emission controls and the benefits to climate and air quality, J. Geophys. Res.-Atmos., 113, D08307, doi:10.1029/2007jd009162, 2008.

Fiore, A. M., Dentener, F. J., Wild, O., Cuvelier, C., Schultz, M. G., Hess, P., Textor, C., Schulz, M., Doherty, R. M., Horowitz, L. W., MacKenzie, I. A., Sanderson, M. G., Shindell, D. T., Stevenson, D. S., Szopa, S., Van Dingenen, R., Zeng, G., Atherton, C., Bergmann, D., Bey, I., Carmichael, G., Collins, W. J., Duncan, B. N., Faluvegi, G., Folberth, G., Gauss, M., Gong, S., Hauglustaine, D., Holloway, T., Isaksen, I. S. A., Jacob, D. J., Jonson, J. E., Kaminski, J. W., Keating, T. J., Lupu, A., Marmer, E., Montanaro, V., Park, R. J., Pitari, G., Pringle, K. J., Pyle, J. A., Schroeder, S., Vivanco, M. G., Wind, P., Wojcik, G., Wu, S., and Zuber, A.: Multimodel estimates of intercontinental source-receptor relationships for ozone pollution, J. Geophys. Res.-Atmos., 114, D04301, doi:10.1029/2008jd010816, 2009.

Fiore, A. M., Levy II, H., and Jaffe, D. A.: North American isoprene influence on intercontinental ozone pollution, Atmos. Chem. Phys., 11, 1697-1710, doi:10.5194/acp-11-1697-2011, 2011.

Fiore, A. M., Naik, V., Spracklen, D. V., Steiner, A., Unger, N., Prather, M., Bergmann, D., Cameron-Smith, P. J., Cionni, I., Collins, W. J., Dalsoren, S., Eyring, V., Folberth, G. A., Ginoux, P., Horowitz, L. W., Josse, B., Lamarque, J.-F., MacKenzie, I. A., Nagashima, T., O'Connor, F. M., Righi, M., Rumbold, S. T., Shindell, D. T., Skeie, R. B., Sudo, K., Szopa, S., Takemura, T., and Zeng, G.: Global air quality and climate, Chem. Soc. Rev., 41, 6663-6683, 2012a. 
Fiore, A. M., Naik, V., Spracklen, D. V., Steiner, A., Unger, N., Prather, M., Bergmann, D., Cameron-Smith, P. J., Cionni, I., Collins, W. J., Dalsoren, S., Eyring, V., Folberth, G. A., Ginoux, P., Horowitz, L. W., Josse, B., Lamarque, J. F., MacKenzie, I. A., Nagashima, T., O’Connor, F. M., Righi, M., Rumbold, S. T., Shindell, D. T., Skeie, R. B., Sudo, K., Szopa, S., Takemura, T., and Zeng, G.: Global air quality and climate, Chem. Soc. Rev., 41, 6663-6683, doi:10.1039/c2cs35095e, 2012b.

Fiore, A. M., Oberman, J. T., Lin, M. Y., Zhang, L., Clifton, O. E., Jacob, D. J., Naik, V., Horowitz, L. W., Pinto, J. P., and Milly, G. P.: Estimating North American background ozone in U.S. surface air with two independent global models: Variability, uncertainties, and recommendations, Atmos. Environ., 96, 284-300, doi:10.1016/j.atmosenv.2014.07.045, 2014.

Fiscus, E. L., Fitzgarrald, L. B., and Burkey, K. O.: Crop responses to ozone: uptake, modes of action, carbon assimilation and partitioning, Plant, Cell Environ., 28, 997-1011, 2005.

Fishman, J., Watson, C. E., Larsen, J. C., and Logan, J. A.: Distribution of Tropospheric Ozone Determined from Satellite Data, J. Geophys. Res.-Atmos., 95, 3599-3617, 1990.

Fishman, J., Belina, K. M., and Encarnación, C. H.: The St. Louis Ozone Gardens: Visualizing the Impact of a Changing Atmosphere, Bull. Am. Meteorol. Soc., 95, 1171-1176, doi:10.1175/bams-d-13-00009.1, 2014.

Foret, G., Eremenko, M., Cuesta, J., Sellitto, P., Barré, J., Gaubert, B., Coman, A., Dufour, G., Liu, X., Joly, M., Doche, C., and Beekmann, M.: Ozone pollution: What can we see from space? A case study, J. Geophys. Res.-Atmos., 119, 2013JD021340, doi:10.1002/2013jd021340, 2014.

Fortems-Cheiney, A., Chevallier, F., Pison, I., Bousquet, P., Szopa, S., Deeter, M. N., and Clerbaux, C.: Ten years of CO emissions as seen from Measurements of Pollution in the Troposphere (MOPITT), J. Geophys. Res.-Atmos., 116, D05304, doi:10.1029/2010jd014416, 2011.

Fowler, D., Flechard, C., Cape, J. N., Storeton-West, R. L., and Coyle, M.: Measurements of ozone deposition to vegetation quantifying the flux, the stomatal and nonstomatal components, Water Air Soil Pollut., 130, 63-74, doi:10.1023/a:1012243317471, 2001.

Fowler, D., Pilegaard, K., Sutton, M. A., Ambus, P., Raivonen, M., Duyzer, J., Simpson, D., Fagerli, H., Fuzzi, S., Schjoerring, J. K., Granier, C., Neftel, A., Isaksen, I. S. A., Laj, P., Maione, M., Monks, P. S., Burkhardt, J., Daemmgen, U., Neirynck, J., Personne, E., Wichink-Kruit, R., Butterbach-Bahl, K., Flechard, C., Tuovinen, J. P., Coyle, M., Gerosa, G., Loubet, B., Altimir, N., Gruenhage, L., Ammann, C., Cieslik, S., Paoletti, E., Mikkelsen, T. N., Ro-Poulsen, H., Cellier, P., Cape, J. N., Horvath, L., Loreto, F., Niinemets, U., Palmer, P. I., Rinne, J., Misztal, P., Nemitz, E., Nilsson, D., Pryor, S., Gallagher, M. W., Vesala, T., Skiba, U., Brueggemann, N., Zechmeister-Boltenstern, S., Williams, J., O'Dowd, C., Facchini, M. C., de Leeuw, G., Flossman, A., Chaumerliac, N., and Erisman, J. W.: Atmospheric composition change: Ecosystems-Atmosphere interactions, Atmos. Environ., 43, 5193-5267, doi:10.1016/j.atmosenv.2009.07.068, 2009.

Fowler, D., Brunkreef, B., Fuzzi, S., Monks, P. S., Sutton, M. A., Brasseur, G. P., Friedrich, R., Passante, L. G., and JimenezMingo, J. M.: Research Findings in support of the EU Air Quality
Review, Publications office of the European Union, Luxembourg, 2013a.

Fowler, D., Coyle, M., Skiba, U., Sutton, M. A., Cape, J. N., Reis, S., Sheppard, L. J., Jenkins, A., Grizzetti, B., Galloway, J. N., Vitousek, P., Leach, A., Bouwman, A. F., Butterbach-Bahl, K., Dentener, F., Stevenson, D., Amann, M., and Voss, M.: The global nitrogen cycle in the twenty-first century, Philos. Trans. R Soc. B-Biol. Sci., 368, 20130164, doi:10.1098/rstb.2013.0164, 2013b.

Fowler, D., Steadman, C. E., Stevenson, D., Coyle, M., Rees, R. M., Skiba, U. M., Sutton, M. A., Cape, J. N., Dore, A. J., Vieno, M., Simpson, D., Zaehle, S., Stocker, B. D., Rinaldi, M., Facchini, M. C., Flechard, C. R., Nemitz, E., Twigg, M., Erisman, J. W., and Galloway, J. N.: Effects of global change during the 21st century on the nitrogen cycle, Atmos. Chem. Phys. Discuss., 15, 1747-1868, doi:10.5194/acpd-15-1747-2015, 2015.

Francis, X. V., Chemel, C., Sokhi, R. S., Norton, E. G., Ricketts, H. M. A., and Fisher, B. E. A.: Mechanisms responsible for the build-up of ozone over South East England during the August 2003 heatwave, Atmos. Environ., 45, 6880-6890, doi:10.1016/j.atmosenv.2011.04.035, 2011.

Freitas, S. R., Longo, K. M., Chatfield, R., Latham, D., Silva Dias, M. A. F., Andreae, M. O., Prins, E., Santos, J. C., Gielow, R., and Carvalho Jr., J. A.: Including the sub-grid scale plume rise of vegetation fires in low resolution atmospheric transport models, Atmos. Chem. Phys., 7, 3385-3398, doi:10.5194/acp-7-3385-2007, 2007.

Fromm, M., Lindsey, D. T., Servranckx, R., Yue, G., Trickl, T., Sica, R., Doucet, P., and Godin-Beekmann, S. E.: The untold story of pyrocumulonimbus, Bull. Am. Meteorol. Soc., 91, 1193-1209, doi:10.1175/2010bams3004.1, 2010.

Frost, G. J., Ellison, G. B., and Vaida, V.: Organic peroxyl radical photolysis in the near-infrared: Effects on tropospheric chemistry, J. Phys. Chem. A, 103, 10169-10178, 1999.

Frost, G. J., Falke, S. R., Granier, C., Keating, T., Lamarque, J. F., Melamed, M. L., Middleton, P., Petron, G., and Smith, S. J.: New Directions: Toward a community emissions approach, Atmos. Environ., 51, 333-334, doi:10.1016/j.atmosenv.2012.01.055, 2012.

Fry, M. M., Naik, V., West, J. J., Schwarzkopf, M. D., Fiore, A. M., Collins, W. J., Dentener, F. J., Shindell, D. T., Atherton, C., Bergmann, D., Duncan, B. N., Hess, P., MacKenzie, I. A., Marmer, E., Schultz, M. G., Szopa, S., Wild, O., and Zeng, G.: The influence of ozone precursor emissions from four world regions on tropospheric composition and radiative climate forcing, J. Geophys. Res.-Atmos., 117, D07306, doi:10.1029/2011jd017134, 2012.

Fuentes, J. D., Gillespie, T. J., Denhartog, G., and Neumann, H. H.: Ozone Deposition onto a Deciduous Forest During Dry and Wet Conditions, Agr. Forest Meteorol., 62, 1-18, 1992.

Fuglestvedt, J. S., Shine, K. P., Berntsen, T., Cook, J., Lee, D. S., Stenke, A., Skeie, R. B., Velders, G. J. M., and Waitz, I. A.: Transport impacts on atmosphere and climate: Metrics, Atmos. Environ., 44, 4648-4677, doi:10.1016/j.atmosenv.2009.04.044, 2010.

Fuhrer, J.: Ozone risk for crops and pastures in present and future climates, Naturwissenschaften, 96, 173-194, doi:10.1007/s00114-008-0468-7, 2009. 
Fuzzi, S., Baltensperger, U., Carslaw, K., Decesari, S., Denier van der Gon, H., Facchini, M. C., Fowler, D., Koren, I., Langford, B., Lohmann, U., Nemitz, E., Pandis, S., Riipinen, I., Rudich, Y., Schaap, M., Slowik, J., Spracklen, D. V., Vignati, E., Wild, M., Williams, M., and Gilardoni, S.: Particulate matter, air quality and climate: lessons learned and future needs, Atmos. Chem. Phys. Discuss., 15, 521-744, doi:10.5194/acpd-15-5212015, 2015.

Gallagher, M. W., Beswick, K. M., and Coe, H.: Ozone deposition to coastal waters, Q. J. Roy. Meteorol. Soc., 127, 539-558, 2001.

Galloway, J. N., Aber, J. D., Erisman, J. W., Seitzinger, S. P., Howarth, R. W., Cowling, E. B., and Cosby, B. J.: The nitrogen cascade, Bioscience, 53, 341-356, doi:10.1641/00063568(2003)053[0341:tnc]2.0.co;2, 2003.

Galloway, J. N., Dentener, F. J., Capone, D. G., Boyer, E. W., Howarth, R. W., Seitzinger, S. P., Asner, G. P., Cleveland, C. C., Green, P. A., Holland, E. A., Karl, D. M., Michaels, A. F., Porter, J. H., Townsend, A. R., and Vorosmarty, C. J.: Nitrogen cycles: past, present, and future, Biogeochemistry, 70, 153-226, doi:10.1007/s10533-004-0370-0, 2004.

Ganzeveld, L., Helmig, D., Fairall, C. W., Hare, J., and Pozzer, A.: Atmosphere-ocean ozone exchange: A global modeling study of biogeochemical, atmospheric, and waterside turbulence dependencies, Global Biogeochem. Cy., 23, GB4021, doi:10.1029/2008gb003301, 2009.

Garg, A., Shukla, P. R., and Kapshe, M.: The sectoral trends of multigas emissions inventory of India, Atmos. Environ., 40, 4608-4620, doi:10.1016/j.atmosenv.2006.03.045, 2006.

Garny, H., Grewe, V., Dameris, M., Bodeker, G. E., and Stenke, A.: Attribution of ozone changes to dynamical and chemical processes in CCMs and CTMs, Geosci. Model Dev., 4, 271-286, doi:10.5194/gmd-4-271-2011, 2011.

Gaubert, B., Coman, A., Foret, G., Meleux, F., Ung, A., Rouil, L., Ionescu, A., Candau, Y., and Beekmann, M.: Regional scale ozone data assimilation using an ensemble Kalman filter and the CHIMERE chemical transport model, Geosci. Model Dev., 7, 283-302, doi:10.5194/gmd-7-283-2014, 2014.

Gauss, M., Myhre, G., Isaksen, I. S. A., Grewe, V., Pitari, G., Wild, O., Collins, W. J., Dentener, F. J., Ellingsen, K., Gohar, L. K., Hauglustaine, D. A., Iachetti, D., Lamarque, F., Mancini, E., Mickley, L. J., Prather, M. J., Pyle, J. A., Sanderson, M. G., Shine, K. P., Stevenson, D. S., Sudo, K., Szopa, S., and Zeng, G.: Radiative forcing since preindustrial times due to ozone change in the troposphere and the lower stratosphere, Atmos. Chem. Phys., 6, 575-599, doi:10.5194/acp-6-575-2006, 2006.

Gerosa, G., Vitale, M., Finco, A., Manes, F., Denti, A. B., and Cieslik, S.: Ozone uptake by an evergreen Mediterranean Forest (Quercus ilex) in Italy. Part I: Micrometeorological flux measurements and flux partitioning, Atmos. Environ., 39, 3255-3266, 2005.

Gerosa, G., Finco, A., Mereu, S., Vitale, M., Manes, F., and Denti, A. B.: Comparison of seasonal variations of ozone exposure and fluxes in a Mediterranean Holm oak forest between the exceptionally dry 2003 and the following year, Environ. Pollut., 157, 1737-1744, doi:10.1016/j.envpol.2007.11.025, 2009.

Ghude, S. D., Jain, S. L., Arya, B. C., Beig, G., Ahammed, Y. N., Kumar, A., and Tyagi, B.: Ozone in ambient air at a tropical megacity, Delhi: characteristics, trends and cumula- tive ozone exposure indices, J. Atmos. Chem., 60, 237-252, doi:10.1007/s10874-009-9119-4, 2008.

Ghude, S. D., Jena, C., Chate, D. M., Beig, G., Pfister, G. G., Kumar, R., and Ramanathan, V.: Reductions in India's crop yield due to ozone, Geophys. Res. Lett., 41, GL060930, doi:10.1002/2014g1060930, 2014.

Giglio, L. and Kendall, J. D.: Commentary on "Improving the seasonal cycle and interannual variations of biomass burning aerosol sources" by Generoso et al., Atmos. Chem. Phys., 4, 585-587, doi:10.5194/acp-4-585-2004, 2004.

Gilman, J. B., Lerner, B. M., Kuster, W. C., and de Gouw, J. A.: Source Signature of Volatile Organic Compounds from Oil and Natural Gas Operations in Northeastern Colorado, Environ. Sci. Technol., 47, 1297-1305, doi:10.1021/es304119a, 2013.

Glotfelty, T., Zhang, Y., Karamchandani, P., and Streets, D. G.: Will the role of intercontinental transport change in a changing climate?, Atmos. Chem. Phys., 14, 9379-9402, doi:10.5194/acp14-9379-2014, 2014.

Goldstein, A. H. and Galbally, I. E.: Known and Unexplored Organic Constituents in the Earth's Atmosphere, Environ. Sci Technol., 1, 1515-1521, 2007.

Granat, L. and Richter, A.: Dry Deposition to Pine of SulfurDioxide and Ozone at Low Concentration, Atmos. Environ., 29, 1677-1683, 1995.

Granier, C., Artaxo, P., and Reeves, C. E.: Emissions of Atmospheric Trace compounds, Kluwer, 545 pp., 2004.

Granier, C., Lamarque, J. F., Mieville, A., Muller, J. F., Olivier, J., Orlando, J., Peters, J., Petron, G., Tyndall, G., and Wallens, S.: POET, a database of surface emissions of ozone precursors, edited by: IPSL, available at: http://www.aero.jussieu.fr/projet/ ACCENT/POET.php (last access: 11 August 2015), 2005.

Granier, C., Niemeier, U., Jungclaus, J. H., Emmons, L., Hess, P., Lamarque, J. F., Walters, S., and Brasseur, G. P.: Ozone pollution from future ship traffic in the Arctic northern passages, Geophys. Res. Lett., 33, L13807, doi:10.1029/2006g1026180, 2006.

Granier, C., Bessagnet, B., Bond, T., D’Angiola, A., van der Gon, H. D., Frost, G. J., Heil, A., Kaiser, J. W., Kinne, S., Klimont, Z., Kloster, S., Lamarque, J. F., Liousse, C., Masui, T., Meleux, F., Mieville, A., Ohara, T., Raut, J. C., Riahi, K., Schultz, M G., Smith, S. J., Thompson, A., van Aardenne, J., van der Werf, G. R., and van Vuuren, D. P.: Evolution of anthropogenic and biomass burning emissions of air pollutants at global and regional scales during the 1980-2010 period, Climatic Change, 109, 163-190, doi:10.1007/s10584-011-0154-1, 2011.

Grannas, A. M., Jones, A. E., Dibb, J., Ammann, M., Anastasio, C., Beine, H. J., Bergin, M., Bottenheim, J., Boxe, C. S., Carver, G., Chen, G., Crawford, J. H., Dominé, F., Frey, M. M., Guzmán, M. I., Heard, D. E., Helmig, D., Hoffmann, M. R., Honrath, R. E., Huey, L. G., Hutterli, M., Jacobi, H. W., Klán, P., Lefer, B., McConnell, J., Plane, J., Sander, R., Savarino, J., Shepson, P. B., Simpson, W. R., Sodeau, J. R., von Glasow, R., Weller, R., Wolff, E. W., and Zhu, T.: An overview of snow photochemistry: evidence, mechanisms and impacts, Atmos. Chem. Phys., 7, 43294373, doi:10.5194/acp-7-4329-2007, 2007.

Grantz, D. A., Zhang, X. J., Massman, W. J., Denhartog, G., Neumann, H. H., and Pederson, J. R.: Effects of stomatal conductance and surface wetness on ozone deposition in field-grown grape, Atmos. Environ., 29, 3189-3198, 1995. 
Grantz, D. A., Zhang, X. J., Massman, W. J., Delany, A., and Pederson, J. R.: Ozone deposition to a cotton (Gossypium hirsutum L) field: stomatal and surface wetness effects during the California Ozone Deposition Experiment, Agr. Forest Meteorol., 85, 19-31, doi:10.1016/s0168-1923(96)02396-9, 1997.

Grewe, V.: Impact of lightning on air chemistry and climate, in: Lightning principles, Instruments and applications: Review of modern lightning research edited by: Betz, H. D., Schumann, U., and Laroche, P., Springer-Verlag Berlin Germany, 690 pp., 2008.

Grewe, V., Dahlmann, K., Matthes, S., and Steinbrecht, W.: Attributing ozone to $\mathrm{NO}_{x}$ emissions: Implications for climate mitigation measures, Atmos. Environ., 59, 102-107, doi:10.1016/j.atmosenv.2012.05.002, 2012a.

Grewe, V., Dahlmann, K., Matthes, S., and Steinbrecht, W.: Attributing ozone to $\mathrm{NO}_{x}$ emissions: Implications for climate mitigation measures, Atmos. Environ., 59, 102-107, doi:10.1016/j.atmosenv.2012.05.002, 2012b.

Grontoft, T.: Measurements and modelling of the ozone deposition velocity to concrete tiles, including the effect of diffusion, Atmos. Environ., 38, 49-58, 2004.

Großmann, K., Frieß, U., Peters, E., Wittrock, F., Lampel, J., Yilmaz, S., Tschritter, J., Sommariva, R., von Glasow, R., Quack, B., Krüger, K., Pfeilsticker, K., and Platt, U.: Iodine monoxide in the Western Pacific marine boundary layer, Atmos. Chem. Phys., 13, 3363-3378, doi:10.5194/acp-13-3363-2013, 2013.

Grünhage, L., Pleijel, H., Mills, G., Bender, J., Danielsson, H., Lehmann, Y., Castell, J. F., and Bethenod, O.: Updated stomatal flux and flux-effect models for wheat for quantifying effects of ozone on grain yield, grain mass and protein yield, Environ. Pollut., 165, 147-157, doi:10.1016/j.envpol.2012.02.026, 2012.

Gryparis, A., Forsberg, B., Katsouyanni, K., Analitis, A., Touloumi, G., Schwartz, J., Samoli, E., Medina, S., Anderson, H. R., Niciu, E. M., Wichmann, H.-E., Kriz, B., Kosnik, M., Skorkovsky, J., Vonk, J. M., and Dortbudak, Z.: Acute effects of ozone on mortality from the "Air Pollution and Health: A European Approach" Project, Am. J. Respir. Crit. Care Med., 170, 1080-1087, 2004.

Guenther, A., Hewitt, C., Erickson, D., Fall, R., Geron, C., Graedel, T., Harley, P., Klinger, L., Lerdau, M., McKay, W., Pierce, T., Scholes, R., Steinbrecher, R., Tallamraju, R., Taylor, J., and Zimmerman, P.: A global model of natural volatile organic compound emissions, J. Geophys. Res., 100, 8873-8892, 1995.

Guenther, A., Karl, T., Harley, P., Wiedinmyer, C., Palmer, P. I., and Geron, C.: Estimates of global terrestrial isoprene emissions using MEGAN (Model of Emissions of Gases and Aerosols from Nature), Atmos. Chem. Phys., 6, 3181-3210, doi:10.5194/acp-63181-2006, 2006.

Guenther, A. B., Zimmerman, P. R., Harley, P. C., Monson, R. K., and Fall, R.: Isoprene and monoterpene emission rate variability - model evaluations and sensitivity analyses, J. Geophys. Res.Atmos., 98, 12609-12617, doi:10.1029/93jd00527, 1993.

Guenther, A. B., Zimmerman, P. R., Harley, P. C., Monson, R. K., and Fall, R.: Isoprene and monoterpene emission ratevariabilitymodel evaluations and sensitivity analyses, J. Geophys. Res., 98, 12609-12617, 2003.

Guenther, A. B., Jiang, X., Heald, C. L., Sakulyanontvittaya, T., Duhl, T., Emmons, L. K., and Wang, X.: The Model of Emissions of Gases and Aerosols from Nature version 2.1 (MEGAN2.1): an extended and updated framework for modeling biogenic emis- sions, Geosci. Model Dev., 5, 1471-1492, doi:10.5194/gmd-51471-2012, 2012.

Guerreiro, C. B. B., Foltescu, V., and de Leeuw, F.: Air quality status and trends in Europe, Atmos. Environ., 98, 376-384, doi:10.1016/j.atmosenv.2014.09.017, 2014.

Guttikunda, S. K., Tang, Y., Carmichael, G. R., Kurata, G., Pan, L., Streets, D. G., Woo, J. H., Thongboonchoo, N., and Fried, A.: Impacts of Asian megacity emissions on regional air quality during spring 2001, J. Geophys. Res., 110, D20301, doi:10.1029/2004JD004921, 2005.

Haagen-Smit, A. J.: Chemistry and Physiology of Los Angeles Smog, Indust. Eng. Chem., 44, 1342-1346, doi:10.1021/ie50510a045, 1952.

Hand, E.: China blamed for U.S. ozone, Science, 345, 1233-1233, 2014.

Hansen, J., Sato, M., Ruedy, R., Nazarenko, L., Lacis, A., Schmidt, G. A., Russell, G., Aleinov, I., Bauer, M., Bauer, S., Bell, N., Cairns, B., Canuto, V., Chandler, M., Cheng, Y., Del Genio, A., Faluvegi, G., Fleming, E., Friend, A., Hall, T., Jackman, C., Kelley, M., Kiang, N., Koch, D., Lean, J., Lerner, J., Lo, K., Menon, S., Miller, R., Minnis, P., Novakov, T., Oinas, V., Perlwitz, J., Perlwitz, J., Rind, D., Romanou, A., Shindell, D., Stone, P., Sun, S., Tausnev, N., Thresher, D., Wielicki, B., Wong, T., Yao, M., and Zhang, S.: Efficacy of climate forcings, J. Geophys. Res.Atmos., 110, D18104, doi:10.1029/2005jd005776, 2005.

Hao, W. M. and Liu, M. H.: Spatial and temporal distribution of tropical biomass burning, Global Biogeochem. Cy., 8, 495-504, 1994.

Hardacre, C., Wild, O., and Emberson, L.: An evaluation of ozone dry deposition in global scale chemistry climate models, Atmos. Chem. Phys., 15, 6419-6436, doi:10.5194/acp-15-64192015, 2015.

Hardacre, C. J., Palmer, P. I., Baumanns, K., Rounsevell, M., and Murray-Rust, D.: Probabilistic estimation of future emissions of isoprene and surface oxidant chemistry associated with land-use change in response to growing food needs, Atmos. Chem. Phys., 13, 5451-5472, doi:10.5194/acp-13-5451-2013, 2013.

Hartley, W. N.: On the absorption spectrum of ozone, J. Chem. Soc., Trans., 1881, 57-60, doi:10.1039/CT8813900057, 1881.

Hauglustaine, D. A. and Brasseur, G. P.: Evolution of tropospheric ozone under anthropogenic activities and associated radiative forcing of climate, J. Geophys. Res.-Atmos., 106, 32337-32360, doi:10.1029/2001jd900175, 2001.

Hauglustaine, D. A. and Koffi, B.: Boundary layer ozone pollution caused by future aircraft emissions, Geophys. Res. Lett., 39, L13808, doi:10.1029/2012g1052008, 2012.

Hayes, F., Jones, M. L. M., Mills, G., and Ashmore, M.: Meta-analysis of the relative sensitivity of semi-natural vegetation species to ozone, Environ. Pollut., 146, 754-762, doi:10.1016/j.envpol.2006.06.011, 2007.

Heal, M. R., Heaviside, C., Doherty, R. M., Vieno, M., Stevenson, D. S., and Vardoulakis, S.: Health burdens of surface ozone in the UK for a range of future scenarios, Environ. Int., 61, 36-44, doi:10.1016/j.envint.2013.09.010, 2013.

Heard, D. E. and Pilling, M. J.: Measurement of $\mathrm{OH}$ and $\mathrm{HO}_{2}$ in the Troposphere, Chem. Rev., 103, 5163-5198, 2003.

Hedegaard, G. B., Brandt, J., Christensen, J. H., Frohn, L. M., Geels, C., Hansen, K. M., and Stendel, M.: Impacts of climate change on air pollution levels in the Northern Hemisphere with 
special focus on Europe and the Arctic, Atmos. Chem. Phys., 8, 3337-3367, doi:10.5194/acp-8-3337-2008, 2008.

Hedegaard, G. B., Christensen, J. H., and Brandt, J.: The relative importance of impacts from climate change vs. emissions change on air pollution levels in the 21st century, Atmos. Chem. Phys., 13, 3569-3585, doi:10.5194/acp-13-3569-2013, 2013.

Hegglin, M. I. and Shepherd, T. G.: Large climate-induced changes in ultraviolet index and stratosphere-to-troposphere ozone flux, Nat. Geosci., 2, 687-691, 2009.

Held, I. M. and Soden, B. J.: Robust responses of the hydrological cycle to global warming, J. Climate, 19, 5686-5699, doi:10.1175/jcli3990.1, 2006.

Helmig, D., Oltmans, S., Carlson, D., Lamarque, J.-F., Jones, A. E., Labuschagne, C., Anlauf, K., and Hayden, K.: A review of surface ozone in the polar regions, Atmos. Environ., 41, 51385161, doi:10.1016/j.atmosenv.2006.09.053, 2007.

Helmig, D., Johnson, B., Oltmans, S. J., Neff, W., Eisele, F., and Davis, D. D.: Elevated ozone in the boundarylayer at South Pole, Atmos. Environ., 42, 2788-2803, doi:10.1016/j.atmosenv.2006.12.032, 2008a.

Helmig, D., Johnson, B. J., Warshawsky, M., Morse, T., Neff, W. D., Eisele, F., and Davis, D. D.: Nitric oxide in the boundarylayer at South Pole during the Antarctic Tropospheric Chemistry Investigation (ANTCI), Atmos. Environ., 42, 2817-2830, $2008 \mathrm{~b}$.

Hess, P., Kinnison, D., and Tang, Q.: Ensemble simulations of the role of the stratosphere in the attribution of northern extratropical tropospheric ozone variability, Atmos. Chem. Phys., 15, 23412365, doi:10.5194/acp-15-2341-2015, 2015.

Hess, P. G. and Zbinden, R.: Stratospheric impact on tropospheric ozone variability and trends: 1990-2009, Atmos. Chem. Phys., 13, 649-674, doi:10.5194/acp-13-649-2013, 2013.

Hewitt, C. N., MacKenzie, A. R., Di Carlo, P., Di Marco, C. F., Dorsey, J. R., Evans, M., Fowler, D., Gallagher, M. W., Hopkins, J. R., Jones, C. E., Langford, B., Lee, J. D., Lewis, A. C., Lim, S. F., McQuaid, J., Misztal, P., Moller, S. J., Monks, P. S., Nemitz, E., Oram, D. E., Owen, S. M., Phillips, G. J., Pugh, T. A. M., Pyle, J. A., Reeves, C. E., Ryder, J., Siong, J., Skiba, U., and Stewart, D. J.: Nitrogen management is essential to prevent tropical oil palm plantations from causing groundlevel ozone pollution, Proc. Natl. Acad. Sci. USA, 106, 1844718451, doi:10.1073/pnas.0907541106, 2009.

Hewitt, C. N., Ashworth, K., Boynard, A., Guenther, A., Langford, B., MacKenzie, A. R., Misztal, P. K., Nemitz, E., Owen, S. M., Possell, M., Pugh, T. A. M., Ryan, A. C., and Wild, O.: Groundlevel ozone influenced by circadian control of isoprene emissions, Nat. Geosci., 4, 671-674, doi:10.1038/ngeo1271, 2011.

Hirdman, D., Burkhart, J. F., Sodemann, H., Eckhardt, S., Jefferson, A., Quinn, P. K., Sharma, S., Ström, J., and Stohl, A.: Longterm trends of black carbon and sulphate aerosol in the Arctic: changes in atmospheric transport and source region emissions, Atmos. Chem. Phys., 10, 9351-9368, doi:10.5194/acp-10-93512010, 2010.

Hodnebrog, O., Stordal, F., and Berntsen, T. K.: Does the resolution of megacity emissions impact large scale ozone?, Atmos. Environ., 45, 6852-6862, doi:10.1016/j.atmosenv.2011.01.012, 2011.

Hogg, A., Uddling, J., Ellsworth, D., Carroll, M. A., Pressley, S., Lamb, B., and Vogel, C.: Stomatal and non-stomatal fluxes of ozone to a northern mixed hardwood forest, Tellus Ser. B, 59, 514-525, doi:10.1111/j.1600-0889.2007.00269.x, 2007.
Hooghiemstra, P. B., Krol, M. C., Bergamaschi, P., de Laat, A. T. J., van der Werf, G. R., Novelli, P. C., Deeter, M. N., Aben, I., and Rockmann, T.: Comparing optimized CO emission estimates using MOPITT or NOAA surface network observations, J. Geophys. Res.-Atmos., 117, D06309, doi:10.1029/2011jd017043, 2012.

Horowitz, L. W., Fiore, A. M., Milly, G. P., Cohen, R. C., Perring, A., Wooldridge, P. J., Hess, P. G., Emmons, L. K., and Lamarque, J. F.: Observational constraints on the chemistry of isoprene nitrates over the eastern United States, J. Geophys. Res.-Atmos., 112, D12S08, doi:10.1029/2006jd007747, 2007.

Hov, O., Schmidbauer, N., and Oehme, M.: Light-hydrocarbons in the Norwegian Arctic, Atmos. Environ., 23, 2471-2482, doi:10.1016/0004-6981(89)90258-8, 1989.

Hsu, J. and Prather, M. J.: Stratospheric variability and tropospheric ozone, J. Geophys. Res.-Atmos., 114, D06102, doi:10.1029/2008jd010942, 2009.

Hsu, A., Reuben, A., Shindell, D., de Sherbinin, A., and Levy, M.: Toward the next generation of air quality monitoring indicators, Atmos. Environ., 80, 561-570, doi:10.1016/j.atmosenv.2013.07.036, 2013.

HTAP: Hemispheric Transport of Air Pollution, UNECE, Geneva 2010.

Huang, K., Fu, J. S., Hsu, N. C., Gao, Y., Dong, X. Y., Tsay, S. C., and Lam, Y. F.: Impact assessment of biomass burning on air quality in Southeast and East Asia during BASE-ASIA, Atmos. Environ., 78, 291-302, doi:10.1016/j.atmosenv.2012.03.048, 2013.

Hudman, R. C., Jacob, D. J., Cooper, O. R., Evans, M. J., Heald, C. L., Park, R. J., Fehsenfeld, F. C., Flocke, F., Holloway, J., Hübler, G., Kita, K., Koike, M., Kondo, Y., Neuman, A., Nowak, J., Oltmans, S., Parrish, D., Roberts, J. M., and Ryerson, T. B.: Ozone production in transpacific Asian pollution plumes and implications for ozone air quality in California, J. Geophys. Res., 109, D23S10, doi:10.1029/2004JD004974, 2004.

Hudman, R. C., Murray, L. T., Jacob, D. J., Turquety, S., Wu, S., Millet, D. B., Avery, M., Goldstein, A. H., and Holloway, J.: North American influence on tropospheric ozone and the effects of recent emission reductions: Constraints from ICARTT observations, J. Geophys. Res.-Atmos., 114, D07302, doi:10.1029/2008jd010126, 2009.

Hughes, K., Lightfoot, P., and Pilling, M.: Direct measurements of the peroxy-hydroperoxy radical isomerisation, a key step in hydrocarbon combustion, Chem. Phys. Lett., 191, 581-586, 1992.

Huo, H., Yao, Z. L., Zhang, Y. Z., Shen, X. B., Zhang, Q., Ding, Y., and He, K. B.: On-board measurements of emissions from lightduty gasoline vehicles in three mega-cities of China, Atmos. Environ., 49, 371-377, doi:10.1016/j.atmosenv.2011.11.005, 2012.

Im, U. and Kanakidou, M.: Impacts of East Mediterranean megacity emissions on air quality, Atmos. Chem. Phys., 12, 6335-6355, doi:10.5194/acp-12-6335-2012, 2012.

Inness, A., Baier, F., Benedetti, A., Bouarar, I., Chabrillat, S., Clark, H., Clerbaux, C., Coheur, P., Engelen, R. J., Errera, Q., Flemming, J., George, M., Granier, C., Hadji-Lazaro, J., Huijnen, V., Hurtmans, D., Jones, L., Kaiser, J. W., Kapsomenakis, J., Lefever, K., Leitão, J., Razinger, M., Richter, A., Schultz, M. G., Simmons, A. J., Suttie, M., Stein, O., Thépaut, J.-N., Thouret, V., Vrekoussis, M., Zerefos, C., and the MACC team: The MACC reanalysis: an 8 yr data set of atmospheric composition, Atmos. 
Chem. Phys., 13, 4073-4109, doi:10.5194/acp-13-4073-2013, 2013.

IPCC: Climate Change 2007: The Physical Science Basis. Contribution of Working Group I to the Fourth Assessment Report of the Intergovernmental Panel on Climate Change. Chapter 1, Historical Overview of Climate change, in: Intergovernmental Panel on Climate Change Climate change: The Physical Science Basis, Contribution of Working Group I to the Fourth Assessment Report of the IPCC, Cambridge University Press, Cambridge, 79131, 2007.

IPCC: Climate Change 2013 - The Physical Science Basis, Cambridge University Press, Cambridge, 1552 pp., 2013.

Isaksen, I., Berntsen, T., Dalsøren, S., Eleftheratos, K., Orsolini, Y., Rognerud, B., Stordal, F., Søvde, O., Zerefos, C., and Holmes, C.: Atmospheric Ozone and Methane in a Changing Climate, Atmosphere, 5, 518-535, 2014.

Isaksen, I. S. A., Granier, C., Myhre, G., Berntsen, T. K., Dalsoren, S. B., Gauss, M., Klimont, Z., Benestad, R., Bousquet, P., Collins, W., Cox, T., Eyring, V., Fowler, D., Fuzzi, S., Jockel, P., Laj, P., Lohmann, U., Maione, M., Monks, P., Prevot, A. S. H., Raes, F., Richter, A., Rognerud, B., Schulz, M., Shindell, D., Stevenson, D. S., Storelvmo, T., Wang, W. C., van Weele, M., Wild, M., and Wuebbles, D.: Atmospheric composition change: Climate-Chemistry interactions, Atmos. Environ., 43, 5138-5192, doi:10.1016/j.atmosenv.2009.08.003, 2009.

Ito, A., Sillman, S., and Penner, J. E.: Global chemical transport model study of ozone response to changes in chemical kinetics and biogenic volatile organic compounds emissions due to increasing temperatures: Sensitivities to isoprene nitrate chemistry and grid resolution, J. Geophys. Res.-Atmos., 114, D09301, doi:10.1029/2008jd011254, 2009.

Jacob, D. J. and Winner, D. A.: Effect of climate change on air quality, Atmos. Environ., 43, 51-63, doi:10.1016/j.atmosenv.2008.09.051, 2009.

Jacob, D. J., Heikes, B. G., Fan, S. M., Logan, J. A., Mauzerall, D. L., Bradshaw, J. D., Singh, H. B., Gregory, G. L., Talbot, R. W., Blake, D. R., and Sachse, G. W.: Origin of ozone and $\mathrm{NO}_{x}$ in the tropical troposphere: A photochemical analysis of aircraft observations over the South Atlantic basin, J. Geophys. Res.-Atmos., 101, 24235-24250, doi:10.1029/96jd00336, 1996.

Jacob, D. J., Logan, J. A., and Murti, P. P.: Effect of rising Asian emissions on surface ozone in the United States, Geophys. Res. Lett., 26, 2175-2178, 1999.

Jacob, D. J., Crawford, J. H., Maring, H., Clarke, A. D., Dibb, J. E., Emmons, L. K., Ferrare, R. A., Hostetler, C. A., Russell, P. B., Singh, H. B., Thompson, A. M., Shaw, G. E., McCauley, E., Pederson, J. R., and Fisher, J. A.: The Arctic Research of the Composition of the Troposphere from Aircraft and Satellites (ARCTAS) mission: design, execution, and first results, Atmos. Chem. Phys., 10, 5191-5212, doi:10.5194/acp-10-5191-2010, 2010.

Jacobson, M. Z. and Streets, D. G.: Influence of future anthropogenic emissions on climate, natural emissions, and air quality, J. Geophys. Res.-Atmos., 114, D08118, doi:10.1029/2008jd011476, 2009.

Jaffe, D., Anderson, T., Covert, D., Kotchenruther, R., Trost, B., Danielson, J., Simpson, W., Berntsen, T., Karlsdottir, S., Blake, D., Harris, J., Carmichael, G., and Itsushi, U.: Transport of Asian air pollution to North America, Geophys. Res. Lett., 26, 711714,1999
Jaffe, D. A. and Wigder, N. L.: Ozone production from wildfires: A critical review, Atmos. Environ., 51, 1-10, doi:10.1016/j.atmosenv.2011.11.063, 2012.

Janssens-Maenhout, G., Petrescu, A., Muntean, M., and Blujdeau, V.: Verifying Greenhouse Gas Emissions: Methods to Support International Climate Agreements, Greenhouse gas measurement and management, JRC, Ispra, Italy, 132-133, 2011.

Janssens-Maenhout, G., Dentener, F., Van Aardenne, J., Monni, S., Pagliari, V., Orlandini, L., Klimont, Z., Kurokawa, J., Akimoto, H., Ohara, T., Wankmueller, R., Battye, B., Grano, D., Zuber, A., and Keating, T.: EDGAR-HTAP: a Harmonized Gridded Air Pollution Emission Dataset Based on National Inventories, European Commission Publications Office, Ispra, Italy, 2012.

Jenkin, M. E.: Trends in ozone concentration distributions in the UK since 1990: Local, regional and global influences, Atmos. Environ., 42, 5434-5445, doi:10.1016/j.atmosenv.2008.02.036, 2008.

Jenkin, M. E. and Clemitshaw, K. C.: Ozone and other secondary photochemical pollutants: chemical processes governing their formation in the planetary boundary layer, Atmos. Environ,, 34, 2499-2527, 2000.

Jerrett, M., Burnett, R. T., Pope, C. A., Ito, K., Thurston, G., Krewski, D., Shi, Y. L., Calle, E., and Thun, M.: Long-Term Ozone Exposure and Mortality, N. Engl. J. Med., 360, 10851095, doi:10.1056/NEJMoa0803894, 2009.

Jones, A. E., Anderson, P. S., Wolff, E. W., Roscoe, H. K., Marshall, G. J., Richter, A., Brough, N., and Colwell, S. R.: Vertical structure of Antarctic tropospheric ozone depletion events: characteristics and broader implications, Atmos. Chem. Phys., 10, 7775-7794, doi:10.5194/acp-10-7775-2010, 2010a.

Jones, C. E., Hornsby, K. E., Sommariva, R., Dunk, R. M., Von Glasow, R., McFiggans, G., and Carpenter, L. J.: Quantifying the contribution of marine organic gases to atmospheric iodine, Geophys. Res. Lett., 37, L18804, doi:10.1029/2010g1043990, 2010 b.

Jonquieres, I., Marenco, A., Maalej, A., and Rohrer, F.: Study of ozone formation and transatlantic transport from biomass burning emissions over West Africa during the airborne Tropospheric Ozone Campaigns TROPOZ I and TROPOZ II, J. Geophys. Res.Atmos., 103, 19059-19073, doi:10.1029/98jd00819, 1998.

Jonson, J. E., Simpson, D., Fagerli, H., and Solberg, S.: Can we explain the trends in European ozone levels?, Atmos. Chem. Phys., 6, 51-66, doi:10.5194/acp-6-51-2006, 2006.

Jonson, J. E., Tarrason, L., Klein, H., Vestreng, V., Cofala, J., and Whall, C.: Effects of ship emissions on European groundlevel ozone in 2020, Int. J. Remote Sens., 30, 4099-4110, doi:10.1080/01431160902821858, 2009.

Junge, C. E.: Global ozone budget and exchange between and stratosphere and troposphere, Tellus, 14, 363-377, 1962.

Kaiser, J. W., Heil, A., Andreae, M. O., Benedetti, A., Chubarova, N., Jones, L., Morcrette, J.-J., Razinger, M., Schultz, M. G., Suttie, M., and van der Werf, G. R.: Biomass burning emissions estimated with a global fire assimilation system based on observed fire radiative power, Biogeosciences, 9, 527-554, doi:10.5194/bg-9-527-2012, 2012.

Kaiser, J. W., Andela, N., Heil, A., Leeuwen, T. T. v., Werf, G. R. V. d., Wooster, M. J., Remy, S., and Schultz, M. G.: Assessment of the Global Fire Assimilation System (GFASv1), available at: http://gmes-atmosphere.eu (last access: 4 August 2015), 2013.

Kalabokas, P. D., Cammas, J.-P., Thouret, V., Volz-Thomas, A., Boulanger, D., and Repapis, C. C.: Examination of the atmo- 
spheric conditions associated with high and low summer ozone levels in the lower troposphere over the eastern Mediterranean, Atmos. Chem. Phys., 13, 10339-10352, doi:10.5194/acp-1310339-2013, 2013.

Kang, M., Kanno, C. M., Reid, M. C., Zhang, X., Mauzerall, D. L., Celia, M. A., Chen, Y., and Onstott, T. C.: Direct measurements of methane emissions from abandoned oil and gas wells in Pennsylvania, Proc. Natl. Aca. Sci., 111, 18173-18177, doi:10.1073/pnas.1408315111, 2014.

Kargbo, D. M., Wilhelm, R. G., and Campbell, D. J.: Natural Gas Plays in the Marcellus Shale: Challenges and Potential Opportunities, Environ. Sci. Technol., 44, 5679-5684, 2010.

Karion, A., Sweeney, C., Petron, G., Frost, G., Hardesty, R. M., Kofler, J., Miller, B. R., Newberger, T., Wolter, S., Banta, R., Brewer, A., Dlugokencky, E., Lang, P., Montzka, S. A., Schnell, R., Tans, P., Trainer, M., Zamora, R., and Conley, S.: Methane emissions estimate from airborne measurements over a western United States natural gas field, Geophys. Res. Lett., 40, 43934397, doi:10.1002/grl.50811, 2013.

Karlsson, P., Braun, S., Broadmeadow, M., Elvira, S., Emberson, L., Gimeno, B. S., Le Thiec, D., Novak, K., Oksanen, E., Schaub, M., Uddling, J., and Wilkinson, M.: Risk assessments for forest trees: The performance of the ozone flux versus the AOT concepts, Environ. Pollut., 146, 608-616, doi:10.1016/j.envpol.2006.06.012, 2007.

Karnosky, D. F., Skelly, J. M., Percy, K. E., and Chappelka, A. H.: Perspectives regarding 50 years of research on effects of tropospheric ozone air pollution on US forests, Environ. Pollut., 147, 489-506, doi:10.1016/j.envpol.2006.08.043, 2007.

Katragkou, E., Zanis, P., Kioutsioukis, I., Tegoulias, I., Melas, D., Krueger, B. C., and Coppola, E.: Future climate change impacts on summer surface ozone from regional climate-air quality simulations over Europe, J. Geophys. Res.-Atmos., 116, D22307, doi:10.1029/2011jd015899, 2011.

Katzenstein, A. S., Doezema, L. A., Simpson, I. J., Blake, D. R., and Rowland, F. S.: Extensive regional atmospheric hydrocarbon pollution in the southwestern United States, Proc. Natl. Aca. Sci., 100, 11975-11979, doi:10.1073/pnas.1635258100, 2003.

Kawase, H., Nagashima, T., Sudo, K., and Nozawa, T.: Future changes in tropospheric ozone under Representative Concentration Pathways (RCPs), Geophys. Res. Lett., 38, L05801, doi:10.1029/2010g1046402, 2011.

Keenan, T. F. and Niinemets, U.: Circadian control of global isoprene emissions, Nat. Geosci., 5, 435-435, doi:10.1038/ngeo1500, 2012.

Keene, W. C., Long, M. S., Pszenny, A. A. P., Sander, R., Maben, J. R., Wall, A. J., O'Halloran, T. L., Kerkweg, A., Fischer, E. V., and Schrems, O.: Latitudinal variation in the multiphase chemical processing of inorganic halogens and related species over the eastern North and South Atlantic Oceans, Atmos. Chem. Phys., 9, 7361-7385, doi:10.5194/acp-9-7361-2009, 2009.

Kemball-Cook, S., Bar-Ilan, A., Grant, J., Parker, L., Jung, J. G., Santamaria, W., Mathews, J., and Yarwood, G.: Ozone Impacts of Natural Gas Development in the Haynesville Shale, Environ. Sci. Technol., 44, 9357-9363, doi:10.1021/es1021137, 2010.

Kercher, J. P., Riedel, T. P., and Thornton, J. A.: Chlorine activation by $\mathrm{N}_{2} \mathrm{O}_{5}$ : simultaneous, in situ detection of $\mathrm{ClNO}_{2}$ and $\mathrm{N}_{2} \mathrm{O}_{5}$ by chemical ionization mass spectrometry, Atmos. Meas. Tech., 2, 193-204, doi:10.5194/amt-2-193-2009, 2009.
Khoder, M. I.: Diurnal, seasonal and weekdays-weekends variations of ground level ozone concentrations in an urban area in greater Cairo, Environ. Monitor. Assess., 149, 349-362, doi:10.1007/s10661-008-0208-7, 2009.

Kim, C. S., Alexis, N. E., Rappold, A. G., Kehrl, H., Hazucha, M. J., Lay, J. C., Schmitt, M. T., Case, M., Devlin, R. B., Peden, D. B., and Diaz-Sanchez, D.: Lung Function and Inflammatory Responses in Healthy Young Adults Exposed to 0.06 ppm Ozone for 6.6 Hours, Am. J. Resp. Crit. Care Med., 183, 1215-1221, doi:10.1164/rccm.201011-1813OC, 2011.

Kim, S., VandenBoer, T. C., Young, C. J., Riedel, T. P., Thornton, J. A., Swarthout, B., Sive, B., Lerner, B., Gilman, J. B., Warneke, C., Roberts, J. M., Guenther, A., Wagner, N. L., Dubé, W. P., Williams, E., and Brown, S. S.: The primary and recycling sources of OH during the NACHTT-2011 campaign: HONO as an important $\mathrm{OH}$ primary source in the wintertime, J. Geophys. Res.-Atmos., 119, JD019784, doi:10.1002/2013jd019784, 2014.

Kim, S. W., Heckel, A., Frost, G. J., Richter, A., Gleason, J., Burrows, J. P., McKeen, S., Hsie, E. Y., Granier, C., and Trainer, M.: $\mathrm{NO}_{2}$ columns in the western United States observed from space and simulated by a regional chemistry model and their implications for $\mathrm{NO}_{x}$ emissions, J. Geophys. Res.-Atmos., 114, D11301, doi:10.1029/2008jd011343, 2009.

Kinney, P. L.: Climate Change, Air Quality, and Human Health, Am. J. Prev. Med., 35, 459-467, doi:10.1016/j.amepre.2008.08.025, 2008.

Kley, D., Geiss, H., and Mohnen, V. A.: Tropospheric ozone at elevated sites and precursor emissions in the United-States and Europe, Atmos. Environ., 28, 149-158, doi:10.1016/13522310(94)90030-2, 1994.

Klimont, Z., Kupiainen, K., Heyes, C., Cofala, J., Rafaj, P., Höglund-Isaksson, L., Borken, J., Schöpp, W., Winiwarter, W., Purohit, P., Bertok, I., and Sander, R.: ECLIPSE V4a: Global emission data set developed with the GAINS model for the period 2005 to 2050 Key features and principal data sources, 2013a.

Klimont, Z., Smith, S. J., and Cofala, J.: The last decade of global anthropogenic sulfur dioxide: 2000-2011 emissions, Environ. Res. Lett., 8, 014003, doi:10.1088/1748-9326/8/1/014003, 2013b.

Kline, N. D. and Miller, T. A.: Observation of the electronic transition of $\mathrm{C}_{6}-\mathrm{C}_{10}$ peroxy radicals, Chem. Phys. Lett., 601, 149-154, 2014.

Kloster, S., Mahowald, N. M., Randerson, J. T., Thornton, P. E., Hoffman, F. M., Levis, S., Lawrence, P. J., Feddema, J. J., Oleson, K. W., and Lawrence, D. M.: Fire dynamics during the 20th century simulated by the Community Land Model, Biogeosciences, 7, 1877-1902, doi:10.5194/bg-7-1877-2010, 2010.

Knorr, W., Lehsten, V., and Arneth, A.: Determinants and predictability of global wildfire emissions, Atmos. Chem. Phys., 12, 6845-6861, doi:10.5194/acp-12-6845-2012, 2012.

Kondo, Y., Takegawa, N., Matsui, H., Miyakawa, T., Koike, M., Miyazaki, Y., Kanaya, Y., Mochida, M., Kuwata, M., Morino, Y., and Shiraiwa, M.: Formation and Transport of Aerosols in Tokyo in Relation to Their Physical and Chemical Properties: A Review, J. Meteorol. Soc. Jpn., 88, 597-624, doi:10.2151/jmsj.2010-401, 2010.

Koo, J.-H., Wang, Y., Kurosu, T. P., Chance, K., Rozanov, A., Richter, A., Oltmans, S. J., Thompson, A. M., Hair, J. W., Fenn, M. A., Weinheimer, A. J., Ryerson, T. B., Solberg, S., Huey, L. 
G., Liao, J., Dibb, J. E., Neuman, J. A., Nowak, J. B., Pierce, R. B., Natarajan, M., and Al-Saadi, J.: Characteristics of tropospheric ozone depletion events in the Arctic spring: analysis of the ARCTAS, ARCPAC, and ARCIONS measurements and satellite BrO observations, Atmos. Chem. Phys., 12, 9909-9922, doi:10.5194/acp-12-9909-2012, 2012.

Kopacz, M., Jacob, D. J., Fisher, J. A., Logan, J. A., Zhang, L., Megretskaia, I. A., Yantosca, R. M., Singh, K., Henze, D. K., Burrows, J. P., Buchwitz, M., Khlystova, I., McMillan, W. W., Gille, J. C., Edwards, D. P., Eldering, A., Thouret, V., and Nedelec, P.: Global estimates of CO sources with high resolution by adjoint inversion of multiple satellite datasets (MOPITT, AIRS, SCIAMACHY, TES), Atmos. Chem. Phys., 10, 855-876, doi:10.5194/acp-10-855-2010, 2010.

Kort, E. A., Frankenberg, C., Costigan, K. R., Lindenmaier, R., Dubey, M. K., and Wunch, D.: Four corners: The largest US methane anomaly viewed from space, Geophys. Res. Lett., 41, GL061503, doi:10.1002/2014gl061503, 2014.

Koumoutsaris, S., Bey, I., Generoso, S., and Thouret, V.: Influence of El Nino-Southern Oscillation on the interannual variability of tropospheric ozone in the northern midlatitudes, J. Geophys. Res.-Atmos., 113, D19301, doi:10.1029/2007jd009753, 2008.

Krewski, D., Jerrett, M., Burnett, R. T., Ma, R., Hughes, E., Shi, Y., Turner, M. C., Pope, C. A., Thurston, G., Calle, E. E., and Thun, M. J.: Extended follow-up and spatial analysis of the American Cancer Society study linking particulate air pollution and mortality, Health Effects Institute, Boston, 2009.

Krupa, S. V. and Manning, W. J.: Atmospheric ozone: formation and effects on vegetation, Environ. Pollut., 50, 101-137, 1988.

Kuenen, J., Gon, J. H. D. V. D., Visschedijk, A., and Brugh, H. V. D.: High resolution European emission inventory for the years 2003-2007, TNO, Utrecht, 2011.

Kuenen, J. J. P., Visschedijk, A. J. H., Jozwicka, M., and Denier van der Gon, H. A. C.: TNO-MACC_II emission inventory; a multiyear (2003-2009) consistent high-resolution European emission inventory for air quality modelling, Atmos. Chem. Phys., 14, 10963-10976, doi:10.5194/acp-14-10963-2014, 2014.

Kukkonen, J., Olsson, T., Schultz, D. M., Baklanov, A., Klein, T., Miranda, A. I., Monteiro, A., Hirtl, M., Tarvainen, V., Boy, M., Peuch, V.-H., Poupkou, A., Kioutsioukis, I., Finardi, S., Sofiev, M., Sokhi, R., Lehtinen, K. E. J., Karatzas, K., San José, R., Astitha, M., Kallos, G., Schaap, M., Reimer, E., Jakobs, H., and Eben, K.: A review of operational, regional-scale, chemical weather forecasting models in Europe, Atmos. Chem. Phys., 12, 1-87, doi:10.5194/acp-12-1-2012, 2012.

Kumar, P. and Imam, B.: Footprints of air pollution and changing environment on the sustainability of built infrastructure, Sci. Total Environ., 444, 85-101, doi:10.1016/j.scitotenv.2012.11.056, 2013.

Kurokawa, J., Ohara, T., Morikawa, T., Hanayama, S., JanssensMaenhout, G., Fukui, T., Kawashima, K., and Akimoto, H.: Emissions of air pollutants and greenhouse gases over Asian regions during 2000-2008: Regional Emission inventory in ASia (REAS) version 2, Atmos. Chem. Phys., 13, 11019-11058, doi:10.5194/acp-13-11019-2013, 2013.

Kurpius, M. and Goldstein, A. H.: Gas-phase chemistry dominates $\mathrm{O} 3$ loss to a forest, implying a source of aerosols and hydroxyl radicals to the atmosphere, Geophys. Res. Lett., 30, 1371, doi:10.1029/2002GL016785, 2003.
Kvalevåg, M. M. and Myhre, G.: The effect of carbonnitrogen coupling on the reduced land carbon sink caused by tropospheric ozone, Geophys. Res. Lett., 40, 3227-3231, doi:10.1002/grl.50572, 2013.

Kwak, K. H. and Baik, J. J.: Diurnal variation of $\mathrm{NO}_{x}$ and ozone exchange between a street canyon and the overlying air, Atmos. Environ., 86, 120-128, doi:10.1016/j.atmosenv.2013.12.029, 2014.

Lahoz, W. A., Peuch, V. H., Orphal, J., Attié, J. L., Chance, K., Liu, X., Edwards, D., Elbern, H., Flaud, J. M., Claeyman, M., and Amraoui, L. E.: Monitoring Air Quality from Space: The Case for the Geostationary Platform, Bull. Am. Meteorol. Soc., 93, 221-233, doi:10.1175/bams-d-11-00045.1, 2011.

Laj, P., Klausen, J., Bilde, M., Plass-Duelmer, C., Pappalardo, G., Clerbaux, C., Baltensperger, U., Hjorth, J., Simpson, D., Reimann, S., Coheur, P. F., Richter, A., De Maziere, M., Rudich, Y., McFiggans, G., Torseth, K., Wiedensohler, A., Morin, S., Schulz, M., Allan, J. D., Attie, J. L., Barnes, I., Birmili, W., Cammas, J. P., Dommen, J., Dorn, H. P., Fowler, D., Fuzzi, S., Glasius, M., Granier, C., Hermann, M., Isaksen, I. S. A., Kinne, S., Koren, I., Madonna, F., Maione, M., Massling, A., Moehler, O., Mona, L., Monks, P. S., Muller, D., Muller, T., Orphal, J., Peuch, V. H., Stratmann, F., Tanre, D., Tyndall, G., Riziq, A. A., Van Roozendael, M., Villani, P., Wehner, B., Wex, H., and Zardini, A. A.: Measuring atmospheric composition change, Atmos. Environ., 43, 5351-5414, doi:10.1016/j.atmosenv.2009.08.020, 2009.

Lamarque, J. F., Hess, P., Emmons, L., Buja, L., Washington, W., and Granier, C.: Tropospheric ozone evolution between 1890 and 1990, J. Geophys. Res.-Atmos., 110, D08304, doi:10.1029/2004jd005537, 2005.

Lamarque, J.-F., Bond, T. C., Eyring, V., Granier, C., Heil, A., Klimont, Z., Lee, D., Liousse, C., Mieville, A., Owen, B. Schultz, M. G., Shindell, D., Smith, S. J., Stehfest, E., Van Aardenne, J., Cooper, O. R., Kainuma, M., Mahowald, N., McConnell, J. R., Naik, V., Riahi, K., and van Vuuren, D. P.: Historical (1850-2000) gridded anthropogenic and biomass burning emissions of reactive gases and aerosols: methodology and application, Atmos. Chem. Phys., 10, 7017-7039, doi:10.5194/acp10-7017-2010, 2010.

Lamsal, L. N., Martin, R. V., Padmanabhan, A., van Donkelaar, A., Zhang, Q., Sioris, C. E., Chance, K., Kurosu, T. P., and Newchurch, M. J.: Application of satellite observations for timely updates to global anthropogenic $\mathrm{NO}_{x}$ emission inventories, Geophys. Res. Lett., 38, L05810, doi:10.1029/2010gl046476, 2011.

Langner, J., Engardt, M., and Andersson, C.: European summer surface ozone 1990-2100, Atmos. Chem. Phys., 12, 10097-10105, doi:10.5194/acp-12-10097-2012, 2012a.

Langner, J., Engardt, M., Baklanov, A., Christensen, J. H., Gauss, M., Geels, C., Hedegaard, G. B., Nuterman, R., Simpson, D., Soares, J., Sofiev, M., Wind, P., and Zakey, A.: A multi-model study of impacts of climate change on surface ozone in Europe, Atmos. Chem. Phys., 12, 10423-10440, doi:10.5194/acp12-10423-2012, 2012b.

Lary, D. J.: Halogens and the chemistry of the free troposphere, Atmos. Chem. Phys., 5, 227-237, doi:10.5194/acp-5-227-2005, 2005.

Lathiere, J., Hewitt, C. N., and Beerling, D. J.: Sensitivity of isoprene emissions from the terrestrial biosphere to 20th century changes in atmospheric $\mathrm{CO}_{2}$ concentration, cli- 
mate, and land use, Global Biogeochem. Cy., 24, GB1004, doi:10.1029/2009gb003548, 2010.

Launiainen, S., Katul, G. G., Gronholm, T., and Vesala, T.: Partitioning ozone fluxes between canopy and forest floor by measurements and a multi-layer model, Agr. Forest Meteorol., 173, 85-99, doi:10.1016/j.agrformet.2012.12.009, 2013.

Law, K. S. and Stohl, A.: Arctic air pollution: Origins and impacts, Science, 315, 1537-1540, doi:10.1126/science.1137695, 2007.

Law, K. S., Stohl, A., Quinn, P. K., Brock, C., Burkhart, J., Paris, J.-D., Ancellet, G., Singh, H. B., Roiger, A., Schlager, H., Dibb, J., Jacob, D. J., Arnold, S. R., Pelon, J., and Thomas, J. L.: Arctic Air Pollution: New Insights From POLARCAT-I PY, Bull. Am. Meteorol. Soc., doi:10.1175/bams-d-13-00017.1, 2014.

Lawler, M. J., Finley, B. D., Keene, W. C., Pszenny, A. A. P., Read, K. A., von Glasow, R., and Saltzman, E. S.: Pollutionenhanced reactive chlorine chemistry in the eastern tropical Atlantic boundary layer, Geophys. Res. Lett., 36, L08810, doi:10.1029/2008g1036666, 2009.

Lawler, M. J., Sander, R., Carpenter, L. J., Lee, J. D., von Glasow, R., Sommariva, R., and Saltzman, E. S.: $\mathrm{HOCl}$ and $\mathrm{Cl}_{2}$ observations in marine air, Atmos. Chem. Phys., 11, 7617-7628, doi:10.5194/acp-11-7617-2011, 2011.

Lawler, M. J., Mahajan, A. S., Saiz-Lopez, A., and Saltzman, E. S.: Observations of $\mathrm{I}_{2}$ at a remote marine site, Atmos. Chem. Phys., 14, 2669-2678, doi:10.5194/acp-14-2669-2014, 2014.

Lawrence, M. G. and Lelieveld, J.: Atmospheric pollutant outflow from southern Asia: a review, Atmos. Chem. Phys., 10, 1101711096, doi:10.5194/acp-10-11017-2010, 2010.

Lee, J. D., Lewis, A. C., Monks, P. S., Jacob, M., Hamilton, J. F., Hopkins, J. R., Watson, N. M., Saxton, J. E., Ennis, C., Carpenter, L. J., Carslaw, N., Fleming, Z., Bandy, B. J., Oram, D. E., Penkett, S. A., Slemr, J., Norton, E., Rickard, A. R., Whalley, L. K., Heard, D. E., Bloss, W. J., Gravestock, T., Smit, S. C., Stanton, J., Pilling, M. J., and Jenkin, M. E.: Ozone photochemistry and elevated isoprene during the UK heatwave of august 2003, Atmos. Environ., 40, 7598-7613, 2006.

Lee, K.-Y., Kwak, K.-H., Ryu, Y.-H., Lee, S.-H., and Baik, J.J.: Impacts of biogenic isoprene emission on ozone air quality in the Seoul metropolitan area, Atmos. Environ., 96, 209-219, doi:10.1016/j.atmosenv.2014.07.036, 2014.

Lefohn, A. S., Hazucha, M. J., Shadwick, D., and Adams, W. C.: An alternative form and level of the human health ozone standard, Inhalation Toxicol., 22, 999-1011, doi:10.3109/08958378.2010.505253, 2010.

Lefohn, A. S., Emery, C., Shadwick, D., Wernli, H., Jung, J., and Oltmans, S. J.: Estimates of background surface ozone concentrations in the United States based on modelderived source apportionment, Atmos. Environ., 84, 275-288, doi:10.1016/j.atmosenv.2013.11.033, 2014.

Leighton, P. A.: Photochemistry of Air Pollution, Academic Press, New York, 1961.

Lelieveld, J. and Dentener, F. J.: What controls tropospheric ozone?, J. Geophys. Res.-Atmos., 105, 3531-3551, doi:10.1029/1999jd901011, 2000.

Lelieveld, J., Berresheim, H., Borrmann, S., Crutzen, P. J., Dentener, F. J., Fischer, H., Feichter, J., Flatau, P. J., Heland, J., Holzinger, R., Korrmann, R., Lawrence, M. G., Levin, Z., Markowicz, K. M., Mihalopoulos, N., Minikin, A., Ramanathan, V., de Reus, M., Roelofs, G. J., Scheeren, H. A., Sciare, J.,
Schlager, H., Schultz, M., Siegmund, P., Steil, B., Stephanou, E. G., Stier, P., Traub, M., Warneke, C., Williams, J., and Zieraus, H.: Global air pollution crossroads over the Mediterranean, Science, 298, 794-799, 2002.

Lelieveld, J., van Aardenne, J., Fischer, H., de Reus, M., Williams, J., and Winkler, P.: Increasing ozone over the Atlantic Ocean, Science, 304, 1483-1487, 2004.

Lelieveld, J., Butler, T. M., Crowley, J. N., Dillon, T. J., Fischer, H., Ganzeveld, L., Lawrence, M. G., Martinez, M., Taraborrelli, D., and Williams, J.: Atmospheric oxidation capacity sustained by a tropical forest, Nature, 452, 737-740 2008.

Lelieveld, J., Hoor, P., Jöckel, P., Pozzer, A., Hadjinicolaou, P., Cammas, J.-P., and Beirle, S.: Severe ozone air pollution in the Persian Gulf region, Atmos. Chem. Phys., 9, 1393-1406, doi:10.5194/acp-9-1393-2009, 2009.

Leung, F.-Y., Logan, J. A., Park, R., Hyer, E., Kasischke, E., Streets, D., and Yuganov, L.: Impacts of enhanced biomass burning in the boreal forests in 1998 on tropospheric chemistry and the sensitivity of model results to the injection height of emissions J. Geophys. Res., 112, D10313, doi:10.1029/2006JD008132, 2007.

Levy, H., Moxim, W. J., and Kasibhatla, P. S.: A global three-dimensional time-dependent lightning source of tropospheric $\mathrm{NO}_{x}$, J. Geophys. Res.-Atmos., 101, 22911-22922, doi:10.1029/96jd02341, 1996.

Lewis, A. C., Evans, M. J., Methven, J., Watson, N. M., Lee, J. D., Hopkins, J. R., Purvis, R. M., Arnold, S. R., McQuaid, J. B., Whalley, L. K., Pilling, M. J., Heard, D. E., Monks, P. S., Parker, A. E., Reeves, C. E., Oram, D. E., Mills, G., Bandy, B. J., Stewart, D., Coe, H., Williams, P., and Crosier, J.: Chemical composition observed over the mid-Atlantic and the detection of pollution signatures far from source regions, J. Geophys. Res., 112, D10S39, doi:10.1029/2006JD007584, 2007.

Lewis, A. C., Evans, M. J., Hopkins, J. R., Punjabi, S., Read, K. A., Purvis, R. M., Andrews, S. J., Moller, S. J., Carpenter, L. J., Lee, J. D., Rickard, A. R., Palmer, P. I., and Parrington, M.: The influence of biomass burning on the global distribution of selected non-methane organic compounds, Atmos. Chem. Phys., 13, 851-867, doi:10.5194/acp-13-851-2013, 2013.

Li, M., Zhang, Q., Streets, D. G., He, K. B., Cheng, Y. F., Emmons, L. K., Huo, H., Kang, S. C., Lu, Z., Shao, M., Su, H., Yu, X., and Zhang, Y.: Mapping Asian anthropogenic emissions of nonmethane volatile organic compounds to multiple chemical mechanisms, Atmos. Chem. Phys., 14, 5617-5638, doi:10.5194/acp14-5617-2014, 2014a.

Li, X. Y., Liu, J. F., Mauzerall, D. L., Emmons, L. K., Walters, S., Horowitz, L. W., and Tao, S.: Effects of trans-Eurasian transport of air pollutants on surface ozone concentrations over Western China, J. Geophys. Res.-Atmos., 119, 12338-12354, doi:10.1002/2014jd021936, 2014b.

Liao, J., Sihler, H., Huey, L. G., Neuman, J. A., Tanner, D. J., Friess, U., Platt, U., Flocke, F. M., Orlando, J. J., Shepson, P. B., Beine, H. J., Weinheimer, A. J., Sjostedt, S. J., Nowak, J. B., Knapp, D. J., Staebler, R. M., Zheng, W., Sander, R., Hall, S. R., and Ullmann, K.: A comparison of Arctic BrO measurements by chemical ionization mass spectrometry and long path-differential optical absorption spectroscopy, J. Geophys. Res.-Atmos., 116, D00R02, doi:10.1029/2010jd014788, 2011.

Liao, J., Huey, L. G., Liu, Z., Tanner, D. J., Cantrell, C. A., Orlando, J. J., Flocke, F. M., Shepson, P. B., Weinheimer, A. J., Hall, S. R., 
Ullmann, K., Beine, H. J., Wang, Y., Ingall, E. D., Stephens, C. R., Hornbrook, R. S., Apel, E. C., Riemer, D., Fried, A., Mauldin, R. L., III, Smith, J. N., Staebler, R. M., Neuman, J. A., and Nowak, J. B.: High levels of molecular chlorine in the Arctic atmosphere, Nat. Geosci., 7, 91-94, doi:10.1038/ngeo2046, 2014.

Lightfoot, P. D., Cox, R., Crowley, J., Destriau, M., Hayman, G., Jenkin, M., Moortgat, G., and Zabel, F.: Organic peroxy radicals: kinetics, spectroscopy and tropospheric chemistry, Atmos. Environ. Part A, 26, 1805-1961, 1992.

Lim, S. S., Vos, T., Flaxman, A. D., Danaei, G., Shibuya, K., Adair-Rohani, H., Amann, M., Anderson, H. R., Andrews, K. G., Aryee, M., Atkinson, C., Bacchus, L. J., Bahalim, A. N., Balakrishnan, K., Balmes, J., Barker-Collo, S., Baxter, A., Bell, M. L., Blore, J. D., Blyth, F., Bonner, C., Borges, G., Bourne, R., Boussinesq, M., Brauer, M., Brooks, P., Bruce, N. G., Brunekreef, B., Bryan-Hancock, C., Bucello, C., Buchbinder, R., Bull, F., Burnett, R. T., Byers, T. E., Calabria, B., Carapetis, J., Carnahan, E., Chafe, Z., Charlson, F., Chen, H. L., Chen, J. S., Cheng, A. T. A., Child, J. C., Cohen, A., Colson, K. E., Cowie, B. C., Darby, S., Darling, S., Davis, A., Degenhardt, L., Dentener, F., Des Jarlais, D. C., Devries, K., Dherani, M., Ding, E. L., Dorsey, E. R., Driscoll, T., Edmond, K., Ali, S. E., Engell, R. E., Erwin, P. J., Fahimi, S., Falder, G., Farzadfar, F., Ferrari, A., Finucane, M. M., Flaxman, S., Fowkes, F. G. R., Freedman, G., Freeman, M. K., Gakidou, E., Ghosh, S., Giovannucci, E., Gmel, G., Graham, K., Grainger, R., Grant, B., Gunnell, D., Gutierrez, H. R., Hall, W., Hoek, H. W., Hogan, A., Hosgood, H. D., Hoy, D., Hu, H., Hubbell, B. J., Hutchings, S. J., Ibeanusi, S. E., Jacklyn, G. L., Jasrasaria, R., Jonas, J. B., Kan, H. D., Kanis, J. A., Kassebaum, N., Kawakami, N., Khang, Y. H., Khatibzadeh, S., Khoo, J. P., Kok, C., Laden, F., Lalloo, R., Lan, Q., Lathlean, T., Leasher, J. L., Leigh, J., Li, Y., Lin, J. K., Lipshultz, S. E., London, S., Lozano, R., Lu, Y., Mak, J., Malekzadeh, R., Mallinger, L., Marcenes, W., March, L., Marks, R., Martin, R., McGale, P., McGrath, J., Mehta, S., Mensah, G. A., Merriman, T. R., Micha, R., Michaud, C., Mishra, V., Hanafiah, K. M., Mokdad, A. A., Morawska, L., Mozaffarian, D., Murphy, T., Naghavi, M., Neal, B., Nelson, P. K., Nolla, J. M., Norman, R., Olives, C., Omer, S. B., Orchard, J., Osborne, R., Ostro, B., Page, A., Pandey, K. D., Parry, C. D. H., Passmore, E., Patra, J., Pearce, N., Pelizzari, P. M., Petzold, M., Phillips, M. R., Pope, D., Pope, C. A., Powles, J., Rao, M., Razavi, H., Rehfuess, E. A., Rehm, J. T., Ritz, B., Rivara, F. P., Roberts, T., Robinson, C., Rodriguez-Portales, J. A., Romieu, I., Room, R., Rosenfeld, L. C., Roy, A., Rushton, L., Salomon, J. A., Sampson, U., Sanchez-Riera, L., Sanman, E., Sapkota, A., Seedat, S., Shi, P. L., Shield, K., Shivakoti, R., Singh, G. M., Sleet, D. A., Smith, E., Smith, K. R., Stapelberg, N. J. C., Steenland, K., Stockl, H., Stovner, L. J., Straif, K., Straney, L., Thurston, G. D., Tran, J. H., Van Dingenen, R., van Donkelaar, A., Veerman, J. L., Vijayakumar, L., Weintraub, R., Weissman, M. M., White, R. A., Whiteford, H., Wiersma, S. T., Wilkinson, J. D., Williams, H. C., Williams, W., Wilson, N., Woolf, A. D., Yip, P., Zielinski, J. M., Lopez, A. D., Murray, C. J. L., and Ezzati, M.: A comparative risk assessment of burden of disease and injury attributable to 67 risk factors and risk factor clusters in 21 regions, 1990-2010: a systematic analysis for the Global Burden of Disease Study 2010, Lancet, 380, 2224-2260, 2012.

Lin, J. T., Pan, D., Davis, S. J., Zhang, Q., He, K. B., Wang, C., Streets, D. G., Wuebbles, D. J., and Guan,
D. B.: China's international trade and air pollution in the United States, Proc. Natl. Acad. Sci. USA, 111, 1736-1741, doi:10.1073/pnas.1312860111, 2014.

Lin, M., Horowitz, L. W., Oltmans, S. J., Fiore, A. M., and Fan, S.: Tropospheric ozone trends at Mauna Loa Observatory tied to decadal climate variability, Nat. Geosci., 7, 136-143, doi:10.1038/ngeo2066, 2014.

Lin, M. Y., Fiore, A. M., Cooper, O. R., Horowitz, L. W., Langford, A. O., Levy, H., II, Johnson, B. J., Naik, V., Oltmans, S. J., and Senff, C. J.: Springtime high surface ozone events over the western United States: Quantifying the role of stratospheric intrusions, J. Geophys. Res., 117, D00V22, doi:10.1029/2012jd018151, 2012a.

Lin, M. Y., Fiore, A. M., Horowitz, L. W., Cooper, O. R., Naik, V., Holloway, J., Johnson, B. J., Middlebrook, A. M., Oltmans, S. J., Pollack, I. B., Ryerson, T. B., Warner, J. X., Wiedinmyer, C., Wilson, J., and Wyman, B.: Transport of Asian ozone pollution into surface air over the western United States in spring, J. Geophys. Res.-Atmos., 117, D00V07, doi:10.1029/2011jd016961, 2012 b.

Liousse, C., Assamoi, E., Criqui, P., Granier, C., and Rosset, R.: Explosive growth in African combustion emissions from 2005 to 2030, Environ. Res. Lett., 9, 035003, doi:10.1088/17489326/9/3/035003, 2014.

Lipsett, M. J., Ostro, B. D., Reynolds, P., Goldberg, D., Hertz, A., Jerrett, M., Smith, D. F., Garcia, C., Chang, E. T., and Bernstein, L.: Long-Term Exposure to Air Pollution and Cardiorespiratory Disease in the California Teachers Study Cohort, Am. J. Resp. Crit. Care Med., 184, 828-835, doi:10.1164/rccm.2010122082 OC, 2011.

Liu, G., Liu, J., Tarasick, D. W., Fioletov, V. E., Jin, J. J., Moeini, O., Liu, X., Sioris, C. E., and Osman, M.: A global tropospheric ozone climatology from trajectory-mapped ozone soundings, Atmos. Chem. Phys., 13, 10659-10675, doi:10.5194/acp13-10659-2013, 2013.

Liu, H., Wang, X. M., Pang, J. M., and He, K. B.: Feasibility and difficulties of China's new air quality standard compliance: PRD case of $\mathrm{PM}_{2.5}$ and ozone from 2010 to 2025, Atmos. Chem. Phys., 13, 12013-12027, doi:10.5194/acp-13-12013-2013, 2013.

Liu, X., Chance, K., Sioris, C. E., Kurosu, T. P., Spurr, R. J. D., Martin, R. V., Fu, T. M., Logan, J. A., Jacob, D. J., Palmer, P. I., Newchurch, M. J., Megretskaia, I. A., and Chatfield, R. B.: First directly retrieved global distribution of tropospheric column ozone from GOME: Comparison with the GEOS-CHEM model, J. Geophys. Res.-Atmos., 111, D02308, doi:10.1029/2005jd006564, 2006.

Liu, Y., Shao, M., Fu, L. L., Lu, S. H., Zeng, L. M., and Tang, D. G.: Source profiles of volatile organic compounds (VOCs) measured in China: Part I, Atmos. Environ., 42, 6247-6260, doi:10.1016/j.atmosenv.2008.01.070, 2008.

Logan, J. A.: Tropospheric ozone - seasonal behaviour, trends, and anthropogenic influence, J. Geophys. Res.-Atmos., 90, 1046310482, 1985.

Logan, J. A., Staehelin, J., Megretskaia, I. A., Cammas, J. P., Thouret, V., Claude, H., De Backer, H., Steinbacher, M., Scheel, H. E., Stubi, R., Frohlich, M., and Derwent, R.: Changes in ozone over Europe: Analysis of ozone measurements from sondes, regular aircraft (MOZAIC) and alpine surface sites, J. Geophys. Res.-Atmos., 117, D09301, doi:10.1029/2011jd016952, 2012. 
Long, M. S., Keene, W. C., Easter, R. C., Sander, R., Liu, X., Kerkweg, A., and Erickson, D.: Sensitivity of tropospheric chemical composition to halogen-radical chemistry using a fully coupled size-resolved multiphase chemistry-global climate system: halogen distributions, aerosol composition, and sensitivity of climate-relevant gases, Atmos. Chem. Phys., 14, 3397-3425, doi:10.5194/acp-14-3397-2014, 2014

Lu, X. H., Jiang, H., Zhang, X. Y., Liu, J. X., Zhang, Z., Jin, J. X., Wang, Y., Xu, J. H., and Cheng, M. M.: Estimated global nitrogen deposition using NO2 column density, Int. J. Remote Sens., 34, 8893-8906, doi:10.1080/01431161.2013.853894, 2013.

Maccarone, A. T., Kirk, B. B., Hansen, C. S., Griffiths, T. M., Olsen, S., Trevitt, A. J., and Blanksby, S. J.: Direct observation of photodissociation products from phenylperoxyl radicals isolated in the gas phase, J. Am. Chem. Soc., 135, 9010-9014, 2013.

MacDonald, S. M., Gómez Martín, J. C., Chance, R., Warriner, S., Saiz-Lopez, A., Carpenter, L. J., and Plane, J. M. C.: A laboratory characterisation of inorganic iodine emissions from the sea surface: dependence on oceanic variables and parameterisation for global modelling, Atmos. Chem. Phys., 14, 5841-5852, doi:10.5194/acp-14-5841-2014, 2014

MacKenzie, A. R., Langford, B., Pugh, T. A. M., Robinson, N., Misztal, P. K., Heard, D. E., Lee, J. D., Lewis, A. C., Jones, C. E., Hopkins, J. R., Phillips, G., Monks, P. S., Karunaharan, A., Hornsby, K. E., Nicolas-Perea, V., Coe, H., Gabey, A. M., Gallagher, M. W., Whalley, L. K., Edwards, P. M., Evans, M. J., Stone, D., Ingham, T., Commane, R., Furneaux, K. L., McQuaid, J. B., Nemitz, E., Seng, Y. K., Fowler, D., Pyle, J. A., and Hewitt, C. N.: The atmospheric chemistry of trace gases and particulate matter emitted by different land uses in Borneo, Philos. Trans. R. Soc. B-Biol. Sci., 366, 3177-3195, doi:10.1098/rstb.2011.0053, 2011.

Mahajan, A. S., Oetjen, H., Saiz-Lopez, A., Lee, J. D., McFiggans, G. B., and Plane, J. M. C.: Reactive iodine species in a semi-polluted environment, Geophys. Res. Lett., 36, L16803, doi:10.1029/2009g1038018, 2009.

Mahajan, A. S., Shaw, M., Oetjen, H., Hornsby, K. E., Carpenter, L. J., Kaleschke, L., Tian-Kunze, X., Lee, J. D., Moller, S. J., Edwards, P., Commane, R., Ingham, T., Heard, D. E., and Plane, J. M. C.: Evidence of reactive iodine chemistry in the Arctic boundary layer, J. Geophys. Res.-Atmos., 115, D20303, doi:10.1029/2009jd013665, 2010.

Manders, A. M. M., van Meijgaard, E., Mues, A. C., Kranenburg, R., van Ulft, L. H., and Schaap, M.: The impact of differences in large-scale circulation output from climate models on the regional modeling of ozone and PM, Atmos. Chem. Phys., 12, 9441-9458, doi:10.5194/acp-12-9441-2012, 2012.

Mao, J. Q., Paulot, F., Jacob, D. J., Cohen, R. C., Crounse, J. D., Wennberg, P. O., Keller, C. A., Hudman, R. C., Barkley, M. P., and Horowitz, L. W.: Ozone and organic nitrates over the eastern United States: Sensitivity to isoprene chemistry, J. Geophys. Res.-Atmos., 118, 11256-11268, doi:10.1002/jgrd.50817, 2013.

Marais, E. A., Jacob, D. J., Wecht, K., Lerot, C., Zhang, L., Yu, K., Kurosu, T. P., Chance, K., and Sauvage, B.: Anthropogenic emissions in Nigeria and implications for atmospheric ozone pollution: A view from space, Atmos. Environ., 99, 32-40, doi:10.1016/j.atmosenv.2014.09.055, 2014.

Marenco, A., Gouget, H., Nedelec, P., Pages, J. P., and Karcher, F.: Evidence of a long-term increase in tropospehric ozone from Pic Du Midi data series - consequences - positive radiative forcing, J. Geophys. Res.-Atmos., 99, 16617-16632, doi:10.1029/94jd00021, 1994.

Mari, C. H., Cailley, G., Corre, L., Saunois, M., Attié, J. L., Thouret, V., and Stohl, A.: Tracing biomass burning plumes from the Southern Hemisphere during the AMMA 2006 wet season experiment, Atmos. Chem. Phys., 8, 3951-3961, doi:10.5194/acp8-3951-2008, 2008.

Marlier, M. E., Voulgarakis, A., Shindell, D. T., Faluvegi, G., Henry, C. L., and Randerson, J. T.: The role of temporal evolution in modeling atmospheric emissions from tropical fires, Atmos. Environ., 89, 158-168, doi:10.1016/j.atmosenv.2014.02.039, 2014.

Martin, R. V., Parrish, D. D., Ryerson, T. B., Nicks, D. K., Chance, K., Kurosu, T. P., Jacob, D. J., Sturges, E. D., Fried, A., and Wert, B. P.: Evaluation of GOME satellite measurements of tropospheric $\mathrm{NO}_{2}$ and $\mathrm{HCHO}$ using regional data from aircraft campaigns in the southeastern United States, J. Geophys. Res.Atmos., 109, D24307, doi:10.1029/2004JD004869, 2004.

Martin, R. V.: Satellite remote sensing of surface air quality, Atmos. Environ., 42, 7823-7843, doi:10.1016/j.atmosenv.2008.07.018, 2008.

Martins, V., Miranda, A. I., Carvalho, A., Schaap, M., Borrego, C., and Sa, E.: Impact of forest fires on particulate matter and ozone levels during the 2003, 2004 and 2005 fire seasons in Portugal, Sci. Total Environ., 414, 53-62, doi:10.1016/j.scitotenv.2011.10.007, 2012.

Matyssek, R., Sandermann, H., Wieser, G., Booker, F., Cieslik, S., Musselman, R., and Ernst, D.: The challenge of making ozone risk assessment for forest trees more mechanistic, Environ. Pollut., 156, 567-582, doi:10.1016/j.envpol.2008.04.017, 2008.

Matyssek, R., Karnosky, D. F., Wieser, G., Percy, K., Oksanen, E., Grams, T. E. E., Kubiske, M., Hanke, D., and Pretzsch, H.: Advances in understanding ozone impact on forest trees: Messages from novel phytotron and free-air fumigation studies, Environ. Pollut., 158, 1990-2006, doi:10.1016/j.envpol.2009.11.033, 2010.

Mauzerall, D. L., Jacob, D. J., Fan, S. M., Bradshaw, J. D., Gregory, G. L., Sachse, G. W., and Blake, D. R.: Origin of tropospheric ozone at remote high northern latitudes in summer, J. Geophys. Res.-Atmos., 101, 4175-4188, doi:10.1029/95jd03224, 1996.

McCarthy, M. C., Cheng, L., Crabtree, K. N., Martinez Jr., O., Nguyen, T. L., Womack, C. C., and Stanton, J. F.: The Simplest Criegee Intermediate $\left(\mathrm{H}_{2} \mathrm{CO}-\mathrm{O}\right)$ : Isotopic Spectroscopy, Equilibrium Structure, and Possible Formation from Atmospheric Lightning, J. Phys. Chem. Lett., 4, 4133-4139, 2013.

McFiggans, G.: Marine aerosols and iodine emissions, Nature, 433, p. E13, doi:10.1038/nature03372, 2005.

McFiggans, G., Bale, C. S. E., Ball, S. M., Beames, J. M., Bloss, W. J., Carpenter, L. J., Dorsey, J., Dunk, R., Flynn, M. J., Furneaux, K. L., Gallagher, M. W., Heard, D. E., Hollingsworth, A. M., Hornsby, K., Ingham, T., Jones, C. E., Jones, R. L., Kramer, L. J., Langridge, J. M., Leblanc, C., LeCrane, J.-P., Lee, J. D., Leigh, R. J., Longley, I., Mahajan, A. S., Monks, P. S., Oetjen, H., Orr-Ewing, A. J., Plane, J. M. C., Potin, P., Shillings, A. J. L., Thomas, F., von Glasow, R., Wada, R., Whalley, L. K., and Whitehead, J. D.: Iodine-mediated coastal particle formation: an overview of the Reactive Halogens in the Marine Boundary Layer (RHaMBLe) Roscoff coastal study, Atmos. Chem. Phys., 10, 2975-2999, doi:10.5194/acp-10-2975-2010, 2010. 
McKay, W. A., Stephens, B. A., and Dollard, G. J.: Laboratory measurements of ozone deposition to sea-water and other saline solutions, Atmos. Environ. Part A, 26, 3105-3110, 1992.

McLinden, C. A., Olsen, S. C., Hannegan, B., Wild, O., Prather, M. J., and Sundet, J.: Stratospheric ozone in 3-D models: A simple chemistry and the cross-tropopause flux, J. Geophys. Res.Atmos., 105, 14653-14665, doi:10.1029/2000jd900124, 2000.

McMeeking, G. R., Bart, M., Chazette, P., Haywood, J. M., Hopkins, J. R., McQuaid, J. B., Morgan, W. T., Raut, J.-C., Ryder, C. L., Savage, N., Turnbull, K., and Coe, H.: Airborne measurements of trace gases and aerosols over the London metropolitan region, Atmos. Chem. Phys., 12, 5163-5187, doi:10.5194/acp12-5163-2012, 2012.

McPeters, R. D., Labow, G. J., and Logan, J. A.: Ozone climatological profiles for satellite retrieval algorithms, J. Geophys. Res.Atmos., 112, D05308, doi:10.1029/2005jd006823, 2007.

Mead, M. I., Popoola, O. A. M., Stewart, G. B., Landshoff, P., Calleja, M., Hayes, M., Baldovi, J. J., McLeod, M. W., Hodgson, T. F., Dicks, J., Lewis, A., Cohen, J., Baron, R., Saffell, J. R., and Jones, R. L.: The use of electrochemical sensors for monitoring urban air quality in low-cost, high-density networks, Atmos. Environ., 70, 186-203, doi:10.1016/j.atmosenv.2012.11.060, 2013.

Meleux, F., Solmon, F., and Giorgi, F.: Increase in summer European ozone amounts due to climate change, Atmos. Environ., 41, 7577-7587, 2007.

Melkonyan, A., and Kuttler, W.: Long-term analysis of $\mathrm{NO}, \mathrm{NO}_{2}$ and $\mathrm{O}_{3}$ concentrations in North RhineWestphalia, Germany, Atmos. Environ., 60, 316-326, doi:10.1016/j.atmosenv.2012.06.048, 2012.

Mickley, L. J., Jacob, D., and Rind, D.: Uncertainty in preindustrial abundance of tropospheric ozone: Implications for radiative forcing calculations, J. Geophys. Res., 106, 3389-3399, 2001.

Mielke, L. H., Furgeson, A., and Osthoff, H. D.: Observation of $\mathrm{CINO}_{2}$ in a Mid-Continental Urban Environment, Environ. Sci. Technol., 45, 8889-8896, doi:10.1021/es201955u, 2011.

Mielke, L. H., Stutz, J., Tsai, C., Hurlock, S. C., Roberts, J. M., Veres, P. R., Froyd, K. D., Hayes, P. L., Cubison, M. J., Jimenez, J. L., Washenfelder, R. A., Young, C. J., Gilman, J. B., de Gouw, J. A., Flynn, J. H., Grossberg, N., Lefer, B. L., Liu, J., Weber, R. J., and Osthoff, H. D.: Heterogeneous formation of nitryl chloride and its role as a nocturnal $\mathrm{NO}_{x}$ reservoir species during CalNex-LA 2010, J. Geophys. Res.-Atmos., 118, 10638-10652, doi:10.1002/jgrd.50783, 2013.

Mieville, A., Granier, C., Liousse, C., Guillaume, B., Mouillot, F., Lamarque, J. F., Gregoire, J. M., and Petron, G.: Emissions of gases and particles from biomass burning during the 20th century using satellite data and an historical reconstruction, Atmos. Environ., 44, 1469-1477, doi:10.1016/j.atmosenv.2010.01.011, 2010.

Miller, S. M., Matross, D. M., Andrews, A. E., Millet, D. B., Longo, M., Gottlieb, E. W., Hirsch, A. I., Gerbig, C., Lin, J. C., Daube, B. C., Hudman, R. C., Dias, P. L. S., Chow, V. Y., and Wofsy, S. C.: Sources of carbon monoxide and formaldehyde in North America determined from high-resolution atmospheric data, Atmos. Chem. Phys., 8, 7673-7696, doi:10.5194/acp-8-7673-2008, 2008.

Mills, G.: Mapping critical levels for vegetation of the LRTAP Convention Manual of Methodologies for Modelling and Mapping Effects of Air Pollution, 2014.
Mills, G. and Harmens, H.: Ozone pollution: A hidden threat to food security, Centre for Ecology and Hydrology, Bangor, UK, 2011.

Mills, G., Buse, A., Gimeno, B., Bermejo, V., Holland, M., Emberson, L., and Pleijel, H.: A synthesis of AOT40-based response functions and critical levels of ozone for agricultural and horticultural crops, Atmos. Environ., 41, 2630-2643, doi:10.1016/j.atmosenv.2006.11.016, 2007a.

Mills, G., Hayes, F., Jones, M. L. M., and Cinderby, S.: Identifying ozone-sensitive communities of (semi-)natural vegetation suitable for mapping exceedance of critical levels, Environ. Pollut., 146, 736-743, doi:10.1016/j.envpol.2006.04.005, 2007b.

Mills, G., Hayes, F., Simpson, D., Emberson, L., Norris, D., Harmens, H., and Buker, P.: Evidence of widespread effects of ozone on crops and (semi-)natural vegetation in Europe (1990-2006) in relation to AOT40-and flux-based risk maps, Glob. Change Biol., 17, 592-613, doi:10.1111/j.1365-2486.2010.02217.x, 2011a.

Mills, G., Pleijel, H., Braun, S., Buker, P., Bermejo, V., Calvo, E., Danielsson, H., Emberson, L., Fernandez, I. G., Grunhage, L., Harmens, H., Hayes, F., Karlsson, P. E., and Simpson, D.: New stomatal flux-based critical levels for ozone effects on vegetation, Atmos. Environ., 45, 5064-5068, doi:10.1016/j.atmosenv.2011.06.009, 2011 b.

Millstein, D. E. and Harley, R. A.: Impact of climate change on photochemical air pollution in Southern California, Atmos. Chem. Phys., 9, 3745-3754, doi:10.5194/acp-9-3745-2009, 2009.

Molina, M. J. and Molina, L. T.: Megacities and atmospheric pollution, J. Air Waste Manage. Assoc., 54, 644-680, 2004.

Monks, P. S.: A review of the observations and origins of the spring ozone maximum, Atmos. Environ., 34, 3545-3561, 2000.

Monks, P. S.: Gas-phase radical chemistry in the troposphere, Chem. Soc. Rev., 34, 376-395, 2005.

Monks, P. S. and Bierle, S.: Applications of Tropospheric Composition Observations from Satellites, in: The Remote Sensing of Tropospheric Composition from Space, edited by: Burrows, J. P., Platt, U., and Borrell, P., Phys. Earth Space Environ., 536 pp., 2011.

Monks, P. S.: European pollution: Investigate smog to inform policy, Nature, 509, 427-427, doi:10.1038/509427a, 2014.

Monks, P. S., Granier, C., Fuzzi, S., Stohl, A., Williams, M. L., Akimoto, H., Amann, M., Baklanov, A., Baltensperger, U., Bey, I., Blake, N., Blake, R. S., Carslaw, K., Cooper, O. R., Dentener, F., Fowler, D., Fragkou, E., Frost, G. J., Generoso, S., Ginoux, P., Grewe, V., Guenther, A., Hansson, H. C., Henne, S., Hjorth, J., Hofzumahaus, A., Huntrieser, H., Isaksen, I. S. A., Jenkin, M. E., Kaiser, J., Kanakidou, M., Klimont, Z., Kulmala, M., Laj, P., Lawrence, M. G., Lee, J. D., Liousse, C., Maione, M., McFiggans, G., Metzger, A., Mieville, A., Moussiopoulos, N., Orlando, J. J., O’Dowd, C. D., Palmer, P. I., Parrish, D. D., Petzold, A., Platt, U., Poeschl, U., Prevot, A. S. H., Reeves, C. E., Reimann, S., Rudich, Y., Sellegri, K., Steinbrecher, R., Simpson, D., ten Brink, H., Theloke, J., van der Werf, G. R., Vautard, R., Vestreng, V., Vlachokostas, C., and von Glasow, R.: Atmospheric composition change - global and regional air quality, Atmos. Environ. 43, 5268-5350, doi:10.1016/j.atmosenv.2009.08.021, 2009.

Monks, S. A., Arnold, S. R., Emmons, L. K., Law, K. S., Turquety, S., Duncan, B. N., Flemming, J., Huijnen, V., Tilmes, S., Langner, J., Mao, J., Long, Y., Thomas, J. L., Steenrod, S. D., Raut, J. C., Wilson, C., Chipperfield, M. P., Diskin, G. S., Weinheimer, A., Schlager, H., and Ancellet, G.: Multi-model study of 
chemical and physical controls on transport of anthropogenic and biomass burning pollution to the Arctic, Atmos. Chem. Phys., 15, 3575-3603, doi:10.5194/acp-15-3575-2015, 2015.

Moody, J. L., Oltmans, S. J., Levy, H., and Merrill, J. T.: Transport, climatology of tropospheric ozone - Bermuda, 1988-1991, J. Geophys. Res.-Atmos., 100, 7179-7194, doi:10.1029/94jd02830, 1995.

Myhre, G., Shindell, D., Bréon, F.-M., Collins, W., Fuglestvedt, J., Huang, J., Koch, D., Lamarque, J.-F., Lee, D., Mendoza, B., Nakajima, T., Robock, A., Stephens, G., Takemura, T., and Zhang, H.: Anthropogenic and Natural Radiative Forcing, in: Climate Change, The Physical Science Base, Contribution of Working Group 1 to the Fifth Assessment report of the intergovernmental panel on climate change, Cambridge, UK, 2013.

Naddafi, K., Hassanvand, M. S., Yunesian, M., Momeniha, F., Nabizadeh, R., Faridi, S., and Gholampour, A.: Health impact assessment of air pollution in megacity of Tehran, Iran, Iran. J. Environ. Health Sci. Eng., 9, 28, doi:10.1186/1735-2746-9-28, 2012.

Nakicenovic, N., Alcamo, J., Davis, G., de Vries, B., Fenhann, J., Gaffin, S., Gregory, K., Grubler, A., Jung, T. Y., Kram, T., La Rovere, E. L., Michaelis, L., Mori, S., Morita, T., Pepper, W., Pitcher, H. M., Price, L., Riahi, K., Roehrl, A., Rogner, H.-H., Sankovski, A., Schlesinger, M., Shukla, P., Smith, S. J., Swart, R., van Rooijen, S., Victor, N., and Dadi, Z.: Special Report on Emissions Scenarios: a special report of Working Group III of the Intergovernmental Panel on Climate Change, Other Information: PBD: 03 October 2000, Cambridge University Press', New York, 2000.

Nedelec, P., Thouret, V., Brioude, J., Sauvage, B., Cammas, J. P., and Stohl, A.: Extreme CO concentrations in the upper troposphere over northeast Asia in June 2003 from the in situ MOZAIC aircraft data, Geophys. Res. Lett., 32, L14807, doi:10.1029/2005g1023141, 2005.

Neirynck, J., Gielen, B., Janssens, I. A., and Ceulemans, R.: Insights into ozone deposition patterns from decade-long ozone flux measurements over a mixed temperate forest, J. Environ. Monit., 14, 1684-1695, doi:10.1039/c2em10937a, 2012.

Neu, J. L., Flury, T., Manney, G. L., Santee, M. L., Livesey, N. J., and Worden, J.: Tropospheric ozone variations governed by changes in stratospheric circulation, Nat. Geosci., 7, 340-344, doi:10.1038/ngeo2138, 2014.

Nisbet, E. G., Dlugokencky, E. J., and Bousquet, P.: Methane on the Rise-Again, Science, 343, 493-495, doi:10.1126/science.1247828, 2014.

Nowack, P. J., Abraham, N. L., Maycock, A. C., Braesicke, P., Gregory, J. M., Joshi, M. M., Osprey, A., and Pyle, J. A.: A large ozone-circulation feedback and its implications for global warming assessments, Nat. Clim. Chang., 5, 41-45, doi:10.1038/nclimate2451, 2015.

O'Connor, F. M., Johnson, C. E., Morgenstern, O., Abraham, N. L., Braesicke, P., Dalvi, M., Folberth, G. A., Sanderson, M. G., Telford, P. J., Voulgarakis, A., Young, P. J., Zeng, G., Collins, W. J., and Pyle, J. A.: Evaluation of the new UKCA climatecomposition model - Part 2: The Troposphere, Geosci. Model Dev., 7, 41-91, doi:10.5194/gmd-7-41-2014, 2014.

OECD: OECD Environmental Outlook to 2050, OECD Publishing, 2012.
Ohara, T., Akimoto, H., Kurokawa, J., Horii, N., Yamaji, K., Yan, X., and Hayasaka, T.: An Asian emission inventory of anthropogenic emission sources for the period 1980-2020, Atmos. Chem. Phys., 7, 4419-4444, doi:10.5194/acp-7-4419-2007, 2007.

Ojha, N., Naja, M., Sarangi, T., Kumar, R., Bhardwaj, P., Lal, S., Venkataramani, S., Sagar, R., Kumar, A., and Chandola, H. C.: On the processes influencing the vertical distribution of ozone over the central Himalayas: Analysis of yearlong ozonesonde observations, Atmos. Environ., 88, 201-211, doi:10.1016/j.atmosenv.2014.01.031, 2014.

Olaguer, E. P.: The potential near-source ozone impacts of upstream oil and gas industry emissions, J. Air Waste Manage., 62, 966977, doi:10.1080/10962247.2012.688923, 2012.

Olivier, J. G. J., Van Aardenne, J. A., Dentener, F. J., Pagliari, V., Ganzeveld, L. N., and Peters, J. A. H. W.: Recent trends in global greenhouse gas emissions:regional trends 1970-2000 and spatial distributionof key sources in 2000, Environ. Sci., 2, 81-99, doi:10.1080/15693430500400345, 2005.

Olsen, S. C., Brasseur, G. P., Wuebbles, D. J., Barrett, S. R. H., Dang, H., Eastham, S. D., Jacobson, M. Z., Khodayari, A., Selkirk, H., Sokolov, A., and Unger, N.: Comparison of model estimates of the effects of aviation emissions on atmospheric ozone and methane, Geophys. Res. Lett., GL057660, 60046009, doi:10.1002/2013gl057660, 2013.

Olson, J. R., Crawford, J. H., Davis, D. D., Chen, G., Avery, M. A., Barrick, J. D. W., Sachse, G. W., Vay, S. A., Sandholm, S T., Tan, D., Brune, W. H., Faloona, I. C., Heikes, B. G., Shetter, R. E., Lefer, B. L., Singh, H. B., Talbot, R. W., and Blake, D. R.: Seasonal differences in the photochemistry of the South Pacific: A comparison of observations and model results from PEM-Tropics A and B, J. Geophys. Res., 106, 32749-32766, 2001.

Oltmans, S., Schnell, R., Johnson, B., Pétron, G., Mefford, T., and Neely III, R.: Anatomy of wintertime ozone associated with oil and natural gas extraction activity in Wyoming and Utah, Elem. Sci. Anth., 2, 000024, doi:10.12952/journal.elementa.000024, 2014.

Oltmans, S. J., Lefohn, A. S., Harris, J. M., Galbally, I., Scheel, H. E., Bodeker, G., Brunke, E., Claude, H., Tarasick, D., Johnson, B. J., Simmonds, P., Shadwick, D., Anlauf, K., Hayden, K., Schmidlin, F., Fujimoto, T., Akagi, K., Meyer, C., Nichol, S., Davies, J., Redondas, A., and Cuevas, E.: Long term changes in tropospheric ozone, Atmos. Environ., 40, 3156-3173, 2006.

Oltmans, S. J., Johnson, B. J., and Harris, J. M.: Springtime boundary layer ozone depletion at Barrow, Alaska: Meteorological influence, year-to-year variation, and long-term change, J. Geophys. Res., 117, D00R18, doi:10.1029/2011JD016889, 2012.

Oltmans, S. J., Lefohn, A. S., Shadwick, D., Harris, J. M., Scheel, H. E., Galbally, I., Tarasick, D. W., Johnson, B. J., Brunke, E. G., Claude, H., Zeng, G., Nichol, S., Schmidlin, F., Davies, J., Cuevas, E., Redondas, A., Naoe, H., Nakano, T., and Kawasato, T.: Recent tropospheric ozone changes - A pattern dominated by slow or no growth, Atmos. Environ., 67, 331-351, doi:10.1016/j.atmosenv.2012.10.057, 2013.

Oman, L. D., Douglass, A. R., Ziemke, J. R., Rodriguez, J. M., Waugh, D. W., and Nielsen, J. E.: The ozone response to ENSO in Aura satellite measurements and a chemistry- 
climate simulation, J. Geophys. Res.-Atmos., 118, 965-976, doi:10.1029/2012jd018546, 2013.

Ordoñez, C., Brunner, D., Staehelin, J., Hadjinicolaou, P., Pyle, J. A., Jonas, M., Wernli, H., and Prevot, A. S. H.: Strong influence of lowermost stratospheric ozone on lower tropospheric background ozone changes over Europe, Geophys. Res. Lett., 34, L07805, doi:10.1029/2006g1029113, 2007.

Orlando, J. J. and Tyndall, G. S.: Laboratory studies of organic peroxy radical chemistry: an overview with emphasis on recent issues of atmospheric significance, Chem. Soc. Rev., 41, 62946317, doi:10.1039/c2cs35166h, 2012.

Osthoff, H. D., Roberts, J. M., Ravishankara, A. R., Williams, E. J., Lerner, B. M., Sommariva, R., Bates, T. S., Coffman, D., Quinn, P. K., Dibb, J. E., Stark, H., Burkholder, J. B., Talukdar, R. K., Meagher, J., Fehsenfeld, F. C., and Brown, S. S.: High levels of nitryl chloride in the polluted subtropical marine boundary layer, Nat. Geosci., 1, 324-328, 2008.

Ouyang, B., McLeod, M. W., Jones, R. L., and Bloss, W. J.: $\mathrm{NO}_{3}$ radical production from the reaction between the Criegee intermediate $\mathrm{CH}_{2} \mathrm{OO}$ and $\mathrm{NO}_{2}$, Phys. Chem. Chem. Phys., 15, 17070-17075, doi:10.1039/c3cp53024h, 2013.

Padro, J.: Observed Characteristics of the Dry Deposition Velocity of $\mathrm{O} 3$ and So2 above a Wet Deciduous Forest, Sci. Total Environ., 147, 395-400, 1994.

Palmer, P. I., Jacob, D. J., Fiore, A. M., Martin, R. V., Chance, K., and Kurosu, T. P.: Mapping isoprene emissions over North America using formaldehyde column observations from space, J. Geophys. Res.-Atmos., 108, 4180, doi:10.1029/2002JD002153, 2003

Palmer, P. I., Parrington, M., Lee, J. D., Lewis, A. C., Rickard, A. R., Bernath, P. F., Duck, T. J., Waugh, D. L., Tarasick, D. W., Andrews, S., Aruffo, E., Bailey, L. J., Barrett, E., Bauguitte, S. J.-B., Curry, K. R., Di Carlo, P., Chisholm, L., Dan, L., Forster, G., Franklin, J. E., Gibson, M. D., Griffin, D., Helmig, D., Hopkins, J. R., Hopper, J. T., Jenkin, M. E., Kindred, D., Kliever, J., Le Breton, M., Matthiesen, S., Maurice, M., Moller, S., Moore, D. P., Oram, D. E., O'Shea, S. J., Owen, R. C., Pagniello, C. M. L. S., Pawson, S., Percival, C. J., Pierce, J. R., Punjabi, S., Purvis, R. M., Remedios, J. J., Rotermund, K. M., Sakamoto, K. M., da Silva, A. M., Strawbridge, K. B., Strong, K., Taylor, J., Trigwell, R., Tereszchuk, K. A., Walker, K. A., Weaver, D., Whaley, C., and Young, J. C.: Quantifying the impact of BOReal forest fires on Tropospheric oxidants over the Atlantic using Aircraft and Satellites (BORTAS) experiment: design, execution and science overview, Atmos. Chem. Phys., 13, 6239-6261, doi:10.5194/acp-13-6239-2013, 2013.

Pappin, A. J. and Hakami, A.: Attainment vs Exposure: Ozone Metric Responses to Source-Specific $\mathrm{NO}_{x}$ Controls Using Adjoint Sensitivity Analysis, Environ. Sci. Technol., 47, 13519-13527, doi:10.1021/es4024145, 2013.

Paris, J.-D., Stohl, A., Ciais, P., Néd'elec, P., Belan, B. D., Arshinov, M. Yu., and Ramonet, M.: Source-receptor relationships for airborne measurements of $\mathrm{CO}_{2}, \mathrm{CO}$ and $\mathrm{O}_{3}$ above Siberia: a cluster-based approach, Atmos. Chem. Phys., 10, 1671-1687, doi:10.5194/acp-10-1671-2010, 2010.

Parrella, J. P., Jacob, D. J., Liang, Q., Zhang, Y., Mickley, L. J., Miller, B., Evans, M. J., Yang, X., Pyle, J. A., Theys, N., and Van Roozendael, M.: Tropospheric bromine chemistry: implications for present and pre-industrial ozone and mercury, Atmos. Chem. Phys., 12, 6723-6740, doi:10.5194/acp-12-6723-2012, 2012.

Parrington, M., Palmer, P. I., Henze, D. K., Tarasick, D. W., Hyer, E. J., Owen, R. C., Helmig, D., Clerbaux, C., Bowman, K. W., Deeter, M. N., Barratt, E. M., Coheur, P.-F., Hurtmans, D., Jiang, Z., George, M., and Worden, J. R.: The influence of boreal biomass burning emissions on the distribution of tropospheric ozone over North America and the North Atlantic during 2010, Atmos. Chem. Phys., 12, 2077-2098, doi:10.5194/acp-12-20772012, 2012.

Parrington, M., Palmer, P. I., Lewis, A. C., Lee, J. D., Rickard, A. R., Di Carlo, P., Taylor, J. W., Hopkins, J. R., Punjabi, S., Oram, D. E., Forster, G., Aruffo, E., Moller, S. J., Bauguitte, S. J.-B., Allan, J. D., Coe, H., and Leigh, R. J.: Ozone photochemistry in boreal biomass burning plumes, Atmos. Chem. Phys., 13, 73217341, doi:10.5194/acp-13-7321-2013, 2013.

Parrish, D. D. and Zhu, T.: Clean Air for Megacities, Science, 326, 674-675, doi:10.1126/science.1176064, 2009.

Parrish, D. D., Millet, D. B., and Goldstein, A. H.: Increasing ozone in marine boundary layer inflow at the west coasts of North America and Europe, Atmos. Chem. Phys., 9, 1303-1323, doi:10.5194/acp-9-1303-2009, 2009.

Parrish, D. D., Singh, H. B., Molina, L., and Madronich, S.: Air quality progress in North American megacities: A review, Atmos. Environ., 45, 7015-7025, doi:10.1016/j.atmosenv.2011.09.039, 2011.

Parrish, D. D., Law, K. S., Staehelin, J., Derwent, R., Cooper, O. R., Tanimoto, H., Volz-Thomas, A., Gilge, S., Scheel, H.-E., Steinbacher, M., and Chan, E.: Long-term changes in lower tropospheric baseline ozone concentrations at northern mid-latitudes, Atmos. Chem. Phys., 12, 11485-11504, doi:10.5194/acp-1211485-2012, 2012.

Parrish, D. D., Law, K. S., Staehelin, J., Derwent, R., Cooper, O. R., Tanimoto, H., Volz-Thomas, A., Gilge, S., Scheel, H. E., Steinbacher, M., and Chan, E.: Lower tropospheric ozone at northern midlatitudes: Changing seasonal cycle, Geophys. Res. Lett., 40, 1631-1636, doi:10.1002/grl.50303, 2013.

Parrish, D. D., Lamarque, J. F., Naik, V., Horowitz, L., Shindell, D. T., Staehelin, J., Derwent, R., Cooper, O. R., Tanimoto, H., Volz-Thomas, A., Gilge, S., Scheel, H. E., Steinbacher, M., and Frohlich, M.: Long-term changes in lower tropospheric baseline ozone concentrations: Comparing chemistry-climate models and observations at northern midlatitudes, J. Geophys. Res.-Atmos., 119, 5719-5736, doi:10.1002/2013jd021435, 2014.

Paulot, F., Crounse, J. D., Kjaergaard, H. G., Kürten, A., Clair, J. M. S., Seinfeld, J. H., and Wennberg, P. O.: Unexpected epoxide formation in the gas-phase photooxidation of isoprene, Science, 325, 730-733, 2009.

Paulot, F., Henze, D. K., and Wennberg, P. O.: Impact of the isoprene photochemical cascade on tropical ozone, Atmos. Chem. Phys., 12, 1307-1325, doi:10.5194/acp-12-1307-2012, 2012.

Pausata, F. S. R., Pozzoli, L., Vignati, E., and Dentener, F. J.: North Atlantic Oscillation and tropospheric ozone variability in Europe: model analysis and measurements intercomparison, Atmos. Chem. Phys., 12, 6357-6376, doi:10.5194/acp-12-63572012, 2012.

Pechtl, S. and von Glasow, R.: Reactive chlorine in the marine boundary layer in the outflow of polluted continen- 
tal air: A model study, Geophys. Res. Lett., 34, L11813, doi:10.1029/2007g1029761, 2007.

Peeters, J., Nguyen, T. L., and Vereecken, L.: HOx radical regneration in the oxidation of isoprene, Phys. Chem. Chem Phys., 11, 5935-5939, 2009.

Petron, G., Granier, C., Khattatov, B., Yudin, V., Lamarque, J. F., Emmons, L., Gille, J., and Edwards, D. P.: Monthly CO surface sources inventory based on the 20002001 MOPITT satellite data, Geophys. Res. Lett., 31, L21107, doi:10.1029/2004g1020560, 2004.

Pétron, G., Frost, G., Miller, B. R., Hirsch, A. I., Montzka, S. A., Karion, A., Trainer, M., Sweeney, C., Andrews, A. E., Miller, L., Kofler, J., Bar-Ilan, A., Dlugokencky, E. J., Patrick, L., Moore, C. T., Ryerson, T. B., Siso, C., Kolodzey, W., Lang, P. M., Conway, T., Novelli, P., Masarie, K., Hall, B., Guenther, D., Kitzis, D., Miller, J., Welsh, D., Wolfe, D., Neff, W., and Tans, P.: Hydrocarbon emissions characterization in the Colorado Front Range: A pilot study, J. Geophys. Res.-Atmos., 117, D04304, doi:10.1029/2011jd016360, 2012.

Pfister, G., Hess, P. G., Emmons, L. K., Lamarque, J. F., Wiedinmyer, C., Edwards, D. P., Petron, G., Gille, J. C., and Sachse, G. W.: Quantifying CO emissions from the 2004 Alaskan wildfires using MOPITT CO data, Geophys. Res. Lett., 32, L11809, doi:10.1029/2005g1022995, 2005.

Pfister, G. G., Walters, S., Lamarque, J. F., Fast, J., Barth, M. C., Wong, J., Done, J., Holland, G., and Bruyere, C. L.: Projections of future summertime ozone over the US, J. Geophys. Res.Atmos., 119, 5559-5582, doi:10.1002/2013jd020932, 2014.

Phillips, G. J., Tang, M. J., Thieser, J., Brickwedde, B., Schuster, G., Bohn, B., Lelieveld, J., and Crowley, J. N.: Significant concentrations of nitryl chloride observed in rural continental Europe associated with the influence of sea salt chloride and anthropogenic emissions, Geophys. Res. Lett., 39, L10811, doi:10.1029/2012g1051912, 2012.

Piedrahita, R., Xiang, Y., Masson, N., Ortega, J., Collier, A., Jiang, Y., Li, K., Dick, R. P., Lv, Q., Hannigan, M., and Shang, L.: The next generation of low-cost personal air quality sensors for quantitative exposure monitoring, Atmos. Meas. Tech., 7, 3325-3336, doi:10.5194/amt-7-3325-2014, 2014.

Pleijel, H., Karlsson, G. P., Danielsson, H., and Sellden, G.: Surface wetness enhances ozone deposition to a pasture canopy, Atmos. Environ., 29, 3391-3393, 1995.

Pohler, D., Vogel, L., Friess, U., and Platt, U.: Observation of halogen species in the Amundsen Gulf, Arctic, by active long-path differential optical absorption spectroscopy, Proc. Natl. Acad. Sci. USA, 107, 6582-6587, doi:10.1073/pnas.0912231107, 2010.

Pommier, M., Mc Linden, C. A., Neuman, J. A., and Nowak, J. B.: Biomass burning in Siberia as a source of $\mathrm{BrO}$ to the Arctic free troposphere, Atmos. Environ., 62, 416-423, doi:10.1016/j.atmosenv.2012.08.070, 2012.

Porter, W. C., Barsanti, K. C., Baughman, E. C., and Rosenstiel, T. N.: Considering the Air Quality Impacts of Bioenergy Crop Production: A Case Study Involving Arundo donax, Environ. Sci. Technol., 46, 9777-9784, doi:10.1021/es3010841, 2012.

Prather, M., Gauss, M., Berntsen, T., Isaksen, I., Sundet, J., Bey, I., Brasseur, G., Dentener, F., Derwent, R., Stevenson, D., Grenfell, L., Hauglustaine, D., Horowitz, L., Jacob, D., Mickley, L., Lawrence, M., von Kuhlmann, R., Muller, J. F., Pitari, G.,
Rogers, H., Johnson, M., Pyle, J., Law, K., van Weele, M., and Wild, O.: Fresh air in the 21 st century?, Geophys. Res. Lett., 30, 1100, doi:10.1029/2002g1016285, 2003.

Prather, M. J., Zhu, X., Tang, Q., Hsu, J. N., and Neu, J. L.: An atmospheric chemist in search of the tropopause, J. Geophys. Res.Atmos., 116, D04306, doi:10.1029/2010jd014939, 2011.

Price, C. and Rind, D.: A simple lightning parameterization for calculating global lightning distributions, J. Geophys. Res., 97, 9919-9933, 1992.

Puentedura, O., Gil, M., Saiz-Lopez, A., Hay, T., Navarro-Comas, M., Gómez-Pelaez, A., Cuevas, E., Iglesias, J., and Gomez, L.: Iodine monoxide in the north subtropical free troposphere, Atmos. Chem. Phys., 12, 4909-4921, doi:10.5194/acp-12-49092012, 2012.

Rama Gopal, K., Lingaswamy, A. P., Arafath, S. M., Balakrishnaiah, G., Pavan Kumari, S., Uma Devi, K., Siva Kumar Reddy, N., Raja Obul Reddy, K., Reddy, R. R., Abdul Azeem, P., and Lal, S.: Seasonal heterogeneity in ozone and its precursors $\left(\mathrm{NO}_{x}\right)$ by in-situ and model observations on semi-arid station in Anantapur (A.P), South India, Atmos. Environ., 84, 294-306, doi:10.1016/j.atmosenv.2013.10.014, 2014.

Rasmussen, D. J., Hu, J. L., Mahmud, A., and Kleeman, M. J.: The Ozone-Climate Penalty: Past, Present, and Future, Environ. Sci. Technol., 47, 14258-14266, doi:10.1021/es403446m, 2013.

Read, K. A., Mahajan, A. S., Carpenter, L. J., Evans, M. J., Faria, B. V. E., Heard, D. E., Hopkins, J. R., Lee, J. D., Moller, S. J., Lewis, A. C., Mendes, L., McQuaid, J. B., Oetjen, H., Saiz-Lopez, A., Pilling, M. J., and Plane, J. M. C.: Extensive halogen-mediated ozone destruction over the tropical Atlantic Ocean, Nature, 453, 1232-1235, 2008.

Real, E., Law, K. S., Weinzierl, B., Fiebig, M., Petzold, A., Wild, O., Methven, J., Arnold, S., Stohl, A., Huntrierser, H., Roiger, A., Schlager, H., Stewart D., Avery, M., Sachse, G., Browell, E., Ferrare, R., and Blake, D.: Processes influencing ozone levels in Alaskan forest fire plumes during long-range transport over the North Atlantic, J. Geophys. Res., 112, D10S41, doi:10.1029/2006JD007576, 2007.

Redelsperger, J. L., Thorncroft, C. D., Diedhiou, A., Lebel, T., Parker, D. J., and Polcher, J.: African monsoon multidisciplinary analysis - An international research project and field campaign, Bull. Am. Meteorol. Soc., 87, 1739-1746, doi:10.1175/bams-8712-1739, 2006.

Reeve, N. and Toumi, R.: Lightning activity as an indicator of climate change, Q. J. Roy. Meteorol. Soc., 125, 893-903, doi:10.1002/qj.49712555507, 1999.

Reeves, C. E., Formenti, P., Afif, C., Ancellet, G., Attié, J.-L., Bechara, J., Borbon, A., Cairo, F., Coe, H., Crumeyrolle, S., Fierli, F., Flamant, C., Gomes, L., Hamburger, T., Jambert, C., Law, K. S., Mari, C., Jones, R. L., Matsuki, A., Mead, M. I., Methven, J., Mills, G. P., Minikin, A., Murphy, J. G., Nielsen, J. K., Oram, D. E., Parker, D. J., Richter, A., Schlager, H., Schwarzenboeck, A., and Thouret, V.: Chemical and aerosol characterisation of the troposphere over West Africa during the monsoon period as part of AMMA, Atmos. Chem. Phys., 10, 7575-7601, doi:10.5194/acp-10-7575-2010, 2010.

Reich, P. B. and Amundson, R. G.: Ambient levels of ozone reduce net photosynthesis in tree and crop species, Science, 230, 566$570,1985$. 
Reidmiller, D. R., Fiore, A. M., Jaffe, D. A., Bergmann, D., Cuvelier, C., Dentener, F. J., Duncan, B. N., Folberth, G., Gauss, M., Gong, S., Hess, P., Jonson, J. E., Keating, T., Lupu, A., Marmer, E., Park, R., Schultz, M. G., Shindell, D. T., Szopa, S., Vivanco, M. G., Wild, O., and Zuber, A.: The influence of foreign vs. North American emissions on surface ozone in the US, Atmos. Chem. Phys., 9, 5027-5042, doi:10.5194/acp-9-5027-2009, 2009.

Riahi, K., Dentener, F., Gielen, D., Grubler, A., Jewell, J., Klimont, Z., Krey, V., McCollum, D., Pachauri, S., Rao, S., van Ruijven, B., van Vuuren, D. P., and Wilson, C.: Energy Pathways for Sustainable Development, in: Global Energy Assessment: Toward a Sustainable Future, edited by: Nakicenovic, N., IIASA, Laxenburg, Austria and Cambridge University Press, Cambridge, United Kingdom and New York, NY, 2012.

Riedel, T. P., Bertram, T. H., Crisp, T. A., Williams, E. J., Lerner, B. M., Vlasenko, A., Li, S.-M., Gilman, J., de Gouw, J., Bon, D. M., Wagner, N. L., Brown, S. S., and Thornton, J. A.: Nitryl Chloride and Molecular Chlorine in the Coastal Marine Boundary Layer, Environ. Sci. Technol., 46, 10463-10470, doi:10.1021/es204632r, 2012.

Riedel, T. P., Wagner, N. L., Dube, W. P., Middlebrook, A. M., Young, C. J., Ozturk, F., Bahreini, R., VandenBoer, T. C., Wolfe, D. E., Williams, E. J., Roberts, J. M., Brown, S. S., and Thornton, J. A.: Chlorine activation within urban or power plant plumes: Vertically resolved $\mathrm{ClNO}_{2}$ and $\mathrm{Cl}_{2}$ measurements from a tall tower in a polluted continental setting, J. Geophys. Res.-Atmos., 118, 8702-8715, doi:10.1002/jgrd.50637, 2013.

Rodriguez, M. A., Barna, M. G., and Moore, T.: Regional Impacts of Oil and Gas Development on Ozone Formation in the Western United States, J. Air Waste Manage., 59, 1111-1118, doi:10.3155/1047-3289.59.9.1111, 2009.

Rondon, A., Johansson, C., and Granat, L.: Dry Deposition of Nitrogen-Dioxide and Ozone to Coniferous Forests, J. Geophys. Res.-Atmos., 98, 5159-5172, 1993.

Roscoe, H. K., Brough, N., Jones, A. E., Wittrock, F., Richter, A., Van Roozendael, M., and Hendrick, F.: Characterisation of vertical $\mathrm{BrO}$ distribution during events of enhanced tropospheric BrO in Antarctica, from combined remote and in-situ measurements, J. Quant. Spectr. Radiat. Trans., 138, 70-81, doi:10.1016/j.jqsrt.2014.01.026, 2014.

Royal Society: Ground-level ozone in the 21st century: future trends, impacts and policy implications, The Royal Society, London, 2008

Rypdal, K., Berntsen, T., Fuglestvedt, J. S., Aunan, K., Torvanger, A., Stordal, F., Pacyna, J. M., and Nygaard, L. P.: Tropospheric ozone and aerosols in climate agreements: scientific and political challenges, Environ. Sci. Policy, 8, 29-43, doi:10.1016/j.envsci.2004.09.003, 2005.

Sahu, S. K., Beig, G., and Parkhi, N. S.: Emerging pattern of anthropogenic $\mathrm{NO}_{x}$ emission over Indian subcontinent during 1990s and 2000s, Atmos. Pollut. Res., 3, 262-269, doi:10.5094/apr.2012.021, 2012.

Saide, P., Bocquet, M., Osses, A., and Gallardo, L.: Constraining surface emissions of air pollutants using inverse modelling: method intercomparison and a new two-step twoscale regularization approach, Tellus Ser. B, 63, 360-370, doi:10.1111/j.1600-0889.2011.00529.x, 2011.
Saiz-Lopez, A. and von Glasow, R.: Reactive halogen chemistry in the troposphere, Chem. Soc. Rev., 41, 6448-6472, doi:10.1039/c2cs35208g, 2012.

Saiz-Lopez, A., Plane, J. M. C., Mahajan, A. S., Anderson, P. S., Bauguitte, S. J.-B., Jones, A. E., Roscoe, H. K., Salmon, R. A., Bloss, W. J., Lee, J. D., and Heard, D. E.: On the vertical distribution of boundary layer halogens over coastal Antarctica: implications for $\mathrm{O}_{3}, \mathrm{HO}_{\mathrm{x}}, \mathrm{NO}_{\mathrm{x}}$ and the $\mathrm{Hg}$ lifetime, Atmos. Chem. Phys., 8, 887-900, doi:10.5194/acp-8-887-2008, 2008.

Saiz-Lopez, A., Plane, J. M., Baker, A. R., Carpenter, L. J., von Glasow, R., Gómez Martín, J. C., McFiggans, G., and Saunders, R. W.: Atmospheric chemistry of iodine, Chem. Rev., 112, 17731804, 2011.

Saiz-Lopez, A., Lamarque, J.-F., Kinnison, D. E., Tilmes, S., Ordóñez, C., Orlando, J. J., Conley, A. J., Plane, J. M. C., Mahajan, A. S., Sousa Santos, G., Atlas, E. L., Blake, D. R., Sander, S. P., Schauffler, S., Thompson, A. M., and Brasseur, G.: Estimating the climate significance of halogen-driven ozone loss in the tropical marine troposphere, Atmos. Chem. Phys., 12, 3939-3949, doi:10.5194/acp-12-3939-2012, 2012a.

Saiz-Lopez, A., Plane, J. M. C., Baker, A. R., Carpenter, L. J., von Glasow, R., Martin, J. C. G., McFiggans, G., and Saunders, R. W.: Atmospheric Chemistry of Iodine, Chem. Rev., 112, 17731804, doi:10.1021/cr200029u, 2012 b.

Salawitch, R. J., Canty, T., Kurosu, T., Chance, K., Liang, Q., da Silva, A., Pawson, S., Nielsen, J. E., Rodriguez, J. M., Bhartia P. K., Liu, X., Huey, L. G., Liao, J., Stickel, R. E., Tanner, D. J., Dibb, J. E., Simpson, W. R., Donohoue, D., Weinheimer, A., Flocke, F., Knapp, D., Montzka, D., Neuman, J. A., Nowak, J. B., Ryerson, T. B., Oltmans, S., Blake, D. R., Atlas, E. L., Kinnison, D. E., Tilmes, S., Pan, L. L., Hendrick, F., Van Roozendael, M., Kreher, K., Johnston, P. V., Gao, R. S., Johnson, B., Bui, T. P., Chen, G., Pierce, R. B., Crawford, J. H., and Jacob, D. J.: A new interpretation of total column $\mathrm{BrO}$ during Arctic spring, Geophys. Res. Lett., 37, L21805, doi:10.1029/2010g1043798, 2010.

Sanchez-Ccoyllo, O. R., Silva Dias, P. L., Andrade, M. D., and Freitas, S. R.: Determination of $\mathrm{O}_{3}, \mathrm{CO}$ and PM10 transport in the metropolitan area of Sao Paulo, Brazil through synoptic-scale analysis of back trajectories, Meteorol. Atmos. Phys., 92, 83-93, doi:10.1007/s00703-005-0139-6, 2006.

Sanchez, M. L., Rodriguez, R., and Lopez, A.: Ozone dry deposition in a semi-arid steppe and in a coniferous forest in southern Europe, J. Air Waste Manage. Assoc., 47, 792-799, 1997.

Sander, R., Keene, W. C., Pszenny, A. A. P., Arimoto, R., Ayers, G. P., Baboukas, E., Cainey, J. M., Crutzen, P. J., Duce, R. A., Hönninger, G., Huebert, B. J., Maenhaut, W., Mihalopoulos, N., Turekian, V. C., and Van Dingenen, R.: Inorganic bromine in the marine boundary layer: a critical review, Atmos. Chem. Phys., 3, 1301-1336, doi:10.5194/acp-3-1301-2003, 2003.

Sanderson, M. G., Jones, C. D., Collins, W. J., Johnson, C. E., and Derwent, R. G.: Effect of climate change on isoprene emissions and surface ozone levels, Geophys. Res. Lett., 30, 1936, doi:10.1029/2003g1017642, 2003.

Sarwar, G., Simon, H., Bhave, P., and Yarwood, G.: Examining the impact of heterogeneous nitryl chloride production on air quality across the United States, Atmos. Chem. Phys., 12, 6455-6473, doi:10.5194/acp-12-6455-2012, 2012.

Sauvage, B., Thouret, V., Cammas, J.-P., Gheusi, F., Athier, G., and Nédélec, P.: Tropospheric ozone over Equatorial Africa: regional 
aspects from the MOZAIC data, Atmos. Chem. Phys., 5, 311335, doi:10.5194/acp-5-311-2005, 2005.

Sauvage, B., Thouret, V., Thompson, A. M., Witte, J. C., Cammas, J. P., Nedelec, P., and Athier, G.: Enhanced view of the "tropical Atlantic ozone paradox" and "zonal wave one" from the in situ MOZAIC and SHADOZ data, J. Geophys. Res., 111, D01301, doi:10.1029/2005JD006241, 2006.

Sauvage, B., Martin, R. V., van Donkelaar, A., and Ziemke, J. R.: Quantification of the factors controlling tropical tropospheric ozone and the South Atlantic maximum, J. Geophys. Res., 112, D11309, doi:10.1029/2006JD008008, 2007a.

Sauvage, B., Thouret, V., Cammas, J. P., Brioude, J., Nedelec, P., and Mari, C.: Meridional ozone gradients in the African upper troposphere, Geophys. Res. Lett., 34, L03817, doi:10.1029/2006GL028542, 2007b.

Saylor, R. D. and Stein, A. F.: Identifying the causes of differences in ozone production from the CB05 and CBMIV chemical mechanisms, Geosci. Model Dev., 5, 257-268, doi:10.5194/gmd-5257-2012, 2012.

Schneising, O., Burrows, J. P., Dickerson, R. R., Buchwitz, M., Reuter, M., and Bovensmann, H.: Remote sensing of fugitive methane emissions from oil and gas production in North American tight geologic formations, Earth's Future, 2, 548-558, doi:10.1002/2014ef000265, 2014.

Schnell, R. C., Oltmans, S. J., Neely, R. R., Endres, M. S., Molenar, J. V., and White, A. B.: Rapid photochemical production of ozone at high concentrations in a rural site during winter, Nat. Geosci., 2, 120-122, doi:10.1038/ngeo415, 2009.

Schönbein, C. F.: Über die Natur eigenthümlichen Grueches, welcher sich sowohl am positiven Pole einer Saüle während der Wasserelektrolys, wie auch beim Ausströmen der gewöhnlichen Elektrizität aus Spotzen entwickelt, Ann. Phys., 135, 240-255, 1843.

Schultz, M., Rast, S., van het Bolscher, M., Pulles, T., Brand, R., Pereira, J., Mota, B., Spessa, A., Dalsøren, S., van Nojie, T., and Szopa, S.: Emission data sets and methodologies for estimating emissions, Final Report, Jülich/Hamburg, Germany 2007a.

Schultz, M. G., Backman, L., Balkanski, Y., Bjoerndalsaeter, S., Brand, R., Burrows, J. P., Dalsoeren, S., Vasconcelos, M. d., Grodtmann, B., Hauglustaine, D. A., Heil, A., Hoelzemann, J. J., Isaksen, I. S. A., Kaurola, J., Knorr, W., LadstaetterWeißenmayer, A., Mota, B., Oom, D., Pacyna, J., Panasiuk, D., Pereira, J. M. C., Pulles, T., Pyle, J., Rast, S., Richter, A., Savage, N., Schnadt, C., Schulz, M., Spessa, A., Staehelin, J., Sundet, J. K., Szopa, S., Thonicke, K., Bolscher, M. V. H., Noije, T. V., Velthoven, P. V., Vik, A. F., and Wittrock, F.: REanalysis of the TROpospheric chemical composition over the past 40 years (RETRO) - A long-term global modeling study of tropospheric chemistry - Final Report, Jülich/Hamburg, Germany, 2007b.

Schultz, M. G., Heil, A., Hoelzemann, J. J., Spessa, A., Thonicke, K., Goldammer, J., Held, A. C., and Pereira, J. M.: Global Emissions from Wildland Fires from 1960 to 2000, Global Biogeochem. Cy., 22, GB2002, doi:10.1029/2007GB003031, 2008.

Schumann, U. and Huntrieser, H.: The global lightning-induced nitrogen oxides source, Atmos. Chem. Phys., 7, 3823-3907, doi:10.5194/acp-7-3823-2007, 2007.

Seinfeld, J. H. and Pandis, S. N.: Atmospheric Chemistry and Physics: From Air Pollution to Climate Change, 2nd Edn., Wiley, 2006.
Sekiya, T. and Sudo, K.: Roles of transport and chemistry processes in global ozone change on interannual and multidecadal time scales, J. Geophys. Res.-Atmos., 119, 4903-4921, doi:10.1002/2013jd020838, 2014.

Sellitto, P., Dufour, G., Eremenko, M., Cuesta, J., Dauphin, P., Forêt, G., Gaubert, B., Beekmann, M., Peuch, V.-H., and Flaud, J.-M.: Analysis of the potential of one possible instrumental configuration of the next generation of IASI instruments to monitor lower tropospheric ozone, Atmos. Meas. Tech., 6, 621-635, doi:10.5194/amt-6-621-2013, 2013.

Sheps, L.: Absolute Ultraviolet Absorption Spectrum of a Criegee Intermediate CH2OO, J. Phys. Chem. Lett., 4, 4201-4205, 2013.

Shindell, D.: Local and remote contributions to Arctic warming, Geophys. Res. Lett., 34, L14704, doi:10.1029/2007g1030221, 2007.

Shindell, D., Faluvegi, G., Lacis, A., Hansen, J., Ruedy, R., and Aguilar, E.: Role of tropospheric ozone increases in 20thcentury climate change, J. Geophys. Res.-Atmos., 111, L04803, doi:10.1029/2005jd006348, 2006.

Shindell, D., Schulz, M., Ming, Y., Takemura, T., Faluvegi, G., and Ramaswamy, V.: Spatial scales of climate response to inhomogeneous radiative forcing, J. Geophys. Res.-Atmos., 115, D19110, doi:10.1029/2010jd014108, 2010.

Shindell, D., Kuylenstierna, J. C. I., Vignati, E., van Dingenen, R., Amann, M., Klimont, Z., Anenberg, S. C., Muller, N., Janssens-Maenhout, G., Raes, F., Schwartz, J., Faluvegi, G., Pozzoli, L., Kupiainen, K., Höglund-Isaksson, L., Emberson, L., Streets, D., Ramanathan, V., Hicks, K., Oanh, N. T. K., Milly, G., Williams, M., Demkine, V., and Fowler, D.: Simultaneously Mitigating Near-Term Climate Change and Improving Human Health and Food Security, Science, 335, 183-189, doi:10.1126/science.1210026, 2012.

Shindell, D. T.: Inhomogeneous forcing and transient climate sensitivity, Nat. Clim. Chang., 4, 274-277, doi:10.1038/nclimate2136, 2014.

Shindell, D. T., Faluvegi, G., Bell, N., and Schmidt, G. A.: An emissions-based view of climate forcing by methane and tropospheric ozone, Geophys. Res. Lett., 32, L04803, doi:10.1029/2004g1021900, 2005.

Shindell, D. T., Chin, M., Dentener, F., Doherty, R. M., Faluvegi, G., Fiore, A. M., Hess, P., Koch, D. M., MacKenzie, I. A., Sanderson, M. G., Schultz, M. G., Schulz, M., Stevenson, D. S., Teich, H., Textor, C., Wild, O., Bergmann, D. J., Bey, I., Bian, H., Cuvelier, C., Duncan, B. N., Folberth, G., Horowitz, L. W., Jonson, J., Kaminski, J. W., Marmer, E., Park, R., Pringle, K. J., Schroeder, S., Szopa, S., Takemura, T., Zeng, G., Keating, T. J., and Zuber, A.: A multi-model assessment of pollution transport to the Arctic, Atmos. Chem. Phys., 8, 5353-5372, doi:10.5194/acp-85353-2008, 2008.

Shindell, D. T., Faluvegi, G., Koch, D. M., Schmidt, G. A., Unger, N., and Bauer, S. E.: Improved Attribution of Climate Forcing to Emissions, Science, 326, 716-718, doi:10.1126/science.1174760, 2009.

Shindell, D. T., Lamarque, J.-F., Schulz, M., Flanner, M., Jiao, C., Chin, M., Young, P. J., Lee, Y. H., Rotstayn, L., Mahowald, N., Milly, G., Faluvegi, G., Balkanski, Y., Collins, W. J., Conley, A. J., Dalsoren, S., Easter, R., Ghan, S., Horowitz, L., Liu, X., Myhre, G., Nagashima, T., Naik, V., Rumbold, S. T., Skeie, R., Sudo, K., Szopa, S., Takemura, T., Voulgarakis, A., Yoon, J.-H., 
and Lo, F.: Radiative forcing in the ACCMIP historical and future climate simulations, Atmos. Chem. Phys., 13, 2939-2974, doi:10.5194/acp-13-2939-2013, 2013.

Sicard, P., De Marco, A., Troussier, F., Renou, C., Vas, N., and Paoletti, E.: Decrease in surface ozone concentrations at Mediterranean remote sites and increase in the cities, Atmos. Environ., 79, 705-715, doi:10.1016/j.atmosenv.2013.07.042, 2013.

Siegert, F., Ruecker, G., Hinrichs, A., and Hoffmann, A. A.: Increased damage from fires in logged forests during droughts caused by El Nino, Nature, 414, 437-440, doi:10.1038/35106547, 2001

Silva, G. D., Graham, C., and Wang, Z.-F.: Unimolecular $\beta$ hydroxyperoxy radical decomposition with $\mathrm{OH}$ recycling in the photochemical oxidation of isoprene, Environ. Sci. Technol., 44, 250-256, 2009.

Silva, R. A., West, J. J., Zhang, Y., Anenberg, S. C., Lamarque, J.F., Shindell, D. T., Collins, W. J., Dalsoren, S., Faluvegi, G., Folberth, G., Horowitz, L. W., Nagashima, T., Naik, V., Rumbold, S., Skeie, R., Sudo, K., Takemura, T., Bergmann, D., CameronSmith, P., Cionni, I., Doherty, R. M., Eyring, V., Josse, B., MacKenzie, I. A., Plummer, D., Righi, M., Stevenson, D. S., Strode, S., Szopa, S., and Zeng, G.: Global premature mortality due to anthropogenic outdoor air pollution and the contribution of past climate change, Environ. Res. Lett., 8, UNSP 034005, doi:10.1088/1748-9326/8/3/034005, 2013.

Simmonds, P. G., Derwent, R. G., Manning, A. L., and Spain, G.: Significant growth in surface ozone at Mace Head, Ireland, 1987-2003, Atmos. Environ., 38, 4769-4778, 2004.

Simon, H., Kimura, Y., McGaughey, G., Allen, D. T., Brown, S. S., Osthoff, H. D., Roberts, J. M., Byun, D., and Lee, D.: Modeling the impact of $\mathrm{ClNO}_{2}$ on ozone formation in the Houston area, J. Geophys. Res.-Atmos., 114, D00F03, doi:10.1029/2008jd010732, 2009.

Simon, H., Kimura, Y., McGaughey, G., Allen, D. T., Brown, S. S., Coffman, D., Dibb, J., Osthoff, H. D., Quinn, P., Roberts, J. M., Yarwood, G., Kemball-Cook, S., Byun, D., and Lee, D.: Modeling heterogeneous $\mathrm{ClNO}_{2}$ formation, chloride availability, and chlorine cycling in Southeast Texas, Atmos. Environ., 44, 54765488, doi:10.1016/j.atmosenv.2009.09.006, 2010.

Simon, H., Reff, A., Wells, B., Xing, J., and Frank, N.: Ozone Trends Across the United States over a Period of Decreasing $\mathrm{NO}_{x}$ and VOC Emissions, Environ. Sci. Technol., 49, 186-195, doi:10.1021/es504514z, 2015.

Simpson, D., Arneth, A., Mills, G., Solberg, S., and Uddling, J.: Ozone - the persistent menace: interactions with the $\mathrm{N}$ cycle and climate change, Curr. Opinion Environ. Sustain., 9-10, 919,doi:10.1016/j.cosust.2014.07.008, 2014.

Simpson, W. R., von Glasow, R., Riedel, K., Anderson, P., Ariya, P., Bottenheim, J., Burrows, J., Carpenter, L. J., Frieß, U., Goodsite, M. E., Heard, D., Hutterli, M., Jacobi, H.-W., Kaleschke, L., Neff, B., Plane, J., Platt, U., Richter, A., Roscoe, H., Sander, R., Shepson, P., Sodeau, J., Steffen, A., Wagner, T., and Wolff, E.: Halogens and their role in polar boundary-layer ozone depletion, Atmos. Chem. Phys., 7, 4375-4418, doi:10.5194/acp-74375-2007, 2007.

Sindelarova, K., Granier, C., Bouarar, I., Guenther, A., Tilmes, S., Stavrakou, T., Müller, J.-F., Kuhn, U., Stefani, P., and Knorr, W.: Global data set of biogenic VOC emissions calculated by the
MEGAN model over the last 30 years, Atmos. Chem. Phys., 14, 9317-9341, doi:10.5194/acp-14-9317-2014, 2014.

Singh, H. B., Anderson, B. E., Brune, W. H., Cai, C., Cohen, R. C., Crawford, J. H., Cubison, M. J., Czech, E. P., Emmons, L., Fuelberg, H. E., Huey, G., Jacob, D. J., Jimenez, J. L., Kaduwela, A., Kondo, Y., Mao, J., Olson, J. R., Sachse, G. W., Vay, S. A., Weinheimer, A., Wennberg, P. O., Wisthaler, A., and Team, A. S.: Pollution influences on atmospheric composition and chemistry at high northern latitudes: Boreal and California forest fire emissions, Atmos. Environ., 44, 4553-4564, doi:10.1016/j.atmosenv.2010.08.026, 2010.

Sinha, B., Singh Sangwan, K., Maurya, Y., Kumar, V., Sarkar, C., Chandra, B. P., and Sinha, V.: Assessment of crop yield losses in Punjab and Haryana using two years of continuous in-situ ozone measurements, Atmos. Chem. Phys. Discuss., 15, 2355-2404, doi:10.5194/acpd-15-2355-2015, 2015.

Sinha, V., Kumar, V., and Sarkar, C.: Chemical composition of premonsoon air in the Indo-Gangetic Plain measured using a new air quality facility and PTR-MS: high surface ozone and strong influence of biomass burning, Atmos. Chem. Phys., 14, 59215941, doi:10.5194/acp-14-5921-2014, 2014.

Siour, G., Colette, A., Menut, L., Bessagnet, B., Coll, I., and Meleux, F.: Bridging the scales in a eulerian air quality model to assess megacity export of pollution, Environ. Modell. Softw., 46, 271-282, doi:10.1016/j.envsoft.2013.04.001, 2013.

Sitch, S., Smith, B., Prentice, I. C., Arneth, A., Bondeau, A., Cramer, W., Kaplan, J. O., Levis, S., Lucht, W., Sykes, M. T., Thonicke, K., and Venevsky, S.: Evaluation of ecosystem dynamics, plant geography and terrestrial carbon cycling in the LPJ dynamic global vegetation model, Glob. Change Biol., 9, 161-185, doi:10.1046/j.1365-2486.2003.00569.x, 2003.

Sitch, S., Cox, P. M., Collins, W. J., and Huntingford, C.: Indirect radiative forcing of climate change through ozone effects on the land-carbon sink, Nature, 448, 791-U794, doi:10.1038/nature06059, 2007.

Situ, S., Guenther, A., Wang, X., Jiang, X., Turnipseed, A., Wu, Z., Bai, J., and Wang, X.: Impacts of seasonal and regional variability in biogenic VOC emissions on surface ozone in the Pearl River delta region, China, Atmos. Chem. Phys., 13, 11803 11817, doi:10.5194/acp-13-11803-2013, 2013.

Skeie, R. B., Berntsen, T. K., Myhre, G., Tanaka, K., Kvalevåg, M. M., and Hoyle, C. R.: Anthropogenic radiative forcing time series from pre-industrial times until 2010, Atmos. Chem. Phys., 11, 11827-11857, doi:10.5194/acp-11-11827-2011, 2011.

Smith, K. R., Jerrett, M., Anderson, H. R., Burnett, R. T., Stone, V., Derwent, R., Atkinson, R. W., Cohen, A., Shonkoff, S. B., Krewski, D., Pope, C. A., Thun, M. J., and Thurston, G.: Health and Climate Change 5 Public health benefits of strategies to reduce greenhouse-gas emissions: health implications of short-lived greenhouse pollutants, Lancet, 374, 2091-2103, doi:10.1016/s0140-6736(09)61716-5, 2009.

Smoydzin, L. and von Glasow, R.: Modelling chemistry over the Dead Sea: bromine and ozone chemistry, Atmos. Chem. Phys. 9, 5057-5072, doi:10.5194/acp-9-5057-2009, 2009.

Snyder, E. G., Watkins, T. H., Solomon, P. A., Thoma, E. D., Williams, R. W., Hagler, G. S. W., Shelow, D., Hindin, D. A., Kilaru, V. J., and Preuss, P. W.: The Changing Paradigm of Air Pollution Monitoring, Environ. Sci. Technol., 47, 11369-11377, doi:10.1021/es4022602, 2013. 
Sofiev, M., Vankevich, R., Lotjonen, M., Prank, M., Petukhov, V., Ermakova, T., Koskinen, J., and Kukkonen, J.: An operational system for the assimilation of the satellite information on wildland fires for the needs of air quality modelling and forecasting, Atmos. Chem. Phys., 9, 6833-6847, doi:10.5194/acp-9-68332009, 2009.

Sofiev, M., Vankevich, R., Ermakova, T., and Hakkarainen, J.: Global mapping of maximum emission heights and resulting vertical profiles of wildfire emissions, Atmos. Chem. Phys., 13, 7039-7052, doi:10.5194/acp-13-7039-2013, 2013.

Sommariva, R. and von Glasow, R.: Multiphase Halogen Chemistry in the Tropical Atlantic Ocean, Environ. Sci. Technol., 46, 10429-10437, doi:10.1021/es300209f, 2012.

Sommariva, R., Bloss, W. J., and von Glasow, R.: Uncertainties in gas-phase atmospheric iodine chemistry, Atmos. Environ., 57, 219-232, doi:10.1016/j.atmosenv.2012.04.032, 2012.

Sommariva, R., Blake, R. S., Cuss, R. J., Cordell, R. L., Harrington, J. F., White, I. R., and Monks, P. S.: Observations of the Release of Non-methane Hydrocarbons from Fractured Shale, Environ. Sci. Technol., 48, 8891-8896, doi:10.1021/es502508w, 2014.

Song, J., Lei, W., Bei, N., Zavala, M., de Foy, B., Volkamer, R., Cardenas, B., Zheng, J., Zhang, R., and Molina, L. T.: Ozone response to emission changes: a modeling study during the MCMA-2006/MILAGRO Campaign, Atmos. Chem. Phys., 10, 3827-3846, doi:10.5194/acp-10-3827-2010, 2010.

Squire, O. J., Archibald, A. T., Griffiths, P. T., Jenkin, M. E., Smith, D., and Pyle, J. A.: Influence of isoprene chemical mechanism on modelled changes in tropospheric ozone due to climate and land use over the 21 st century, Atmos. Chem. Phys., 15, 5123-5143, doi:10.5194/acp-15-5123-2015, 2015.

Staehelin, J.: Ozone Measurements and Trends (Troposphere), in: Encyclopedia of Physical Science and Technology, 3rd Edn., edited by: Meyers, R. A., Academic Press, New York, 539-561, 2003.

Staehelin, J., Thudium, J., Buehler, R., Volzthomas, A., and Graber, W.: Trends in surface ozone concetrations at Arosa (Switzerland), Atmos. Environ., 28, 75-87, 1994.

Stavrakou, T., Muller, J. F., Boersma, K. F., De Smedt, I., and van der A, R. J.: Assessing the distribution and growth rates of $\mathrm{NO}_{x}$ emission sources by inverting a 10-year record of $\mathrm{NO}_{2}$ satellite columns, Geophys. Res. Lett., 35, L10801, doi:10.1029/2008GL033521, 2008.

Stavrakou, T., Müller, J.-F., De Smedt, I., Van Roozendael, M., van der Werf, G. R., Giglio, L., and Guenther, A.: Evaluating the performance of pyrogenic and biogenic emission inventories against one decade of space-based formaldehyde columns, Atmos. Chem. Phys., 9, 1037-1060, doi:10.5194/acp-9-1037-2009, 2009.

Stavrakou, T., Guenther, A., Razavi, A., Clarisse, L., Clerbaux, C., Coheur, P.-F., Hurtmans, D., Karagulian, F., De Mazière, M., Vigouroux, C., Amelynck, C., Schoon, N., Laffineur, Q., Heinesch, B., Aubinet, M., Rinsland, C., and Müller, J.-F.: First space-based derivation of the global atmospheric methanol emission fluxes, Atmos. Chem. Phys., 11, 4873-4898, doi:10.5194/acp-11-4873-2011, 2011.

Stedman, J. R.: The predicted number of air pollution related deaths in the UK during the August 2003 heatwave, Atmos. Environ., 3, 1087-1090, 2004.
Stein, O., Schultz, M. G., Bouarar, I., Clark, H., Huijnen, V., Gaudel, A., George, M., and Clerbaux, C.: On the wintertime low bias of Northern Hemisphere carbon monoxide found in global model simulations, Atmos. Chem. Phys., 14, 9295-9316, doi:10.5194/acp-14-9295-2014, 2014.

Stella, P., Personne, E., Loubet, B., Lamaud, E., Ceschia, E., Béziat, P., Bonnefond, J. M., Irvine, M., Keravec, P., Mascher, N., and Cellier, P.: Predicting and partitioning ozone fluxes to maize crops from sowing to harvest: the Surfatm- $\mathrm{O}_{3}$ model, Biogeosciences, 8, 2869-2886, doi:10.5194/bg-8-2869-2011, 2011.

Stevenson, D. S. and Derwent, R. G.: Does the location of aircraft nitrogen oxide emissions affect their climate impact?, Geophys. Res. Lett., 36, L17810, doi:10.1029/2009g1039422, 2009.

Stevenson, D. S., Dentener, F. J., Schultz, M. G., Ellingsen, K., van Noije, T. P. C., Wild, O., Zeng, G., Amann, M., Atherton, C. S., Bell, N., Bergmann, D. J., Bey, I., Butler, T., Cofala, J., Collins, W. J., Derwent, R. G., Doherty, R. M., Drevet, J., Eskes, H. J., Fiore, A. M., Gauss, M., Hauglustaine, D. A., Horowitz, L. W., Isaksen, I. S. A., Krol, M. C., Lamarque, J. F., Lawrence, M. G., Montanaro, V., Muller, J. F., Pitari, G., Prather, M. J., Pyle, J. A., Rast, S., Rodriguez, J. M., Sanderson, M. G., Savage, N. H., Shindell, D. T., Strahan, S. E., Sudo, K., and Szopa, S.: Multimodel ensemble simulations of present-day and near-future tropospheric ozone, J. Geophys. Res.-Atmos., 111, D08301, doi:10.1029/2005jd006338, 2006.

Stevenson, D. S., Young, P. J., Naik, V., Lamarque, J.-F., Shindell, D. T., Voulgarakis, A., Skeie, R. B., Dalsoren, S. B., Myhre, G., Berntsen, T. K., Folberth, G. A., Rumbold, S. T., Collins, W. J., MacKenzie, I. A., Doherty, R. M., Zeng, G., van Noije, T. P. C., Strunk, A., Bergmann, D., Cameron-Smith, P., Plummer, D. A., Strode, S. A., Horowitz, L., Lee, Y. H., Szopa, S., Sudo, K., Nagashima, T., Josse, B., Cionni, I., Righi, M., Eyring, V., Conley, A., Bowman, K. W., Wild, O., and Archibald, A.: Tropospheric ozone changes, radiative forcing and attribution to emissions in the Atmospheric Chemistry and Climate Model Intercomparison Project (ACCMIP), Atmos. Chem. Phys., 13, 3063-3085, doi:10.5194/acp-13-3063-2013, 2013.

Stjernberg, A.-C. E., Skorokhod, A., Paris, J. D., Elansky, N., Nedelec, P., and Stohl, A.: Low concentrations of near-surface ozone in Siberia, Tellus Ser. B, 64, 1-13, doi:10.3402/tellusb.v64i0.11607, 2012.

Stock, Z. S., Russo, M. R., Butler, T. M., Archibald, A. T., Lawrence, M. G., Telford, P. J., Abraham, N. L., and Pyle, J. A.: Modelling the impact of megacities on local, regional and global tropospheric ozone and the deposition of nitrogen species, Atmos. Chem. Phys., 13, 12215-12231, doi:10.5194/acp-1312215-2013, 2013.

Stohl, A. and Eckhardt, S.: Intercontinental Transport of Air Pollution: An Introduction, Intercontinental Tranport of Air Pollution, The Handbook of Environmental Chemistry, Part G, Springer, Berlin Heidelberg New York, 2004.

Stohl, A., Bonasoni, P., Cristofanelli, P., Collins, W. J., Feichter, J., Frank, A., Forster, C., Gerasopoulos, E., Gäggeler, H., James, P., Kentarchos, T., Kromp-Kalb, H., Krüger, B., Land, C., Meloen, J., Papayannis, A., Priller, A., Seibert, P., Sprenger, M., Roelofs, G. J., Scheel, H. E., Schnabel, C., Siegmund, P., Tobler, L., Trickl, T., Wernli, H., Wirth, V., Zanis, P., and Zerefos, C.: Stratosphere-troposphere exchange: A review, and what 
we have learned from STACCATO, J. Geophys. Res., 108, 8516, doi:10.1029/2002JD002490, 2003.

Stone, D., Whalley, L. K., and Heard, D. E.: Tropospheric OH and $\mathrm{HO}_{2}$ radicals: field measurements and model comparisons, Chem. Soc. Rev., 41, 6348-6404, doi:10.1039/c2cs35140d, 2012.

Stone, D., Blitz, M., Daubney, L., Howes, N. U., and Seakins, P.: Kinetics of $\mathrm{CH}_{2} \mathrm{OO}$ reactions with $\mathrm{SO}_{2}, \mathrm{NO}_{2}, \mathrm{NO}, \mathrm{H}_{2} \mathrm{O}$ and $\mathrm{CH}_{3} \mathrm{CHO}$ as a function of pressure, Phys. Chem. Chem. Phys., 16, 1139-1149, 2014.

Streets, D. G., Canty, T., Carmichael, G. R., de Foy, B., Dickerson, R. R., Duncan, B. N., Edwards, D. P., Haynes, J. A., Henze, D. K., Houyoux, M. R., Jacob, D. J., Krotkov, N. A., Lamsal, L. N., Liu, Y., Lu, Z., Martin, R. V., Pfister, G. G., Pinder, R. W., Salawitch, R. J., and Wecht, K. J.: Emissions estimation from satellite retrievals: A review of current capability, Atmos. Environ., 77, 1011-1042, doi:10.1016/j.atmosenv.2013.05.051, 2013.

Stuber, N., Ponater, M., and Sausen, R.: Why radiative forcing might fail as a predictor of climate change, Clim. Dynam., 24, 497-510, doi:10.1007/s00382-004-0497-7, 2005.

Stutz, J., Ackermann, R., Fast, J. D., and Barrie, L.: Atmospheric reactive chlorine and bromine at the Great Salt Lake, Utah, Geophys. Res. Lett., 29, 1380, doi:10.1029/2002g1014812, 2002.

Su, Y.-T., Lin, H.-Y., Putikam, R., Matsui, H., Lin, M., and Lee, Y.-P.: Extremely rapid self-reaction of the simplest Criegee intermediate $\mathrm{CH}_{2} \mathrm{OO}$ and its implications in atmospheric chemistry, Nature chemistry, 6 477-483, 2014.

Suddick, E. C., Whitney, P., Townsend, A. R., and Davidson, E. A.: The role of nitrogen in climate change and the impacts of nitrogen-climate interactions in the United States: foreword to thematic issue, Biogeochemistry, 114, 1-10, doi:10.1007/s10533-012-9795-z, 2013.

Sutton, M. A., Howard, C. M., Erisman, J. W., Billen, G., Bleeker, A., Grenfelt, P., Grinsven, H. V., and Grizzetti, B.: The European Nitrogen Assessment: Sources, Effects and Policy Perspectives, Cambridge University Press, Cambridge, 664 pp., 2011.

Szopa, S., Hauglustaine, D. A., Vautard, R., and Menut, L.: Future global tropospheric ozone changes and impact on European air quality, Geophys. Res. Lett., 33, L14805, doi:10.1029/2006GL025860, 2006.

Taatjes, C. A., Meloni, G., Selby, T. M., Trevitt, A. J., Osborn, D. L., Percival, C. J., and Shallcross, D. E.: Direct observation of the gas-phase Criegee intermediate $\left(\mathrm{CH}_{2} \mathrm{OO}\right)$, J. Am. Chem. Soc., 130, 11883-11885, 2008.

Taatjes, C. A., Welz, O., Eskola, A. J., Savee, J. D., Scheer, A. M., Shallcross, D. E., Rotavera, B., Lee, E. P., Dyke, J. M., Mok, D. K., Osborne, D. L., and Percival, C. J.: Direct Measurements of Conformer-Dependent Reactivity of the Criegee Intermediate $\mathrm{CH}_{3} \mathrm{CHOO}$, Science, 340, 177-180, 2013.

Taatjes, C. A., Shallcross, D. E., and Percival, C. J.: Research frontiers in the chemistry of Criegee intermediates and tropospheric ozonolysis, Phys. Chem. Chem. Phys., 16, 1704-1718, doi:10.1039/c3cp52842a, 2014.

Tagaris, E., Manomaiphiboon, K., Liao, K.-J., Leung, L. R., Woo, J.-H., He, S., Amar, P., and Russell, A. G.: Impacts of global climate change and emissions on regional ozone and fine particulate matter concentrations over the United States, J. Geophys. Res.-Atmos., 112, D14312, doi:10.1029/2006JD008262, 2007.
Tagaris, E., Sotiropoulou, R. E. P., Gounaris, N., Andronopoulos, S., and Vlachogiannis, D.: Impact of biogenic emissions on ozone and fine particles over Europe: Comparing effects of temperature increase and a potential anthropogenic $\mathrm{NO}_{x}$ emissions abatement strategy, Atmos. Environ., 98, 214-223, doi:10.1016/j.atmosenv.2014.08.056, 2014.

Tai, A. P. K., Mickley, L. J., Heald, C. L., and Wu, S. L.: Effect of $\mathrm{CO}_{2}$ inhibition on biogenic isoprene emission: Implications for air quality under 2000 to 2050 changes in climate, vegetation, and land use, Geophys. Res. Lett., 40, 3479-3483, doi:10.1002/grl.50650, 2013.

Tai, A. P. K., Martin, M. V., and Heald, C. L.: Threat to future global food security from climate change and ozone air pollution, Nature Clim. Change, 4, 817-821, doi:10.1038/nclimate2317, 2014.

Tang, G., Li, X., Wang, Y., Xin, J., and Ren, X.: Surface ozone trend details and interpretations in Beijing, 2001-2006, Atmos. Chem. Phys., 9, 8813-8823, doi:10.5194/acp-9-8813-2009, 2009.

Tang, H., Pang, J., Zhang, G., Takigawa, M., Liu, G., Zhu, J., and Kobayashi, K.: Mapping ozone risks for rice in China for years 2000 and 2020 with flux-based and exposure-based doses, Atmos. Environ., 86, 74-83, doi:10.1016/j.atmosenv.2013.11.078, 2014.

Tang, Q., Prather, M. J., and Hsu, J.: Stratosphere-troposphere exchange ozone flux related to deep convection, Geophys. Res. Lett., 38, L03806, doi:10.1029/2010g1046039, 2011.

Tang, Q., Hess, P. G., Brown-Steiner, B., and Kinnison, D. E.: Tropospheric ozone decrease due to the Mount Pinatubo eruption: Reduced stratospheric influx, Geophys. Res. Lett., 40, 55535558, doi:10.1002/2013g1056563, 2013.

Tarasick, D. W., Fioletov, V. E., Wardle, D. I., Kerr, J. B., and Davies, J.: Changes in the vertical distribution of ozone over Canada from ozonesondes: 1980-2001, J. Geophys. Res.Atmos., 110, D02304, doi:10.1029/2004jd004643, 2005.

Tarasova, O. A., Brenninkmeijer, C. A. M., Jöckel, P., Zvyagintsev, A. M., and Kuznetsov, G. I.: A climatology of surface ozone in the extra tropics: cluster analysis of observations and model results, Atmos. Chem. Phys., 7, 6099-6117, doi:10.5194/acp-76099-2007, 2007.

Tas, E., Peleg, M., Matveev, V., Zingler, J., and Luria, M.: Frequency and extent of bromine oxide formation over the Dead Sea, J. Geophys. Res.-Atmos., 110, D11304, doi:10.1029/2004jd005665, 2005.

Teixeira, E., Fischer, G., van Velthuizen, H., van Dingenen, R., Dentener, F., Mills, G., Walter, C., and Ewert, F.: Limited potential of crop management for mitigating surface ozone impacts on global food supply, Atmos. Environ., 45, 2569-2576, doi:10.1016/j.atmosenv.2011.02.002, 2011.

Terao, Y., Logan, J. A., Douglass, A. R., and Stolarski, R. S.: Contribution of stratospheric ozone to the interannual variability of tropospheric ozone in the northern extratropics, J. Geophys. Res.Atmos., 113, D18309, doi:10.1029/2008jd009854, 2008.

Terrenoire, E., Bessagnet, B., Rouïl, L., Tognet, F., Pirovano, G., Létinois, L., Beauchamp, M., Colette, A., Thunis, P., Amann, M., and Menut, L.: High-resolution air quality simulation over Europe with the chemistry transport model CHIMERE, Geosci. Model Dev., 8, 21-42, doi:10.5194/gmd-8-21-2015, 2015.

Thomas, J. L., Stutz, J., Lefer, B., Huey, L. G., Toyota, K., Dibb, J. E., and von Glasow, R.: Modeling chemistry in and above snow 
at Summit, Greenland - Part 1: Model description and results, Atmos. Chem. Phys., 11, 4899-4914, doi:10.5194/acp-11-48992011, 2011.

Thomas, J. L., Dibb, J. E., Huey, L. G., Liao, J., Tanner, D., Lefer, B., von Glasow, R., and Stutz, J.: Modeling chemistry in and above snow at Summit, Greenland - Part 2: Impact of snowpack chemistry on the oxidation capacity of the boundary layer, Atmos. Chem. Phys., 12, 6537-6554, doi:10.5194/acp-12-65372012, 2012.

Thomas, J. L., Raut, J.-C., Law, K. S., Marelle, L., Ancellet, G., Ravetta, F., Fast, J. D., Pfister, G., Emmons, L. K., Diskin, G. S., Weinheimer, A., Roiger, A., and Schlager, H.: Pollution transport from North America to Greenland during summer 2008, Atmos. Chem. Phys., 13, 3825-3848, doi:10.5194/acp-13-38252013, 2013.

Thompson, A. M. and Hudson, R. D.: Tropical tropospheric ozone (TTO) maps from Nimbus 7 and Earth Probe TOMS by the modified-residual method: Evaluation with sondes, ENSO signals, and trends from Atlantic regional time series, J. Geophys. Res.-Atmos., 104, 26961-26975, doi:10.1029/1999jd900470, 1999.

Thompson, A. M., Pickering, K. E., McNamara, D. P., Schoeberl, M. R., Hudson, R. D., Kim, J. H., Browell, E. V., Kirchhoff, V., and Nganga, D.: Where did tropospheric ozone over southern Africa and the tropical Atlantic come from in October 1992? Insights from TOMS, GTE TRACE A, and SAFARI 1992, J. Geophys. Res.-Atmos., 101, 24251-24278, 1996.

Thompson, A. M., Witte, J. C., McPeters, R. D., Oltmans, S. J., Schmidlin, F. J., Logan, J. A., Fujiwara, M., Kirchhoff, V., Posny, F., Coetzee, G. J. R., Hoegger, B., Kawakami, S., Ogawa, T., Johnson, B. J., Vomel, H., and Labow, G.: Southern Hemisphere Additional Ozonesondes (SHADOZ) 1998-2000 tropical ozone climatology - 1. Comparison with Total Ozone Mapping Spectrometer (TOMS) and ground-based measurements, J. Geophys. Res.-Atmos., 108, 8238, doi:10.1029/2001jd000967, 2003a.

Thompson, A. M., Witte, J. C., Oltmans, S. J., Schmidlin, F. J., Logan, J. A., Fujiwara, M., Kirchhoff, V., Posny, F., Coetzee, G. J. R., Hoegger, B., Kawakami, S. J., Ogawa, T., Fortuin, J. P. F., and Kelder, H. M.: Southern Hemisphere Additional Ozonesondes (SHADOZ) 1998-2000 tropical ozone climatology - 2. Tropospheric variability and the zonal wave-one, J. Geophys. Res., 108, 8241, doi:10.1029/2002jd002241 2003b.

Thompson, A. M., Balashov, N. V., Witte, J. C., Coetzee, J. G. R., Thouret, V., and Posny, F.: Tropospheric ozone increases over the southern Africa region: bellwether for rapid growth in Southern Hemisphere pollution?, Atmos. Chem. Phys., 14, 9855-9869, doi:10.5194/acp-14-9855-2014, 2014

Thornton, J. A., Kercher, J. P., Riedel, T. P., Wagner, N. L., Cozic, J., Holloway, J. S., Dube, W. P., Wolfe, G. M., Quinn, P. K., Middlebrook, A. M., Alexander, B., and Brown, S. S.: A large atomic chlorine source inferred from mid-continental reactive nitrogen chemistry, Nature, 464, 271-274, doi:10.1038/nature08905, 2010.

Thouret, V., Saunois, M., Minga, A., Mariscal, A., Sauvage, B., Solete, A., Agbangla, D., Nédélec, P., Mari, C., Reeves, C. E., and Schlager, H.: An overview of two years of ozone radio soundings over Cotonou as part of AMMA, Atmos. Chem. Phys., 9, 6157-6174, doi:10.5194/acp-9-6157-2009, 2009.
Tie, X., Madronich, S., Li, G., Ying, Z., Weinheimer, A., Apel, E., and Campos, T.: Simulation of Mexico City plumes during the MIRAGE-Mex field campaign using the WRF-Chem model, Atmos. Chem. Phys., 9, 4621-4638, doi:10.5194/acp-9-4621-2009, 2009.

Tie, X., Geng, F., Guenther, A., Cao, J., Greenberg, J., Zhang, R., Apel, E., Li, G., Weinheimer, A., Chen, J., and Cai, C.: Megacity impacts on regional ozone formation: observations and WRFChem modeling for the MIRAGE-Shanghai field campaign, Atmos. Chem. Phys., 13, 5655-5669, doi:10.5194/acp-13-56552013, 2013.

Tohjima, Y., Kubo, M., Minejima, C., Mukai, H., Tanimoto, H., Ganshin, A., Maksyutov, S., Katsumata, K., Machida, T., and Kita, K.: Temporal changes in the emissions of $\mathrm{CH}_{4}$ and $\mathrm{CO}$ from China estimated from $\mathrm{CH}_{4} / \mathrm{CO}_{2}$ and $\mathrm{CO} / \mathrm{CO}_{2}$ correlations observed at Hateruma Island, Atmos. Chem. Phys., 14, 1663-1677, doi:10.5194/acp-14-1663-2014, 2014.

Tosca, M. G., Randerson, J. T., Zender, C. S., Nelson, D. L., Diner, D. J., and Logan, J. A.: Dynamics of fire plumes and smoke clouds associated with peat and deforestation fires in Indonesia, J. Geophys. Res.-Atmos., 116, D08207, doi:10.1029/2010jd015148, 2011.

Tost, H., Jöckel, P., and Lelieveld, J.: Lightning and convection parameterisations - uncertainties in global modelling, Atmos. Chem. Phys., 7, 4553-4568, doi:10.5194/acp-7-4553-2007, 2007.

Toumi, R., Haigh, J. D., and Law, K. S.: A tropospheric ozonelightning climate feedback, Geophys. Res. Lett., 23, 1037-1040, doi:10.1029/96gl00944, 1996.

Tressol, M., Ordonez, C., Zbinden, R., Brioude, J., Thouret, V., Mari, C., Nedelec, P., Cammas, J.-P., Smit, H., Patz, H.-W., and Volz-Thomas, A.: Air pollution during the 2003 European heat wave as seen by MOZAIC airliners, Atmos. Chem. Phys., 8, 2133-2150, doi:10.5194/acp-8-2133-2008, 2008.

Turquety, S., Logan, J. A., Jacob, D. J., Hudman, R. C., Leung, F. Y., Heald, C. L., Yantosca, R. M., Wu, S. L., Emmons, L. K., Edwards, D. P., and Sachse, G. W.: Inventory of boreal fire emissions for North America in 2004: the importance of peat burning and pyro-convective injection, J. Geophys. Res., 112, D12S03, doi:10.1029/2006JD007281, 2007.

Tuzet, A., Perrier, A., Loubet, B., and Cellier, P.: Modelling ozone deposition fluxes: The relative roles of deposition and detoxification processes, Agr. Forest Meteorol., 151, 480-492, doi:10.1016/j.agrformet.2010.12.004, 2011.

Unger, N.: Global Climate Forcing by Criteria Air Pollutants, in: Annual Review of Environment and Resources, Vol 37, edited by: Gadgil, A. and Liverman, D. M., Annual Review of Environment and Resources, Annual Reviews, Palo Alto, 1-24, 2012.

U.S. Energy Information Administration Administration: Annual Energy Outlook 2014, with projections to 2040, Washington, DC, 2014a.

U.S. Energy Information Administration Administration: Drilling Productivity Report, 2014b.

Val Martin, M., Honrath, R. E., Owen, R. C., Pfister, G., Fialho, P., and Barata, F.: Significant enhancements of nitrogen oxides, black carbon and ozone in the North Atlantic lower free troposphere resulting from North American boreal wildfires, J. Geophys. Res., 111, D23S60, doi:10.1029/2006JD007530, 2006. 
Val Martin, M., Logan, J. A., Kahn, R. A., Leung, F.-Y., Nelson, D. L., and Diner, D. J.: Smoke injection heights from fires in North America: analysis of 5 years of satellite observations, Atmos. Chem. Phys., 10, 1491-1510, doi:10.5194/acp-10-14912010, 2010.

Val-Martin, M., Heald, C. L., and Arnold, S. R.: Coupling dry deposition to vegetation phenology in the Community Earth System Model: Implications for the simulation of surface $\mathrm{O}_{3}$, Geophys. Res. Lett., 41, 2988-2996, doi:10.1002/2014g1059651, 2014.

Valks, P., Hao, N., Gimeno Garcia, S., Loyola, D., Dameris, M., Jöckel, P., and Delcloo, A.: Tropical tropospheric ozone column retrieval for GOME-2, Atmos. Meas. Tech., 7, 2513-2530, doi:10.5194/amt-7-2513-2014, 2014.

van Aardenne, J. A., Dentener, F. J., Olivier, J. G. J., Klein Goldewijk, C. G. M., and Lelieveld, J.: A $1^{\circ} \times 1^{\circ}$ resolution dataset of historical anthropogenic trace gas emissions for the period 18901990, Global Biogeochem. Cy., 15, 909-928, 2001.

van der Werf, G. R., Randerson, J. T., Giglio, L., Collatz, G. J., Kasibhatla, P. S., and Arellano Jr., A. F.: Interannual variability in global biomass burning emissions from 1997 to 2004, Atmos. Chem. Phys., 6, 3423-3441, doi:10.5194/acp-6-3423-2006, 2006

van der Werf, G. R., Randerson, J. T., Giglio, L., Collatz, G. J., Mu, M., Kasibhatla, P. S., Morton, D. C., DeFries, R. S., Jin, Y., and van Leeuwen, T. T.: Global fire emissions and the contribution of deforestation, savanna, forest, agricultural, and peat fires (19972009), Atmos. Chem. Phys., 10, 11707-11735, doi:10.5194/acp10-11707-2010, 2010.

van Loon, M., Vautard, R., Schaap, M., Bergström, R., Bessagnet, B., Brandt, J., Builtjes, P. J. H., Christensen, J. H., Cuvelier, K., Graf, A., Jonson, J. E., Krol, M., Langner, J., Roberts, P., Rouil, L., Stern, R., Tarrasón, L., Thunis, P., Vignati, E., White, L., and Wind, P.: Evaluation of long-term ozone simulations from seven regional air quality models and their ensemble average, Atmos. Environ., 41, 2083-2097, 2007.

van Vuuren, D., Edmonds, J., Kainuma, M., Riahi, K., Thomson, A., Hibbard, K., Hurtt, G., Kram, T., Krey, V., Lamarque, J.-F., Masui, T., Meinshausen, M., Nakicenovic, N., Smith, S., and Rose, S.: The representative concentration pathways: an overview, Climatic Change, 109, 5-31, 2011.

Vautard, R., Honore, C., Beekmann, M., and Rouil, L.: Simulation of ozone during August 2003 heat wave and emission control scenarios, Atmos. Environ., 39, 2957-2967, 2005.

Vautard, R., Szopa, S., Beekmann, M., Menut, L., Hauglustaine, D. A., Rouil, L., and Roemer, M.: Are decadal anthropogenic emission changes in Europe consistent with surface ozone observations?, Geophys. Res. Lett., 33, L13810, doi:10.1029/2006GL026080, 2006.

Venevsky, S.: Importance of aerosols for annual lightning production at global scale, Atmos. Chem. Phys. Discuss., 14, 43034325, doi:10.5194/acpd-14-4303-2014, 2014.

Vieno, M., Dore, A. J., Stevenson, D. S., Doherty, R., Heal, M. R., Reis, S., Hallsworth, S., Tarrason, L., Wind, P., Fowler, D., Simpson, D., and Sutton, M. A.: Modelling surface ozone during the 2003 heat-wave in the UK, Atmos. Chem. Phys., 10, 7963-7978, doi:10.5194/acp-10-7963-2010, 2010.

Vijayaraghavan, K., DenBleyker, A., Ma, L., Lindhjem, C., and Yarwood, G.: Trends in on-road vehicle emissions and ambient air quality in Atlanta, Georgia, USA, from the late 1990s through 2009, J. Air Waste Manage., 64, 808-816, doi:10.1080/10962247.2014.892039, 2014.

Vinken, G. C. M., Boersma, K. F., van Donkelaar, A., and Zhang, L.: Constraints on ship $\mathrm{NO}_{\mathrm{x}}$ emissions in Europe using GEOSChem and $\mathrm{OMI}$ satellite $\mathrm{NO}_{2}$ observations, Atmos. Chem. Phys., 14, 1353-1369, doi:10.5194/acp-14-1353-2014, 2014.

Volz, A. and Kley, D.: Evaluation of the Montsouris Series of Ozone Measurements Made in the 19th-Century, Nature, 332, 240-242, 1988.

von Glasow, R.: Atmospheric chemistry in volcanic plumes, Proc. Natl. Acad. Sci. USA, 107, 6594-6599, doi:10.1073/pnas.0913164107, 2010.

von Glasow, R. and Crutzen, P. J.: Model study of multiphase DMS oxidation with a focus on halogens, Atmos. Chem. Phys., 4, 589608, doi:10.5194/acp-4-589-2004, 2004.

von Kuhlmann, R., Lawrence, M. G., Crutzen, P. J., and Rasch, P. J.: A model for studies of tropospheric ozone and nonmethane hydrocarbons: Model description and ozone results, J. Geophys. Res.-Atmos., 108, 4294, doi:10.1029/2002jd002893, 2003 a.

von Kuhlmann, R., Lawrence, M. G., Crutzen, P. J., and Rasch, P. J.: A model for studies of tropospheric ozone and nonmethane hydrocarbons: Model evaluation of ozone-related species, J. Geophys. Res.-Atmos., 108, 4729, doi:10.1029/2002jd003348, 2003 b.

von Schneidemesser, E. and Monks, P. S.: Air Quality and Climatesynergies and trade-offs, Environ. Sci. Proc. Impacts, 15, 13151325, doi:10.1039/c3em00178d, 2013.

von Schneidemesser, E., Monks, P. S., and Plass-Duelmer, C.: Global comparison of VOC and CO observations in urban areas, Atmos. Environ., 44, 5053-5064, 2010.

von Schneidemesser, E., Monks, P. S., Gros, V., Gauduin, J., and Sanchez, O.: How important is biogenic isoprene in an urban environment? A study in London and Paris, Geophys. Res. Lett., 38, L19804, doi:10.1029/2011g1048647, 2011.

von Schneidemesser, E., Monks, P. S., Allan, J. D., Bruhwiler, L., Forster, P., Fowler, D., Lauer, A., Morgan, W. T., Paasonen, P., Righi, M., Sindelarova, K., and Sutton, M. A.: Chemistry and the Linkages between Air Quality and Climate Change, Chem. Rev., 115, 3856-3897, doi:10.1021/acs.chemrev.5b00089, 2015.

Voulgarakis, A., Savage, N. H., Wild, O., Braesicke, P., Young, P. J., Carver, G. D., and Pyle, J. A.: Interannual variability of tropospheric composition: the influence of changes in emissions, meteorology and clouds, Atmos. Chem. Phys., 10, 2491-2506, doi:10.5194/acp-10-2491-2010, 2010.

Voulgarakis, A., Hadjinicolaou, P., and Pyle, J. A.: Increases in global tropospheric ozone following an El Nino event: examining stratospheric ozone variability as a potential driver, Atmos. Sci. Lett., 12, 228-232, doi:10.1002/asl.318, 2011.

Wagg, S., Mills, G., Hayes, F., Wilkinson, S., Cooper, D., and Davies, W. J.: Reduced soil water availability did not protect two competing grassland species from the negative effects of increasing background ozone, Environ. Pollut., 165, 91-99, doi:10.1016/j.envpol.2012.02.010, 2012.

Wagner, N. L., Riedel, T. P., Roberts, J. M., Thornton, J. A., Angevine, W. M., Williams, E. J., Lerner, B. M., Vlasenko, A., Li, S. M., Dube, W. P., Coffman, D. J., Bon, D. M., de Gouw, J. A., Kuster, W. C., Gilman, J. B., and Brown, S. S.: The sea breeze/land breeze circulation in Los Angeles and its influence 
on nitryl chloride production in this region, J. Geophys. Res.Atmos., 117, D00V24, doi:10.1029/2012jd017810, 2012.

Walker, T. W., Jones, D. B. A., Parrington, M., Henze, D. K., Murray, L. T., Bottenheim, J. W., Anlauf, K., Worden, J. R., Bowman, K. W., Shim, C., Singh, K., Kopacz, M., Tarasick, D. W., Davies, J., von der Gathen, P., Thompson, A. M., and Carouge, C. C.: Impacts of midlatitude precursor emissions and local photochemistry on ozone abundances in the Arctic, J. Geophys. Res.Atmos., 117, D01305, doi:10.1029/2011jd016370, 2012.

Wang, S. W., Zhang, Q., Streets, D. G., He, K. B., Martin, R. V., Lamsal, L. N., Chen, D., Lei, Y., and Lu, Z.: Growth in $\mathrm{NO}_{\mathrm{x}}$ emissions from power plants in China: bottom-up estimates and satellite observations, Atmos. Chem. Phys., 12, 4429-4447, doi:10.5194/acp-12-4429-2012, 2012.

Warneke, C., de Gouw, J. A., Holloway, J. S., Peischl, J., Ryerson, T. B., Atlas, E., Blake, D., Trainer, M., and Parrish, D. D.: Multiyear trends in volatile organic compounds in Los Angeles, California: Five decades of decreasing emissions, J. Geophys. Res.-Atmos., 117, D00V17, doi:10.1029/2012jd017899, 2012.

Weatherhead, E. C., Reinsel, G. C., Tiao, G. C., Meng, X. L., Choi, D. S., Cheang, W. K., Keller, T., DeLuisi, J., Wuebbles, D. J., Kerr, J. B., Miller, A. J., Oltmans, S. J., and Frederick, J. E.: Factors affecting the detection of trends: Statistical considerations and applications to environmental data, J. Geophys. Res.-Atmos., 103, 17149-17161, doi:10.1029/98jd00995, 1998.

Weatherhead, E. C., Stevermer, A. J., and Schwartz, B. E.: Detecting environmental changes and trends, Phys. Chem. Earth, 27, 399403, doi:10.1016/s1474-7065(02)00019-0, 2002.

Wei, W., Wang, S. X., Chatani, S., Klimont, Z., Cofala, J., and Hao, J. M.: Emission and speciation of non-methane volatile organic compounds from anthropogenic sources in China, Atmos. Environ., 42, 4976-4988, doi:10.1016/j.atmosenv.2008.02.044, 2008.

Weiss, M., Bonnel, P., Kühlwein, J., Provenza, A., Lambrecht, U., Alessandrini, S., Carriero, M., Colombo, R., Forni, F., Lanappe, G., Le Lijour, P., Manfredi, U., Montigny, F., and Sculati, M.: Will Euro 6 reduce the $\mathrm{NO}_{x}$ emissions of new diesel cars? - Insights from on-road tests with Portable Emissions Measurement Systems (PEMS), Atmos. Environ., 62, 657-665, doi:10.1016/j.atmosenv.2012.08.056, 2012.

Wells, K. C., Millet, D. B., Cady-Pereira, K. E., Shephard, M. W., Henze, D. K., Bousserez, N., Apel, E. C., de Gouw, J., Warneke, C., and Singh, H. B.: Quantifying global terrestrial methanol emissions using observations from the TES satellite sensor, Atmos. Chem. Phys., 14, 2555-2570, doi:10.5194/acp-14-25552014, 2014.

Welz, O., Savee, J. D., Osborn, D. L., Vasu, S. S., Percival, C. J., Shallcross, D. E., and Taatjes, C. A.: Direct kinetic measurements of Criegee intermediate $\left(\mathrm{CH}_{2} \mathrm{OO}\right)$ formed by reaction of $\mathrm{CH}_{2} \mathrm{I}$ with $\mathrm{O}_{2}$, Science, 335, 204-207, 2012.

Welz, O., Eskola, A. J., Sheps, L., Rotavera, B., Savee, J. D., Scheer, A. M., Osborn, D. L., Lowe, D., Murray Booth, A., Xiao, P., and others: Rate Coefficients of $\mathrm{C} 1$ and $\mathrm{C} 2$ Criegee Intermediate Reactions with Formic and Acetic Acid Near the Collision Limit: Direct Kinetics Measurements and Atmospheric Implications, Angewandte Chemie, 126, 4635-4638, 2014.

Wesely, M. L., Cook, D. R., and Williams, R. M.: Field measurement of small ozone fluxes to snow, wet bare soil, and lake water, Bound.-Lay. Meteorol., 20, 459-471, doi:10.1007/bf00122295, 1981.
Wespes, C., Emmons, L., Edwards, D. P., Hannigan, J., Hurtmans, D., Saunois, M., Coheur, P.-F., Clerbaux, C., Coffey, M. T., Batchelor, R. L., Lindenmaier, R., Strong, K., Weinheimer, A. J., Nowak, J. B., Ryerson, T. B., Crounse, J. D., and Wennberg, P. O.: Analysis of ozone and nitric acid in spring and summer Arctic pollution using aircraft, ground-based, satellite observations and MOZART-4 model: source attribution and partitioning, Atmos. Chem. Phys., 12, 237-259, doi:10.5194/acp-12-237-2012, 2012.

Wexler, H., Moreland, W. B., and Weyant, W. S.: A preliminary report on ozone observations in little America, Antarctica, Mon. Weather Rev., 88, 43-54, doi:10.1175/15200493(1960)088<0043:aprooo>2.0.co;2, 1960.

Whalley, L. K., Edwards, P. M., Furneaux, K. L., Goddard, A., Ingham, T., Evans, M. J., Stone, D., Hopkins, J. R., Jones, C. E., Karunaharan, A., Lee, J. D., Lewis, A. C., Monks, P. S., Moller, S. J., and Heard, D. E.: Quantifying the magnitude of a missing hydroxyl radical source in a tropical rainforest, Atmos. Chem. Phys., 11, 7223-7233, doi:10.5194/acp-11-7223-2011, 2011.

Whalley, L., Stone, D., and Heard, D.: New Insights into the tropospheric oxidation of Isoprene: Combining field measuremens, laboratory studies, chemical modelling and qualtum theory, in: Atmospheric and Aerosol Chemistry, edited by: McNeill, V. F. and Ariya, P. A., Topics in Current Chemistry, Springer, Berlin Heidelberg, 55-96, 2014.

Wheeler, A. J., Xu, X. H., Kulka, R., You, H. Y., Wallace, L., Mallach, G., Van Ryswyk, K., MacNeill, M., Kearney, J., Rasmussen, P. E., Dabek-Zlotorzynska, E., Wang, D., Poon, R., Williams, R., Stocco, C., Anastassopoulos, A., Miller, J. D., Dales, R., and Brook, J. R.: Windsor, Ontario Exposure Assessment Study: Design and Methods Validation of Personal, Indoor, and Outdoor Air Pollution Monitoring, J. Air Waste Manage., 61, 324-338, doi:10.3155/1047-3289.61.3.324, 2011.

WHO: Health Aspects of Air Pollution with Particulate Matter, Ozone and Nitrogen Dioxide, Bonn, 2003.

WHO: WHO Air quality guidelines for particulate matter, ozone, nitrogen dioxide and sulfur dioxide, 2005.

WHO: Review of evidence on health aspects of air pollution REVIHAAP Project WHO Regional Office for Europe, Copenhagen, 2013.

Wiedinmyer, C., Tie, X. X., Guenther, A., Neilson, R., and Granier, C.: Future changes in biogenic isoprene emissions: How might they affect regional and global atmospheric chemistry?, Earth Interact., 10, 2006.

Wiedinmyer, C., Akagi, S. K., Yokelson, R. J., Emmons, L. K., AlSaadi, J. A., Orlando, J. J., and Soja, A. J.: The Fire INventory from NCAR (FINN): a high resolution global model to estimate the emissions from open burning, Geosci. Model Dev., 4, 625641, doi:10.5194/gmd-4-625-2011, 2011.

Wilcox, L. J., Hoskins, B. J., and Shine, K. P.: A global blended tropopause based on ERA data. Part I: Climatology, Q. J. Roy. Meteorol. Soc., 138, 561-575, doi:10.1002/qj.951, 2012.

Wild, O.: Modelling the global tropospheric ozone budget: exploring the variability in current models, Atmos. Chem. Phys., 7, 2643-2660, doi:10.5194/acp-7-2643-2007, 2007.

Wild, O. and Palmer, P. I.: How sensitive is tropospheric oxidation to anthropogenic emissions?, Geophys. Res. Lett., 35, L22802, doi:10.1029/2008gl035718, 2008. 
Wild, O., Prather, M. J., and Akimoto, H.: Indirect long-term global radiative cooling from $\mathrm{NO}_{x}$ emissions, Geophys. Res. Lett., 28, 1719-1722, doi:10.1029/2000g1012573, 2001.

Wild, O., Pochanart, P., and Akimoto, H.: Trans-Eurasian of ozone and its precursors, J. Geophys. Res., 109, D11302, doi:10.1029/2003JD004501, 2004.

Wild, O., Fiore, A. M., Shindell, D. T., Doherty, R. M., Collins, W. J., Dentener, F. J., Schultz, M. G., Gong, S., MacKenzie, I. A., Zeng, G., Hess, P., Duncan, B. N., Bergmann, D. J., Szopa, S., Jonson, J. E., Keating, T. J., and Zuber, A.: Modelling future changes in surface ozone: a parameterized approach, Atmos. Chem. Phys., 12, 2037-2054, doi:10.5194/acp-12-20372012, 2012.

Wilkinson, S. and Davies, W. J.: Drought, ozone, ABA and ethylene: new insights from cell to plant to community, Plant Cell Environ., 33, 510-525, doi:10.1111/j.1365-3040.2009.02052.x, 2010

Wilkinson, S., Mills, G., Illidge, R., and Davies, W. J.: How is ozone pollution reducing our food supply?, J. Exp. Bot., 63, 527-536, doi:10.1093/jxb/err317, 2012.

Williams, D. E., Henshaw, G. S., Bart, M., Laing, G., Wagner, J., Naisbitt, S., and Salmond, J. A.: Validation of lowcost ozone measurement instruments suitable for use in an airquality monitoring network, Meas. Sci. Technol., 24, 065803, doi:10.1088/0957-0233/24/6/065803, 2013.

Williams, E. R.: Lightning and climate: A review, Atmos. Res., 76, 272-287, doi:10.1016/j.atmosres.2004.11.014, 2005.

Williams, J. E., van Weele, M., van Velthoven, P. F. J., Scheele, M. P., Liousse, C., and van der Werf, G. R.: The Impact of Uncertainties in African Biomass Burning Emission Estimates on Modeling Global Air Quality, Long Range Transport and Tropospheric Chemical Lifetimes, Atmosphere, 3, 132-163, doi:10.3390/atmos3010132, 2012.

Williams, M. L., Atkinson, R. W., Anderson, H. R., and Kelly, F. J.: Associations between daily mortality in London and combined oxidant capacity, ozone and nitrogen dioxide, Air Qual. Atmos Health., doi:10.1007/s11869-014-0249-8, 2014.

Wilson, R. C., Fleming, Z. L., Monks, P. S., Clain, G., Henne, S., Konovalov, I. B., Szopa, S., and Menut, L.: Have primary emission reduction measures reduced ozone across Europe? An analysis of European rural background ozone trends 1996-2005, Atmos. Chem. Phys., 12, 437-454, doi:10.5194/acp-12-437-2012, 2012.

Wittig, V. E., Ainsworth, E. A., Naidu, S. L., Karnosky, D. F., and Long, S. P.: Quantifying the impact of current and future tropospheric ozone on tree biomass, growth, physiology and biochemistry: a quantitative meta-analysis, Glob. Change Biol., 15, 396-424, doi:10.1111/j.1365-2486.2008.01774.x, 2009.

Wu, S., Mickley, L. J., Leibensperger, E. M., Jacob, D. J., Rind, D., and Streets, D. G.: Effects of 2000-2050 global change on ozone air quality in the United States, J. Geophys. Res.-Atmos., 113, D18312, doi:10.1029/2007JD009639, 2008.

Wu, S. L., Mickley, L. J., Jacob, D. J., Logan, J. A., Yantosca, R. M., and Rind, D.: Why are there large differences between models in global budgets of tropospheric ozone?, J. Geophys. Res.-Atmos., 112, D05302, doi:10.1029/2006jd007801, 2007.

Yang, X., Cox, R. A., Warwick, N. J., Pyle, J. A., Carver, G. D., O'Connor, F. M., and Savage, N. H.: Tropospheric bromine chemistry and its impacts on ozone, J. Geophys. Res., 110, D23311, doi:10.1029/2005JD006 244, 2005.

Young, C. J., Washenfelder, R. A., Edwards, P. M., Parrish, D. D., Gilman, J. B., Kuster, W. C., Mielke, L. H., Osthoff, H. D., Tsai, C., Pikelnaya, O., Stutz, J., Veres, P. R., Roberts, J. M., Griffith, S., Dusanter, S., Stevens, P. S., Flynn, J., Grossberg, N., Lefer, B., Holloway, J. S., Peischl, J., Ryerson, T. B., Atlas, E. L., Blake, D. R., and Brown, S. S.: Chlorine as a primary radical: evaluation of methods to understand its role in initiation of oxidative cycles, Atmos. Chem. Phys., 14, 3427-3440, doi:10.5194/acp-14-34272014, 2014.

Young, P. J., Archibald, A. T., Bowman, K. W., Lamarque, J.-F., Naik, V., Stevenson, D. S., Tilmes, S., Voulgarakis, A., Wild, O., Bergmann, D., Cameron-Smith, P., Cionni, I., Collins, W. J., Dalsøren, S. B., Doherty, R. M., Eyring, V., Faluvegi, G., Horowitz, L. W., Josse, B., Lee, Y. H., MacKenzie, I. A., Nagashima, T., Plummer, D. A., Righi, M., Rumbold, S. T., Skeie, R. B., Shindell, D. T., Strode, S. A., Sudo, K., Szopa, S., and Zeng, G.: Preindustrial to end 21 st century projections of tropospheric ozone from the Atmospheric Chemistry and Climate Model Intercomparison Project (ACCMIP), Atmos. Chem. Phys., 13, 20632090, doi:10.5194/acp-13-2063-2013, 2013.

Yu, X., Yuan, Z., Fung, J. C. H., Xue, J., Li, Y., Zheng, J., and Lau, A. K. H.: Ozone changes in response to the heavy-duty diesel truck control in the Pearl River Delta, Atmos. Environ., 88, 269274, doi:10.1016/j.atmosenv.2013.11.022, 2014.

Yu, Y., Sokhi, R. S., Kitwiroon, N., Middleton, D. R., and Fisher, B.: Performance characteristics of MM5-SMOKECMAQ for a summer photochemical episode in southeast England, United Kingdom, Atmos. Environ., 42, 4870-4883, doi:10.1016/j.atmosenv.2008.02051, 2008.

Yuan, T. L., Remer, L. A., Bian, H. S., Ziemke, J. R., Albrecht, R., Pickering, K. E., Oreopoulos, L., Goodman, S. J., Yu, H. B., and Allen, D. J.: Aerosol indirect effect on tropospheric ozone via lightning, J. Geophys. Res.-Atmos., 117, D18213, doi:10.1029/2012jd017723, 2012.

Yue, X. and Unger, N.: Ozone vegetation damage effects on gross primary productivity in the United States, Atmos. Chem. Phys., 14, 9137-9153, doi:10.5194/acp-14-9137-2014, 2014.

Zanis, P., Trickl, T., Stohl, A., Wernli, H., Cooper, O., Zerefos, C., Gaeggeler, H., Schnabel, C., Tobler, L., Kubik, P. W., Priller, A., Scheel, H. E., Kanter, H. J., Cristofanelli, P., Forster, C., James, P., Gerasopoulos, E., Delcloo, A., Papayannis, A., and Claude, H.: Forecast, observation and modelling of a deep stratospheric intrusion event over Europe, Atmos. Chem. Phys., 3, 763-777, doi:10.5194/acp-3-763-2003, 2003.

Zanis, P., Hadjinicolaou, P., Pozzer, A., Tyrlis, E., Dafka, S., Mihalopoulos, N., and Lelieveld, J.: Summertime free-tropospheric ozone pool over the eastern Mediterranean/Middle East, Atmos. Chem. Phys., 14, 115-132, doi:10.5194/acp-14-115-2014, 2014.

Zanobetti, A. and Schwartz, J.: Ozone and Survival in Four Cohorts with Potentially Predisposing Diseases, Am. J. Resp. Crit. Care Med., 184, 836-841, doi:10.1164/rccm.201102-0227OC, 2011.

Zare, A., Christensen, J. H., Gross, A., Irannejad, P., Glasius, M., and Brandt, J.: Quantifying the contributions of natural emissions to ozone and total fine PM concentrations in the Northern Hemisphere, Atmos. Chem. Phys., 14, 2735-2756, doi:10.5194/acp14-2735-2014, 2014. 
Zeng, G. and Pyle, J. A.: Influence of El Nino Southern Oscillation on stratosphere/troposphere exchange and the global tropospheric ozone budget, Geophys. Res. Lett., 32, L01814, doi:10.1029/2004gl021353, 2005.

Zhang, L., Jacob, D. J., Yue, X., Downey, N. V., Wood, D. A., and Blewitt, D.: Sources contributing to background surface ozone in the US Intermountain West, Atmos. Chem. Phys., 14, 52955309, doi:10.5194/acp-14-5295-2014, 2014.

Zhang, L. M., Brook, J. R., and Vet, R.: On ozone dry deposition with emphasis on non-stomatal uptake and wet canopies, Atmos. Environ., 36, 4787-4799, 2002.

Zhang, Q., Streets, D. G., He, K., Wang, Y., Richter, A., Burrows, J. P., Uno, I., Jang, C. J., Chen, D., Yao, Z., and Lei, Y.: $\mathrm{NO}_{x}$ emission trends for China, 1995-2004: The view from the ground and the view from space, J. Geophys. Res.-Atmos., 112, D22306, doi:10.1029/2007JD008684, 2007.

Zhao, Y., Nielsen, C. P., Lei, Y., McElroy, M. B., and Hao, J.: Quantifying the uncertainties of a bottom-up emission inventory of anthropogenic atmospheric pollutants in China, Atmos. Chem. Phys., 11, 2295-2308, doi:10.5194/acp-11-2295-2011, 2011.

Zhao, Y., Zhang, J., and Nielsen, C. P.: The effects of recent control policies on trends in emissions of anthropogenic atmospheric pollutants and CO2 in China, Atmos. Chem. Phys., 13, 487-508, doi:10.5194/acp-13-487-2013, 2013.

Zhong, J., Cai, X. M., and Bloss, W. J.: Modelling segregation effects of heterogeneous emissions on ozone levels in idealised urban street canyons: Using photochemical box models, Environ. Pollut., 188, 132-143, doi:10.1016/j.envpol.2014.02.001, 2014.

Zhou, W., Cohan, D. S., and Henderson, B. H.: Slower ozone production in Houston, Texas following emission reductions: evidence from Texas Air Quality Studies in 2000 and 2006, Atmos. Chem. Phys., 14, 2777-2788, doi:10.5194/acp-14-27772014, 2014.

Zhu, T., Melamed, M., Parrish, D., Gauss, M., Klenner, L. G., Lawrence, M., Konare, A., and Liousse, C.: Impacts of Megacities on Air Pollution and Climate, WMO, Geneva, 2012.
Ziemke, J. R. and Chandra, S.: La Nina and El Nino-induced variabilities of ozone in the tropical lower atmosphere during 1970 2001, Geophys. Res. Lett., 30, 1142, doi:10.1029/2002g1016387, 2003.

Ziemke, J. R., Chandra, S., Duncan, B. N., Froidevaux, L., Bhartia, P. K., Levelt, P. F., and Waters, J. W.: Tropospheric ozone determined from aura OMI and MLS: Evaluation of measurements and comparison with the Global Modeling Initiative's Chemical Transport Model, J. Geophys. Res.-Atmos., 111, D19303, doi:10.1029/2006JD007089, 2006.

Ziemke, J. R., Chandra, S., Oman, L. D., and Bhartia, P. K.: A new ENSO index derived from satellite measurements of column ozone, Atmos. Chem. Phys., 10, 3711-3721, doi:10.5194/acp10-3711-2010, 2010.

Zingler, J. and Platt, U.: Iodine oxide in the Dead Sea Valley: Evidence for inorganic sources of boundary layer IO, J. Geophys. Res.-Atmos., 110, doi:10.1029/2004jd004993, 2005.

Zlatev, Z., Christensen, J., and Hov, O.: A Eulerian air-pollution model for Europe with nonlinear chemistry, J. Atmos. Chem., 15, 1-37, doi:10.1007/bf00053607, 1992.

Zoogman, P., Jacob, D. J., Chance, K., Worden, H. M., Edwards, D. P., and Zhang, L.: Improved monitoring of surface ozone by joint assimilation of geostationary satellite observations of ozone and CO, Atmos. Environ., 84, 254-261, doi:10.1016/j.atmosenv.2013.11.048, 2014.

Zvyagintsev, A. M., Blum, O. B., Glazkova, A. A., Kotel'nikov, S. N., Kuznetsova, I. N., Lapchenko, V. A., Lezina, E. A., Miller, E. A., Milyaev, V. A., Popikov, A. P., Semutnikova, E. G., Tarasova, O. A., and Shalygina, I. Y.: Air pollution over European Russia and Ukraine under the hot summer conditions of 2010, Izv. Atmos. Ocean. Phys., 47, 699-707, doi:10.1134/s0001433811060168, 2011. 